\title{
Semi Analytical Approach for Binary Mixture Conductivity in Hydraulic Fracturing
}

\author{
Vuong V Pham
}

Thesis submitted

to the Benjamin M. Statler College of Engineering and Mineral Resources at West Virginia University

in partial fulfilment of the requirements for the degree of

Master of Science in

Petroleum and Natural Gas Engineering (P.N.G.E)

Ming Gu, Ph.D., Committee Chairperson

Fathi Ebrahim, Ph.D.

Samuel Ameri, P.N.G.E Department Chairperson

Department of Petroleum and Natural Gas Engineering (P.N.G.E)

Morgantown, West Virginia

2020

Keywords: hydraulic conductivity, binary proppant mixtures, semi-analytical modelling, fracturing simulation, sensitivity study, unconventional reservoirs, reservoir simulation 


\section{Abstract \\ Semi Analytical Approach for Binary Mixture Conductivity in Hydraulic Fracturing \\ VUONG V PHAM}

In hydraulic fracturing, a proppant injection schedule practice typically applies a binary proppant mixture (for example: 100 Mesh sand following by 40/70 Mesh sand in well MIP-3H, Marcellus Shale). The former injection agent is finer in size or less resistant to stress, whereas the latter injection agent is coarser in size or more resistant to stress. This practice creates a special region inside the fracture, in which two injected proppant types co-exist and is defined as the mixture zone. This research concentrates on the variability of the mixture zone under impact of different factors, introduces novel semi-analytical modelling approach to better estimate the hydraulic conductivity inside the mixture zone, and further applies this novel approach to prove its efficacy in conductivity estimation and cumulative production prediction.

Variability of the mixture zone is studied by an OAT (One at A Time) sensitivity analysis to examine the percentage of the mixture zone's area over the total propped area under variability of different parameters, including reservoir properties, geo-mechanics, and different design parameters in a proppant injection schedule. The novel semi-analytical model is derived by independent modelling for proppant pack's permeability and width. Permeability model is an improvement from Carman Kozeny equation, in which Internal Specific Area is re-derived to differ a binary mixture from a single proppant type. Fracture width model is derived from Hertzian contact theory under assumptions of parabola distributed stress, elastic behavior and dual-layer schematic. Trust-region method is applied to determine all coefficients in the permeability model, which complies with a non-linear least square problem. Coefficients in the width model are determined by linear approximation from an in-house fracture width database.

Based on satisfied validation results (7.98\%-21.82\% MRE), trust-region algorithm determines the novel model's coefficients using lab data of only two Weight Concentration Ratios. The novel model is expanded to predict binary mixture's conductivity at arbitrary confining stress and Weight Mixing Ratio values, which avoids misleading experimental outcomes. Proppant particle size distribution between two discrete Mesh numbers, deformation complexity between particles (quadratic form) and proppant crush effect are prospective improvements for better modelling validation results. LWAM is proved to overestimate conductivity compared to the novel model. Overestimation degree, which can exceed $70 \%$, is separated into 3 overestimation zones $(\leq 20 \%, 20-60 \%$ and $\geq 60 \%)$ and examined by the comparison matrices. When contrast in density and Mesh size between proppant types in a mixture is clear (for example: mixture 40/70 sand 20/40 ceramic), overestimation is extreme, and when internal contrast between proppant types in a mixture is reduced (for example: mixture 20/40 sand - 20/40 ceramic), overestimation is dampened.

The case study for Marcellus Shale applies comparison matrices to predict LWAM's conductivity overestimation and conduct 1-year and 10-year cumulative production analyses. Reduction of confining stress axis in comparison matrices to 5400-6200 psi with a maximum difference of 200 psi between different depths (based on Marcellus Shale minimum horizontal stress data) allows predictive reasoning for conductivity overestimation from weight concentration ratio distribution. Overestimation for cumulative production data is observed to approach $10.73 \%$ (3.274 MMSCF in the early production time for a quarter fractured area). This suggests the level of risk caused by application of LWAM in reservoir simulation, depending on the intrinsic contrast between proppant types' Mesh sizes and densities, in the selected proppant injection mixture. 


\section{Dedications}

This thesis is totally dedicated to my family members. My father, albeit being a tough father when communicating with his children, always support me financially and never complains about my educational expenses to me or my mother. My mother, who is truly my great supporter, life advisor and listener, has been following me closely since I was born. From her, I continuously learn how to be a kind, educated and thoughtful adult. Without their continuous support, I will never achieve my life targets and proceed higher education successfully. 


\section{Acknowledgements}

Initially, I want to give acknowledgements to Professor Ming Gu, who has been my academic advisor since the starting date of my Master of Science program at West Virginia University. Professor Gu is also my first academic advisor. I am lucky to be admitted in the program and work under his research project. Without his valuable advice, I am not be able to acquire fundamental of academic research (combination of applied Mathematics and relevant physics), learn research skills, and approach final aims of my thesis. I also appreciate Professor Fathi Ebrahim for his advice regarding personal directions for higher education and extra crucial skills besides research skills. Besides, I truly appreciate Professor Samuel Ameri, who accepted me to study and conduct this research under support of Petroleum and Natural Gas Engineering (PNGE) department at West Virginia University. Finally, acknowledgements and appreciations are given to the research start-up package provide by Petroleum and Natural Gas Engineering department at West Virginia University, along with the public database in MSEEL project and DOE funding contribution. 


\section{Table of contents}

\section{Abstract}

List of figures

List of tables

Nomenclature

Introduction

Chapter 1 - Unconventional reservoirs and Hydraulic Fracturing _.........................

1.1. Unconventional resources $\ldots$

1.2. Hydraulic fracturing $\ldots$

1.2.1. Theory of fracturing

1.2.2. Fracture modelling

1.3. Proppant and hydraulic conductivity $\ldots$

1.4. Proppant studies for binary mixtures 10

1.5. Fracture permeability modelling

1.6. Fracture width modelling

Chapter 2 - Non-linear least square problems and Trust-region method _ 18

2.1. Taylor theorem 19

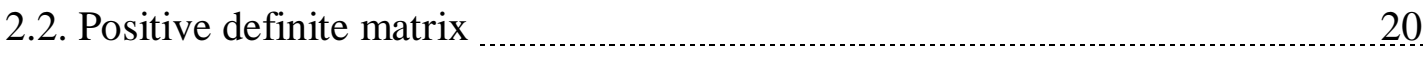

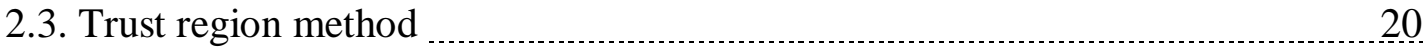

2.4. Setting constraints

Chapter 3 - Sensitivity study $\ldots \ldots$

3.1. Existence of Mixture Zone inside a propped fracture $\ldots \ldots \ldots \ldots$

3.2. Impact of different factors to the Mixture Zone 24

Chapter 4 - Semi-analytical modelling approach $\ldots \ldots$

4.1. Fracture permeability $\quad 30$

4.2. Fracture width $\ldots \ldots \ldots$

4.3. Determination of coefficients $\quad 38$

Chapter 5 - Case study for Marcellus Shale

5.1. Fracture propagation simulator

5.2. Numerical reservoir simulator $\ldots$

Chapter 6 - Results and discussions 49

6.1. Sensitivity study 49 
6.1.2. Summary $\ldots$

6.1.3. Drawback of the sensitivity design $\ldots \ldots \ldots$

6.2. Determination of coefficients

6.2.1. Initial porosity at zero applied stress $\left(\Phi_{\mathrm{o}}\right) \ldots \ldots \ldots \ldots$

6.2.2. Beta coefficient in porosity model $(\beta)$

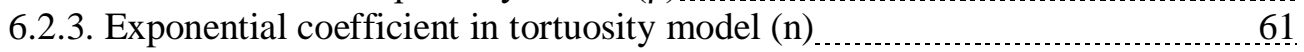

6.3. Semi-analytical modelling validation $\ldots$

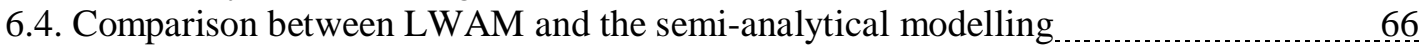

6.4.1. Overview of the comparison results $\quad 67$

6.4.2. Impact of confining pressure and areal concentration ratio variability ......... 70

6.4.3. Summary

6.4.4. Drawbacks of the novel semi-analytical model

6.5. Case study for Marcellus Shale

6.5.1 Review of confining stress data in Marcellus Shale

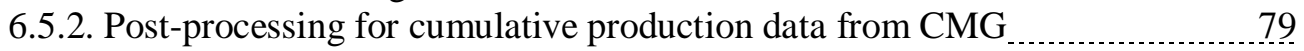

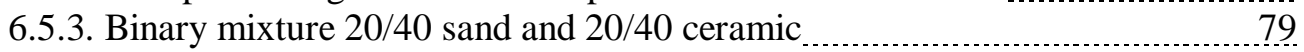

6.5.4. Binary mixture $40 / 70$ sand and $20 / 40$ ceramic $\quad 85$

6.5.5. Binary mixture $40 / 70$ ceramic and $20 / 40$ sand $\ldots$

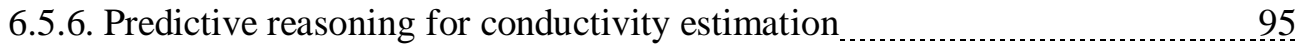

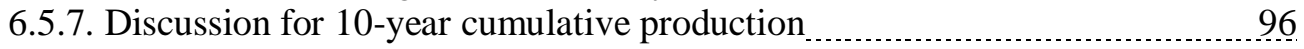

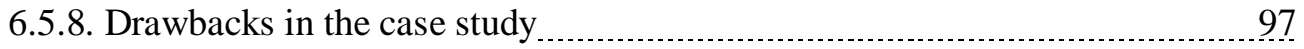

Chapter 7 - Conclusion 99

Chapter 8 - Recommendations for future work 102

References

Appendix $\quad 109$ 


\section{List of figures}

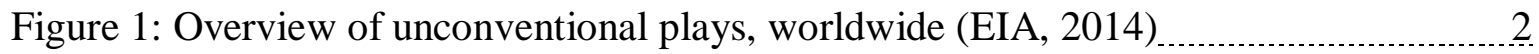

Figure 2: Overview of unconventional play, United States (EIA, 2016) _............................ 3

Figure 3: Principle stresses impacting a portion of rock (Petrowiki) 4

Figure 4: Schematic for a PKN model (Petrowiki) 6

Figure 5: Schematic for a KGD model (Petrowiki) _ _ $\quad 7$

Figure 6: Correction for fracture height in pseudo 3D models (Petrowiki) _......................... 8

Figure 7: Mixture Zone inside half-fracture dimensions

Figure 8: Schematic for a dual-layer unity $\ldots \ldots \ldots$

Figure 9: Schematic for the simulation domain (1/4 of a single fracture's drainage area) in the CMG model (Gu, Kulkarni, Raflee and Ivarrud, 2014) _................................................... 46

Figure 10: Sensitivity results for former injected proppant type's diameter (Diameter 1)...48

Figure 11: Sensitivity results for latter injected proppant type's diameter (Diameter 2) _..... 48

Figure 12: Sensitivity results for former injected proppant type's density (Density 1).......... 49

Figure 13: Sensitivity results for former injected proppant type's density (Density 2)_....... 49

Figure 14: Sensitivity results for injection rate $\quad 50$

Figure 15: Sensitivity results for confining pressure $\quad 50$

Figure 16: Sensitivity results for Poisson Ratio $\quad 53$

Figure 17: Sensitivity results for Young Modulus

Figure 18: Sensitivity results for former injected proppant type's ( $4^{\text {th }}$ time step) $\ldots \ldots \ldots . . \ldots . . . .54$

Figure 19: Sensitivity results for former injected proppant type's ( $5^{\text {th }}$ time step) _............... 54

Figure 20: Summary of the sensitivtiy study for all parameters

Figure 21: Relationship between porosity and former proppant type's volumetric ratio (diameter ratio is 1.5$)$ 60

Figure 22: Validation results for bianry mixture 20/40 sand and 20/40 ceramic __.......... 63

Figure 23: Validation results forbinary mixture 40/70 sand and 20/40 ceramic _...................

Figure 24: Validation results for bianry mixture 40/70 ceramic and 20/40 sand _..............64

Figure 25: Comparison matrix for binary mixture 20/40 sand and 20/40 ceramic _............ 67

Figure 26: Comparison matrix for binary mixture 40/70 sand and 20/40 ceramic $\quad 68$

Figure 27: Comparison matrix for binary mixture 40/70 ceramic and 20/40 sand _ $\quad 68$ 
Figure 28: Matrix of $\partial R D / \partial P_{c}$ for binary mixture 20/40 sand and 20/40 ceramic

Figure 29: Matrix of $\partial R D / \partial R$ for binary mixture 20/40 sand and 20/40 ceramic

Figure 30: Matrix of $\partial R D / \partial P_{c}$ for binary mixture $40 / 70$ sand and 20/40 ceramic 71

Figure 31: Matrix of $\partial R D / \partial R$ for binary mixture 40/70 sand and 20/40 ceramic 72

Figure 32: Matrix of $\partial R D / \partial P_{c}$ for binary mixture $40 / 70$ ceramic and 20/40 sand 72

Figure 33: Matrix of $\partial R D / \partial R$ for binary mixture 40/70 ceramic and 20/40 sand 73

Figure 34: Histogram of confining stress data in Marcellus Shale 77

Figure 35: Histogram of stress difference (within $0.5 \mathrm{ft}$ height), Marcellus Shale 79

Figure 36: Weight Concentration Ratio distribution inside half-fracture, mixture 20/40 sand and 20/40 ceramic injection 80

Figure 37: Historgram of Weight Concentration Ratio distribution, mxiture 20/40 sand and 20/40 ceramic injection

Figure 38: Conductivity estimation inside half-fracture by LWAM, mixture 20/40 sand and 20/40 ceramic injection

Figure 39: Conductivity estimation inside half-fracture by novel semi-analytical model, mixture 20/40 sand and 20/40 ceramic injection 82

Figure 40: Absolute difference (mD-ft) between LWAM and the novel semi-analytical model, mixture 20/40 sand and 20/40 ceramic injection 82

Figure 41: Relative difference $(\%)$ between LWAM and the novel semi-analytical model, , mixture 20/40 sand and 20/40 ceramic injection

Figure 42: Histogram of Relative difference (\%), mixture 20/40 sand and 20/40 ceramic injection. 83

Figure 43: Absolute difference (SCF) between production data by LWAM and the novel semianalytical model, mixture 20/40 sand and 20/40 ceramic injection 84

Figure 44: Relative difference $(\%)$ difference $(\mathrm{SCF})$ between production data by LWAM and the novel semi-analytical model, mixture 20/40 sand and 20/40 ceramic injection 84

Figure 45: Weight Concentration Ratio distribution inside half-fracture, mixture 40/70 sand and 20/40 ceramic injection 86

Figure 46: Historgram of Weight Concentration Ratio distribution, mixture 40/70 sand and 20/40 ceramic injection. 86

Figure 47: Conductivity estimation inside half-fracture by LWAM, mixture 40/70 sand and 20/40 ceramic injection 86

Figure 48: Conductivity estimation inside half-fracture by novel semi-analytical model, mixture 40/70 sand and 20/40 ceramic injection 
Figure 49: Absolute difference ( $\mathrm{mD}$ - $\mathrm{ft})$ between LWAM and the novel semi-analytical model, , mixture 40/70 sand and 20/40 ceramic inejction

Figure 50: Relative difference (\%) between LWAM and the novel semi-analytical model, , mixture 40/70 sand and 20/40 ceramic injection 88

Figure 51: Histogram of Relative difference (\%), mixture 40/70 sand and 20/40 ceramic injection. 88

Figure 52: Absolute difference (SCF) between production data by LWAM and the novel semianalytical model, mixture 40/70 sand and 20/40 ceramic injection 89

Figure 53: Relative difference $(\%)$ between production data by LWAM and the novel semianalytical model, mixture 20/40 sand and 20/40 ceramic injection

Figure 54: Weight Concentration Ratio distribution inside half-fracture, mixture 40/70 ceramic and 20/40 sand injection 90

Figure 55: Historgram of Weight Concentration Ratio distribution, mixture 40/70 ceramic and 20/40 sand injection 91

Figure 56: Conductivity estimation inside half-fracture by LWAM, mixture 40/70 ceramic and 20/40 sand inejction

Figure 57: Conductivity estimation inside half-fracture by LWAM, mixture 40/70 ceramic and 20/40 sand injection

Figure 58: Absolute difference (mD-ft) between LWAM and the novel semi-analytical model, , mixture 40/70 ceramic and 20/40 sand injection 92

Figure 59: Relative difference (\%) between LWAM and the novel semi-analytical model, mixture 40/70 ceramic and 20/40 sand injection 93

Figure 60: Histogram of Relative difference (\%), mixture 40/70 ceramic and 20/40 sand injection 93

Figure 61: Absolute difference (SCF) between production data by LWAM and the novel semianalytical model, mixture 40/70 ceramic and 20/40 sand injection 94

Figure 62: Relative difference $(\%)$ between production data by LWAM and the novel semianalytical model, mixture 40/70 ceramic and 20/40 sand injection 94

Figure 63: Initial result of trust-region method, mixture 20/40 sand and 20/40 ceramic (50\%/50\%) 122

Figure 64: Initial result of trust-region method, mixture 20/40 sand and 20/40 ceramic (25\%/75\%) 122

Figure 65: Initial result of trust-region method, mixture 40/70 sand and 20/40 ceramic (50\%/50\%) 123

Figure 66: Initial result of trust-region method, mixture 40/70 sand and 20/40 ceramic (25\%/75\%) 
Figure 67: Initial result of trust-region method, mixture 20/40 sand and 40/70 ceramic (50\%/50\%) 124

Figure 68: Initial result of trust-region method, mixture 20/40 sand and 40/70 ceramic (50\%/50\%) 124 


\section{List of tables}

Table 1: Base case's value of parameters in the sensitivity study

Table 2: Sensitivity points for 8 parameters (excluding 2 injection time parameters) _.......... 27

Table 3: Sensitivity points for 2 injection time parameters 28

Table 4: Correlation between output and input factors $\quad 55$

Table 5: Values of coefficients and $\mathrm{R}^{2}$ in the permeability model $\quad 58$

Table 6: Sample data of confining stress veresus depth, $0.5 \mathrm{ft}$ increment (Marcellus Shale)

Table 7: FRACPRO ${ }^{\circ}$ database for 20/40 sand $\quad 108$

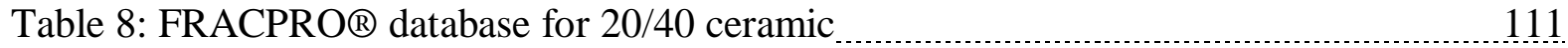

Table 9: FRACPRO® database for 40/70 sand $\quad 113$

Table 10: FRACPRO ${ }^{\circledR}$ database for $40 / 70$ ceramic $\ldots \ldots \ldots$

Table 11: Initial numerical results of all sensitivity incremental points for 8 studied parameters (exception of injection time parameters)

Table 12: Relative deviations from the base case value of all sensitivity incremental points for 8 studied parameters (exception of injection time parameters)

Table 13: Initial numerical results and relative deviations from the base case of all sensitivity incremental points for 2 studied injection time parameters

Table 14: Absolute values of lowest and highest deviations from the base case value for all 10 studied parameters 


\section{Nomenclature}

$\underset{C}{\operatorname{argmin}} F$ : minimization of function $\mathrm{F}$, depending on the variable $\mathrm{C}$ (equation (2.2))

$a$ : radius of contact surface (equation (1.11))

$a_{v}$ : Internal Specific Area

$A$ : contact area of the loaded proppant pack in API conductivity cell

$A_{m i x}$ : fractured area in which two proppant types co-exist (i.e. Mixture Zone area)

$A_{\text {tot }}:$ fractured area in which there exists injected proppant particles

$A_{\text {surface }}$ : surface area of solid particles

$\operatorname{ArConc}_{1}$ : areal concentration of proppant type 1

$\mathrm{ArConc}_{2}$ areal concentration of proppant type 2

$B^{-1}$ : inverse of matrix $\mathrm{B}$

CFD: Computational Fluid Dynamics

$C$ : standard weight concentration in conductivity lab measurements (typically $2 \mathrm{lb} / \mathrm{ft}^{2}$ )

$C_{f}$ : hydraulic conductivity of a fracture

$C_{l a b}:$ conductivity estimation based on lab conditions

$C_{\text {reservoir }}$ : conductivity estimation based on reservoir conditions

$C_{\text {fracture simulator }}$ : conductivity estimation from the fracture propagation simulator

$C_{C M G}$ : conductivity data imported into $\mathrm{CMG}$ reservoir simulator

$C_{L W A M}$ : conductivity estimation using LWAM

$C_{\text {semi-analytical model }}$ : conductivity estimation using the novel conductivity model

$C_{o}$ : initial value for iteration process of variable $\mathrm{C}$

$C_{k}, C_{k-1}$ : value of variable $\mathrm{C}$ (at iterations $\mathrm{k}^{\text {th }}$ and $\mathrm{k}-1^{\text {th }}$ )

$d$ : diameter of flow tubes (in Hagen-Poiseulle equation)

$d_{\text {coarser: }}$ dimeter of the coarser particle type

$d_{\text {finer }}$ : diameter of the finer particle type

$D_{i}(i=1,2)$ : mean diameter of particle types in a binary mixture

$\Delta D$ : width deformation of a proppant pack

$E, v$ : Young Modulus and Poisson Ratio

$E_{r}, v_{r}$ : Young Modulus and Poisson Ratio of contact rock surfaces or steel plates 
$E_{p}, v_{p}$ : Young Modulus and Poisson Ratio of contact proppant particles

$F_{D}$ : multiplication factor for effect of particle size distribution

$f\left(C, x_{\text {data }}\right)$ : general function of the coefficient determination problem (equation (2.1))

$G, E^{*}$ : notation of equivalence to quantity $\frac{E}{1-v^{2}}$

$h$ : total of width deformation and width embedment of a proppant pack

$i(i=1,2)$ : subscript for two proppant types in a binary mixture

ISP: Intermediate Strength Proppant

$I, J, K$ : notations of 3 dimensions in CMG reservoir simulator

KGD: Khrsitianovic Geertsma-de Klerk (name of a 2D fracturing model)

$K_{o}$ : Kozeny empirical constant/coefficient

$k$ : permeability

$k_{f}$ : fracture permeability

$k_{C M G}$ : permeability data imported into CMG reservoir simulator

LWC: Light Weight Ceramic

Mesh: US Sieve size (i.e. the number of openings in one square inch of a screen)

MRE: Mean Relative Error

$M$ : total weight of a proppant pack

$M_{i}(i=1,2)$ : weights of particle types in a binary mixture

$n$ : coefficient in the exponential tortuosity model (equation (1.10))

$n I, n J, n K$ : number of grids for 3 dimensions in $\mathrm{CMG}$ reservoir simulator

$N_{i}(i=1,2)$ : number of particle proppant types in a binary mixture

$N_{\text {mono-i }}(i=1,2)$ : number of particles in a monolayer of proppant types in a binary mixture

OAT: One at a Time

PKN: Perkins Kerns Nordgen (name of a 2D fracturing model)

$P$ : pressure

$P_{L}$ : pressure corresponding to one-half of Langmuir volume $\mathrm{V}_{\mathrm{L}}$ (equation (5.1))

$P_{c}:$ effective confining pressure/stress

$P_{o}$ : pressure/stress at initial condition (i.e. atmospheric condition in this thesis) or maximum contact pressure (in Hertzian contact theory) 
$P_{S}:$ average contact pressure on each proppant particle (equation (4.19))

$\boldsymbol{p}$ : norm of vector $\mathrm{p}$ (i.e. length of vector $\mathrm{p}$ )

$p$ : coefficient in the natural logarithmic tortuosity model (equation (1.8))

$p$ : step size (equation (2.3))

$p_{k}:$ step size between iterations $\mathrm{k}^{\text {th }}$ and $\mathrm{k}-1^{\text {th }}$

$r$ : radius of flow tubes (in Hagen-Poiseuille, equation (1.1)) or distance from the contact point to the located proximity where contact pressure is $\mathrm{P}$ (equation (1.12)

$\mathbb{R}$ : notation for set of all real numbers

$R$ : Weight Ratio, Weight Mixing Ratio, Weight Concentration Ratio, or contact particle's radius

$R^{2}$ : residual error between lab data and modelled data

$R_{a}$ : equivalent radius of the contact object in Hertzian contact theory

RCS: Resin Coated Sand

$s:$ specific surface area

span: set of all possible combinations of two arbitrary vectors (linear algebra, equation (2.7))

TotArConc: total areal concentration

ULW: Ultra-Light Weight

$V_{\text {solid }}$ : volume of solid particles

$V_{\text {one particle type } i}(i=1,2)$ : volume of particle types in a binary mixture

$V_{L}$ : maximum gas volume at infinite pressure (in Langmuir model, equation (5.1))

$x^{T}$ : transpose of vector $\mathrm{x}$ (same notation for transpose of a matrix)

$X$ : coefficient in the square-root tortuosity model (equation (1.9))

$w_{C M G}$ : default width data in $\mathrm{CMG}$ reservoir simulator

$w_{r e f}$ : reference width in the API conductivity cell (for proppant pack's width measurements)

$w_{f}$ : fracture width of a proppant pack under applied effective confining stress

$w_{r}$ : vertical deformation of the contact particle (in Hertzian contact theory)

$w_{f i}(i=1,2)$ : fracture width of a proppant pack (loaded by a single proppant type) under applied effective confining stress

$w_{f 0}$ : fracture width of a proppant pack under zero effective confining stress (i.e. initial fracture width)

$w_{f 0 i}(i=1,2)$ : initial fracture width of proppant types' sub-layers in the dual-layer unity 
$y_{\text {data }}, y_{l a b}:$ general notation of the measured/lab-computed quantity (equation (2.1), (4.44))

$\alpha, \alpha_{1}, \alpha_{2}$ : coefficient to determine the step size (equations (2.6), (2.7))

$\beta$ : compressibility factor or the non-Darcy factor (equation (5.2))

$\gamma:$ skewness in particle size distribution of an arbitrary proppant pack

$\delta$ : maximum width embedment (in Hertzian contact theory) or coefficient of variation in an arbitrary proppant pack (equation (1.5))

$\rho_{i}(i=1,2)$ : densities of particle types in a binary mixture

$\sigma_{H}$ : Minimum horizontal stress (i.e. equivalent to confining stress in this thesis)

$\emptyset$ : porosity

$\emptyset_{o}$ : initial porosity (i.e. porosity of proppant pack at zero applied effective confining stress)

$\tau$ : hydraulic tortuosity

$\tau_{o}$ : initial hydraulic tortuosity (i.e. hydraulic tortuosity of proppant pack at zero applied effective confining stress)

$\partial R D / \partial P_{c}:$ partial derivative of Relative Difference in term of confining pressure

$\partial R D / \partial R$ : partial derivative of Relative Difference in term of weight concentration ratio

$\Delta$ : upper bounded limit for trust-region radius (in trust-region method)

$\nabla$ : first derivative operator (equation (2.3))

$\%$ Mixture Zone: percentage of $A_{\text {mix }}$ compared to $A_{\text {tot }}$

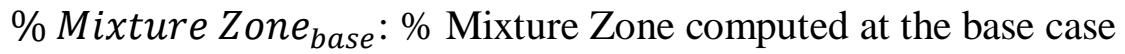

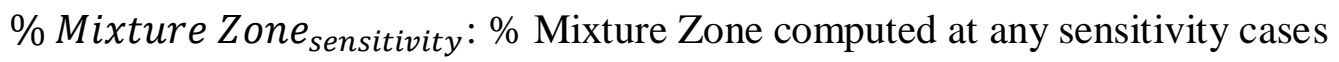




\section{Introduction}

In hydraulic fracturing, proppant injection schedule is planned to maintain high conductive fractures. A proppant injection schedule may apply a binary proppant mixture (100 Mesh sand following by $40 / 70$ Mesh). MIP-3H is an example well in Marcellus Shale which has binary mixture injection practices. The $1^{\text {st }}$ injection proppant type is finer/less resistant to stress (100 Mesh), and the $2^{\text {nd }}$ injection proppant type is coarser/more resistant to stress (40/70 Mesh). Binary mixtures create a region inside the fracture, in which two injected agents co-exist, defined as a mixture zone. Conductivity in this mixture zone is known to be estimated by Linear Weight Average Method (LWAM). However, validation for this model's efficacy has not been conducted. Therfore, this research aims at two purposes. The first purpose is to examine behavior of the mixture zone under changes in reservoir and treatment conditions. The second purpose is to derive a novel conductivity model which is used for mixture zones and expected to quantify conductivity estimation by LWAM.

Behavior of the mixture zone is examined by designing a local and standard One at A Time (OAT) sensitivity method (Morris, 1991). This sensitivity analysis combines a tested model, input and output factor(s). The tested model is an in-house fracture simulator which follows PKN fracture model $(\mathrm{Gu}, 2013)$. Input factors are selected from screening process. Output factor is percentage area of mixture zone. To acquire a novel conductivity model for mixture zones, semianalytical method and independent modelling for permeability and fracture width are directed. Permeability model inherits fundamentals in Carman-Kozeny equation (Kozeny, 1927; Carman, 1939). Internal Specific Area is re-derived for binary mixtures. Fracture width model inherits fundamentals in Hertzian contact (Hertzian, 1882) and elastic behavior concepts. For binary mixtures, an idealized dual-layer schematic is proposed to use these concepts simultaneously. 


\section{CHAPTER 1 -UNCONVENTIONAL RESOURCES AND HYDRAULIC FRACTURING}

\subsection{Unconventional resources}

According to Ehterington (2005), shale resources are characterized by their unability of commerical prodcution witout any stimlation techniqeues and/oir special recovery processes. These resources, which have been founded, investigated and studied for there decades (King, 2010), have been playing a dominant role in creating production benefits and playing a dominant role in the oil and gas industry. Accodring to US Energy Information Administration(EIA) in 2014, shale resources have been recored a remarabkle amount of technically recoverable 345 billion barrels of oil and 7299 trillion cubic feet of gas. Figure 1 presents the contribution of unconventional resrouces worldwide.

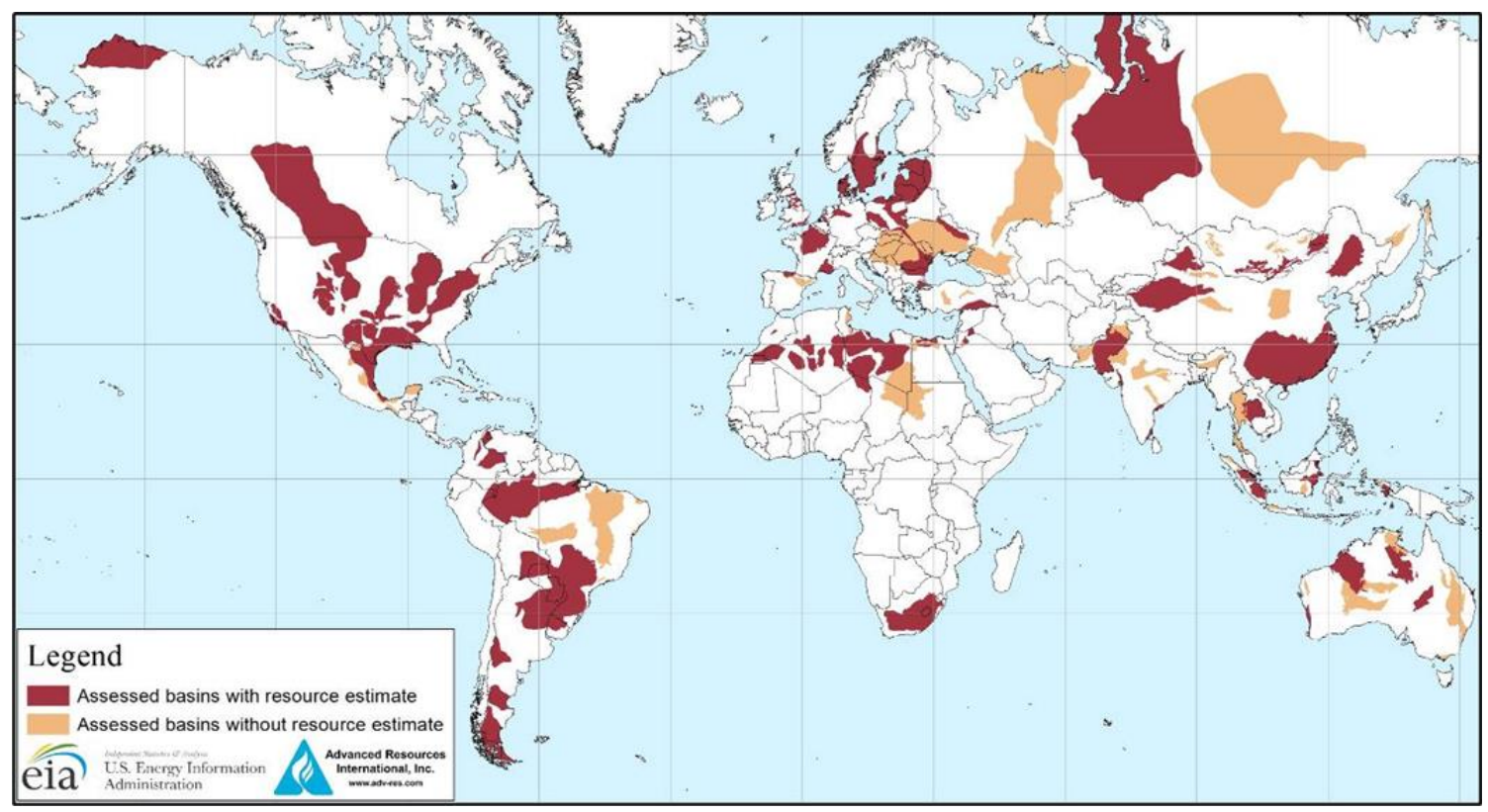

Figre 1 - Overview of unconventional plays, worldwide (EIA, 2014)

Besides existence of unconventional resources worldwide (China, Norway and European countries), US has significant and reputable unconventional deposits. A list of unconventional 
plays in the US include: Bakken in North Dakota, Barnett in Texas, Collingwood-Utica in Michigan, Woodford in Oklahoma, Marcellus in West Virginia and Pennsylvania. Figure 2 presents the contirbution of the unconventional plays in the US.

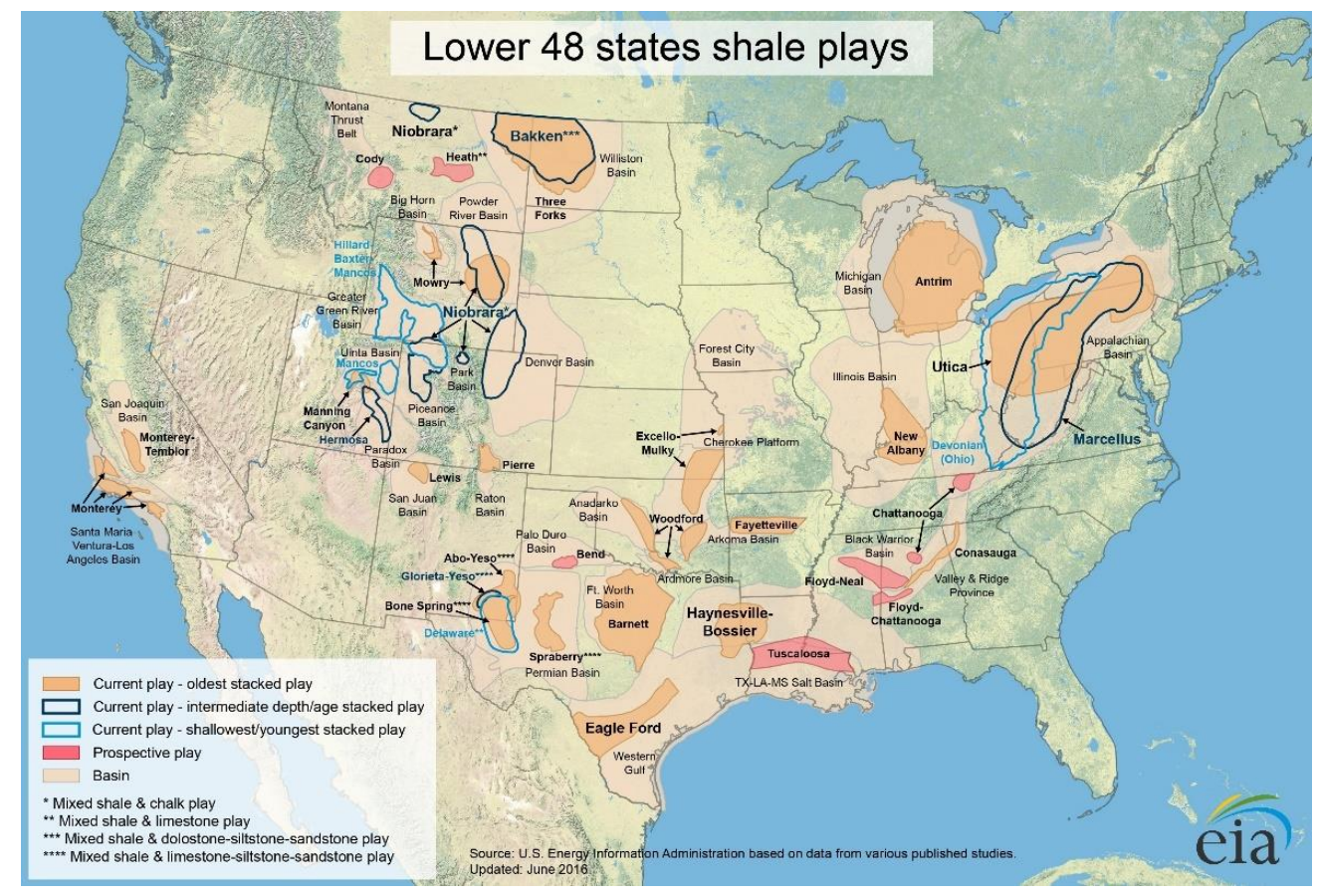

Figure 2 - Overview of unconventional plays, United States (EIA, 2016)

Based on the dominance of the unconventional plays' capablity in figures 1 and 2, it is undeniable to state that investment and study in extracting highest possible amount of petroleum from these unconventional resources is essential and beneficial for the industry. However, the definition of unconventional resources also infer the necessity of special recovery techniques specialized for this type of resources. Stimulation and especially hydraulic fracturing are two most well-known and professionlly-applied techniques for unconventional resources in the industry.

\subsection{Hydraulic fracturing}

\subsubsection{Theory of fracturing}

Early in 1952, hydraulic fracturing concept was introduced by H.K. Van Poolen. Hydraulic fracturing is the application of fluid pressursized injection to a desired section of a formation until 
rock failure occurs. Continuous pumping of fluid extends the break, which creates new and larger flow channels. Additional injection of proppants (for example: Otawa sand, bauxite, Ultra Light Weight -ULW ) supports keeping the fracture open after injection pressure is released from the inejction process. (H. K. Van Poolen, 1952). Based on this author' study and the description of hydraulic fracturing, the technique involves the following fundamentals:

- Principle of rock failure

- Injection of fracturing fluid and proppants

- Creation of highly conductive channels

Within three fundamentals, principle of rock failure is the base in fracturing theory, and it initiates the understanding of the remaining two principles. In the reservoir, rock is affected by different types of stresses. For a microscopic representation under genral scope, figure 3 describes principle stresses which impact a potion of rock's state (H. K. Van Poolen, 1952):

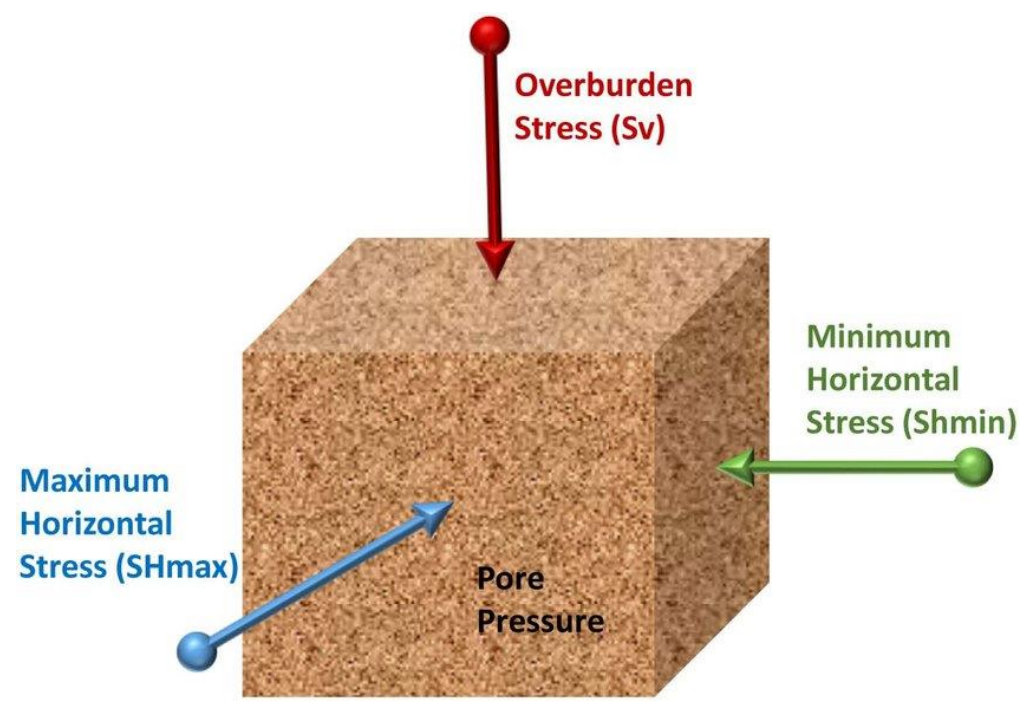

Figure 3 - Principle stresses impacting a portion of rock (Petrowiki)

With an exception of shallow depth, approximately at $1000 \mathrm{ft}$ or shallower (where no formation of interest for petroeleum has been commercially recorded), the value of overburden stress is the largest stress applied to the rock. Additionally, there always exists one lower horizontal 
stress and one higher horizontal stress value, within two present horizontal stresses in figure 3 . The lower horizontal stress value is defined as the Minimum Horizontal Stress, denoted as $\sigma_{H}$. Several studies prove the opening and propagation of a fracutre inside the reservoir rock is perpendiuclar to the direction of the Minimum Horziontal Stress, albeit a few claims of extreme shear should be the main reasoning in replacement of the Minimum Horizontal Stress.

\subsubsection{Fracture modeling}

Fracture propagation modelling started to receive concerns from 1955, when the first twodimensional fracturing model was introduced by Howard and Fast. In the following years, other enhancements of two-dimensional fracture modelling were published, which include: PKN (Perkins, and Kern, 1961, later modified by Nordgen, 1972) and KGD (Khristianovitch and Zheltov, 1955; Klerk and Geertsma, 1969). These modelling approaches have been successful until the interinsic complexity of facture propagation inside the reservoir rock arised more focus for a better fracturing design and treatments. Because of this complexity, pseudo three-dimensional and fully three-dimensional fracture modelling approach began replacing two-dimentional models and have been being widely practiced in the industry. Examples of these approaches include Settari and Cleary (1986), Gu and Leung (1993), Sounes et.al (1993).

In this section, theoretical reviews for both two-dimensional models (including PKN and KGD) and three-dimensional models are provided. Primary, derivation and numerical solutions relevant to all models are fully described in Ming Gu (2013).

\section{PKN model}

PKN model was initially derived by Perkins and Kerns in 1961. There are 4 primary assumptions in the derivation process of $\mathrm{PKN}$, as follows:

- Fracture height is constant and not depdent on fracture length. 
- In the vertical cross-sections (perpendicular to the propagation direction), fracture fluid pressure is constant.

- 2D strain deformation occurs only in the vertical plan.

- The cross-section (vertical section) has an elliptical shape and the maximum width is located at the centre of fracture height.

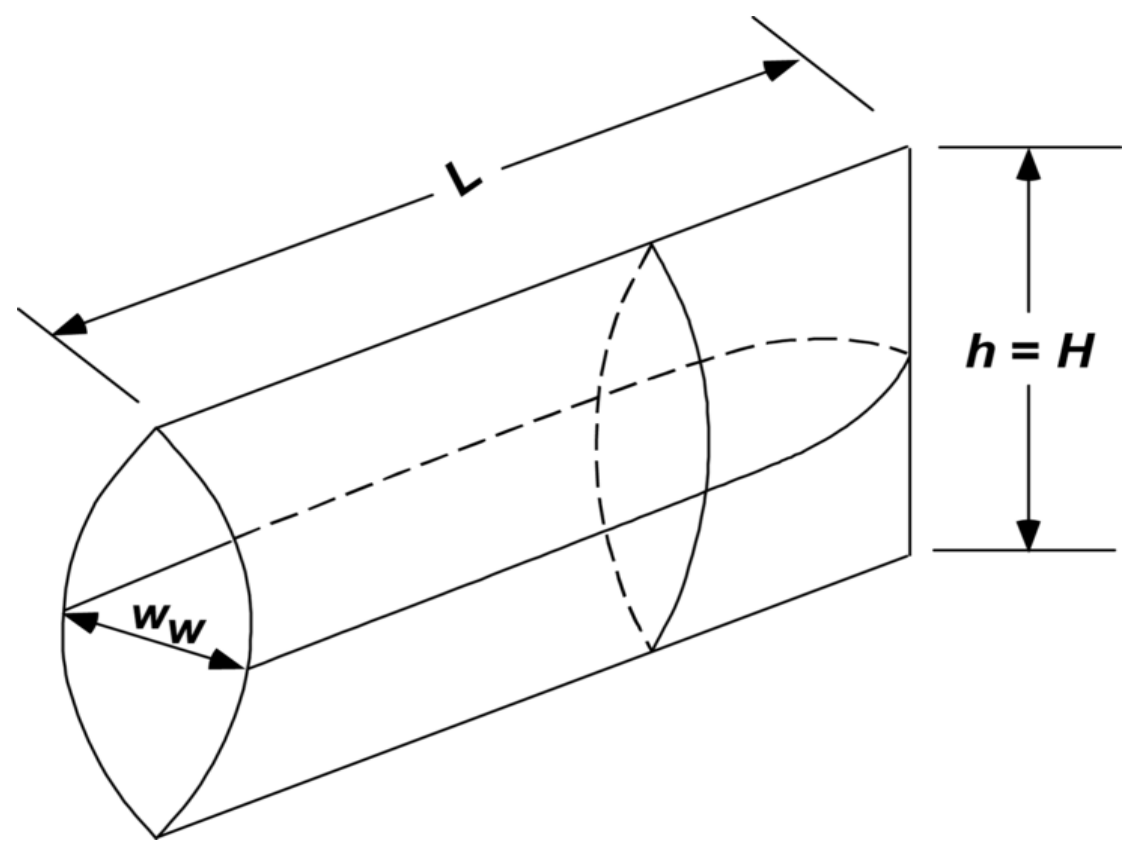

Figure 4 - Schematic for a PKN model (Petrowiki)

Based on these 4 modelling assuptions, the fracture width, maximum fracture width, were acquired. In 1972, concerns for a Newtonian fluid and Laninar flow regime, the pressure gradient along the fracture propagation orientation was derived by Nordgren using the volume balance equation. Nordgen additionally studied the leak-off efffect using constant leak-off rate.

\section{$K G D$ model}

This 2D model exhibits similarities with PKN regarding constant fracture height and variable width values along the fracture length. However, KGD has its own diffrences, as follows:

- Horizontonal plane has elliptical shape (in replacement of vertical plane in PKN) 
- Fluid pressure varies along the propagation orientation (in replacement of constant in PKN)

- Vertical cross-section plane along the fracture height is a rectangular form (in repalcement of a elliptical form in PKN)

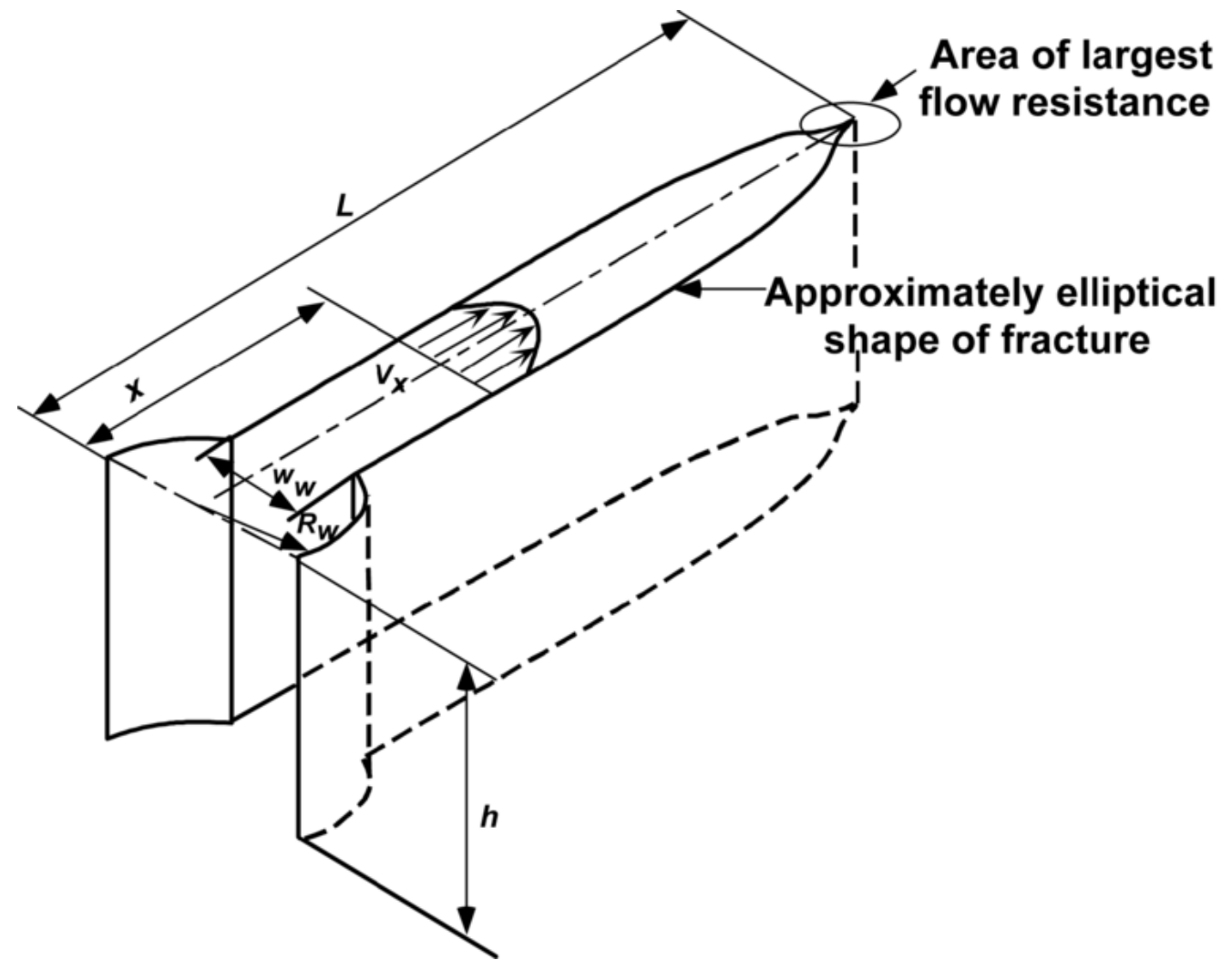

Figure 5 - Schematic for a KGD model (Petrowiki)

\section{Three-dimensional models}

As PKN and KGD are reviewed, both of the 2D models assume constant fracture height as one of their core assumptions prior to the modelling process. However, resonable interpretation from stress contrast between the interest formation and its adjacent formations state that fracture height is variable, since fractures may propagate through the interested formation and reach the adjacent formations. This drawback from 2D models were addressed by three-dimensional models, which imply variable fracture height in the modelling process. 


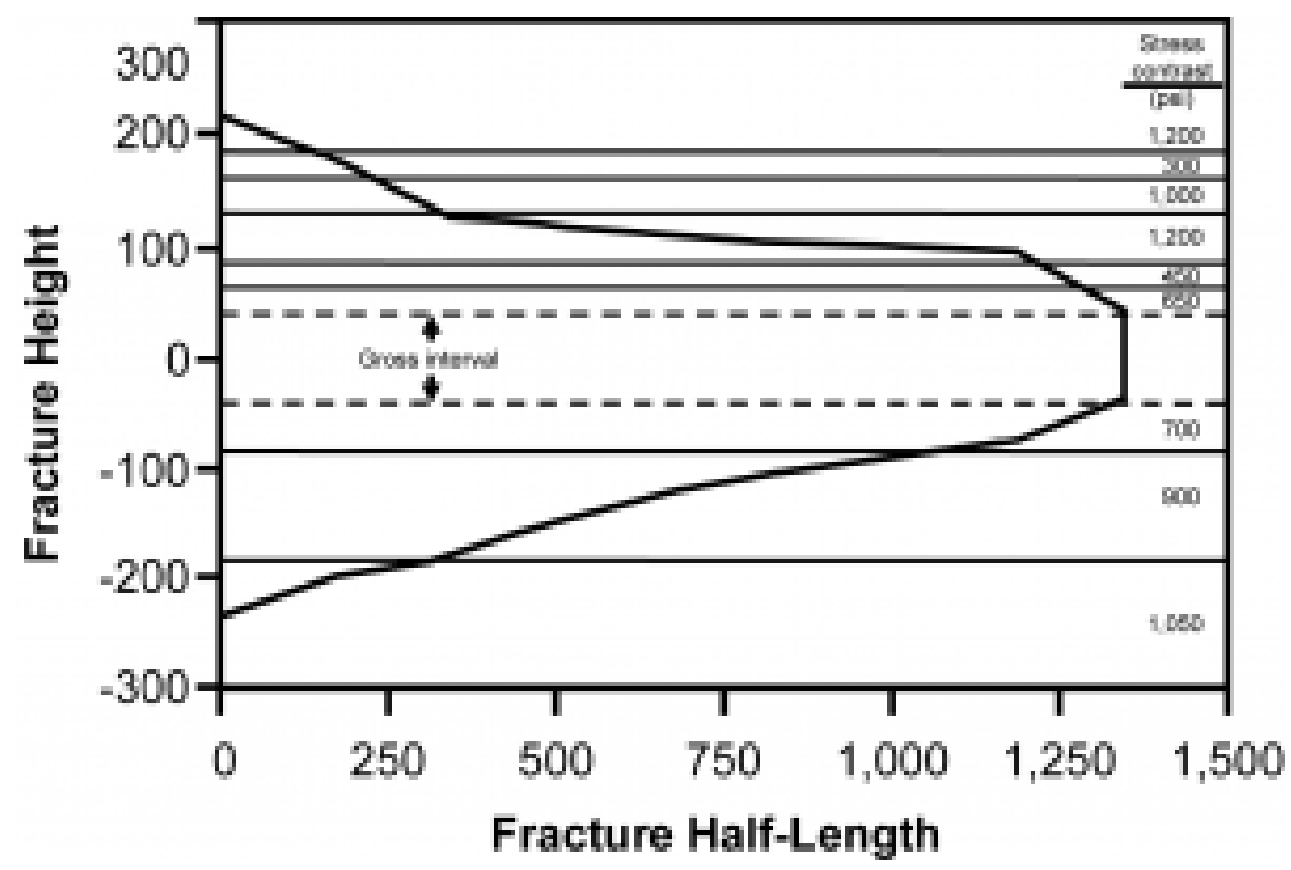

Figure 6 - Correction for fracture height in pseudo 3D models (Petrowiki)

\subsection{Proppants and hydraulic conductivity}

Proppants are natural solid particles (for example: Otawwa sand) or artificallymanufactured particles (for example: synthetic bauxite) which have various physical sizes, densities, chemical properties, and mechanical properties. Based on available records of hydraulic fracturing practice in US shale formations, sand and ceramic are two most common catergories in a total of more than 50 proppant types available in the industry (Michael J. Economides and Tony Martin, 2007).

\section{Sand}

Sand has been undeniably the most common proppant from the time practice of injection solid material into the fractures was initiated (early 1950s). Ottawa sand (i.e "white' sand, originality is Illinois, US) or Hickory sand (i.e. "brown" sand, originality is Texas, US) are two popular names of nature sand proppants. Sand is primarily made of quartz, chemically known as silicon dioxide $\left(\mathrm{SiO}_{2}\right)$, and typically has nominal density $1.631 \mathrm{~g} / \mathrm{cc}$. Being advanced over decades 
of hydraulic fracturing practice, sand proppant has been artifically manufactured besides natural resources (for example: Resin Coated Sand, or RCS) to adapt to harsher stress conditions inside reservoirs. Albeit the fact that sand is inexpensive and readily available because of resource diversity, brtittle failure issue of quarts combined with high level of embedment under contact with rock surfaces at high stress (Michael J. Economides and Tony Martin, 2007) prevent sand from being evaludted as a qualified candidate in all fracturing practices.

\section{Ceramic}

Ceramic was addressed as a better candiate compared to sand, and it was invented in the 1970s. The main chemical component of ceramic is aluminium oxide $\left(\mathrm{Al}_{2} \mathrm{O}_{3}\right)$ and its density is nominally $3.8 \mathrm{~g} / \mathrm{cc}$. Ceramic is known to be typically heavier and better resistant than sand. High resistance proved ceramic's capability in hydraulic fracturing when being applied to deep gas wells. Similar to sand, ceramic has been enhanced to meet the industry's needs. The approach to diversify ceramic is essentially modification in the percentage of aluminium oxide in ceramic proppant types. For example, Intermediate Strength Proppant (ISP) has $70 \% \mathrm{Al}_{2} \mathrm{O}_{3}$, bauxite has $80 \% \mathrm{Al}_{2} \mathrm{O}_{3}$ and Light Weight Ceramic (LWC) has 50\% $\mathrm{Al}_{2} \mathrm{O}_{3}$ (Michael J. Economides and Tony Martin, 2007).

In hydraulic fracturing, proppants play a critial role in performance of effective fractures. Proppants are purposed to sustain from the impact of reservoir stresses, keep the fracture remain open, and artifically open a highly porous and especially permeable medium. This new medium exists as a highly conductive channel to support flow of petroleum fluid from the reservoir into the wellbore (as the natural porosity and permeability of shale are notoriously low). Therefore, efectiveness of proppant inejction is examined by the fluid flow capability of the created conductive channels. Albeit permeability is the petroleum concept to describe the fluid flow capability inside a porous medium, hydraulic conductivity is a more conventional concept to 
describe fluid flow capability inside propped fractures. The definiton of hydraulic conductivity (shortly abbreviated as conductivity in hydraulic fracturirng field) is:

$$
C_{f}=k_{f} w_{f}
$$

Conductivity modelling has been commonly performed by separate modelling for fracture permeability and fracture width. Later in this chapter, review of different modelling approaches for fracture permeability and fracture width are detailed.

\subsection{Proppant studies for binary mixtures}

Since this thesis focuses on studying binary proppant mixtures, review for previous studies regaridng bianry mixtures is certainly necessary. Albeit several studies focusing on permeability and/or conductivity for a single proppant type, binary proppant mixtures have not received similar concern degree. Particularly, binary proppant mixtures, which are composed of two proppant types (differrent in sizes or densities), have been in shortage of experimental data for permeability and/or conductivity. The earlist experimantal study for binary proppant mixutres were conducted by Rober R. McDaniel and John R. Willingham (1978). Recently, other comprehensive studies for binary proppant mixtures were conducted by Eric Schultz at Univeristy of Texas at Austin (2014) and Ming Fan et.al (2020).

In the study by Rober R. McDaniel and John R. Willingham (1978), experiments were performed for permeability mesurements merely. 3 types of materials (Sand, Sinter Bauxite and Glass Beads) and 3 types of Mesh sizes (10-20, 20-40, and 100) were selected. Additionally, 3 weight ratios were prepared for each binary mixture $(90 \% 10 \%, 75 \% / 25 \%$ and $50 \% / 50 \%)$, with two subtle changes to $95 \% / 5 \%$ (from $90 \% / 10 \%$ ) and $80 \% / 20 \%$ (from $75 \% / 25 \%$ ) for one binary mixture. Abeit the diversity of options from these materials and Mesh sizes, only 3 binary mixtures 
were tested in this study. Experimantal settings and mesurement procedure closely followed Darcy’s Law to obatain permeability.

There are advantages in the design of experiments in Rober R. McDaniel and John R. Willingham (1978) compared to Eric Schultz (2014). All studied binary mixtures by these authors were prepared with 3 weight ratios, which provides more certainty in alalysis of coefficients during analytical/semi-analytical modelling process. Furthermore, the binary mixtures of sand (i.e. Hickory Sand - 100 Mesh Sand), which is still a common paractice in the industry because of cost efficiency, was studied more carefully compared to similar sand binary mixtures in Eric Schultz (2014). However, an important disadvantage in the study by these authors is shortage of concern for conducitvity data for tested binary mixtures, which challenges the modelling validation processes and does not support the primary motivation of this thesis.

In the study by Eric Schultz (2014), experiments exhibited a more systematic degree compared to Rober R. McDaniel and John R. Willingham (1978). Since a portion of the lab data by Eric is selected for modelling and validation in this thesis, his expriment settings and options of binary mixtures should be reviewed in further details.

Regarding the options of binary mixtures, 3 types of different materials (sand, ceramic and Ultra Light Weight - ULW), and 2 range of Mesh sizes (20/40 and 40/70) were selected. Besides, at least one weight ratio was dicided to mix the proppant types in a bianry mixture $(25 \% / 75 \%$, or $50 \% / 50 \%$, or both ratios). In specific, these binary mixtures were measured in Eric's study:

- $\quad 20 / 40$ sand and 20/40 ceramic, weight ratio $25 \% / 75 \%$

- $\quad 20 / 40$ sand and 20/40 ceramic, weight ratio 50\%/50\%

- $\quad 20 / 40$ sand and 40/70 ceramic, weight ratio $75 \% / 25 \%$

- $\quad 20 / 40$ sand and 40/70 ceramic, weight ratio 50\%/50\% 
- $20 / 40$ ceramic and $40 / 70$ sand, weight ratio $70 \% / 25 \%$

- $20 / 40$ ceramic and $40 / 70$ sand, weight ratio $50 \% / 50 \%$

- 40/70 sand and 40/70 ceramic, weight ratio 50\%/50\%

- $\quad 20 / 40$ sand and 40/70 sand, weight ratio $50 \% / 50 \%$

- 20/40 sand and 20/40 ULW, weight ratio 50\%/50\%

Regarding the experimental settings, an API conductivity cell assembly coupled with a hydraulic pump were used to measure permeability and width of a loaded proppant pack under equivalent confining stress from the hydraulic pump. The confining stress, exerted from hydraulic pressure from the pump, was applied to the two steel plates in the API conductivity assembly. In addition, a back pressure of 350 psi was pre-set in all experiments to ensure fluid flow inside the loaded proppant pack for permability measurements.

For all binary mixtures listed as above, permeability and proppant pack's width data were recorded for different confining stress (discrete data) between 2000 and 1000 psi (from 5 to 10 data points, depending on the tested binary mixture). Permeability was measured based on application of Darcy's Law. Experimental processes for permeability are examined to have a reasonably low degree of errors in contribution to the overall conductitvity lab data.

Proppant pack's width was measured indirectly using a reference width. This reference width (at each applied stress data point) related to the total height of the API conductivity assembly with no proppant pack loaded inside the cell. Using reference width, proppant pack's width (at each applied stress point) was measured by subtraction of the reference width from the measured width of the API conductivity cell with proppant pack loaded. According to the author's claims, a minor degree of variance during reference width mesurement $(0.02-0.08$ inches $)$ was recorded. However, this degree of variance may convert to a variance range between 20 and $1300 \mathrm{mD}-\mathrm{ft}$ for 
condcutivity data. As a result, experimental processes for proppant pack's width are examined to have noticably higher degree of errors in contribtuion to the overall conductivity lab data. As width mesurement is evaluated as unsatisfaction in degree of mesurement errors, lab data for proppant pack's width is not selected for fracture width modelling. In order to compensate for this unsatisfaction, lab data for propapnt pack's width with higher quality is selected from FRACPRO® databse for modelling in this thesis, which is detailed in chapter 4 and in the Appendix.

Besides evaluation of permeability and proppant pack's width data, another evaluation is required for available lab data from Eric's study. Only 3 binary mixtures (within the total of 6) have available lab data for both weight mixing ratios. Since weight mixing ratio is one of the two priorities in the novel conductivity model, the three binary mixtures with lab data for $25 \% / 75 \%$, and $50 \% / 50 \%$ ratios are selected to be modelled. In consequence, selected list includes 20/40 sand20/40 ceramic, 40/70 sand-20/40 ceramic, and 40/70 ceramic-20/40 sand.

\subsection{Fracture permeability modelling}

As fracture medium contains proppant particles under imapct of different stress orientations, fracture permeability modelling has been evolving from modelling for granular particulate bed medium.

Early approaches, for example in Hagen-Poiseulle equation, modelled the granular bed medium as a tube-bundle schematic. Application of the tube-bundle schematic derived the most generic form of permeability:

$$
k=\frac{\emptyset r^{2}}{8 \tau}
$$

Further concepts as specific surface area $s=\frac{2 \emptyset}{r}$ and closely-reslistic assumption of spherical forms for particles was implied to tranform this concept into $s=\frac{6(1-\emptyset)}{d}$. Under a schematic of identical spherical-formed particles (which can be referred to a single proppant type 
under the use of mean diameter as a representative number), equation (1.2) for permeability is revised as:

$$
k=\frac{d^{2}}{72 \tau} \cdot \frac{\emptyset^{3}}{(1-\varnothing)^{2}}
$$

Carman and Kozeny examined the validity of this permeability model empirically (detailed in Dullien and F.A.L, 1992) because they considered the effect of proppant arrangement, shape factor and pore traejctories. From their studies, an empirical coefficient, which was abbreviated as Carman-Kozeny coefficient, was intergrated into the peremability model as:

$$
k=\frac{d^{2}}{72 K_{o} \tau} \cdot \frac{\emptyset^{3}}{(1-\emptyset)^{2}}
$$

Where $K_{o}$ is 2 for a general particulate bed (Kozeny, 1927). Albeit there has been different modelling appraoches from equation (1.2) (Dullien and F.A.L, 1992), Carman- Kozeny permeability model is extenisvely selected for fracture permeability modelling as a starting point, and further narrowed down to analytical or semi-analytical modelling. One notable modification from Carman-Kozeny equation was implication of particle size distribution inside the granular bed (Panda and Lake, 1994). The multiplication factor which models particle size distribution in their study is formualated as:

$$
F_{D}=\frac{\left(\gamma \delta^{3}+3 \delta^{2}+1\right)^{2}}{\left(1+\delta^{2}\right)^{2}}
$$

By far, effect of confining pressure has not been mentioned, albeit this does not infer that this effect has not been studied. Simple understanding from the definiton of porosity and tortuosity, which are intergrated in the Carman-Kozeny equation, is reaonsable to state their dependency on confining stress (Jia-Hyun dong et.al, 2010; Ricardo Dias et.al, 2006). Consequently, they are modelled as a function of confining stress, and further integrated into the Carman-Kozeny equation as a solid option for a permeaiblity model. A few empirical modelling equations for porosity and 
tortuosity are in this chapter. For porosity, in Jia-jun dong et.al (2010), two most common porosity models were studied for sandstone, limestone and shale:

$$
\begin{aligned}
& \emptyset=\emptyset_{o} e^{-\beta\left(P-P_{o}\right)} \\
& \varnothing=\emptyset_{o}{\frac{P}{P_{o}}}^{-q}
\end{aligned}
$$

Equation (1.6) has been widely used in modelling porosity for sandstone and limestone reservoirs with compressiblity coefficient $\beta$ between $10^{-6}$ and $10^{-4} \mathrm{psi}^{-1}$ scale. However, in fractured media, $\beta$ representes fracture coefficient which can approach $10^{-3}$ scale (Dong chen et.al, 2014). Equation (1.7) is a better option for shale than conventional reservoir rocks. For tortuosity, its models typically integrate porosity as one of the independent variables, and each tortuosity model may limit itself to an empirical porosity range. A critical tortuosity review in Ghanbarian et.al (2013) provides widely-used tortuosity models for different types of granular media:

$$
\begin{aligned}
\tau & =1-p \ln (\varnothing) \\
\tau & =1+X \sqrt{1-\varnothing} \\
\tau & =\emptyset^{-n}
\end{aligned}
$$

Equation (1.8) and (1.9) are typically not applied to a proppant pack's porous media since their porosity range for application exceeds 0.4 or their tested media do not resemble a proppant pack's porous media. Equation (1.10) was referred to model tortuosity for binary spherical mixtures in Mota et.al (2001). In this study, coefficient $n$ in equation (1.10) was experimentally stated between 0.4 and 0.5. However, both Mota et.al (2001) and Ghanbarian et.al (2013) conluded the non-universality of $\mathrm{n}$ and its depedence on some intrinsice property of the modelled medium. This statement allows limited use of equation (1.10) in modelling tortuosity for binary mixtures in this thesis, underlying the modelling context as a reminder.

\subsection{Fracture width modelling}


Similar to permeability, fracture width modelling evolves from modelling of width in a granular bed. Prior to review of fracture width modelling, it is fundamental to review physics of a particle pack under impact of applied stress. In most of fracture width modelling studies, there involve two essential physics: particle deformation and particle contact embedment. Particle deformation is referred to deformation behaviors for a material, beginning from elastic, plastic and eventually material rupture. During the series of deformation behaviors, the particle pack width decreases when applied stress increases.

Particle contact embedment is referred to the phenomenon when there exists contact between any surfaces of similar or different materials. In case of a particle pack, this phenomenon occurs at contact within proppant particles of the pack, and contact between proppant particles and the adjacent rock layers' surfaces (modelled as an elastic, flat surface). In 1882, Hertzian studied these contact embedment phenomena, and this study has been named as Hertzian contact theory (fully described and derived in Anthony C. Fiischer-Cripps, 2007). The theory modelled contact zdeformation occurs in the proximity of the conpact point.

Contact pressure in Hertzian contact theory is modelled as:

$$
P=P_{o}\left(1-\frac{r^{2}}{a^{2}}\right)^{2}, r \ll a
$$

Where $\mathrm{P}$ is the contact pressure at a proximity within the circle of radius $\mathrm{a}, \mathrm{P}_{\mathrm{o}}$ is the maximum contact pressure at the contact point between two objects, and $r$ is the distance from the contact point to the located proximity in which contact pressure is P. Vertical deformation (Anthony C. Fiischer-Cripps, 2007) corresponding to contact pressure in (1.6) is:

$$
w_{r}=\frac{\pi P_{o}}{4 E^{*} a}\left(2 r^{2}-a^{2}\right)
$$

Where $\mathrm{w}_{\mathrm{r}}$ is vertical deformation, and $E^{*}=\frac{E}{1-v^{2}}$. In case the deformation suface is an arc of a circle with radius $R_{a}$, Hertzian proposed the quantity $\mathrm{w}_{\mathrm{r}}$ as: 


$$
w_{r}=w_{o}-\frac{r^{2}}{2 R_{a}}
$$

Where $\mathrm{w}_{\mathrm{o}}$ is the maximum of $\mathrm{w}_{\mathrm{r}}$ when $r=0$. Equations (1.7) and (1.8) have to be equal, therefore $\mathrm{w}_{\mathrm{o}}$ and $R_{a}$ are extracted as:

$$
\begin{aligned}
& W_{o}=\frac{\pi P_{o} R_{a}}{2 E^{*}} \\
& R_{a}=\frac{\pi a P_{o}}{2 E^{*}}
\end{aligned}
$$

Equations (1.9) and (1.10) are modified to derive a realtionship between $\mathrm{w}_{\mathrm{o}}$ and $\mathrm{R}$ as:

$$
a^{2}=R_{a} w_{o}
$$

Application of Hertzian contact theory, primarily using euqations (1.14), (1.15), and (1.16), has been referenced in several proppant pack's width modelling approaches: analytical, semianalytical, numerical, or combination of at least two mentioned methods. Jianchun Guo et.al (2012) combined the contact theory with Laplace mathematical transformation to model realtionship between creep effect and proppant deformation. Khanna et.al (2012) combined Hertzian contact theory, monolayer assumption, particle neigbouring effect, and Computational Fluid Dynamics (CFD) to model proppant deformation in narrow fractures. Yuaning Gao et.al (2013) modelled proppant deformation analytically by modifying Hertzian contact theory for a single-layer pattern in coal beds and extended to multiple-layer pattern. Recently, Jianchun Guo et.al (2017) proposed an analytical model for proppant deformation and embedment by combination of Hertzian contact theory and sparse effect better proppant clusters. Albeit different modelling approaches have been proposed as being reviewed, the modelled assembly is selected to resemble a proppant pack of a single proppant type (i.e. single-sized spherical particles). 


\section{CHAPTER 2: NON - LINEAR LEAST SQUARE PROBLEMS AND TRUST REGION METHOD}

Acknowledgement of theoretical backgrounds, which are related to application in this thesis and described in this chapter, mainly refers to these three references: Numerical Optimization (Jorge Nocedeal and Stephen J. Wright, 1999), Inverse theory for petroleum reservoir characterization and history matching (Dean Stuart Oliver, Ning Liu and Albert Reynolds, 2008), and Optimization Toolbox documentation (MATLAB ${ }^{2}$, version 2019b).

Within the development of any physics-absed modelling aprroach, relevance of constant and coefficients contributes an integrated portion in understanding the behavior of the modelled phenomena. Constants and coefficients represent an intrinsic property of the modelled factor under change of the relevantly-determined factors. One example of a constant is Young Modulus, which represents rate of deformration of a material under its elastic behavior range. One example of a coefficient is the pore compressibility, which represents change of porous volume under change of formation pressure.

Albeit constants and coefficients are intergrated in a physics-based modelling process, they exhibit differences. Constants are naturally more universal than coefficients, which may depend on various modelled phenomena. Consequently, coefficients have their empirically known range of values (i.e. known as constraints) to fit their purposes. Different techniques have been exploited in order to determine the suitable values for coefficients in specific contexts. In the modelled context of this thesis, supportive lab data allows application of numerical optimization techniques to determine the coefficients. For more details, determination of coefficients is processed by solving the following equation(s):

$$
f\left(C, x_{\text {data }}\right)=y_{\text {data }}
$$


Where $\mathrm{C}$ presents the coefficients, $\mathrm{x}_{\text {data }}$ presents the values of experimentally-controlled factors (i.e confining pressure, weight mixing precentages), and $\mathrm{y}_{\text {data }}$ presents the values of measured quantities (i.e. permeability, conductivity). Numerical optimization techniques used to solve the equation(s) are typically linear based solvers or non-linear based solvers (Jorge Nocedeal and Stephen J. Wright, 1999). Because of complexity in petroleum problems, the use non-linear based solvers is typical and further discussed in this chapter.

Non-linear based solvers do not directly solve the aimed variables (which are coefficients $\mathrm{C}$ in this context). In contrast, they estimate the best possible outcomes of the aimed variables by solving the following consequent problem generated from equations (Jorge Nocedeal and Stephen J. Wright, 1999):

$$
\underset{C}{\operatorname{argmin}} F=\left(f\left(C, x_{\text {data }}\right)-y_{\text {data }}\right)^{2}
$$

The function in (2.2) is a representation of a non-linear least-square problem and is defined as the objective function. For a non-linear least square problem, aimed variables are extracted from a sequence of iterations. The sequence starts from a specific $\mathrm{C}_{0}$, updates itself after $\mathrm{k}^{\text {th }}$ iteration as $\mathrm{C}_{\mathrm{k}}=\mathrm{C}_{\mathrm{k}-1}+\mathrm{p}_{\mathrm{k}}$, and stops when the global minimum of the function in (2.2) is approached under desired accuracy degree (i.e. sufficient error tolerance) . The scope of solving the orginial equation(s) in (2.2) now evolves to the scope of solving the objective function. Two categorized directions to solve equation (2.2) are line-search and trust-region methods. Since trust region method exhibits higher flexibility, and better control within a iteration comapred to line-searhc method, it is selected to be used in this thesis. This method and its fundamental backgrounds (Taylor theorem, positive definite matrices) are addressed in this chapter.

\subsection{Taylor theorem}


Presumably a function $f(x)$ exists its first and second derivatives, its dependence on the indepdendent variable $(x+p)$, where $p \in \mathbb{R}$, is exapnded as:

$$
f(x+p)=f(x)+\nabla f(x)^{T} p+\frac{1}{2} p^{T} \nabla^{2} f(x+t p) p, t \in(0,1)
$$

Taylor theorem provides the estimation of function $f(x)$ under a step size $p$. In case the $\mathrm{n}^{\text {th }}$ derivative of $f(x)$ contiuously exitsts, the estimation continues with the term holding $\mathrm{n}^{\text {th }}$ derivative. Within the context of Taylor theorem'use in this thesis for its non-linear least square problems, estimation is limited until second derivative term.

\subsection{Positive definite matrices}

A square matrix A (dimensions $n \times n$ ) is defined as a positive definite matrix if the following condition: $x^{T} A x>0$ is satisfied for all non-zero vector $\mathrm{x}$ with length $\mathrm{n}$.

\subsection{Trust-region method}

\section{Overview of the method}

Trust region method directs toward the global minimum of function (2.2) indirectly by minimizing a model function (different from the function (2.2)) within a selected trust region (commonly a circle). Trust region selection and minimization of the model function are performed in all iterations until reaching global minimum of the model function.

The latter condition infers that the model function has to similarly behave as the function (2.2), within the trust circle. Additionally, function (2.2) is quadratic. As a result, the model function shall be a quadratic estimation of function (2.2) within control by trust circle, and a reasonable selection of which is application of Taylor theorem. In general, selection of the model function is a quadratic function in which the quadractic term may hold a positive definite matrix in replacement of the second derivative as in Taylow theorem. The model function of function $F$ in (2.2) as and the radius of trust circle are notated as $M$ and $\Delta$, respectively. Under step size $p$ 
controlled by the trust circle of radius $\Delta$, Model function $M(x+p)$ is generally written for one interation as follows:

$$
M(x+p)=F(x)+\nabla F(x)^{T} p+\frac{1}{2} p^{T} B(x) p, \boldsymbol{p} \leq \Delta
$$

Where $\boldsymbol{p}$ is the norm of $p$ and $B(x)$ is the positive definite matrix which replaces the second derivative in the quadratic term. Description of $M$ as in (2.4) satisfies the latter condition of trust-region method.

\section{Analysis of the model function under restriction by trust region}

In each iteration, minimization of the model function certainly guides the direction to its global minimum. Furthermore, trust-region method always limits the step size along this direction by the selected trust circle. Based on description of model function $M$ in (2.4), a proper direction and an optimal step size as two requirements, $p$ needs to be determined in each interation in order to minimize $M$.

Minimization of a quadratic function as $M$ in case trust region is neglected is known by interpreting its first derivative:

$$
M^{\prime}(p)=\nabla F+B p, M^{\prime}(p)=0 \leftrightarrow p=B^{-1} \nabla F
$$

In case the trust region is not neglected and $B^{-1} F \leq \Delta$ certainly $p=B^{-1} F$ becomes the solution of $p$ in that specific iteration. Since the condition $B^{-1} F \leq \Delta$ occurs with uncertainty, different techniques have been developed to find the optimal $p$ in case $B^{-1} F \leq \Delta$ is not satisfied. Two examples are Cauchy Point and Dog Leg Method (Jorge Nocedeal and Stephen J. Wright, 1999). There is a similarity in these tecniques' solutions: the optimal $p$ has the general formula as:

$$
p=\alpha \nabla \mathrm{F}, \alpha<0
$$

Therefore, using the span concept in linear algelbra, optimal $p$ in an iteration is generally formulated as: 
$p \in \operatorname{span}\left(\nabla F, B^{-1} \nabla F\right) \leftrightarrow p=\alpha_{1} \nabla F+\alpha_{2} B^{-1} \nabla F,\left(\alpha_{1}, \alpha_{2}\right) \in \mathbb{R}^{2}$

Determination of the optimal $p$ as in (2.7) is the two-dimensional subspace minimization, which is the core intergrated algorithm inside the trust-region method for non-linear least square problems in MATLAB® R2019b Optimization Toolbox.

\subsection{Setting constraints}

From the previous dicussions of solver methods in this chapter, involvement of contraints have not been discussed. In fact, an advantage of solvers for non-linear least square problems (both line search and trust region methods) is their indepence on the aimed variables' constraints. However, modelling approaches for physics-based phenomena always include coefficients' constraints. Therefore, coefficents' constraints have to be enforced along with the solver methods. They should be reasoned properly to fit in the modelling contexts and should not be aligned to the outlier sides when referenced to their empirically known ranges. Further discussions are detailed in chapter 4, which describes the modelling approach of this thesis. 


\section{CHAPTER 3 - SENSITIVITY STUDY}

\subsection{Existence of the Mixture Zone inside a propped fracture}

Accrding to the abstract of this thesis, a descriptive statement for the Mixture Zoneis initiated from inejction of a binary propant mixture. However, clear visualization for this Mixture Zoneis necessary to further study its behaviour under consierable factors (i.e. reservoir properties, inejction schedule design, geomechanics). In order to perform the mentioned visualization, a fracture proppagation simulator is required. For the specific purpose of this thesis, an in-house

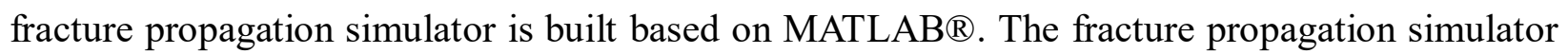
acquires the foundation from PKN fracture model and is desgined expicitly for a binary propant mixture injection. A review of PKN is in chapter I of this thesis. As a reminder from the review of PKN, solutions for the finite-discretization processes inside the numerical solution of PKN include the fracture width. Based on the primary solutions from finite-discretization processses for PKN, the fracture propagation simulator computes additional three quantities for each discretized grid:

- Areal concentration for proppant type 1, which is injected formerly $\left(\operatorname{ArConc}_{1}\right)$

- Areal concentration for proppant type 2, which is injected latterly $\left(A r C o n c_{2}\right)$

- Total areal concentration for a bianry mixture $\left(\operatorname{ArConcTot}=\operatorname{ArConc}_{1}+\right.$ ArConc $\left._{2}\right)$

From these additional quantities, the Weight Concentration Ratio (equivalently to the weight ratio in Eric's experiemntal settings) is defined and computed as follows: $R=\frac{\operatorname{ArConc}_{1}}{\text { ArConcTot }}$. All the Areal Concentrations and Weight Concentration Ratio are 2D matrices in the fracture propgagation simulator, with two dimensions equal the fracture half-length and fracture height. Albeit the fracture propagation simulator is capable of displaying 3D and 2D images for a variety of fracture parameters, the initial most essential result from it is the $2 \mathrm{D}$ image for Areal 
Conductivity Ratio. An example for the binary mixture 40/70 sand and 20/40 ceramic is presented as below:

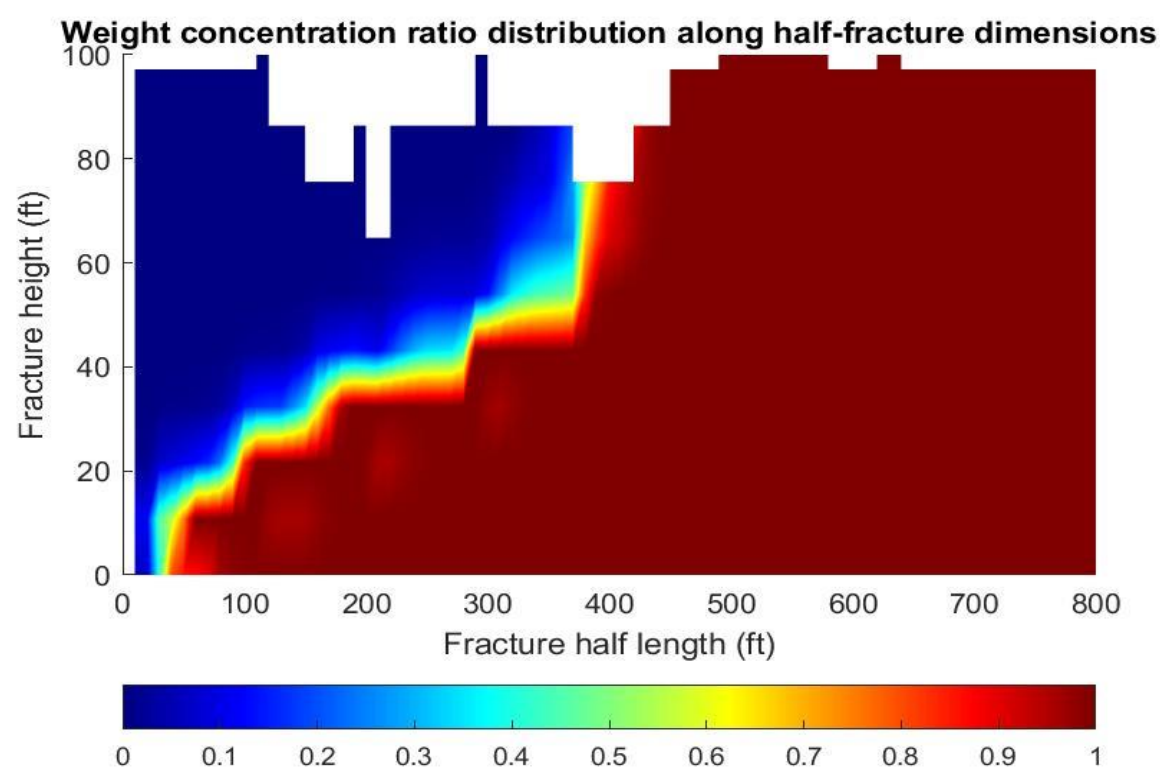

$\underline{\text { Figure } 7 \text { - Mixture Zone inside half-fracture dimensions }}$

The image clearly presents the Mixture Zone. A direct interpretation from the definiton of Weight Concentration Ratio shows that this parameter is ranged between 0 and 1 . The blue zone presents extremely low value of Weight Concentration Ratio (or 0 margin, which infers the dominance of the second injected proppant type) and the red zone presents extremely high value of R (or 1 margin, which infers the dominance of the first injected proppant type). A further look into the image clearly separates the Mixture Zoneinside a half-fracture dimension, in which the color gradient shade lies between the blue region and the region (or the value of Areal Concentraition Ratio is between 0 and 1, which infers the co-existence of both proppant types).

\subsection{Impact of different factors to the Mixture Zone}

Previous interpretation from the fracture propagation simulator shows that the Mixture Zone is evident. Besides the visualization, its variability inside the fracture under different 
conditions is necessary to be studied. Obviously, the variability of Mixture Zone depends mainly on the injection process during any fracturing practices. However, the intrinsic properties of the reservoir additionally do impact the Mixture Zone, since they directly affect proppant behaviors. Therefore, consideration of Mixture Zone's variability inside the fracture requires an evaluation of the injection process and reservoir properties. All possible interfering factors are listed as below:

- Reservoir's pressure properties (the most concerned is the Minimum Horizontal Stress)

- $\quad$ Formation geo-mechanics (i.e. Young Modulus and Poisson Ratio)

- Injection parameters (i.e. rate and time)

- Pumping schedule

- Proppant selection (i.e. Proppant size and density)

According to this prospective factor list and proved existence of 2 injected agents in the Mixture Zone, a further detailed list of 10 parameters are possible to be included in the sensitivity study. This detailed list consists of reservoir's minimum horizontal stress, formation's Young Modulus, formation's Poisson Ratio, injection rate, proppant densities for both agents, proppant sizes for both agents, injection time design for both agents. Based on the capability of the in-house fracture propagation simulator, Mixture Zone variability analysis can be conducted for the detailed list of 10 factors above. In this chapter, a sensitivity analysis is designed to examine the variability of Mixture Zone inside the fracture based on the impact of all possibly considerable parameters. Since the in-house fracture propagation simulator is a numerical simulator, it is capable to numerate the number of grids with at least two proppant types in existence $\left(\mathbf{A}_{\text {mix }}\right)$ and the total grids with existence of any proppant types, $\left(\mathbf{A}_{\text {tot }}\right)$. According to these definitions, the variability of Mixture Zone is numerated as: $\%_{\text {Mixture Zone }}=\frac{\mathbf{A}_{\text {mix }}}{\mathbf{A}_{\text {tot }}}$. 
Since one parameter's effect at a time is concerned and there should be no bias between studied parameters, variability of Mixture Zone can be observed as sole dependency on a parameter using One At a Time (known as OAT) sensitivity analysis (Morris, 1991). Since a fixed base case is initiated and processed for all parameters, the design of this sensitivity analysis complies with standard and local OAT design. Following the course of all selected factors, computation of Mixture Zone variability and the intended design of study, a procedure for the sensitivity analysis is conducted in 7 steps as follows:

1. Initially, imply a base case in the simulator. The base case contains a base numerical set of the 10 parameters selected in this sensitivity study. All the other settings inside the simulator are kept as default during this sensitivity study.

2. Numerate $\%$ Mixture Zone from the simulator after the base case is implied. Record this base \% Mixture Zone.

3. Pre-set a range of sensitivity boundaries for the parameters. In this sensitivity study, a $25 \%$ upper boundary and a $25 \%$ lower boundary from the base case are implied for all parameters.

4. Pre-set finite increment of sensitivity from the sensitivity boundaries. In this sensitivity study, the increment is $5 \%$. Consequently, a sensitivity range for each parameter should consist of 11 numerical values, or 11 sensitivity points (including the base value).

5. From step 1 and step 2 , sensitivity ranges are numerated for all the 10 parameters. Record all generated sensitivity ranges.

6. For every studied parameter, all the remaining 9 parameters are fixed at their base values. Under the pre-set sensitivity range for every parameter, 11 numerical values for 
the \% Mixture Zone are computed at the correspondingly 10 sensitivity points (excluding the base \% Mixture Zone).

7. For every studied parameter, deviation for $\%$ Mixture Zone (at one sensitivity point) from the base \% Mixture Zone (in step 2) are computed using this formula: Deviation $=\%$ MixtureZone $_{\text {Sensitivity }}-\%$ MixtureZone $_{\text {Base }}$.

Table 1 provides the base case's values for all parameters in this sensitivity study.

Table 1 - Base case's value of parameters in the sensitivity study

\begin{tabular}{|c|c|}
\hline Proppant 1 & Sand 40/70 $(0.000335 \mathrm{~m}), 2.75 \mathrm{~g} / \mathrm{cc}$ \\
\hline Proppant 2 & Ceramic $20 / 40(0.000631 \mathrm{~m}), 3.65 \mathrm{~g} / \mathrm{cc}$ \\
\hline Confining Pressure & $7000 \mathrm{psia}$ \\
\hline Injection rate & $0.02 \mathrm{~m}^{3} / \mathrm{s}$ \\
\hline G modulus & $0.4 \mathrm{GPa}$ \\
\hline Poisson Ratio & 0.3 \\
\hline Injection time design & As matrix (*) \\
\hline
\end{tabular}

Table 2 provides the sensitivity points for 8 parameters in this sensitivity study, excluding the two injection time parameters.

Table 2 - Sensitivity points for 8 parameters (excluding 2 injection time parameters)

\begin{tabular}{|c|c|c|c|c|c|c|c|c|}
\hline $\begin{array}{c}\text { Sensitivity } \\
\text { increment }\end{array}$ & $\begin{array}{c}\text { Diameter } \\
1(\mathrm{~m})\end{array}$ & $\begin{array}{c}\text { Diameter } \\
2(\mathrm{~m})\end{array}$ & S.G 1 & S.G 2 & $\begin{array}{c}\text { Injection Rate } \\
\left(\mathrm{m}^{3} / \mathrm{s}\right)\end{array}$ & $\begin{array}{c}\text { Confining } \\
\text { pressure }(\mathrm{psia})\end{array}$ & $\begin{array}{c}\text { Poisson } \\
\text { Ratio }\end{array}$ & $\begin{array}{c}\text { Young Modulus } \\
(\mathrm{GPa})\end{array}$ \\
\hline$-25 \%$ & 0.000251 & 0.000473 & 1.9875 & 2.7375 & 0.015 & 5250 & 0.1875 & 0.3 \\
\hline$-20 \%$ & 0.000268 & 0.000505 & 2.12 & 2.92 & 0.016 & 5600 & 0.2 & 0.32 \\
\hline$-15 \%$ & 0.000285 & 0.000536 & 2.2525 & 3.1025 & 0.017 & 5950 & 0.2125 & 0.34 \\
\hline$-10 \%$ & 0.000302 & 0.000568 & 2.385 & 3.285 & 0.018 & 6300 & 0.225 & 0.36 \\
\hline$-5 \%$ & 0.000318 & 0.000599 & 2.5175 & 3.4675 & 0.019 & 6650 & 0.2375 & 0.38 \\
\hline $5 \%$ & 0.000352 & 0.000663 & 2.7825 & 3.8325 & 0.021 & 7350 & 0.2625 & 0.42 \\
\hline $10 \%$ & 0.000369 & 0.000694 & 2.915 & 4.015 & 0.022 & 7700 & 0.275 & 0.44 \\
\hline $15 \%$ & 0.000385 & 0.000726 & 3.0475 & 4.1975 & 0.023 & 8050 & 0.2875 & 0.46 \\
\hline $20 \%$ & 0.000402 & 0.000757 & 3.18 & 4.38 & 0.024 & 8400 & 0.3 & 0.48 \\
\hline $25 \%$ & 0.000419 & 0.000789 & 3.3125 & 4.5625 & 0.025 & 8750 & 0.3125 & 0.5 \\
\hline
\end{tabular}


Table 3 provides the sensitivity points for 2 injection time parameters.

Table 3 - Sensitivity points for 2 injection time parameters

\begin{tabular}{|c|c|c|c|c|c|c|c|c|c|c|}
\hline $\begin{array}{c}\text { Sensitivity } \\
\text { increments }\end{array}$ & $-25 \%$ & $-20 \%$ & $-15 \%$ & $-10 \%$ & $-5 \%$ & $5 \%$ & $10 \%$ & $15 \%$ & $20 \%$ & $25 \%$ \\
\hline $\begin{array}{c}\text { Former } \\
\text { proppant type } \\
\text { (4th stage) }\end{array}$ & 0.75 & 0.8 & 0.85 & 0.9 & 0.95 & 1.05 & 1.1 & 1.15 & 1.2 & 1.25 \\
\hline $\begin{array}{c}\text { Latter } \\
\text { proppant type } \\
\text { (5th stage) }\end{array}$ & 0.375 & 0.4 & 0.425 & 0.45 & 0.475 & 0.525 & 0.55 & 0.575 & 0.6 & 0.625 \\
\hline
\end{tabular}

Within the total of 10 studied parameters in this sensitivity analysis, eight of them are imported into the in-house fracture propagation simulator directly. The remaining two are required extra processing prior to be imported into the simulator, which include proppant size and injection time design (specifically for slurry injection steps). For processing for proppant size, the original lab data provides the proppant diameters in a Mesh-size range (for example Mesh 20-40). Because of the fracture propagation simulator input design for proppant diameter as a single numerical value in $\mathrm{mm}$, Mesh sizes are converted into $\mathrm{mm}$ using the ISO Sieve Conversion Table and the mean diameter for a Mesh-size range is eventually imported. For processing for injection time design, the in-house facture propagation simulator designs input format for injection time design as a $2 \times 7$ matrix (a form of vectorization in numerical simulation). The injection time design's base case, converted into the simulator's required format, is presented as below:

$$
\left[\begin{array}{ccccccc}
0.2 & 0.4 & 0.7 & \mathbf{1 . 0} & 0 & 0 & 0 \\
0 & 0 & 0 & 0 & \mathbf{0 . 5} & 0.75 & 1.0
\end{array}\right](*)
$$

The simulator designs pad injection time as a unit-pumping time (in minutes). Therefore, slurry injection time equals the element-wise multiplication operation of the formulated matrix above and the unit-pumping time. The flush injection time is independent of the unit-pumping time. 
As a specific design purpose of the matrix for slurry injection steps, the first row of the matrix corresponds to the injection steps of the $1^{\text {st }}$ injected agent and the second row corresponds to the injection steps of the $2^{\text {nd }}$ agent. Since the simulator implies $1^{\text {st }}$ injected agent in the initial 4 steps and the $2^{\text {nd }}$ injected agent in the last 3 steps, the last 3 elements of the first row and the initial 4 elements of the second row are intuitively set to 0 permanently for all simulations.

Based on the matrix's format for injection time design, it is crucial to examine the effect of the intersection between the end of the $1^{\text {st }}$ agent's injection (or its last step) and the beginning of the $2^{\text {nd }}$ agent injection (or its initial step). This effect is concentrated on the difference between the $4^{\text {th }}$ injection time step (last stage to inject the $1^{\text {st }}$ agent, 1.0 in the base case) and the $5^{\text {th }}$ injection time step (first stage to inject the $2^{\text {nd }}$ agent, 0.5 in the base case). Furthermore, both agents' injection time contribute to this difference. As a result, this sensitivity study, regarding the injection time design, both injected agents are examined as follows:

- Initiate the $25 \%$ lower and upper boundaries for the $4^{\text {th }}$ injection step (1.0 in the matrix $(*))$ with a $5 \%$ increment to analyze the impact to the Mixture Zone by the $1^{\text {st }}$ injected agent).

- Initiate the $25 \%$ lower and upper boundaries for the $5^{\text {th }}$ injection stage $(0.5$ in the matrix $\left.{ }^{*}\right)$ ) with a $5 \%$ increment to analyze the impact to the Mixture Zone by the $2^{\text {nd }}$ injected agent).

Impact from the injection time design contributes 2 parameters in the total of 10 studied parameters. Except mentioned changes during the sensitivity analysis, the injection steps remain as the base formulated matrix $(*)$. 


\section{CHAPTER 4 - SEMI-ANALYTICAL MODELING APPROACH}

\subsection{Fracture permeability}

As the review of studies for fracture permeability, it has been studied extensively in the past for a single proppant type, and there are well-known models to estimate this quantity. Within previous modelling approaches, Carman-Kozeny equation is one of the most applicable. Its formulation is reminded as follows:

$$
\mathrm{k}_{\mathrm{f}}=\frac{\emptyset^{3}}{K_{o}(1-\emptyset)^{2}} \times \frac{1}{\tau \mathrm{a}_{\mathrm{v}}^{2}}
$$

When a binary proppant mixture is given consideration, the Carman-Kozeny equation is still effective in application, providing all relevant parameters in the equation need revision. Since the Kozeny coefficient $\mathrm{K}_{\mathrm{o}}$ are not commonly modelled analytically or semi-analytically, this parameter is determined as an independent variable. In the case of general particulate beds, a numerical value of 2 is empirically reasonable (Kozeny, 1937; Panda and Lake, 1994).

With the Kozeny coefficient is exempted from being modelled, the remaining parameters include porosity, tortuosity and the Specific Internal Area. Albeit the definition of Internal Specific Area includes the term $(1-\emptyset)$, this term is re-arranged inside the Carman-Kozeny model for further convenience. Therfore, Specific Internal Area in this study is reduced to the term $\frac{A_{\text {surface }}}{V_{\text {solid }}}$.

Since an agreement in similarity between a proppant pack and a granular bed medium (under applied stress) is previously stated, capable modelling approaches for both porosity and hydraulic tortuosity can be applied for the case of a binary proppant mixture. A widely used model mentioned in Jian-jun dong et.al (2010) for porosity of a granular bed medium under applied stress is:

$$
\emptyset=\emptyset_{0} \mathrm{e}^{-\beta\left(\mathrm{P}-\mathrm{P}_{\mathrm{o}}\right)}
$$


Where: $\beta$ is the rock/formation compressibility coefficient. For hydraulic tortuosity, a previous study by Mota et.al (2001), of which experiments closely match the experiment design for a binary proppant mixture by Eric Schultz (2014), proposed tortuosity as:

$$
\tau=\emptyset^{-\mathrm{n}}
$$

Where $\mathrm{n}$ is an empirical coefficient which was determined between as low as 0.3 to as high as 0.5 in the authors' experiment settings. However, the authors implicitly concluded $\mathrm{n}$ to be not universal and dependent on the intrinsic of the tested binary mixture.

The most comprehensive revision focuses on Specific Internal Area. Referred to the ratio $\frac{A_{\text {surface }}}{V_{\text {solid }}}$, Specific Internal Area is a concept which involves high degree of geometry. For a single proppant type (geometrically modelled as identical spherical-formed particles), this ratio is derived to become $\frac{6}{D}$. The effect of particle size distribution is mitigated by implication of the average particle diameter. Albeit this implication is certainly simplistic, the equation of Internal Specific Area for a single proppant type clearly does not integrate other impacts of proppant properties, besides the proppant size (i.e. average diameter in the ratio).

For a binary proppant mixture, mean diameter is still applied to represent the particle size distribution. However, this intention does not totally mitigate natural complexity in particle size distribution. A kernel density estimator (i.e. KDE) is actually a better supportive property along with mean diameter. Based on the experiment settings in Eric's study, a binary proppant mixture can be modelled as a two-sized particle assembly, coupled with the Weight Concentration Ratio abbreviated as R. In details, a two-sized particle assembly contains:

- Particle type 1 , average diameter $\mathrm{D}_{1}$, density $\rho_{1}$, Weight Concentration Ratio $\mathrm{R}$

- Particle type 2, average diameter $\mathrm{D}_{2}$, density $\rho_{2}$, Weight Concentration Ratio 1-R 
Define $\mathrm{N}_{1}$ and $\mathrm{N}_{2}$ as the number of particles for particle type 1 and particle type 2 , respectively. In addition, area and volume of a spherical form are $\pi D^{2}$ and $\frac{1}{6} \pi D^{3}$, respectively. As a result, $A_{\text {surface }}$ and $V_{\text {solid }}$ in the Specific Internal Area definition are derived as:

$$
\begin{aligned}
& A_{\text {surface }}=\mathrm{N}_{1}\left(\pi \mathrm{D}_{1}^{2}\right)+\mathrm{N}_{2}\left(\pi \mathrm{D}_{2}^{2}\right) \\
& V_{\text {solid }}=\mathrm{N}_{1}\left(\frac{1}{6} \pi \mathrm{D}_{1}^{3}\right)+\mathrm{N}_{2}\left(\frac{1}{6} \pi \mathrm{D}_{2}^{3}\right)
\end{aligned}
$$

Replace $A_{\text {surface }}$ and $V_{\text {solid }}$ into Internal Specific Area:

$$
a_{v}=\frac{N_{1}\left(\pi D_{1}^{2}\right)+N_{2}\left(\pi D_{2}^{2}\right)}{N_{1}\left(\frac{1}{6} \pi D_{1}^{3}\right)+N_{2}\left(\frac{1}{6} \pi D_{2}^{3}\right)}
$$

Based on the definition of $\mathrm{N}_{1}$ and $\mathrm{N}_{2}$, they are further derived as:

$$
\begin{aligned}
& N_{1}=\frac{\mathrm{M}_{1}}{\rho_{1}} \times \frac{1}{\mathrm{~V}_{\text {one particle type } 1}} \\
& N_{2}=\frac{\mathrm{M}_{2}}{\rho_{2}} \times \frac{1}{\mathrm{~V}_{\text {one particle type } 2}}
\end{aligned}
$$

Where $M_{1}$ and $M_{2}$ are masses of particle type 1 and particle type 2, respectively.

Based on the experiment settings in Eric' study, condition, a specified total areal concentration and the area of proppant contact under confining stresses from the API conductivity assembly are pre-set. Notate them as $\mathrm{C}$ (unit in $\mathrm{lbs} / \mathrm{ft}^{2}$ ) and $\mathrm{A}\left(\mathrm{unit}\right.$ in $\mathrm{in}^{2}$ ), the total mass of proppant packed in the API conductivity assembly (notated M) is derived as:

$$
\mathrm{M}=\frac{\mathrm{AC}}{144}(\mathrm{lbs})
$$

A combination with the Weight Ratio R derives $\mathrm{M}_{1}$ and $\mathrm{M}_{2}$ :

$$
\begin{aligned}
& M_{1}=\frac{M R}{\rho_{1}} \\
& M_{2}=\frac{M(1-R)}{\rho_{2}}
\end{aligned}
$$

Replacement of equations for $\mathrm{M}_{1}$ and $\mathrm{M}_{2}$ further derives $\mathrm{N}_{1}$ and $\mathrm{N}_{2}$ as: 


$$
\begin{aligned}
& \mathrm{N}_{1}=\frac{\mathrm{MR}}{\rho_{1}\left(\frac{1}{6} \pi \mathrm{D}_{1}^{3}\right)} \\
& \mathrm{N}_{2}=\frac{\mathrm{M}(1-\mathrm{R})}{\rho_{2}\left(\frac{1}{6} \pi \mathrm{D}_{2}^{3}\right)}
\end{aligned}
$$

Replacement of the equations for $\mathrm{N}_{1}$ and $\mathrm{N}_{2}$ into the equation for Internal Specific Area further derives this ratio as:

$$
a_{v}=\frac{\frac{M R}{\rho_{1}\left(\frac{1}{6} \pi D_{1}^{3}\right)}\left(\pi D_{1}^{2}\right)+\frac{M(1-R)}{\rho_{2}\left(\frac{1}{6} \pi R_{2}^{3}\right)}\left(\pi D_{2}^{2}\right)}{\frac{M R}{\rho_{1}\left(\frac{1}{6} \pi D_{1}^{3}\right)}\left(\frac{1}{6} \pi D_{1}^{3}\right)+\frac{M(1-R)}{\rho_{2}\left(\frac{1}{6} \pi D_{2}^{3}\right)}\left(\pi D_{2}^{3}\right)}
$$

Simplification of the equation above provides the final form of the Internal Specific Area for a binary-sized particle assembly, or a binary proppant mixture as follows:

$$
a_{v}=\frac{6}{D_{1} D_{2}} \times \frac{\rho_{1} D_{1}+\left(\rho_{2} D_{2}-\rho_{1} D_{1}\right) R}{\rho_{1}+\left(\rho_{2}-\rho_{1}\right) R}
$$

Eventually, the modified Carman-Kozeny equation for fracture permeability of a binary proppant mixture is finalized as follows:

$$
\begin{aligned}
k_{f}= & \frac{\emptyset^{3}}{K_{o}(1-\emptyset)^{2}} \times \frac{1}{\tau a_{v}^{2}} \\
& \text { Where: } \varnothing=\emptyset_{\mathrm{o}} \mathrm{e}^{-\beta\left(\mathrm{P}-\mathrm{P}_{\mathrm{o}}\right)}, \tau=\emptyset^{\mathrm{n}}, \text { and } \mathrm{a}_{\mathrm{v}}=\frac{6}{\mathrm{D}_{1} \mathrm{D}_{2}} \times \frac{\rho_{1} \mathrm{D}_{1}+\left(\rho_{2} \mathrm{D}_{2}-\rho_{1} \mathrm{D}_{1}\right) \mathrm{R}}{\rho_{1}+\left(\rho_{2}-\rho_{1}\right) \mathrm{R}} .
\end{aligned}
$$

\subsection{Fracture width}

\subsubsection{Modelling approach for fracture width composed of a single proppant type}

Based on analytical modelling for a particle embedment under parabola stress distribution, Hertzian's contact theory has been commonly used in deriving fracture width models for a single proppant type (under microscopic scale and combination with material elastic behavior for macroscopic scale as a proppant pack). Primary backgrounds which are relevant to Hertzian's contact theory is readily in chapter 1 . Relevant formulas for a single proppant type case are applied in Jianchun Guo et.al (2017) and provided as follows: 


$$
\begin{aligned}
& a=\sqrt{R \delta} \\
& \delta=\left(\frac{3 P_{c}}{E^{*}}\right)^{\frac{2}{3}} \times R\left(\text { where }: \frac{1}{\mathrm{E}^{*}}=\frac{1-\mathrm{v}_{\mathrm{p}}^{2}}{\mathrm{E}_{\mathrm{p}}}+\frac{1-\mathrm{v}_{\mathrm{r}}^{2}}{\mathrm{E}_{\mathrm{r}}}\right) \\
& P_{S}=\frac{4 P_{c} R^{2}}{\pi a^{2}} \\
& \Delta D=\frac{P_{s}}{E_{p}} w_{f 0} \\
& h=2 \times \delta+\Delta D \\
& w_{f}=w_{f 0}-h
\end{aligned}
$$

Where $a$ is the radius of contact, and $\Delta D$ are decrease in fracture by embedment and deformation impact, $h$ is the total decrease in fracture width, $w_{f}$ and $w_{f 0}$ are the initial fracture width (i.e. width with zero exposure to applied stress) and final fracture width after exposure to applied stress. In Eric's experimental settings, the contact surfaces inside the API conductivity assembly are flat steel plates and not rock surfaces as in Jianchun Guo et.al (2017). For steel material, the Young modulus and Poisson ratio are $300 \mathrm{GPa}$ and 0.3 , respectively. As a result, the term $\frac{1-v_{r}^{2}}{E_{r}}$ in the equation to compute $\delta$ is practically 0 . The equation of $E^{*}$, under elimination of the term $\frac{1-v_{r}^{2}}{E_{r}}$, reduces to $\frac{1}{E^{*}}=\frac{1-v_{p}^{2}}{E_{p}}$. Substitution of new equation for $E^{*}$ into the equation for $\delta$, the new equation for $\delta$ is derived as:

$$
\delta=(\mathrm{R} \sqrt[3]{9}) \times\left(\frac{1-\mathrm{v}_{\mathrm{p}}^{2}}{\mathrm{E}_{\mathrm{p}}}\right)^{\frac{2}{3}} \times\left(\sqrt[3]{P_{c}}\right)^{2}
$$

Substitution of new equation for $d$ into equation for $a$, the new equation for $a$ is derived as:

$$
a^{2}=\left(3 P_{c} \times \frac{1-v_{\mathrm{p}}^{2}}{\mathrm{E}_{\mathrm{p}}}\right)^{\frac{2}{3}} \times R^{2}
$$


Substitution of new equation for $a^{2}$ into equation for $P_{S}$, the new equation for $P_{S}$ is derived as:

$$
P_{S}=\frac{4 P_{c}}{\pi \times\left(3 P_{c} \times \frac{1-v_{\mathrm{p}}^{2}}{\mathrm{E}_{\mathrm{p}}}\right)^{\frac{2}{3}}}
$$

Substitution of new equation for $P_{S}$ into equation for $\Delta D$, the new equation for $\Delta D$ is derived as:

$$
\Delta D=\frac{4 \mathrm{w}_{\mathrm{f} 0}}{(\pi \sqrt[3]{9}) \times \sqrt[3]{\mathrm{E}_{\mathrm{p}}\left(1-\mathrm{v}_{\mathrm{p}}^{2}\right)^{2}}} \times \sqrt[3]{P_{c}}
$$

Substitution of new equation for $\Delta D$ into equation for $w_{f}$, the new equation for $w_{f}$ is derived as:

$$
w_{f}=w_{f 0}-\frac{4 w_{f 0}}{(\pi \sqrt[3]{9}) \times \sqrt[3]{E_{p}\left(1-v_{p}^{2}\right)^{2}}} \sqrt[3]{P_{c}}
$$

4.2.2 Modelling approach for fracture width composed of a binary proppant mixture

From a practical viewpoint, proppant particles are randomly distributed in the fracture without any sepcific distribution schematic. However, in order to reasonably concern the fracture width of a binary proppant mixture with integration of the Weight Concentration Ratio, the binarysized particle assembly coupled with a specific distribution schematic is required. Referred back to the description of a binary-sized particle assembly, in case these two particle types are arranged in two separate sub-layers (each layer is composed of one particle type), the integration of R into the derivation approach is more feasible. A schematic for this arrangement, which is defined in this study as a dual-layer unity, is provided in figure 8. Based on the dual-layer unity, Hertzian's contact theory is applied to model the width of each sub-layer in the provided schematic. When being deformed and embedded under applied stress, these two sub-layers deform and embed silmutaneously. The embedment between two sub-layers is neglected. 


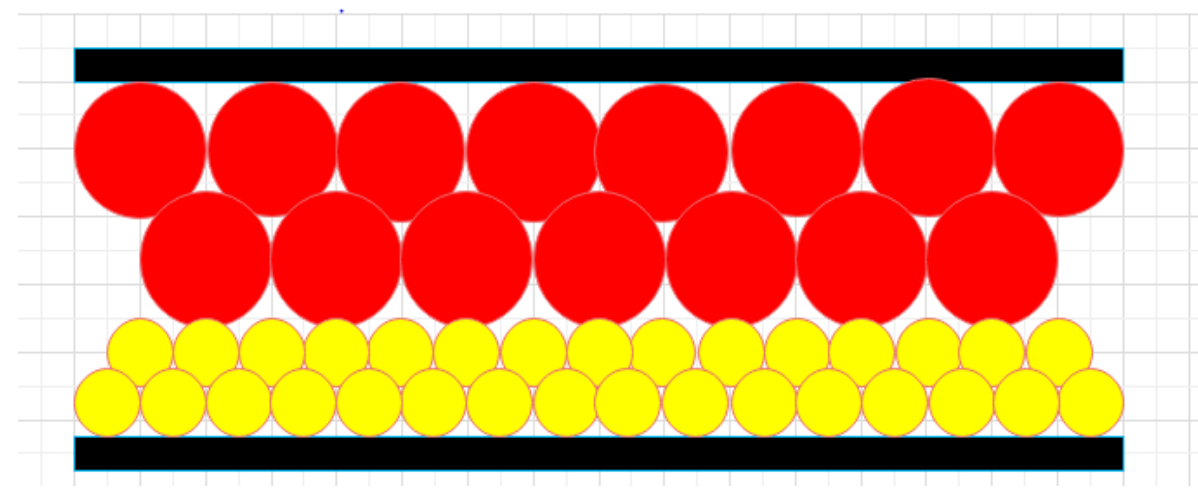

Figure 8 - Schematic for a dual-layer unity

Direct application of Hertzian contact theory into each sub-layer in the schematic provides the equation for their widths as follows:

$$
\begin{aligned}
& w_{f 1}=w_{f 01}-C_{1} \sqrt[3]{P_{c}}, C_{1}=\frac{4 w_{f 01}}{(\pi \sqrt[3]{9}) \times \sqrt[3]{E_{p 1}\left(1-v_{p 1}^{2}\right)^{2}}} \\
& w_{f 2}=w_{f 02}-C_{2} \sqrt[3]{P_{c}}, C_{2}=\frac{4 w_{f 02}}{(\pi \sqrt[3]{9}) \times \sqrt[3]{E_{p_{2}}\left(1-v_{p 2}^{2}\right)^{2}}}
\end{aligned}
$$

A summation of the two equations above formulate the total fracture width after deformation and embedment as:

$$
w_{f}=\left(w_{f 01}+w_{f 02}\right)-\left(C_{1}+C_{2}\right) \sqrt[3]{P_{c}}=w_{f 0}-\left(C_{1}+C_{2}\right) \sqrt[3]{P_{c}}
$$

The terms $C_{1}$ and $C_{2}$ are composed of the sub-term $\left(\sqrt[3]{E_{p}\left(1-v_{p}^{2}\right)^{2}}\right)$, which is a formulation of geo-mechanics properties of each particle type. Consequently, these terms: $\frac{1}{E v_{1}}=$ $\frac{1}{\sqrt[3]{E_{p_{1}}\left(1-v_{p_{1}}^{2}\right)^{2}}}$ and $\frac{1}{E v_{2}}=\frac{1}{\sqrt[3]{E_{p_{2}}\left(1-v_{p_{2}}^{2}\right)^{2}}}$ do not need to be derived further. From the presumable layering schematic, $w_{f 1}$ and $w_{f 2}$ are expected to exhibit certain relationships to the total intial fracture width $\left(w_{f 0}\right)$ and the Weight Concentration Ratio $(\mathrm{R})$. Further continuing derivations validate this assumption. 
According to previous definitions of $\mathrm{N}_{1}$ and $\mathrm{N}_{2}$ in permeability modelling, their equations are reminded as follows:

$$
\begin{aligned}
& N_{1}=\frac{M R}{\rho_{1}\left(\frac{1}{6} \pi D_{1}^{3}\right)} \\
& N_{2}=\frac{M(1-R)}{\rho_{2}\left(\frac{1}{6} \pi D_{2}^{3}\right)}
\end{aligned}
$$

Based on the dual-layer unity, there are several monolayers in the sub-layer of each particle type. In each of these mono-layer, the particles need to fill the contact area (A). Therefore, the number of particles in a monolayer for two particle types, $N_{\text {mono-1 }}$ and $N_{\text {mono-2 }}$, respectively, are derived as:

$$
\begin{aligned}
& N_{\text {mono-1 }}=\frac{A}{\pi D_{1}^{2}} \\
& N_{\text {mono-2 }}=\frac{A}{\pi D_{2}^{2}}
\end{aligned}
$$

From $N_{\text {mono-1 }}$ and $N_{\text {mono-2 }}$, the number of mono-layers for two particle types, $L_{1}$ and $L_{2}$, respectively, are derived as:

$$
\begin{aligned}
& L_{1}=\frac{N_{1}}{N_{\text {mono-1 }}}=\frac{6 C R}{\rho_{1} D_{1}} \\
& L_{2}=\frac{N_{2}}{N_{\text {mono }-2}}=\frac{6 C(1-R)}{\rho_{2} D_{2}}
\end{aligned}
$$

In order to closely resemble practical packing for particles, a stable packing geometry as center cubic packing is selected for this modelling. Under center cubic packing, the initial width for each layer, $w_{f 01}$ and $w_{f 02}$, respectively, are derived as:

$$
\begin{aligned}
& w_{f 01}=\frac{6 \sqrt{2} C R}{\rho_{1}} \\
& w_{f 02}=\frac{6 \sqrt{2} C(1-R)}{\rho_{2}}
\end{aligned}
$$


Where $C$ is weight concentration at lab conditions. Summation of the two equations for $w_{f 01}$ and $w_{f 02}$ provides the total inital fracture width $\left(w_{f 0}\right)$ of a dual-layer unity as:

$$
w_{f 0}=6 \sqrt{2} C\left[\frac{R}{\rho_{1}}+\frac{(1-R)}{\rho_{2}}\right]
$$

Division of each of the two equations for $w_{f 01}$ and $w_{f 02}$ to the equation of total initial fracture width $\left(w_{f 0}\right)$ :

$$
\begin{aligned}
& \frac{w_{f 01}}{w_{f 0}}=\frac{\frac{R}{\rho_{1}}}{\frac{R}{\rho_{1}}+\frac{(1-R)}{\rho_{2}}}=\frac{R \rho_{2}}{R \rho_{2}+(1-R) \rho_{1}}=\frac{Z_{2}}{Z_{2}+Z_{1}} \\
& \frac{w_{f 02}}{w_{f 0}}=\frac{\frac{1-R}{\rho_{2}}}{\frac{R}{\rho_{1}}+\frac{(1-R)}{\rho_{2}}}=\frac{(1-R) \rho_{1}}{R \rho_{2}+(1-R) \rho_{1}}=\frac{Z_{1}}{Z_{2}+Z_{1}}
\end{aligned}
$$

The ratios $\frac{Z_{1}}{Z_{1}+Z_{2}}$ and $\frac{Z_{2}}{Z_{1}+Z_{2}}$ now prove the pre-deterministic viewpoint that $w_{f 1}$ and $w_{f 2}$ are expected to exhibit certain relationships to the total intial fracture width $\left(w_{f 0}\right)$ and the Weight Concentration Ratio (R). Iinvestigation of these ratios into the initially proposed equation for $w_{f}$ provides the final equation of fracture width for a two-sized particle assembly:

$$
\begin{gathered}
w_{f}=w_{f 0}\left[1-\frac{4}{\pi \sqrt[3]{9}}\left(\frac{Z_{2}}{Z_{1}+Z_{2}} \frac{1}{\sqrt[3]{E_{p 1}\left(1-v_{p 1}^{2}\right)^{2}}}+\frac{Z_{1}}{Z_{1}+Z_{2}} \frac{1}{\sqrt[3]{E_{p 2}\left(1-v_{p 2}^{2}\right)^{2}}}\right) \sqrt[3]{P_{c}}\right] \\
\text { Where: } Z_{2}=R \rho_{2}, Z_{1}=(1-R) \rho_{1}
\end{gathered}
$$

\subsection{Determination of coefficients}

From the development of the semi-analytical modelling approach, there are coeficients in the models for both proppant pack's permeability and proppant pack's width. Similar to the development process, set of coefficients in each model is determined independently.

For proppant pack's permeability, before any further determination for the coefficients, the equation (4.16) for the model is necessary to be reminded, as follows: 


$$
k_{f}=\frac{\emptyset^{3}}{K_{o}(1-\emptyset)^{2}} \times \frac{1}{\tau a_{v}^{2}}
$$

Where: $\emptyset=\emptyset_{\mathrm{o}} \mathrm{e}^{-\beta\left(\mathrm{P}-\mathrm{P}_{\mathrm{o}}\right)}, \tau=\emptyset^{\mathrm{n}}$, and $\mathrm{a}_{\mathrm{v}}=\frac{6}{\mathrm{D}_{1} \mathrm{D}_{2}} \times \frac{\rho_{1} \mathrm{D}_{1}+\left(\rho_{2} \mathrm{D}_{2}-\rho_{1} \mathrm{D}_{1}\right) \mathrm{R}}{\rho_{1}+\left(\rho_{2}-\rho_{1}\right) \mathrm{R}}$

In the permeability modelling, tortuosity is a function of porosity under effect of coefficient $\mathrm{n}$, and porosity is a function of applied confining stress under effect of coefficient $\beta$ and the initial porosity $\emptyset_{\mathrm{o}}$ (porosity of the proppant pack at zero applied confining stress). The value of $\mathrm{P}_{\mathrm{o}}$ in the porosity exponential equation is $14.7 \mathrm{psi}$. Consequently, the term $\frac{\emptyset^{3}}{K_{o} \tau(1-\emptyset)^{2}}$ (which has no unit) becomes a function of applied confining stress (at a specific weight mixing ratio), under effect of 3 coefficients: $n, \beta$ and $\emptyset_{\mathrm{o}}$

The Internal Specific Area, $\mathrm{a}_{\mathrm{v}}$, was derived to be dependent on the weight mixing ratio, proppant average diameters, and proppant densities. Equation (4.15) infers that $\mathrm{a}_{\mathrm{v}}$ can be computed for any binary mixtures since average diameters, densities for two proppant types in a mixture and the weight mixing ratio are all provided. Furthermore, a set of measured permeability data for any binary mixtures exhibits a clear relationship to applied confining stress points (preset in the experiments, as aforementioned). A re-arrangement for the permeability equation is now performed as below:

$$
\frac{\emptyset^{3}}{\tau(1-\emptyset)^{2}}=k_{f} a_{v}^{2} K_{o}
$$

Since $a_{v}$ is unique for each tested binary mixture with a specific weight mixing ratio, the above re-arrangement becomes an equation having a general formula as:

$$
k_{f} a_{v}^{2} K_{o}=\frac{\emptyset^{3}}{\tau(1-\emptyset)^{2}}=\frac{\emptyset^{3+n}}{(1-\emptyset)^{2}}=\frac{\emptyset_{o} e^{-\beta\left(P_{c}-P_{0}\right)(3+n)}}{\left(1-\emptyset_{o} e^{-\beta\left(P_{c}-P_{0}\right)}\right)^{2}} \rightarrow y_{l a b}=f\left(P_{c}\right)
$$

Where $y_{l a b}=k_{f} a_{v}^{2} K_{o}$, and $f\left(P_{c}\right)$ is a function of applied confining stress generated from the term $\frac{\emptyset^{3}}{K_{o} \tau(1-\emptyset)^{2}}$. Additional unit conversion is required for the term $k_{f} a_{v}^{2}$ as this term is expected 
to be unit-less, and the appropriate unit conversion factor in this case is determined to be $9.869223 \times 10^{-13}$. Based on the complete derivation for the term $\frac{\emptyset^{3}}{K_{o} \tau(1-\varnothing)^{2}}$ in $(4.44)$ and the form of the general formula above, 3 coefficients (n, $\beta$ and $\emptyset_{0}$ ) are required to be solved for each lab data set of permeability versus applied confining stress. Solutions for these 3 coefficients in equation (4.44) clearly arises a non-linear least-square problem since equation (4.44) resembles equation (2.2). Chapter 2 readily describes trust-region method as an effective option to solve nonlinear least square problems. The remaining aspect for a complete solution is boundary selection.

Boundaries for the coefficients in the converted $f\left(P_{c}\right)$ rely on commonly known ranges of the coefficients, since all of the concerned coefficients in the novel semi-analytical model have been examined and/or validated in previous researches. The use of porosity exponent model has been previously applied in different studies of porous media, for example porosity of sandstone formations. Albeit a general proppant packing may ensemble the environment of a porous media, the two coefficients in the porosity exponent model, including porosity at initial condition (zero applied stress) and compressibility factor are required to be reviewed for suitable boundary selections.

Porosity at initial condition, within the modelling context, is referred to porosity of a twosized particle assembly. Experimentally, porosity of a two-sized assembly was measured in Anthony Diyokeugwu and Paul Glover (2018), and variability of this parameter is known to range between 0.3116 and 0.3716 when the mean diameter ratio in the two-sized system is between 1.5 and 3. Compressibility factor, within the modelling context, is expected to be close to compressibility of unconsolidated formations. Variability of unconsolidated formation's compressibility factor is known to range between $5.5 \times 10^{-6}\left(p s i^{-1}\right)$ and $8.5 \times 10^{-3}\left(p s i^{-1}\right)$. 
From the above reasoning sequence, the expected lower - upper boundaries for $\emptyset_{0}$ and $\beta$ are $0.3116-0.3716$ and $5.5 \times 10^{-6}-8.5 \times 10^{-5}\left(p s i^{-1}\right)$, respectively.

For tortuosity, its intrinsic definition does not lead to any considerable difference between previous studies for porous media and application in the modelling context in this thesis. The most common range for this parameter is between 4.5 and 5.2 (general granular beds, according to modelling examination by Carman (1937) and Kozeny (1927)). When combined with the proposed exponent model for tortuosity and the expected range for porosity at initial conditions, the coefficient $\mathrm{n}$ in the exponent model for tortuosity has expected lower - upper boundaries between 0.3 and 1.2 .

Conclusively, initial settings for the trust-region method in MATLAB® Optimization Toolbox (R2019b) to solve the objective equation (4.44) are listed as follows:

- Sub-problem algorithm for the model function: factorization

- Maximum iteration allowance: 500

- Objective function's tolerance: $1.0 \cdot 10^{-7}$

- Initialization of the coefficients in the algorithm: $\left[0.25,1.0 \cdot 10^{-5}, 0.8\right]$

For proppant pack's width, relatively similar coefficient determination procedure is processed. Before any determination for the coefficients, equation (4.42) for the model is reminded, as follows:

$$
w_{f}=w_{f 0}\left[1-\frac{4}{\pi \sqrt[3]{9}}\left(\frac{Z_{1}}{Z_{1}+Z_{2}} \frac{1}{\sqrt[3]{E_{p 1}\left(1-v_{p 1}^{2}\right)^{2}}}+\frac{Z_{2}}{Z_{1}+Z_{2}} \frac{1}{\sqrt[3]{E_{p 2}\left(1-v_{p 2}^{2}\right)^{2}}}\right) \sqrt[3]{P_{c}}\right]
$$

Where $Z_{2}=R \rho_{2}, Z_{1}=(1-R) \rho_{1}$. Equation (4.42) requires the terms $w_{f 0}$, $\sqrt[3]{E_{p 1}\left(1-v_{p 1}^{2}\right)^{2}}$, and $\sqrt[3]{E_{p 2}\left(1-v_{p 2}^{2}\right)^{2}}$ to be determined. However, as mentioned in chapter 1 , 
available width data in Eric (2014) does not satisfy to be used for the modelling approach in this thesis, and an alternative is required. The alternative starts from the approach to model proppant pack's width itself. In chapter 4 , the terms $w_{f 0}$ and $\sqrt[3]{E_{p}\left(1-v_{p}^{2}\right)^{2}}$ exist in equation (4.27) which models width for a single proppant type. A substitution database from FRACPRO ${ }^{\circledR}$ is exatracted for all proppant types in the studied binary mixtures. The list of all componenets contain 20/40 sand, 20/40 ceramic, 40/70 sand and 40/70 ceramic. The database has width data of all proppant types in the list, which is measured under experimental settings similar to Eric's experiments. For each single proppant type in the list, substituted width data allows extraction of the terms $w_{f 0}$ and $\sqrt[3]{E_{p}\left(1-v_{p}^{2}\right)^{2}}$ using equation (4.27). Substitution database and extraction process to obtain the terms $w_{f 0}$ and $\sqrt[3]{E_{p}\left(1-v_{p}^{2}\right)^{2}}$ are in the Appendix.

As a result, the terms $\sqrt[3]{E_{p 1}\left(1-v_{p 1}^{2}\right)^{2}}$ and $\sqrt[3]{E_{p 2}\left(1-v_{p 2}^{2}\right)^{2}}$ in equation (4.42) are extracted using the substitution database. Under the fact that modelling in this thesis is based on the API unit's dimensions in Eric's experiments, initial widths for sole packing of each proppant type in a binary mixture $\left(w_{f 0}\right.$ in $\left.(4.27)\right)$ and initial width for packing of the corresponding binary mixture $\left(w_{f 0}\right.$ in (4.42) are clsoely equal. Equivalently:

$$
w_{f 1} \approx w_{f 2} \approx w_{f 0}
$$

Where $w_{f 1}$ and $w_{f 2}$ are initial widths for sole packing of the first and second proppant type in a binary mixture, and they are also extracted using substitution dataset and equation (4.27). Combined with (4.45), equations (4.40) and (4.41) are revised as:

$$
\frac{w_{f 01}}{w_{f 1}}=\frac{Z_{2}}{Z_{2}+Z_{1}}
$$


$\frac{w_{f 01}}{w_{f 2}}=\frac{Z_{1}}{Z_{2}+Z_{1}}$

Equations (4.46), (4.47) and (4.30) are combined to linearly approximated $w_{f 0}$ in equation (4.42) as:

$$
w_{f 0}=\frac{Z_{1}}{Z_{2}+Z_{1}} w_{f 2}+\frac{z_{2}}{Z_{2}+Z_{1}} w_{f 1}
$$

From the coefficient determination procedures for the semi-analytical modelling, the conductivity lab data, albeit being provided, is not facilitated during any coefficient determination procedures. The reason for this obmission is that conductivity lab data will be faciliated during the modelling validation (in chapter 6) for better robustness of the derived conductivity model. 


\section{CHAPTER 5 - CASE STUDY FOR MARCELLUS SHALE}

This case study, which implies reservoir properties, geo-mechanics and fracture treatment design of well MIP-3H (Marcellus Shale), practically better quantifies the application of the developed semi-analytical modelling approach when compared to LWAM. Conductivity estimation and cumulative production prediction (up to 10 years) are two selected criteria. To conduct this case study and acquire the comparison results, a fracture propgation simulator and a numerical reservoir simulator are combined. This combination is proposed to transform the conductivity data by a modelling approach (LWAM or the novel semi-analytical, from the fracture propagation simulator) to permeability data for the fracture. The transformed permeability data is further imported into the numerical reservoir simulator in order to observe the impact on cumulative prodcution data. This chapter describes the two simulators and their facilitation in this case study. Since three bianry mixtures are selected to be studied and modelled in this thesis, all of them are implemented as test cases for Marcellus Shale.

\subsection{Fracture propagation simulator}

Albeit the study in this thesis primarily focuses on modelling development and validation, propsepctive applications from the novel conducitvity modelling require at least a fracture propagation simulation program. Therefore, an in-house fracture propagation simultor was built to support these potential applications.

A general description for the fracture propagation simulator is detailed chapter 3. However, the use of this simulator for conductivity estimation and transformation from conductivity to permeability are detailed in this chapter.

\subsubsection{Conductitvy estimation}


As this thesis studies 3 sepcific binary mixtures (selected and described in chapter I), corresponding Mesh sizes and densities are recored to sepcify the matched binary mixture (i.e $1^{\text {st }}$ inejction: $40 / 70$ sand and $2^{\text {nd }}$ inejction: $20 / 40$ ceramic). The binary mixture specification (including two proppant types and the order of injection as the prvious example) combined with the Weight Concentration Ratio matrix are further inputted into the conductivity estimation procedure. For the value of Weight Concentration Ratio in a digitized grid, conductivity estimations by LWAM and the semi-analytical modelling are performed since they are both functions of confining stress (equivalently minimum horizontal stress encoded in the simulator) and Areal Concentration Ratio. Conductity estimations by both models have to be linearly scaled to the total areal concentration value of the grid (reservoir condition) from $2 \mathrm{lb} / \mathrm{ft}^{2}$ (lab condition), as follows: $C_{\text {reservoir }}=$ $C_{l a b} \frac{\text { ArConcTot }}{2}$. Conductivity estimation for proppant concentration conditon inside the reservoir is the final computation process. By sole use of the fracture propagation simulator, conductivity estimation can be satisfied.

\subsubsection{Tranformation from conductivity to permeability}

Transformation from conductivity data (generated by modelling approaches, LWAM or the semi-analytical model) to permeability data (imported into the numerical reservoir simulator) needs two requirements. The former requiremnt is the default fracture width in CMG (a numerical value), which facilitates the following data conversion: $k_{C M G}=\frac{C_{C M G}}{w_{C M G}}=\frac{C_{\text {fracture simulator }}}{w_{C M G}}$ (all variables are $2 \mathrm{D}$ matrices, except $\left.w_{C M G}\right)$. The latter requirement is an intergration in dimensions with the numerical reservoir simulator. In this thesis, $\mathrm{CMG}$ is used as a $3 \mathrm{D}$ numerical reservoir simulator. In $\mathrm{CMG}, 3$ dimensions are declared: I, J, and $\mathrm{K}$. The number of grids for these dimentions are denoted as $\mathrm{nI}, \mathrm{nJ}$, and $\mathrm{nK}$, respectitvely. However, permeability data in CMG is 
declared as a 2D matrix with dimensions of $\left(\mathrm{nJ}^{*} \mathrm{nK}\right) * \mathrm{nI}$. The structure of this $2 \mathrm{D}$ matrix is constructed as follows:

- The row $n I=1$ stores the fracture permeability data

- The rows of other $n I$ values store the formation permeability data

As a result, fracture half-length and fracture width grid dimensions should be designed in the fracture simulator to be identical to the $\mathrm{J}$ and $\mathrm{K}$ grid dimensions in $\mathrm{CMG}$, respectively. Following the dimension intergration as described, all nuemrical values in the previously computed $k_{C M G}$ are converted into the row $n I=1$ of a new $k_{C M G}$, and the remaining rows in the new $k_{C M G}$ hold the permeability value of the formation (i.e. Marcellus Shale in this case study). The new $k_{C M G}$ is imported into the permeability decleration of the CMG input file (i.e. a .DAT format file).

\subsection{Numerical reservoir simulator}

As afrementioned, CMG sotware is used as the numerical reservoir simulator in this thesis and it is coupled with the in-house fracture propagation simulator for cumulative production prediction. This CMG model was proposed by a groups of authors (Gu, Kulkarni, Raflee and Ivarrud) in 2014, and was comprehensively detailed by Courtney L. Rubin in 2018 for a parametric study.

\section{Simulation domain}

One-fourth of a single fracture's drainage area is selected as the reservoir simulation region. Bi-wingle fracture geometry is implied in the CMG model, which directly consolidate with the 2D-PKN in the fracture propagation simulator. According to the simulation domain and the assumed fracture geometry, cumulative production for a horizontal well equals a multiplication of 
the cumulative production from the $\mathrm{CMG}$ model by $4 N_{\text {fractures }}$ (the number of one-fourth simulation resgion in a horizontal well).

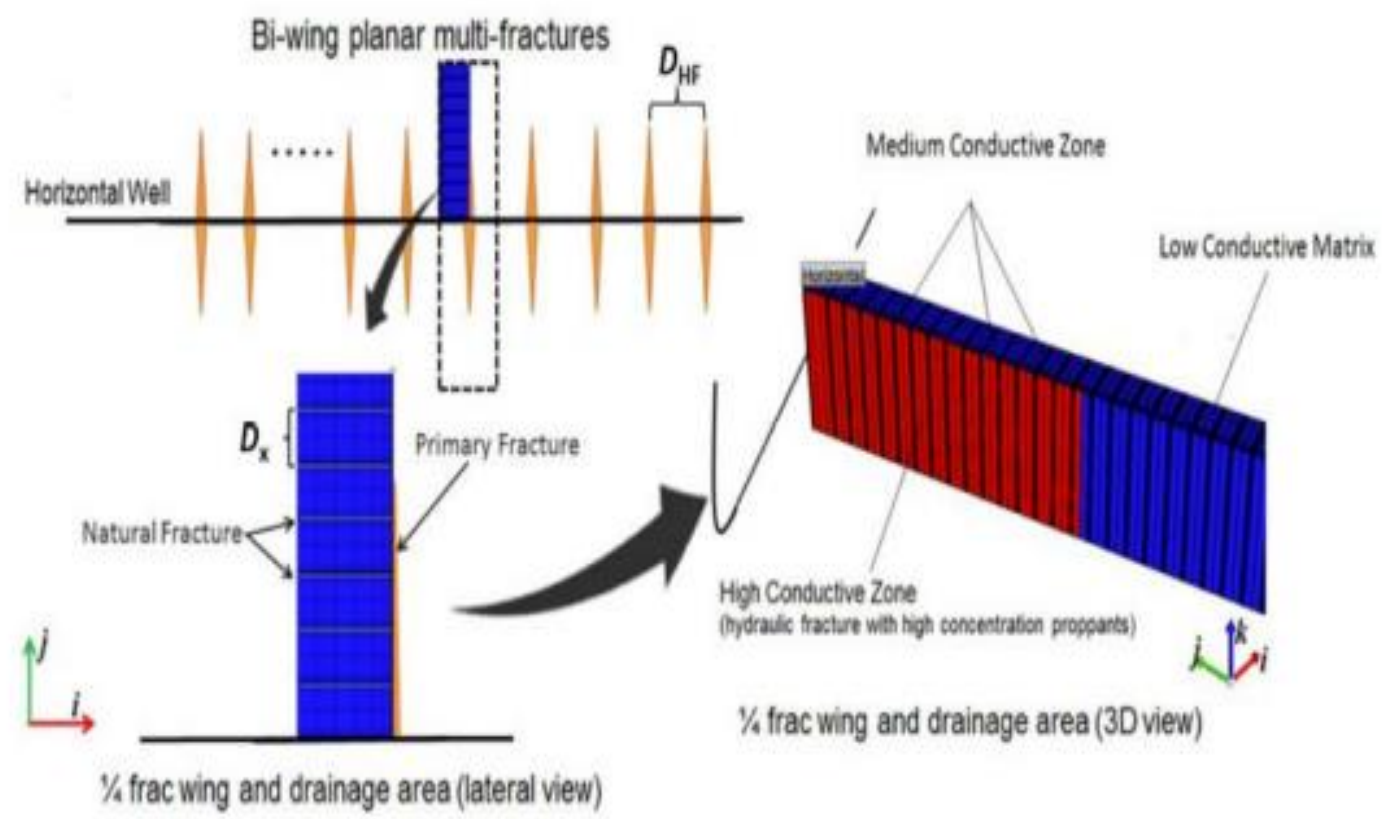

Figure 9 - Schematic for the simulation domain (1/4 of a single fracture's drainage area) in the CMG model (Gu, Kulkarni, Raflee and Ivarrud, 2014)

\section{Reservoir homogeneity}

Since this thesis focuses on the effect from the hydraulic fracture's permeability, simpified assumption of homoneneity in the reservoir is implied albeit Marcellus Shale is a heterogeneous formation. Based on the assumption of homogeneity, the permeability matrix data $k_{C M G}$ has an identical value for all rows of $\mathrm{nI}$ different from 1 (which is the reservoir permeability value). In addtion, Logarithmic Local Grid Refinement (LLGR) is implied to reflect transient flow regime between the reservoir's intrinsic permeability zone and the fractured channels' permeability zone.

\section{Gas desorption}

Effect of gas desorption is a requirement since Marcellus Shale is a dry gas reservoir. Langmuir isotherm equation (type I), which assumes dynamic equilibrium at constant temperature 
and pressure between absorbed and non-absorbed gas, is used to model the desorption effect (Langmuir, 1918). The Langmuir pressure $\left(\mathrm{P}_{\mathrm{L}}\right)$ and Langmuir volume $\left(\mathrm{V}_{\mathrm{L}}\right)$ are correlated by the following relationship:

$$
v(P)=\frac{V_{L} P}{P+P_{L}}
$$

Where $\mathrm{v}(\mathrm{p})$ is the absorption gas volume as pressure $\mathrm{P}, \mathrm{V}_{\mathrm{L}}$ is the maximum gas volume at infinite pressure, and $\mathrm{P}_{\mathrm{L}}$ is the pressure which corresponds to one half of Langmuir volume. The optimal values of Langmuir pressure and Langmuir volume are selected based on experiment results in Yu et.al (2016).

\section{Flow regime}

Within the hydraulic fractures as highly conductive channels for fluid flow, turbulence flow (or non-Darcy flow) is implied in replacement of Darcy flow. In this CMG model, Forchheimer flow equation $(\mathrm{Gu}, 2013)$ is used. The non-Darcy factor is computed as follows:

$$
\beta=\frac{1.485 \cdot 10^{9}}{\emptyset k^{1.021}}
$$

Where $\beta$ is the non-Darcy factor in $1 / \mathrm{ft}$. Since equation (5.2) has been implied in a variety of porous media with satisfying precision, its implication in this CMG model is reasonable (Courtney Rubin, 2018). 


\section{CHAPTER 6 - RESULTS AND DISCUSSIONS}

\subsection{Sensitivity study}

6.1.1. Dependency of mixture zone on studied factors

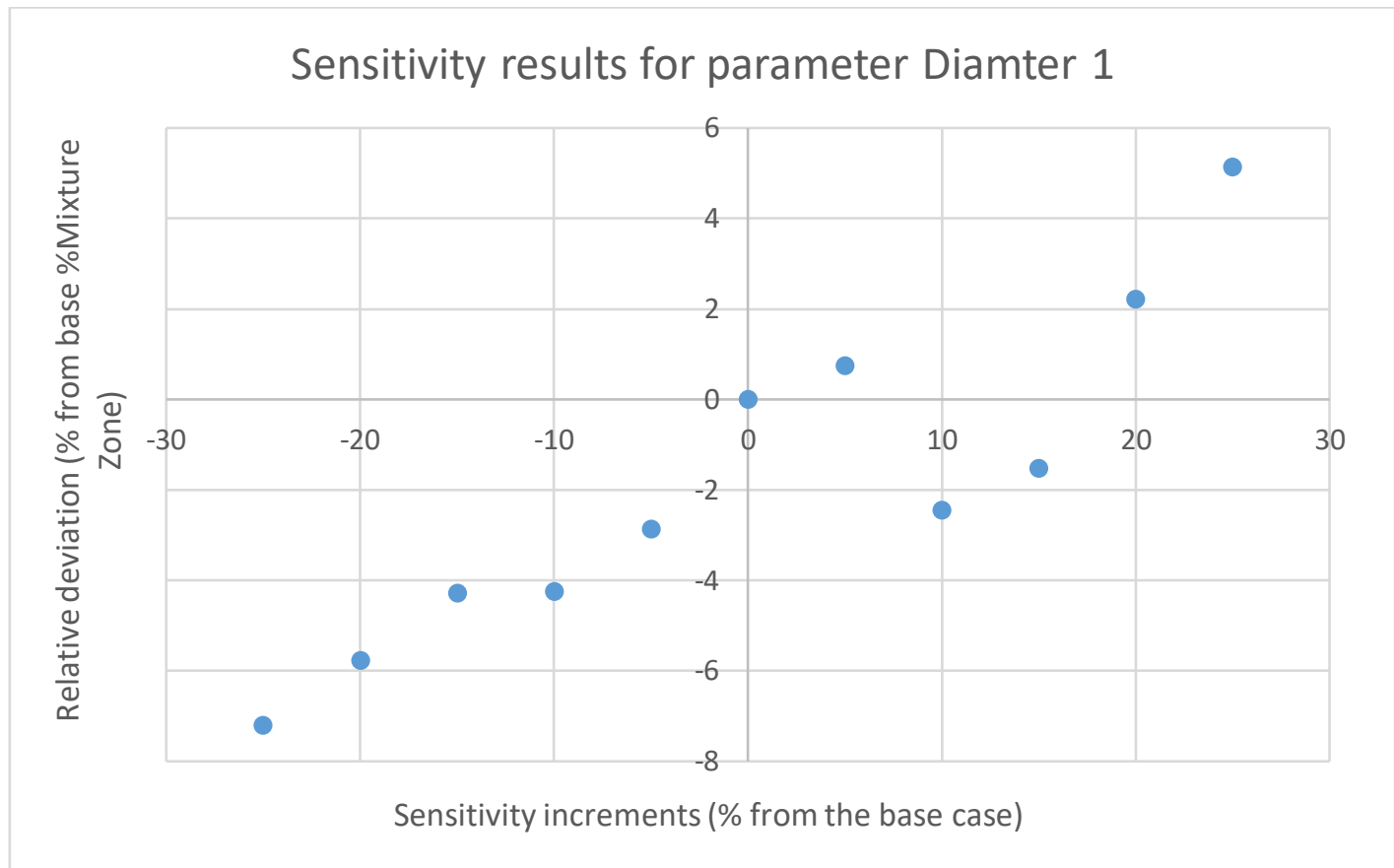

Figure 10 - Sensitivity results for former injected proppant type's diameter (Diameter 1)

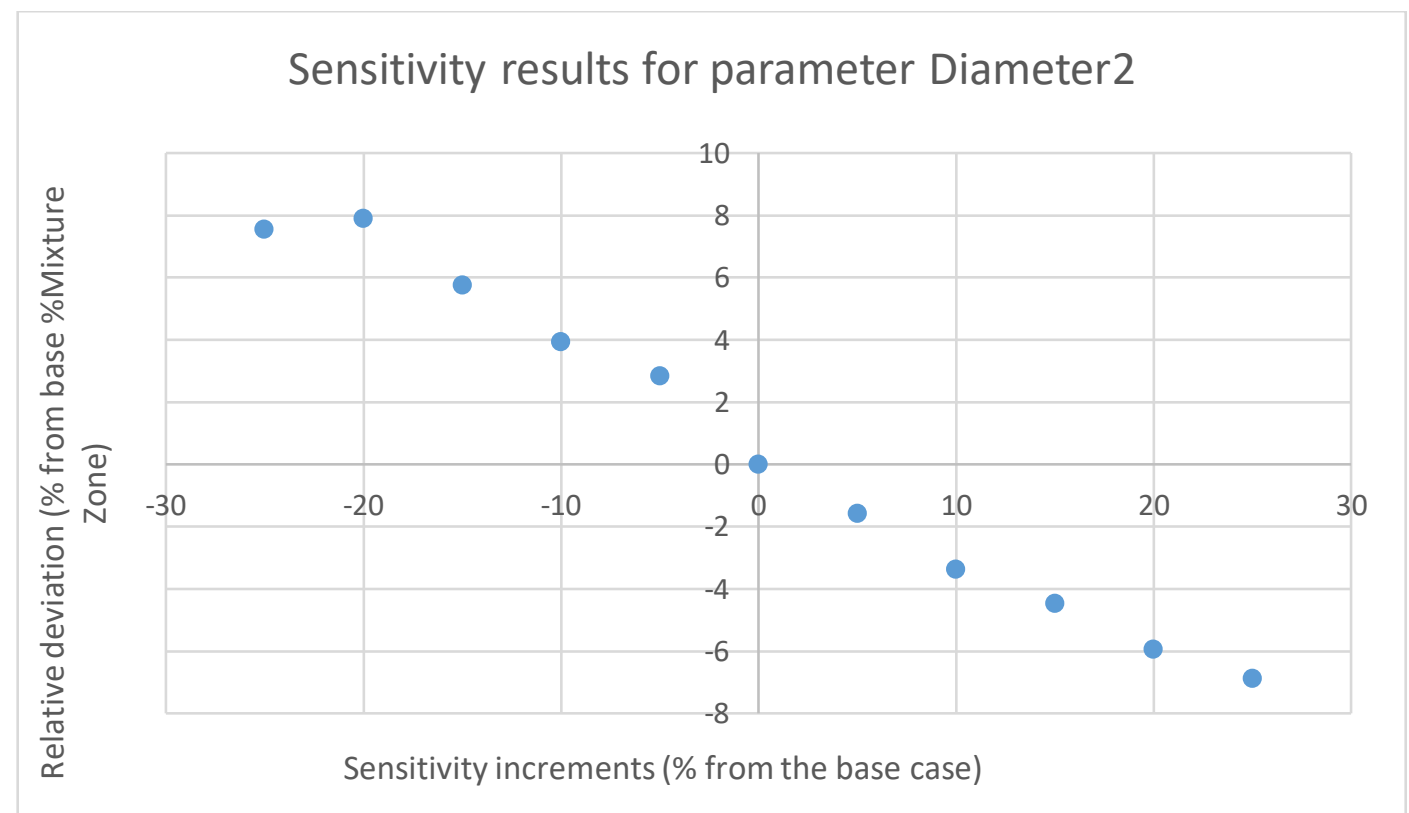

Figure 11 - Sensitivity results for latter injected proppant type's diameter (Diameter 2) 


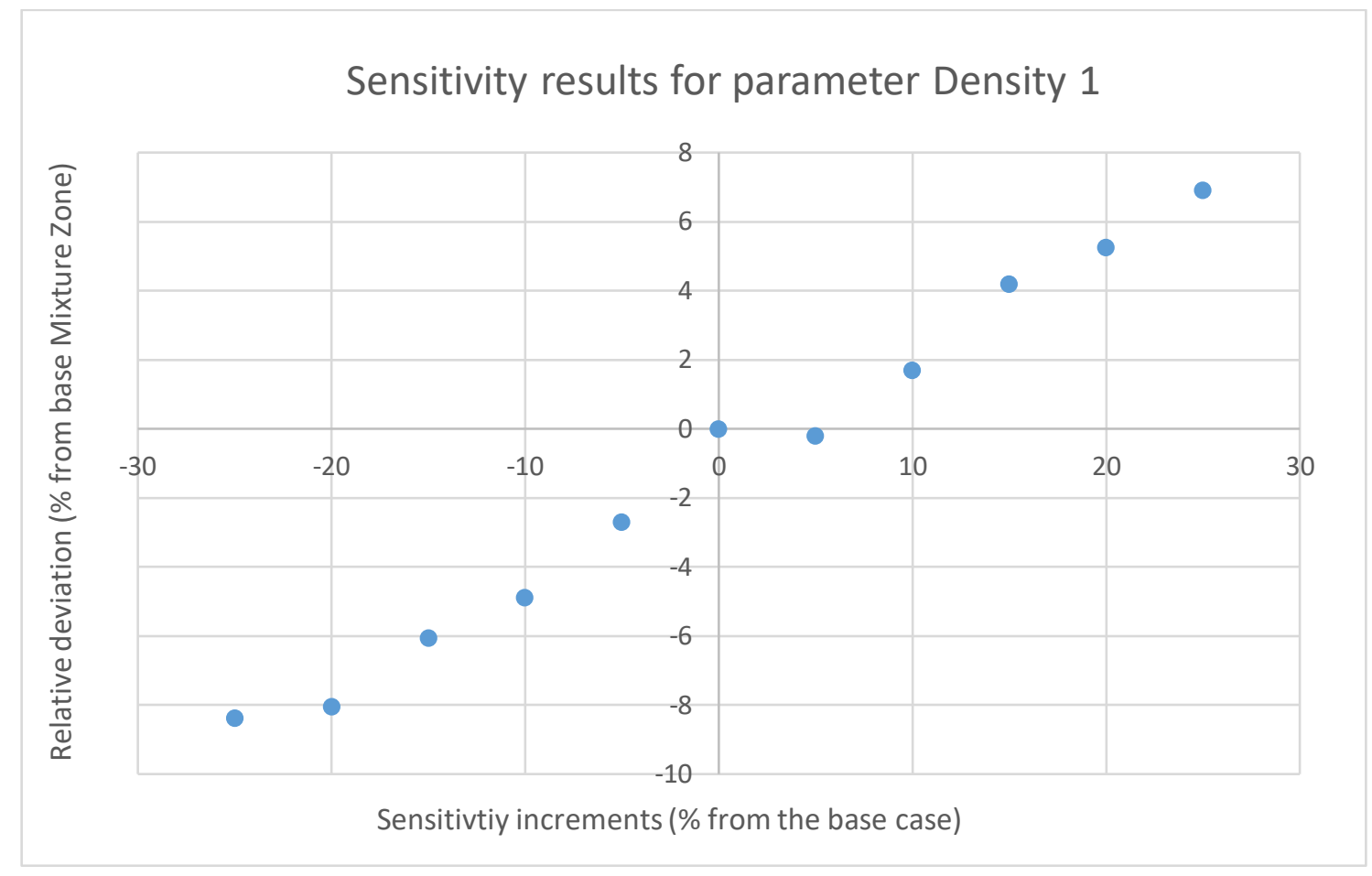

Figure 12 - Sensitivity results for former injected proppant type's density (Density 1)

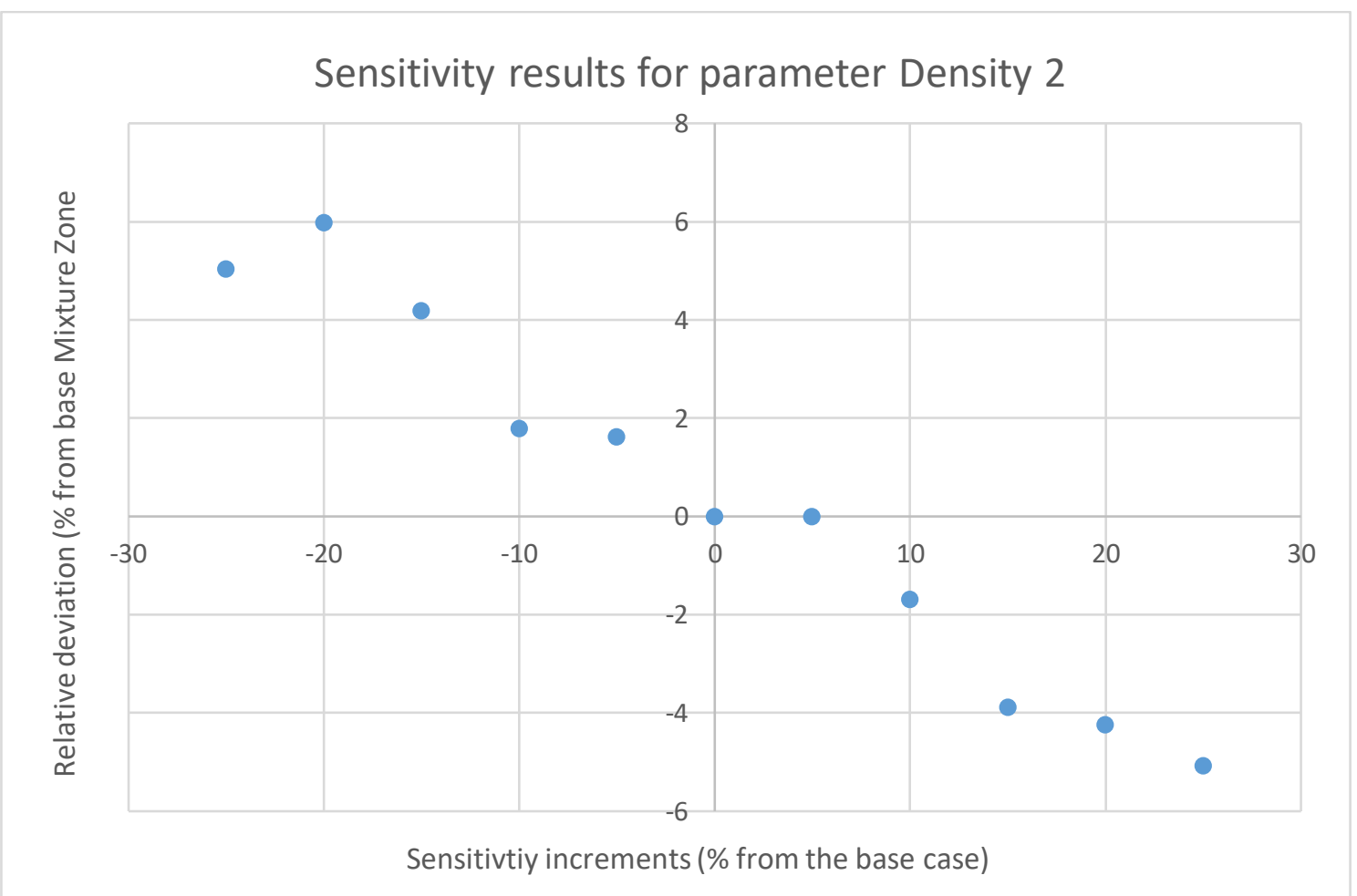

Figure 13 - Sensitivity results for former injected proppant type's density (Density 2) 


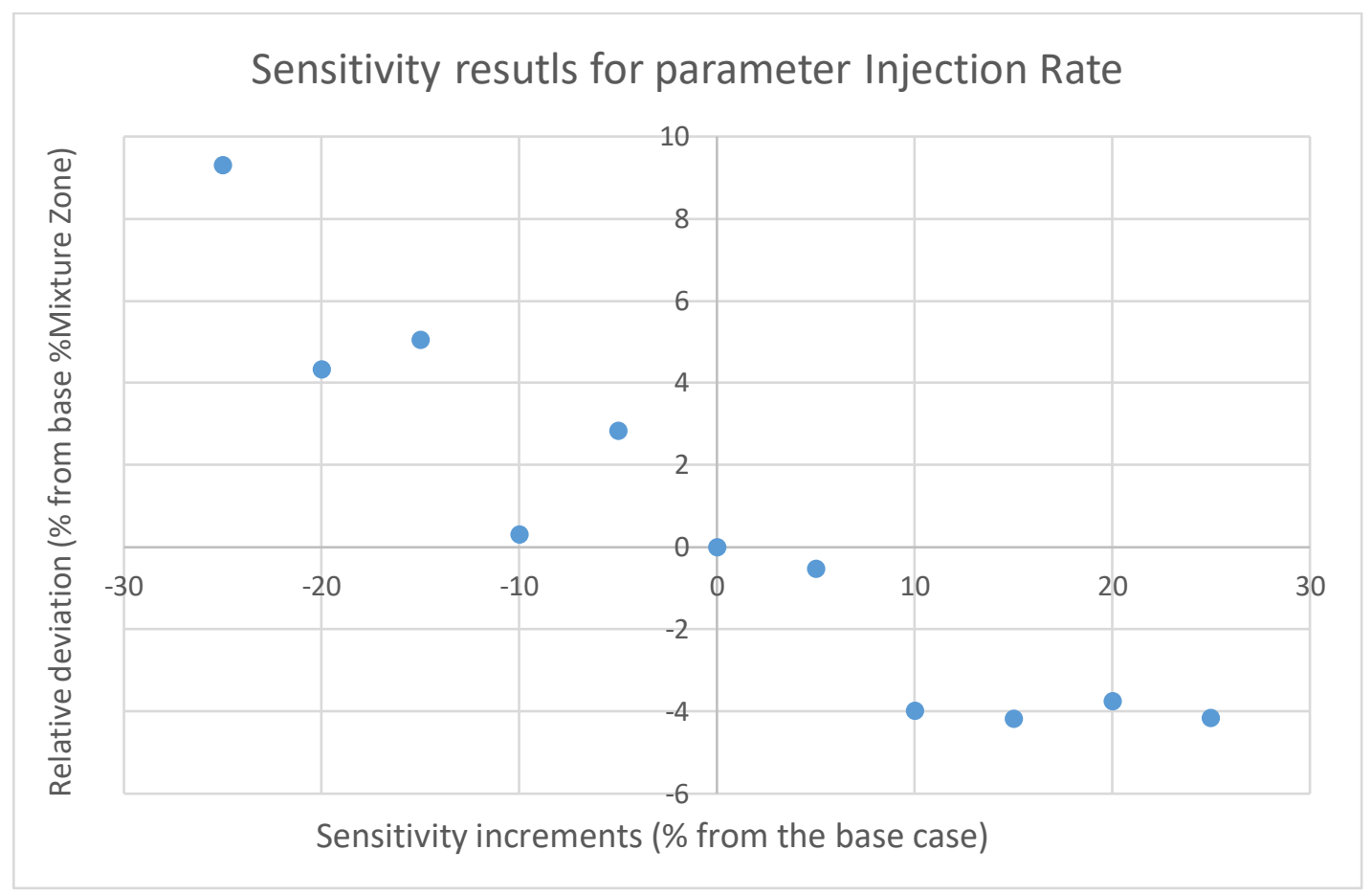

Figure 14 - Sensitivity results for injection rate

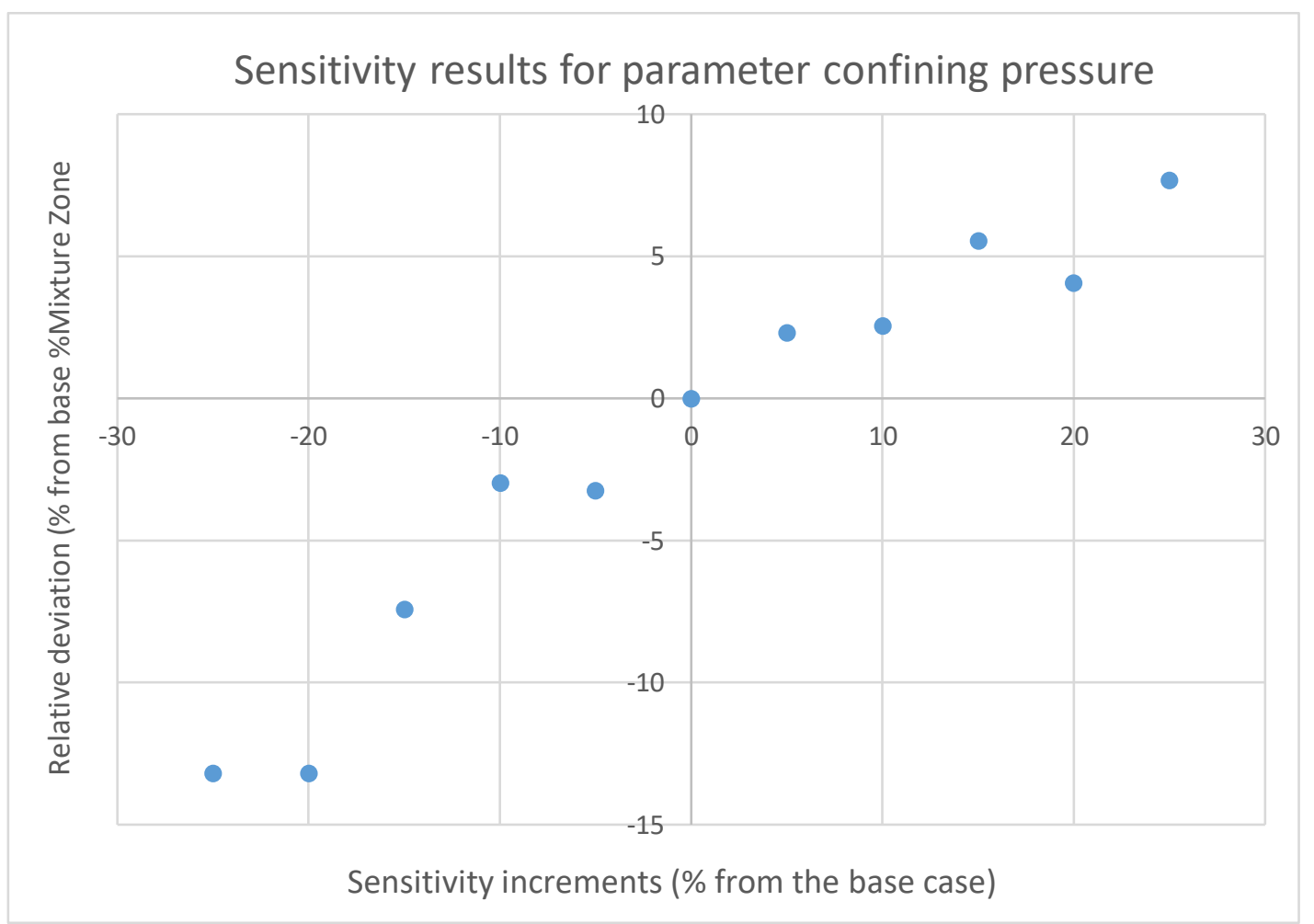

Figure 15 - Sensitivity results for confining pressure 


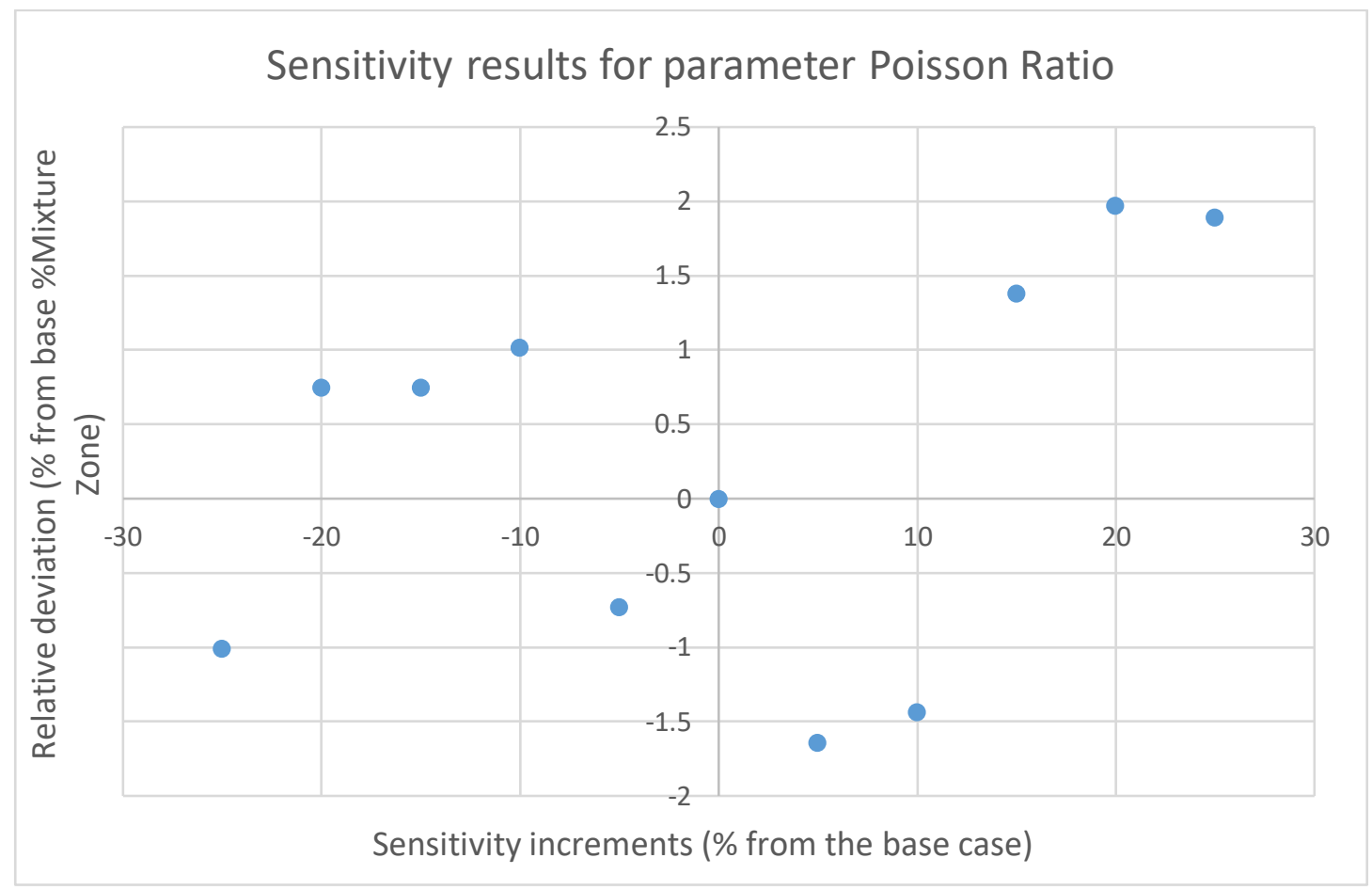

Figure 16 - Sensitivity results for Poisson Ratio

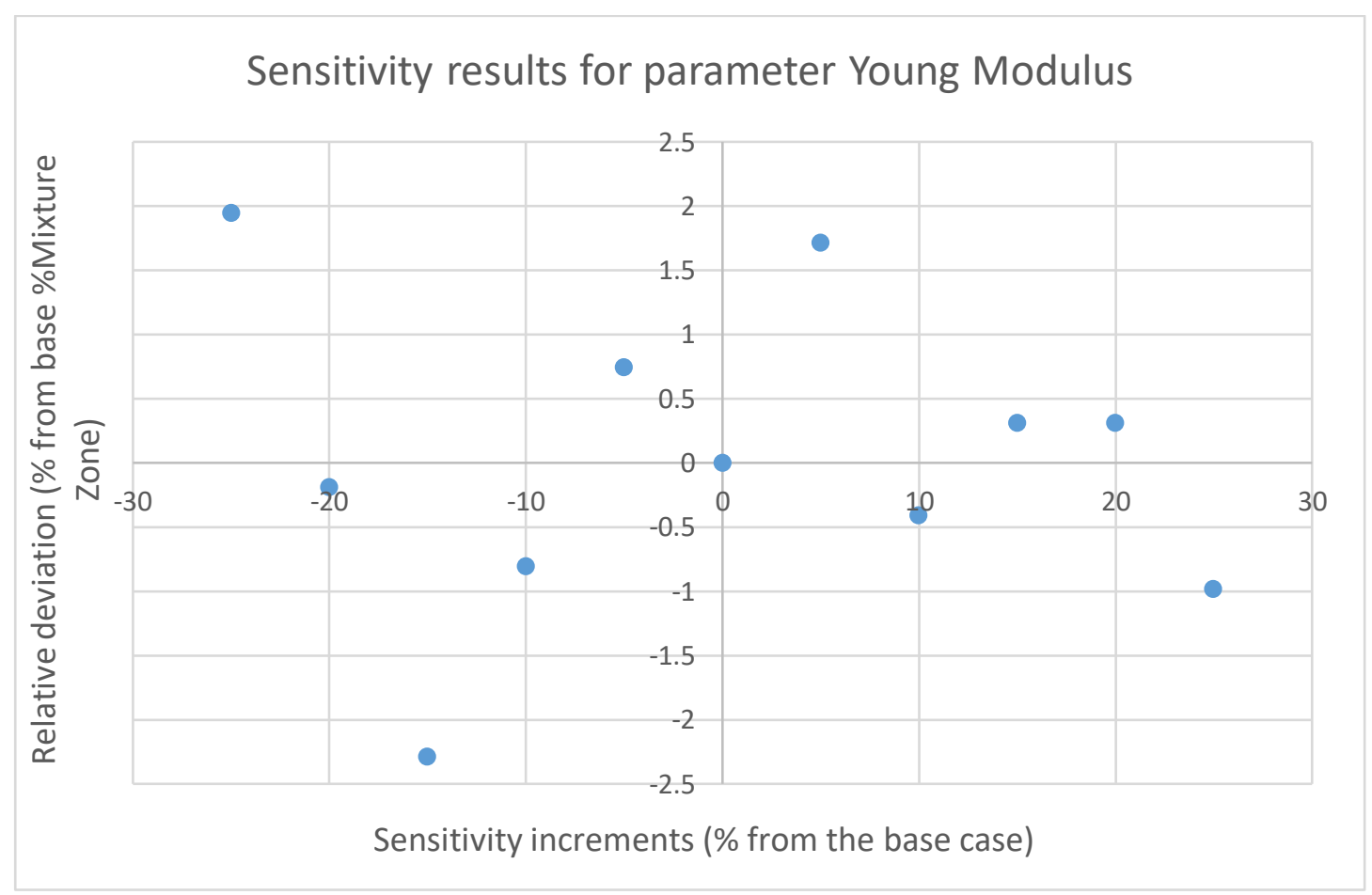

Figure 17 - Sensitivity results for Young Modulus 


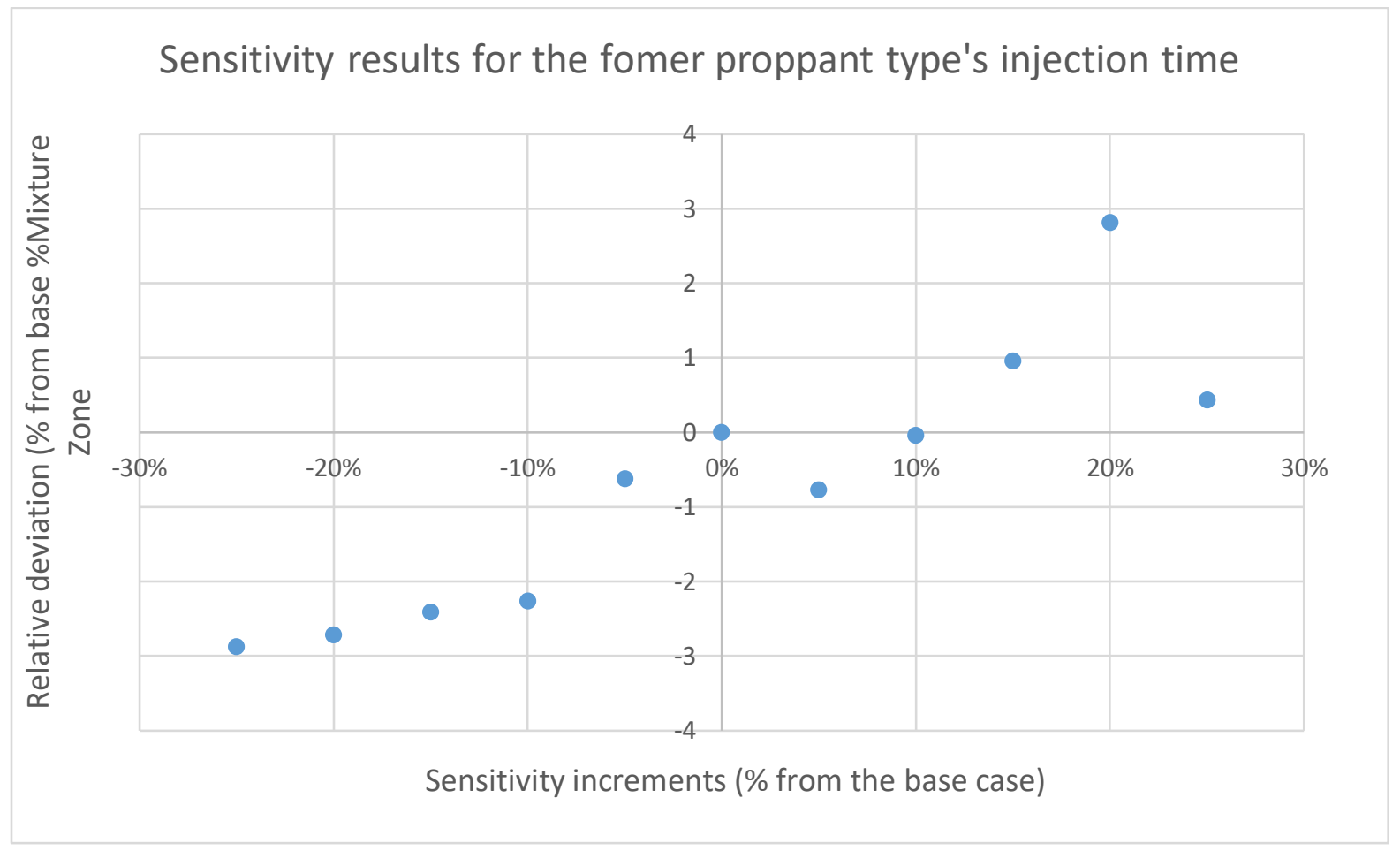

Figure 18 - Sensitivity results for former injected proppant type's ( $4^{\text {th }}$ time step)

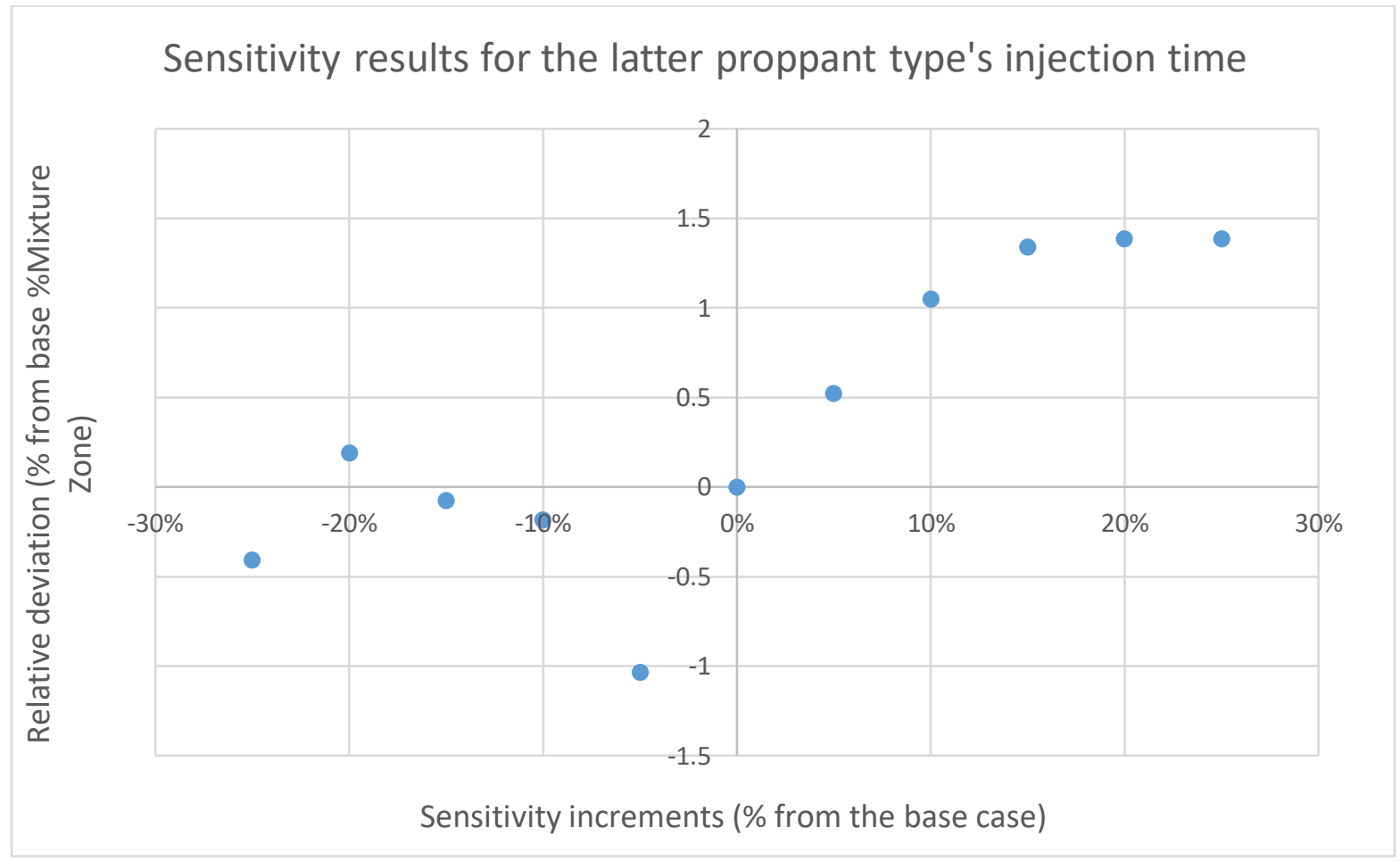

Figure 19 - Sensitivity results for former injected proppant type's $\left(5^{\text {th }}\right.$ time step $)$ 
Figures 10-19 present figurative outcomes of the sensitivity study for the 10 parameters listed in chapter 4 . The $\mathrm{x}$ axis in figures 10-19 present the sensitivity increments (i.e. percentage increments from the base case's value in chapter 3). The y axis presents relative deviation (i.e. \% deviation from the base case's value of all sensitivity incremental points in chapter 3). All the numerical outcomes of the sensitivity study which provide the data for plotting figures 9-18 are detailed in the Appendix.

Confining pressure presents the heaviest impact on the mixture zone with a sensitivity in a range of up to $13.17 \%$ from the base case. Increasing the confining pressure increases the mixture zone and vice versa. Rate of increase when increasing confining pressure is lower than rate of decrease when decreasing confining pressure. Injection rate also presents a high impact on the mixture zone $(9.29 \%$ to $-4.15 \%)$. The dependence of mixture zone on injection is generally inversely proportional, and the rate of decrease is rapid until 10\% increase from the base case. However, when the injection rate increases to exceed $10 \%$ from the base case, the impact on mixture zone maintains at approximately $-4 \%$. Poisson Ratio and Young Modulus both present fluctuations regarding their impact to the mixture zone. Their impact is observed to be not significant compared to confining pressure and injection rate (up to $2.28 \%$ from the base case).

Both proppant diameters and densities present high and clear behavior of impact to the mixture zone, and expected degree of impact to the mixture zone for these parameters is equivalent. Increase in dimeter and density of the former injected proppant type increases impact on the mixture zone, whereas the reverse behavior is observed for the latter inject proppant type.

Increase in injection time of the former proppant type (focus of sensitivity at the $4^{\text {th }}$ stage) increases the mixture zone and vice versa. Rate of increase when increasing this parameter is sharper than rate of decrease when this parameter decreases. Injection time of the latter proppant 
type (focus of sensitivity at the $5^{\text {th }}$ stage) increases the mixture zone when the change of this parameter is within $10 \%$ from the base case. When this parameter increases more than $10 \%$ from the base case, change to the mixture zone approaches and stabilizes at closely $1.5 \%$. In contrast, when this parameter decreases more than $10 \%$ from the base case, the mixture zones slightly fluctuates within the $0.5 \%$ from the base case. Injection time of the former proppant type's impact to mixture zone is higher (-2.87\% to $2.81 \%)$ compared to impact from injection time of the latter proppant type (-1.03\% to $1.39 \%)$.

\subsubsection{Summary}

Table 4: Correlation between output and input factors

\begin{tabular}{|c|c|}
\hline Input factor & Correlation sign \\
\hline Diameter (former proppant) & + \\
\hline Diameter (latter proppant) & - \\
\hline Density (former proppant) & + \\
\hline Density (latter proppant) & - \\
\hline Injection rate & + \\
\hline Confining pressure & No clear correlation \\
\hline Young Modulus & No clear correlation \\
\hline Poisson Ratio & + \\
\hline Injection time (former proppant) & + \\
\hline Injection time (latter proppant) & + \\
\hline
\end{tabular}

Table 4 provides the first summary viewpoint for this sensitivtiy study, which is conducted through observations of propsective correlations between output factor (\% of Mixture Zone area) and studied input factors (equivalently, observations from figures 10-19). A positive sign indicates proportional correlation between output factor and the corresponding input factor. A negative sign indicates inversely proportional correaltion between output factor and the corressponding input factor. Description "No clear correlation" deos not clearly indicate a positive or a negative sign. 
Based on table 4, assumptions in the sensitivity design (i.e. the standard, local OAT sensitivity method) and the tested model (i.e. the in-house fracture propagation simulator), geo-mechanics properties do not present any clear behaviors of their impact to the Mixture Zone, albeit they are widely known to be core influcers which affects fractured area.

The second summary viewpoint for this sensitivity study is presented through the tornado plot in figure 20. Based on the tornado plot, assumptions in the sensitivity design and the tested model, confining stress and the proppant's properties show the biggest effect to the mixture zone. Geo-mechanics properties (i.e. Young Modulus and Poisson Ratio) show insignificant effect to the mixture zone. Former proppant type's density and later proppant type's diameter contribute similar degree of impact to the mixture zone. Similarly, former proppant type's diameter and latter proppant type's density contribute similar degree of impact to the mixture zone. The degree of impact from these proppant parameters is slightly lower compared to the previously mentioned proppant parameters. The last 4 parameters in the tornado chart (i.e. injection time for the former proppant type and below) are insignificant influencers to the Mixture Zone.

Conslusions from the sensitivity study based on table 4 and figure 20 are capable of predictive applications as the following examples. Utica Shale should have a larger mixture zone compared to Marcellus Shale based on the impact from confining pressure, as Utica has a higher confning sress than Marcellus. Provided that the mixture zone for injection of 40/70 sand and 20/40 ceramic is known, an injection of binary mixture 20/40 sand and 20/40 ceramic should expand the mixture zone because of impact from higher size of the former proppant type. Similarly, an injection of binary mixture 40/70 ceramic and 20/40 sand should also expand the mixture zone because of imapct from higher density of the former proppant type and lower density of the latter coponent. Within all factors from the sensitivity study which may contribute to modelling 
development in chapter 4 and assumptions in the in-house fracture propagation simulator, closure pressure and proppant's properties provide indication that they need higher weighting factors whereas the geo-mechanics properties provide indication that they need lower weighting factors.

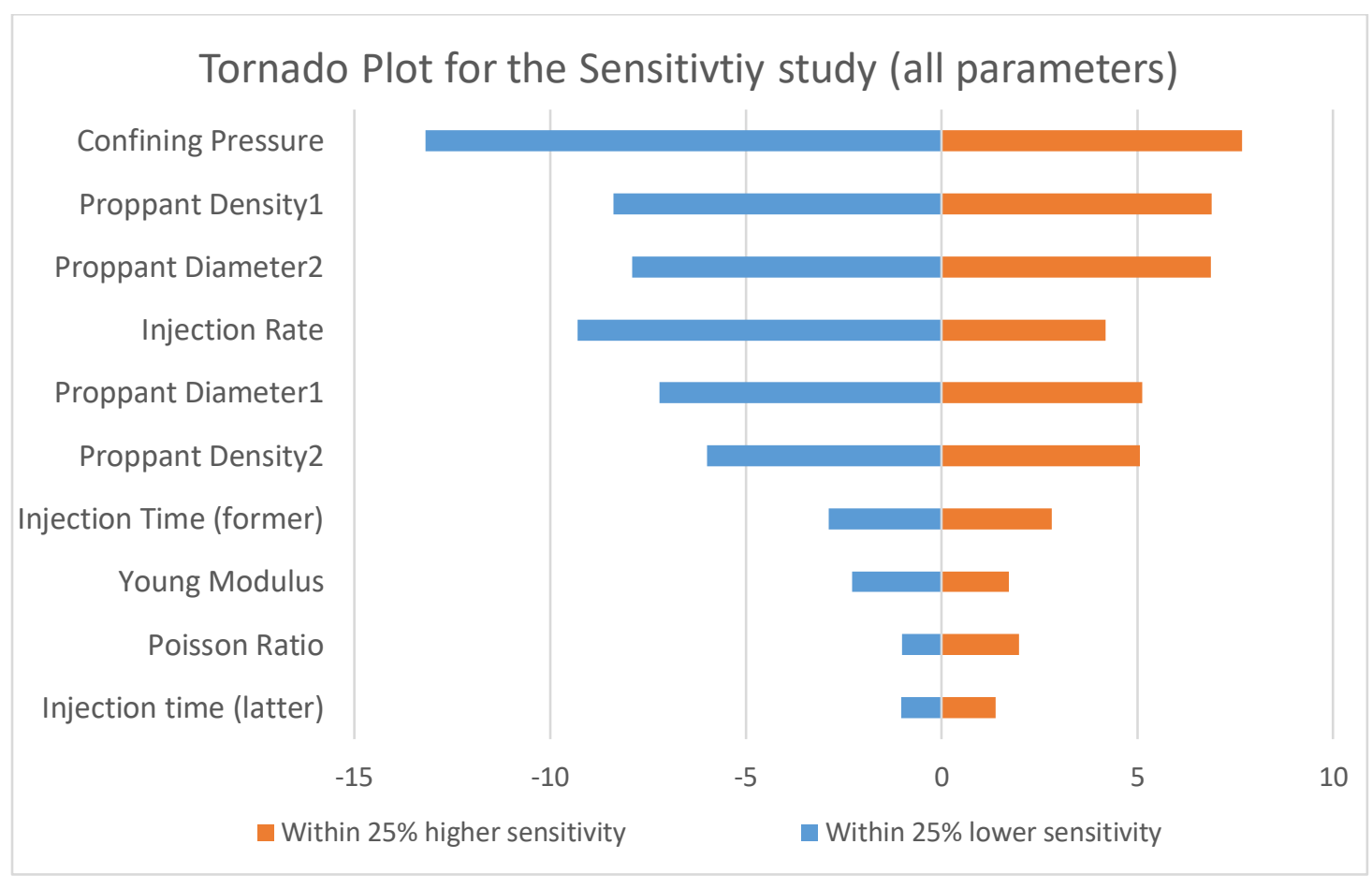

Figure 20 - Summary of the sensitivtiy study for all parameters

\subsubsection{Drawbacks of the sensitivity study's design}

Since the sensitivity study is designed to examine local contribution of a factor's impact to the mixture zone and the sensitivity behavior of input factors are small around an expected value, application of standard OAT and finite-difference approximation (Morris, 1991) are accepted. However, the scale of the sensitivity analysis in this chapter can be expanded to a global sensitivity analysis. According to Morris global sensitivity design (Morris, 1991), the base case is generated as each run within analysis for one input factor. Consequently, the computation runs required scale up to factorial of 10 (i.e. 10!), presumably applied to this thesis, and the analysis for variance of 
the mixture zone (i.e. the output factor) is obviously more feasible compared to the current design in this chapter.

Another aspect to be considered is dependency within the input factors. In the list of input factors, three are classified as reservoir relevant (reservoir group), which include confining stress, Young Modulus and Poisson Ratio. The remaining seven are classified as treatment relevant (treatment group). While the factors in the reservoir group exhibit certain correlation (i.e. factor interactions), the factors in the treatment group can be claimed as independent. Therefore, application of elementary effect (Morris, 1991) is only reasonable for the treatment group. In addition, the variance in the reservoir group's factors is known from field measurement's analysis, besides their physics-based relationship. Contribution from these concerns can lead to better design and more realistic discussions for impact from the reservoir's group to mixture zone.

\subsection{Determination of coefficients}

As described in chapter 4 , the coefficients for permeability modelling approach requires facilitation of trust-region-reflective algorithm under control of boundary conditions. Table 4 provides numerical values of all coefficients in the permeability modelling approach and the $\mathrm{R}^{2}$ (i.e. residual error) values for 6 selected lab data sets. Graphical outcomes visualizing the efficacy of the selected algorithm are in the Appendix.

$\underline{\text { Table } 5 \text { - Values of coefficients and } \mathrm{R}^{2} \text { in the permeability model }}$

\begin{tabular}{|c|c|c|c|c|}
\hline Binary mixture and weight mixing ratio & $\Phi_{\mathbf{o}}$ & $\boldsymbol{\beta}(\mathbf{1} / \mathbf{p s i})$ & $\mathbf{n}$ & $\mathbf{R}^{\mathbf{2}}$ error \\
\hline 20/40 sand and 20/40 ceramic, 50/50 & 0.374456 & $6.75 \mathrm{E}-05$ & 0.399795 & $1.34 \mathrm{E}-05$ \\
\hline 20/40 sand and 20/40 ceramic, 25/75 & 0.356449 & $2.58 \mathrm{E}-05$ & 0.47776 & $2.38 \mathrm{E}-06$ \\
\hline 40/70 sand and 20/40 ceramic, 50/50 & 0.358651 & $6.32 \mathrm{E}-05$ & 0.401368 & $3.77 \mathrm{E}-06$ \\
\hline 40/70 sand and 20/4 0ceramic, 25/75 & 0.360489 & $6.35 \mathrm{E}-05$ & 0.44827 & $5.86 \mathrm{E}-06$ \\
\hline 40/70 ceramic and 20/40 sand, 50/50 & 0.31414 & $2.53 \mathrm{E}-05$ & 0.614715 & $1.56 \mathrm{E}-07$ \\
\hline 40/70 ceramic and 20/40 sand, 25/75 & 0.326409 & $3.25 \mathrm{E}-05$ & 0.588929 & $1.52 \mathrm{E}-06$ \\
\hline
\end{tabular}


The residual errors in table 5 are acceptably minimal, which indicate high efficacy of the selected algorithm. However, under a modelling development for a physic-based phenomenon, physcial interpretation for the coefficients is an obligation before further applications. In the context of this thesis, examination for coefficients are based on two indepdent criteria: the physical quantity they relate to (i.e porosity, hydraulic tortuosity) and the effects from intrinsic properties of the modelled phenomenon (i.e. the proppant types in the bianry mixture and the weight mixing ratio, or Areal Concentration Ratio). The former criteria is implied in the contraints of the coefficents is already described in chapter 4 . In this chapter, the latter criteria is discussed in term of coefficient-based.

\subsubsection{Initial porosity at zero applied stress $\left(\Phi_{\mathrm{o}}\right)$}

$\Phi_{\mathrm{o}}$ is initially porosity of the proppant pack at zero applied stress. Because of its definition, $\Phi_{\mathrm{o}}$ highly depends on the packing of proppant particles and does not depend on confining stress. Reasonably, $\Phi_{\mathrm{o}}$ shall exhibit close relationship with volumetric ratio (which is consequently converted to weight ratio, or $\mathrm{R}$ as notation defines) between two proppant types in a binary mixture. However, this relationship should be better analytically reasoned based on an experimental study by Anthony Diyokeugwu and Paul Glover (2018). The study focused on correlation between porosity, $\frac{D_{\text {coarser }}}{D_{\text {finer }}}$ ratio (i.e. diameter ratio), and finer proppant type's volumetric ratio in binary mixtures, which is represented in figure 21 .

Limited to the modelling context in this thesis, the diameter ratios of three studied binary mixtures are averagely between 1.12 and 2.1 , which leads to a porosity range between $30 \%$ and $40 \%$. Overall, porosity values in table 4 satisfy this nominal range. For binary mixture $20 / 40$ sand and 20/40 ceramic, the finer proppant type's volumetric ratios are 0.682 (i.e. equivalent $50 \%$ weight of 20/40 sand) and 0.417 (i.e. equivalent $25 \%$ weight of 20/40 sand), respectively. Since 
0.682 and 0.417 exceed the critical volumetric ratio of finer proppant type $(0.25-0.35), \Phi_{\mathrm{o}}$ value

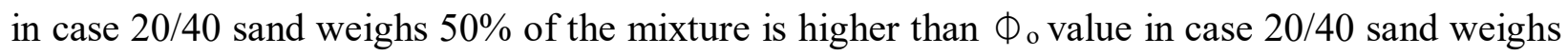
$25 \%$ of the mixture. For binary mixture $40 / 70$ sand and 20/40 ceramic, the finer proppant type's volumetric ratios are 0.682 (i.e. equivalent $50 \%$ weight of $40 / 70$ sand) and 0.417 (i.e. equivalent $25 \%$ weight of $40 / 70$ sand), respectively. Since 0.682 and 0.417 exceed the critical volumetric ratio of finer proppant type $(0.25-0.35), \Phi_{\mathrm{o}}$ value in case $40 / 70$ sand weighs $50 \%$ of the mixture is higher than $\Phi_{o}$ value in case $40 / 70$ sand weighs $25 \%$ of the mixture. For binary mixture $40 / 70$ ceramic and 20/40 sand, the finer proppant type's volumetric ratios are 0.318 (i.e. equivalent $50 \%$ weight of $40 / 70$ ceramic) and 0.135 (i.e. equivalent $25 \%$ weight of $40 / 70$ ceramic), respectively. Compared to the critical volumetric ratio of finer proppant type $(0.25-0.35), 0.318$ is in the critical range whereas 0.135 is smaller than the critical range. As a result, $\Phi_{\mathrm{o}}$ value in case 40/70 ceramic weighs $50 \%$ of the mixture is lower than $\Phi_{\mathrm{o}}$ value in case $40 / 70$ ceramic weighs $25 \%$ of the mixture. All numerical values of term $\Phi_{\mathrm{o}}$ from table 4 successfully reflects analytical reasoning of all studied binary mixtures.

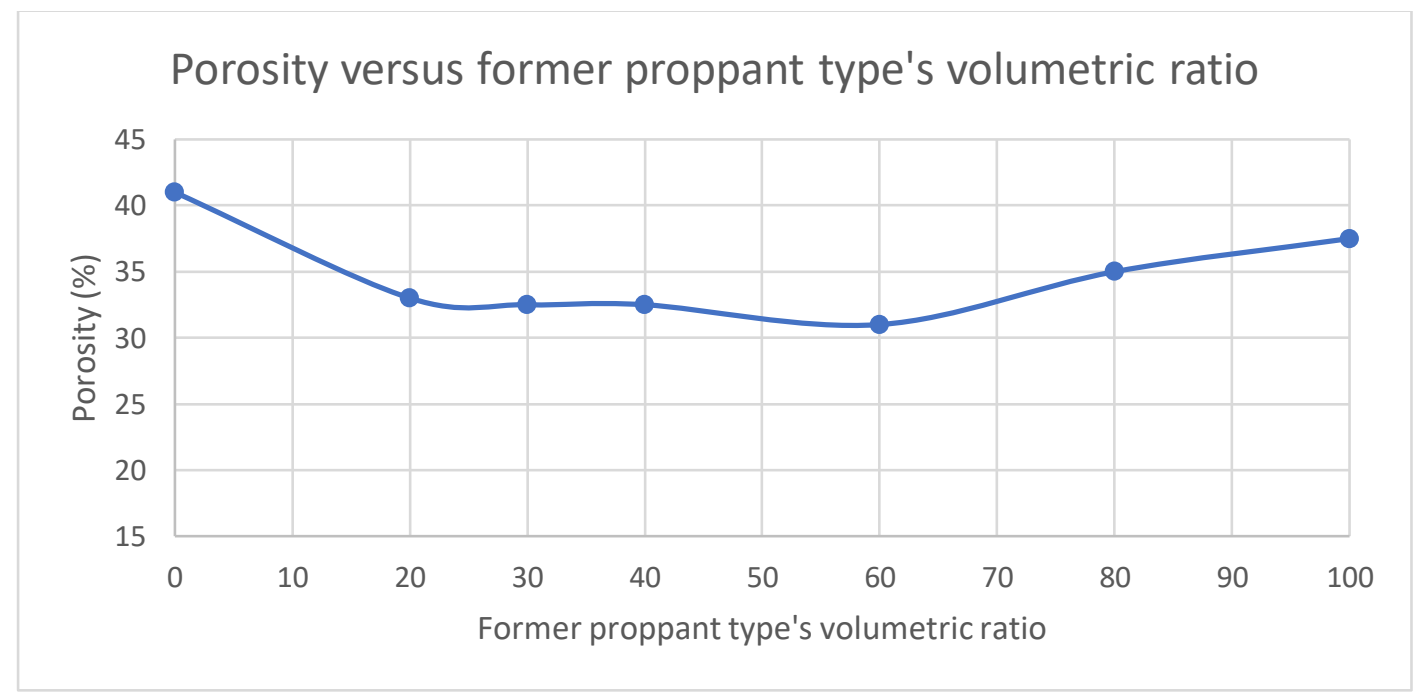

Figure 21 - Relationship between porosity and former proppant type's volumetric ratio

(diameter ratio is 1.5$)$ 


\subsubsection{Beta coefficient in porosity model $(\beta)$}

$\beta$ is the compressibility factor in porosity exponent model (equation (4.2)). Overall, $\beta$ values in tables 4 satisfy the nominal range of rock compressibility, which is between $1.5 \cdot 10^{-6}$ and $8.5 \cdot 10^{-5}$. Because proppant packs in Eric's experiments are compressed by steel plates, they have high compressibility potential. As a result, $\beta$ values in tables 4 are reasonable to be all in $10^{-}$ ${ }^{5}$ scale and not $10^{-6}$ scale. Furthermore, compressibility factor $\beta$ relates directly to size and strength of the material. In a binary mixture, more weight of the weaker or coarser proppant type leads to expectation of a higher compressibility factor.

For binary mixture 20/40 sand and 20/40 ceramic, more weigh of 20/40 sand shall expect higher compression under applied stress. Therefore, compressibility factor in case 50\% 20/40 sand weight in the mixture is higher than compressibility factor in case $25 \% 20 / 40$ sand weight in the mixture. For binary mixture $40 / 70$ sand and 20/40 ceramic, albeit proppant type 20/40 ceramic is stronger, Eric's experiments present its close similarity of compression under applied stress compared to $40 / 70$ sand. Therefore, compressibility factor in case 50\% 40/70 sand weight in the mixture is slightly lower than compressibility factor in case $25 \% 40 / 70$ sand weight in the mixture. For binary mixture 40/70 ceramic and 20/40 sand, more weigh of 20/40 sand shall expect higher compression under applied stress. Therefore, compressibility factor in case 50\% 40/70 ceramic weight in the mixture is lower than compressibility factor in case $25 \% 40 / 70$ ceramic weight in the mixture. All numerical values of term $\beta$ from table 4 successfully reflects analytical reasoning of all studied binary mixtures.

\subsubsection{Exponential coefficient in tortuosity model (n)}

$\mathrm{n}$ is the coefficient in the tortuosity exponential model (equation (4.3)). As reviewed in chapter 1 , nominal range of $\mathrm{n}$ values is $0.4-0.5$. However, complexity caused by packing because 
of experimental conditions does not guarantee the nominal range (Ricardo et.al, 2006; Mota et.al, 2001). In Eric's experiments, the proppant is blended uniformly prior to conducting the tests, therefore a highly dense packing is possible. The values of $n$ for binary mixture 40/70 ceramic and 20/40 sand reflects the above reasoning, otherwise other binary mixtures have nominal $n$ values.

Another aspect which requires discussion is partial impact of coefficient $n$. Because porosity exists in equation (4.3), integration of equation (4.2) into (4.3) revises (4.3) as:

$$
\tau=\left(\emptyset_{o} e^{-\beta\left(P-P_{o}\right)}\right)^{-n}=\emptyset_{o}^{-n} \cdot e^{\beta n\left(P-P_{o}\right)}=\tau_{o} e^{\beta n\left(P-P_{o}\right)}
$$

In equation (6.1), $\tau_{o}=\emptyset_{o}^{-n}$ is the initial tortuosity (at zero applied stress) since $\phi_{\mathrm{n}}$ is porosity at zero applied stress. The term $\beta n$ is the increase rate of tortuosity since this term is positive. Equation (6.1) claims that impact of coefficient $\mathrm{n}$ to tortuosity should be reasoned through at least one of the two factors, $\tau_{o}$ or $\beta n$. Based on Ghanbarian et.al (2013), two porous media having similar porosity may not have similar tortuosity, and two porous media having slightly different porosity may still have closely equal tortuosity. As a result, analytical reasoning for factor $\tau_{o}$ is not feasible, and $\beta n$ remains as the sole option to examine impact of $\mathrm{n}$.

For binary mixture 20/40 sand and 20/40 ceramic, 20/40 sand is easier to be crushed into significant smaller Mesh sizes compared to 20/40 ceramic because of material's intrinsic property (numerical results in Eric, 2014). Therefore, more concentration of 20/40 sand leads to higher possibility of a higher tortuosity increase rate. From table 4, tortuosity increase rate in two cases, $50 \%$ weight of $20 / 40$ sand and $25 \%$ weight of $20 / 40$ sand, equals $2.7 \cdot 10^{-5}$ and $1.233 \cdot 10^{-5}$. For binary mixture $40 / 70$ sand and 20/40 ceramic, $20 / 40$ ceramic is, in fact, easier to be crushed into smaller Mesh sizes compared to $40 / 70$ sand because of original size dominance instead of material's intrinsic property (numerical results in Eric, 2014). Therefore, more concentration of 20/40 ceramic leads to higher possibility of a higher tortuosity increase rate. From table 4, 
tortuosity increase rate in two cases, $50 \%$ weight of $20 / 40$ ceramic and $25 \%$ weight of $20 / 40$ ceramic, equals $2.534 \cdot 10^{-5}$ and $2.847 \cdot 10^{-5}$. For binary mixture $40 / 70$ ceramic and $20 / 40$ sand, 20/40 sand is, in clearly easier to be crushed into smaller Mesh sizes compared to 40/70 ceramic because of both original size and material's intrinsic property (numerical results in Eric, 2014). Therefore, more concentration of 40/70 ceramic leads to higher possibility of a lower tortuosity increase rate. From table 4, tortuosity increase rate in two cases, 50\% weight of 40/70 ceramic and $25 \%$ weight of $40 / 70$ ceramic, equals $1.556 \cdot 10^{-5}$ and $1.914 \cdot 10^{-5}$. All numerical values of term $\beta n$ from table 4 successfully reflects analytical reasoning of all studied binary mixtures.

\subsection{Semi-ananlytical modeling validation}

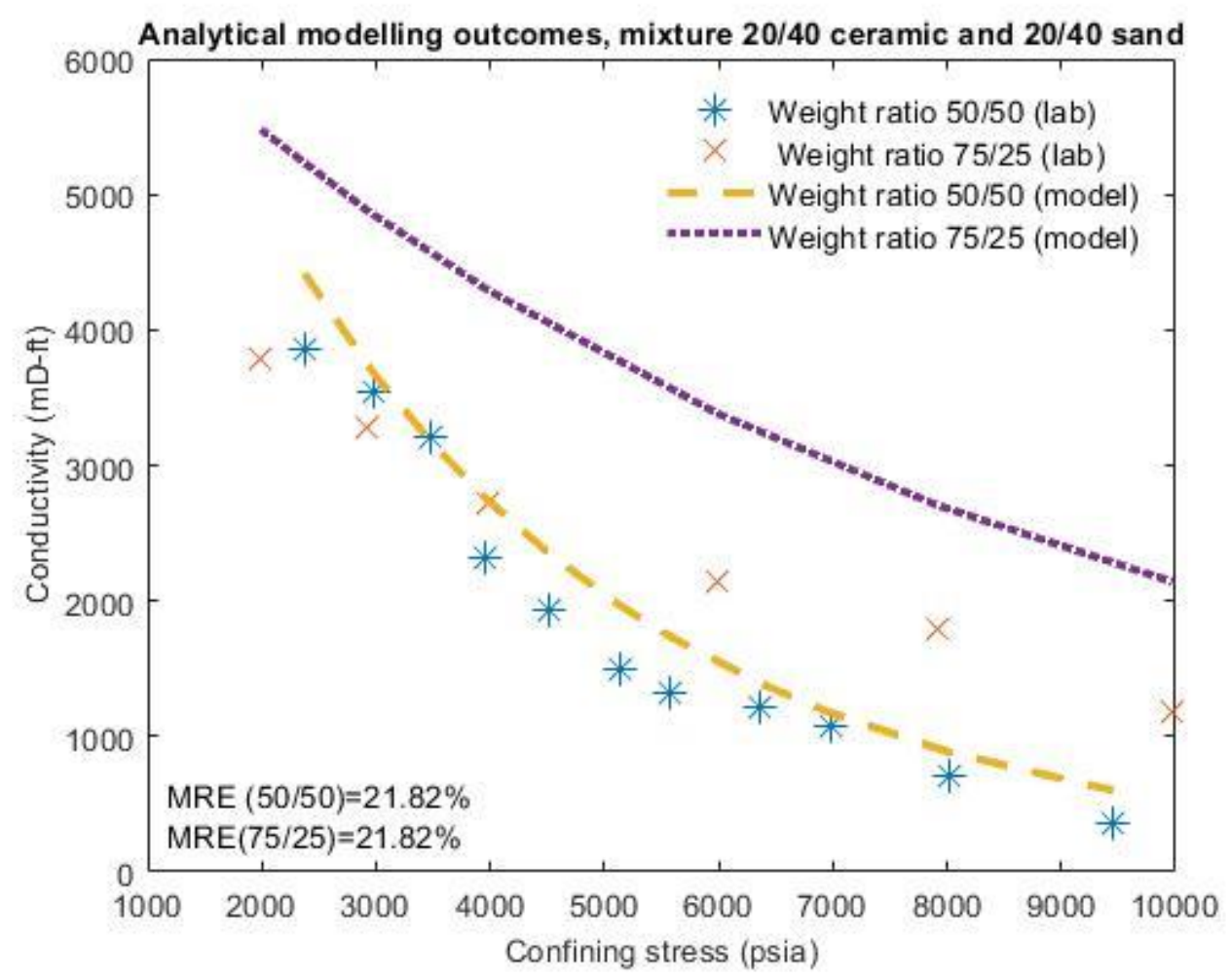

Figure 22 - Validation results for bianry mixture $20 / 40$ sand and 20/40 ceramic 


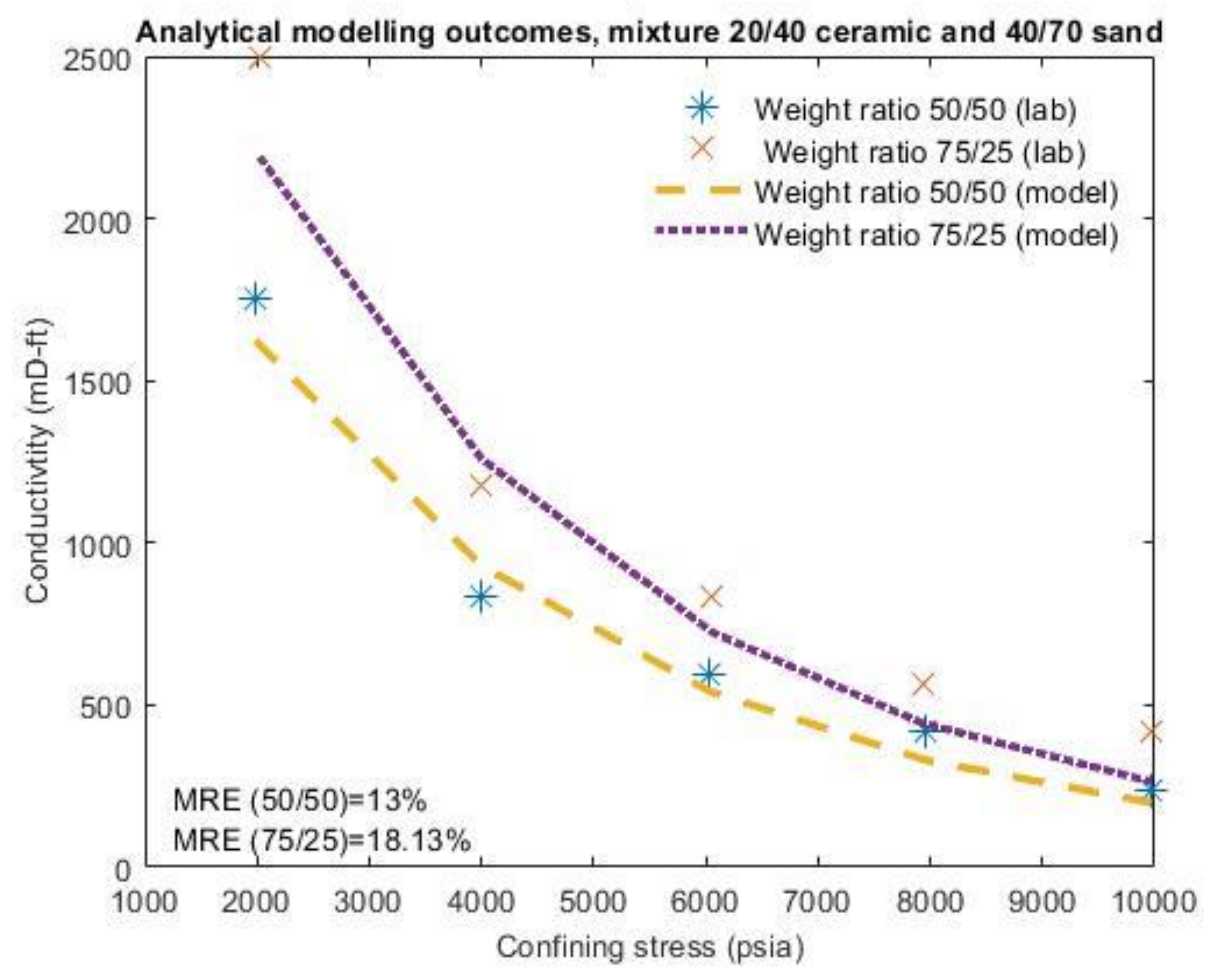

Figure 23 - Validation results forbinary mixture 40/70 sand and 20/40 ceramic

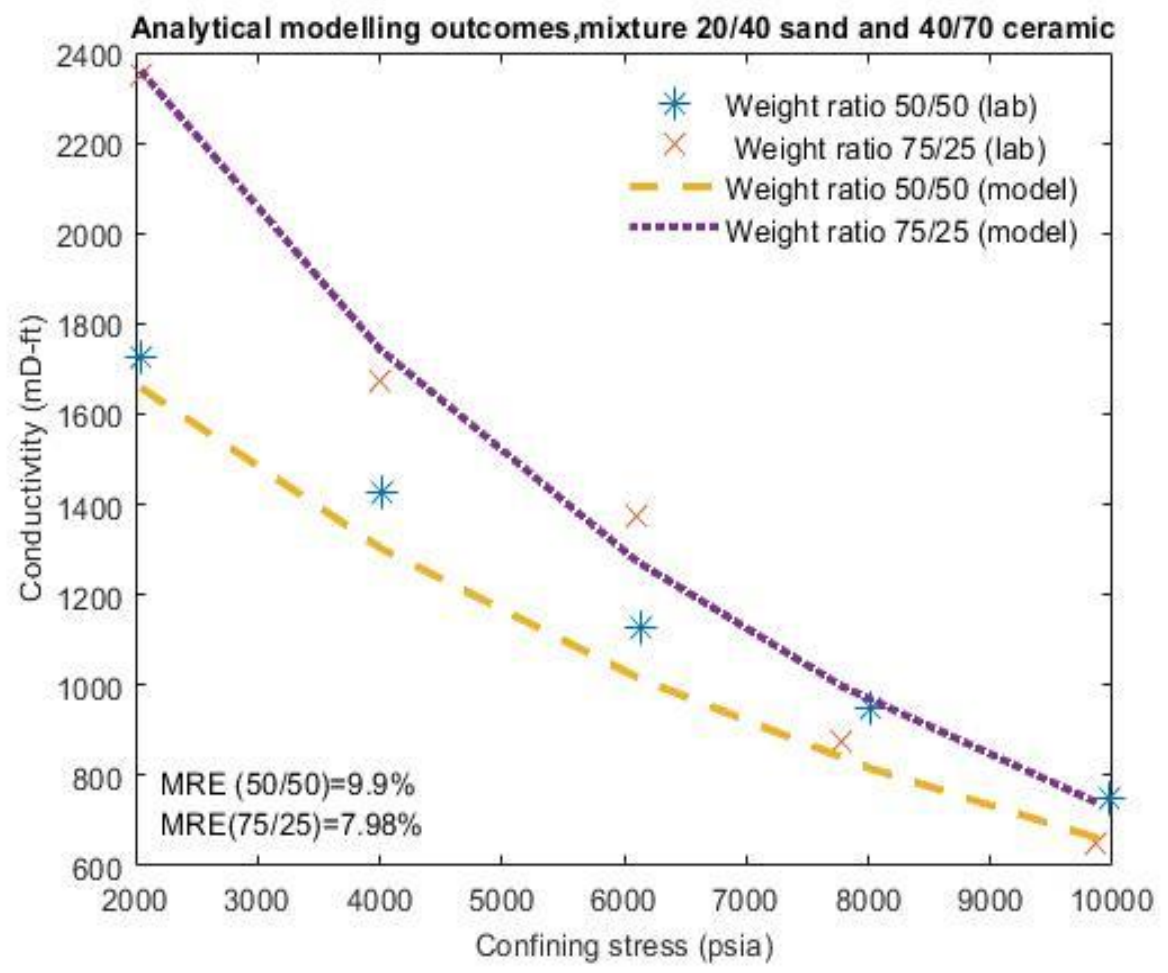

Figure 24 - Validation results for bianry mixture 40/70 ceramic and 20/40 sand 
As stated in chapter 4 , conductivity lab data is used to perform modelling validation. Figures 20-22 present graphical outcomes of the modelling validation for all 6 selected lab data sets. The Mean Square Errors (MREs) between the prediction from the semi-analytical model and the lab data for mixture $40 / 70$ sand and $20 / 40$ ceramic (figure 23 ) range from $0.82-16 \%$, which is considered as acceptable constraints. Two outliers with higher relative difference error are at the areal concentration $0.5 / 4000 \mathrm{psi}$ and at the areal concentration $0.75 / 10000$ psi. For mixture $20 / 40$ sand - 40/70 ceramic (figure 24), MREs are lower than mixture 20/40 ceramic - 40/70 sand as they range from $0.17-10.7 \%$ with two outliners at $0.5 / 8000$ psi and $0.75 / 10000$ psi. For mixture $20 / 40$ ceramic - 20/40 sand (figure 22), it is clear to observe that the MREs are significantly higher than the normality from the two remaining mixtures. Higher MREs for mixture 20/40 ceramic - 20/40 sand are referred to the lab data for the proppant pack's width, which behaves significantly out of the expected normality from proppant physics (deformation and embedment). This profound impact from lab data is contributed by the large deviations of the reference with, $w_{\text {ref }}$, at each measured confining stress points (as explained in the equipment description in this paper), and mixture 20/40 ceramic - 20/40 sand was observed to have highest deviations within all 3 selected mixtures. Ceramic with large diameter size as 20/40 Mesh has permeability of hundreds Darcy at low confining pressure (nearly 350 Darcy at 2000 psi from measured data), which turns a slight deviation of 0.02 inches in width (based on author's claim in Eric Schultz, 2014) to a $583 \mathrm{mD}$-ft deviation in measured conductivity.

Another factor which prevents the best validation outcomes is the incorporation between all possible proppant physics into the fracture width model, which include proppant deformation, proppant embedment, and proppant crush effect at a certain confining stress. In the derived semianalytical model, only proppant deformation was taken into consideration under the assumption 
of elastic behaviour of material. Proppant embedment, even neglected at the contact between proppant particles and the steel plates, is still considerable between the proppant layers (as shown in the schematic of the layering system), and Hertzian contact theory is further needed for the case of two spherical surfaces at all contact surfaces between the layers. Proppant crush effect, at a certain confining pressure, may completely change the decrease trend of the proppant pack's width behaviour and become harder to be modelled as areal concentration ratio-dependent implementation. In figure 7, an observation from the conductivity lab data for mixture 20/40 sand and 40/70 ceramic indicates proppant crush effect at a certain confining stress larger than $6000 \mathrm{psi}$. For this mixture, at the areal concentration 0.75 (more weight of 20/40 sand), conductivity drops drastically from approximately $1500 \mathrm{mD}$ - $\mathrm{ft}$ to a close of $1000 \mathrm{mD}$ - $\mathrm{ft}$ when confining stress changes from 6000 psi to 8000 psi. Since large diameter sand as 20/40 Mesh exhibits clear crush effect, it explains the conductivity drop as aforementioned. Consequently, current implementation of proppant embedment and the crush effect will significantly increase the complexity of the width model, and the semi-analytical model for the proppant pack's width was acquired without their full contributions.

\subsection{Comparison between LWAM and the semi-analytical modeling}

In chapter 4, the development of the novel semi-analytical modelling is based on dependency on confining pressure, $P_{c}$ (or minimum hornizontal stress) and the weight mixing ratio, $R$ (or Areal Concentration Ratio). To further interpret the efficacy of the novel semi-analytical model and predictable impact of confining stress or Weight Concentration Ratio variability (as they are two core variables for both LWAM and the novel semi-analytical model), a comprehensive comparsion between the two models is conducted for each studied binar mixtures. In order to conduct the comparison as mentioned, the following procedure is facilitated: 
1. Two discrete ranges for $P_{c}$ and $R$ are initated. The ranges for $P_{c}$ and $R$ are 2000-1000 psi (100 psi increment, 81 discrete values) and 0.01-0.99 (0.01 increment, 99 discrete values), respectively.

2. For each pair of values for $P_{c}$ and $R$ from the two discrete ranges (171 pairs in total), conductivtiy estimation for both models is computed. This computation process creates two conducitvity matrixces for the two models, both of which have dimensions of $99 \times 81$.

3. Relative difference of the novel semi-analytical model compared to LWAM is computed as follows: Relative Difference $=\frac{C_{L W A M}-C_{\text {semi-analytical model }}}{C_{L W A M}} \times 100$. As being expected, the quantity Relative Difference is also a matrix with dimensions of $99 \times 81$. Matrices representing Relative Difference are defined as comparison matrices

4. Two-dimensional plot of Relative Difference is perfomed. The two X and $\mathrm{Y}$ axes present discrete ranges for quantities $P_{c}$ and $R$, and the quantity Relative Difference is presented by a color scale.

6.4.1. Overview of the comparison results

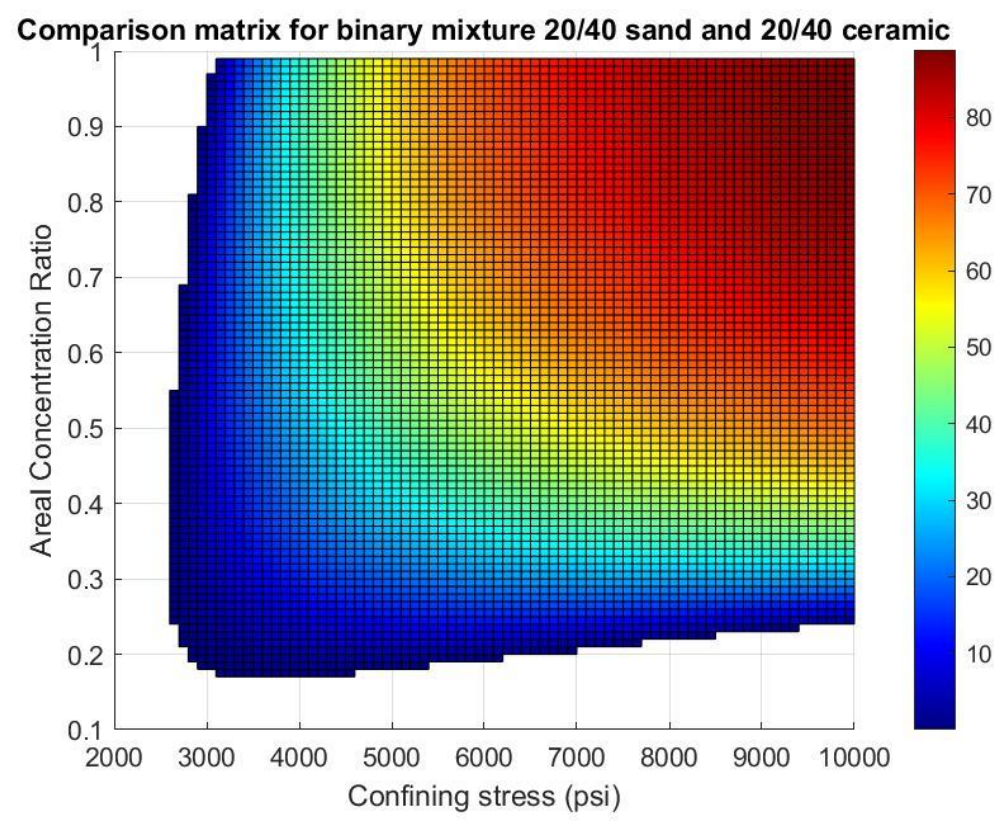


Figure 25 - Comparison matrix for binary mixture 20/40 sand and 20/40 ceramic

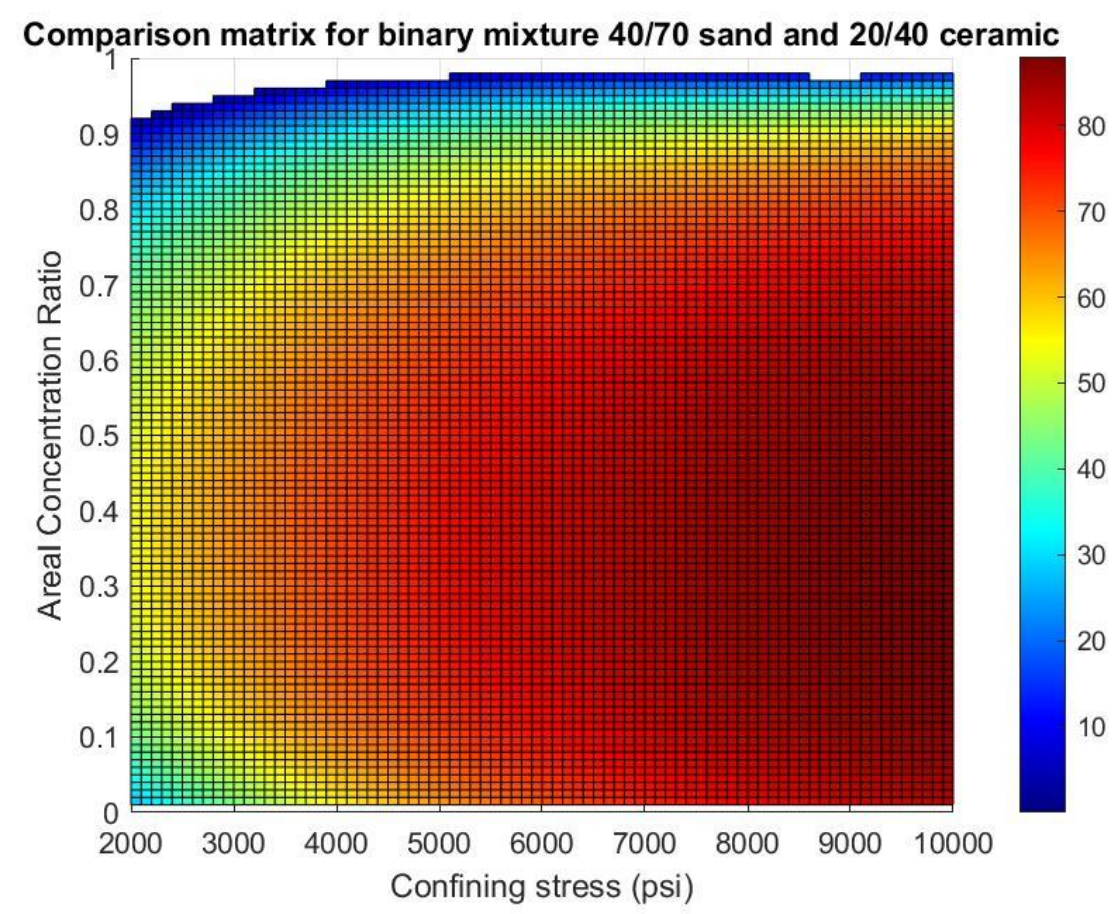

Figure 26 - Comparison matrix for binary mixture $40 / 70$ sand and 20/40 ceramic

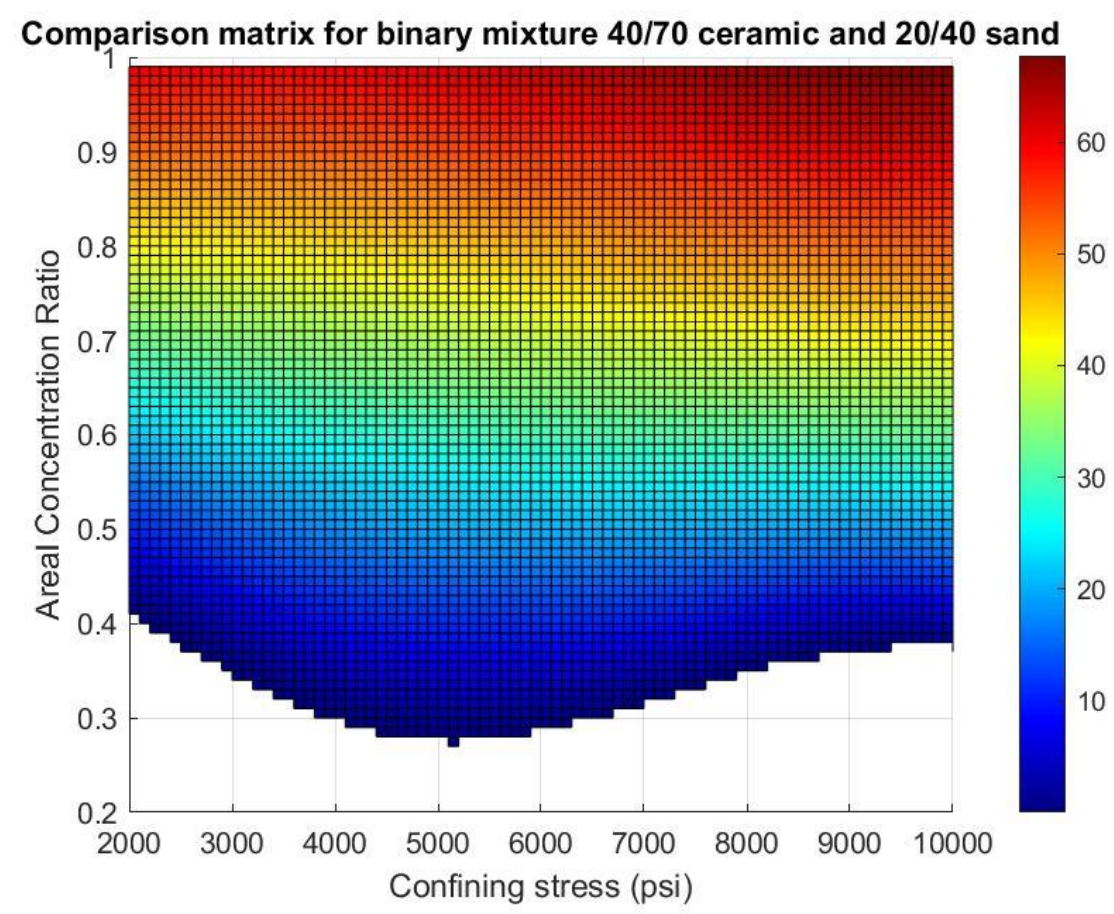

Figure 27 - Comparison matrix for binary mixture $40 / 70$ ceramic and 20/40 sand 
Figures 25-27 provide two-dimensional plots of the comparison outcomes for all 3 binary mixtures. An initial observation for these plots clarifies conductivity overestimation by LWAM compared to the novel semi-analytical model for a majority of pairs of $P_{c}$ and $R$ values. Furthermre, two essential analysis, which include qualitative understanding of LWAM's overestimation for different conditions of $P_{c}$ and $R$ and prospective improvements for the novel semi-analytical model, can be conducted. Within all studied binary mixtures, increase in $P_{c}$ and/or $R$ intensifies LWAM's overestimation at difference rates, depending on the intrinsic properties of the binary mixture . According to the added color scale for Relative Difference in figures 25-27, LWAM's overestimation can be classified in three distinguisable zones: low overestimation $(20 \%$ and below), moderate overestimation (20-60\%) and high overestimation (60\% and above).

For binary mixture 20/40 ceramic and 20/40 sand, figure 25 indicates a central region of high overestimation in which high racoordinates of $P_{c}$ and $R$ are observed at 8000-1000 psi and 0.7-0.99, respectively. The centre of this area has $P_{c}$ and $R$ coordinates of $0.99-10000$ psi. Movement away from the central region in both decreasing directions of $P_{c}$ and $R$ (i.e. change diagonally from $P_{c}$ and $R$ coordinates of (0.99-10000 psi) to (0.01-2000 psi)) decreases Relative Difference diagonally from high overestimation zone to low overestimation zone. In addition, these zones are separated parabolally.

For binary 20/40 ceramic and 40/70 sand, a similar central region of high Relative Difference zone exists in figure 26, albeit the center of this area has $P_{c}$ and $R$ coordinates of approximately $0.35-10000$ psi. Movement away from the central area in the deacreasing direction of confining pressure i.e. change horizontally from $P_{c}$ and $R$ coordinates of 0.35-10000 psi in the decreasing direction of $P_{c}$ axis) decreases Relative Difference 
horizontally from high overestimation zone to low overestimation zone along the $R$ axis. Similarly to the binary mixture $20 / 40$ sand and 20/40 ceramic, these zones are aseparated parabolally.

For binary mixture 20/40 sand and 40/70 ceramic, there is no central region in figure 27 . In replacement of a central area, the high, moderate and low overestimation zones expand along the $P_{c}$ axis. Additionally, these zones in figure 25 are separated almost linearly along the decresing direction of $R$ axis (i.e. approximately 0.55 between the low and moderate zones, and 0.7 between the moderate and high overestimation zones).

\subsubsection{Impact of confining pressure and Weight Concentration Ratio variability}

Besides the overview of the comparison outcomes, figures 25-27 are capable of suppporting predictions regarding the overestimation degree of LWAM, under conditions of confining pressure and Weight Concentration Ratio variation. In addition, partial derivative matrices (in term of confining pressure, $\partial R D / \partial P_{c}$ and areal concentration ratio, $\partial R D / \partial R$ ) presented in figures 28 33 can further disclose rate of overestimation under those specific conditions.

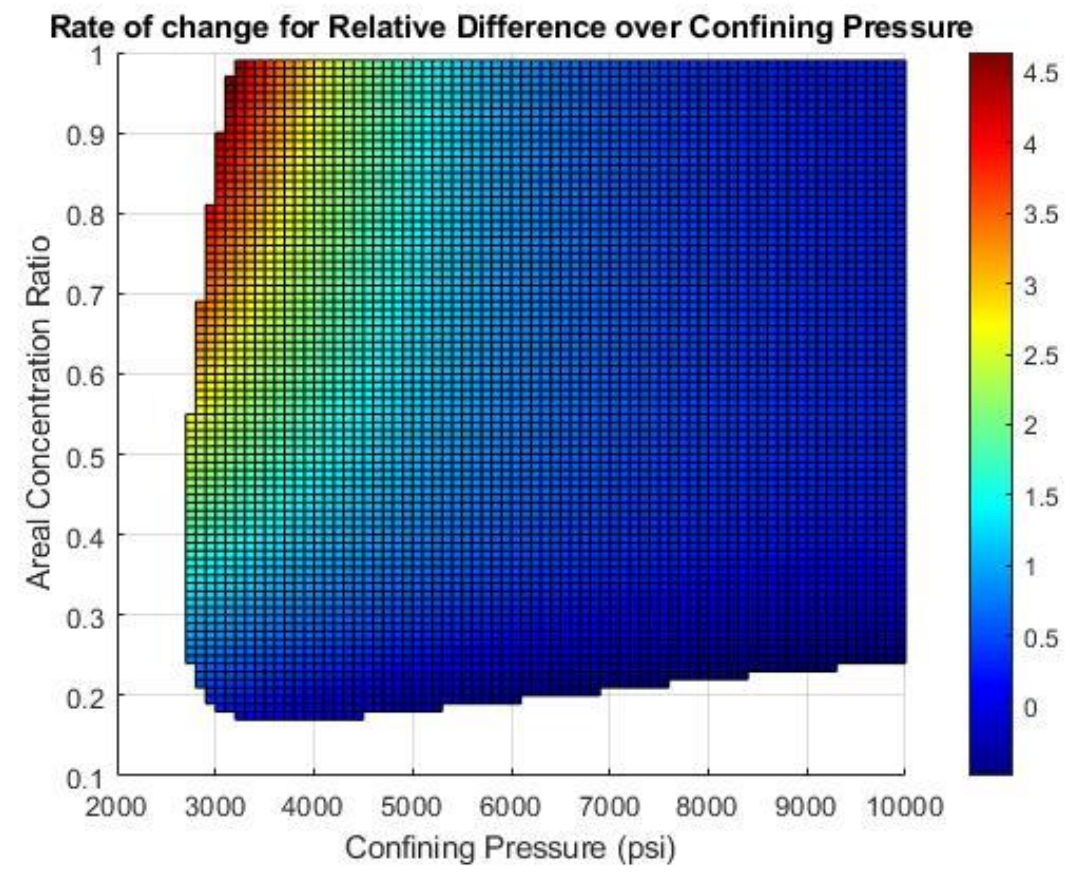

Figure 28 - Matrix of $\partial R D / \partial P_{c}$ for binary mixture $20 / 40$ sand and 20/40 ceramic 


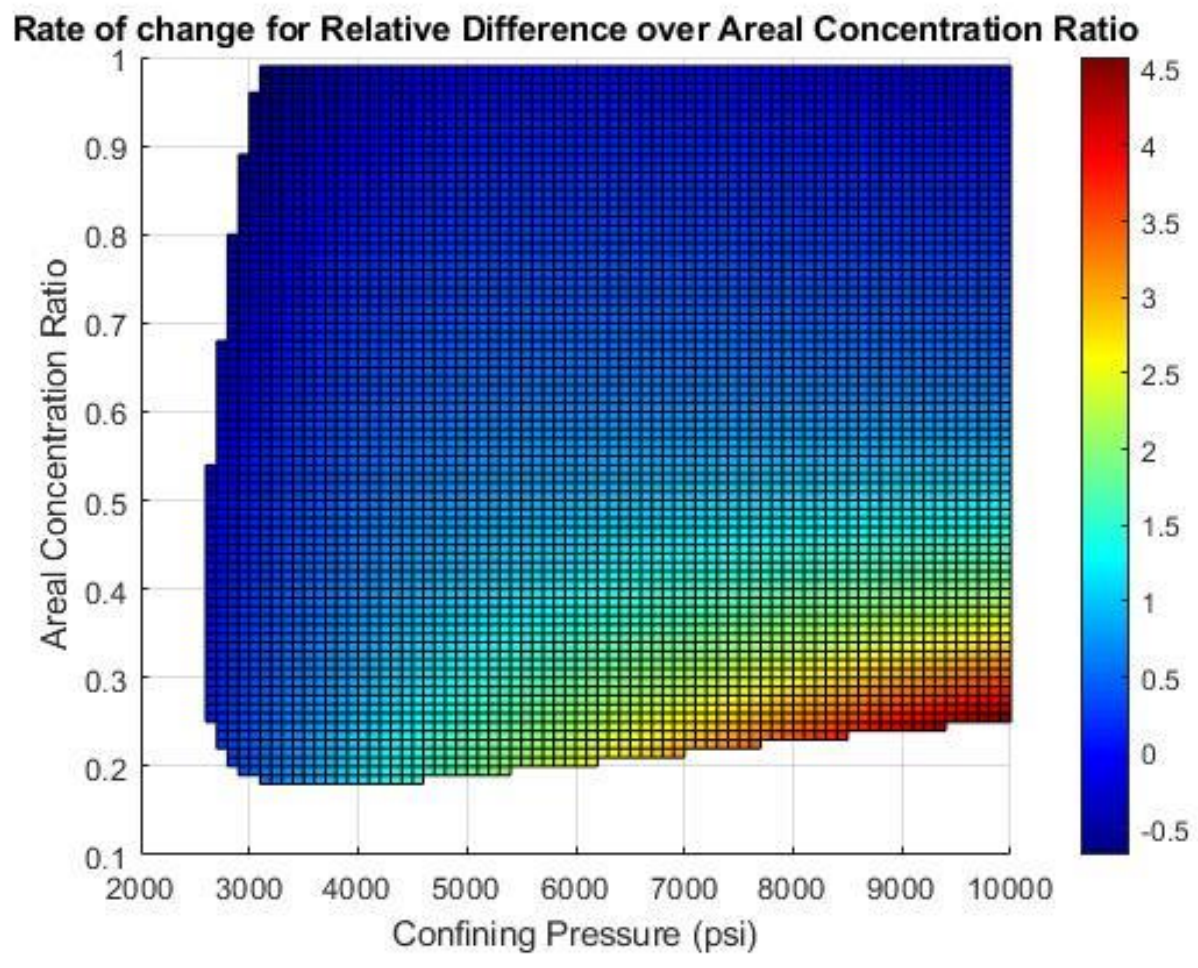

Figure 29 - Matrix of $\partial R D / \partial R$ for binary mixture 20/40 sand and 20/40 ceramic

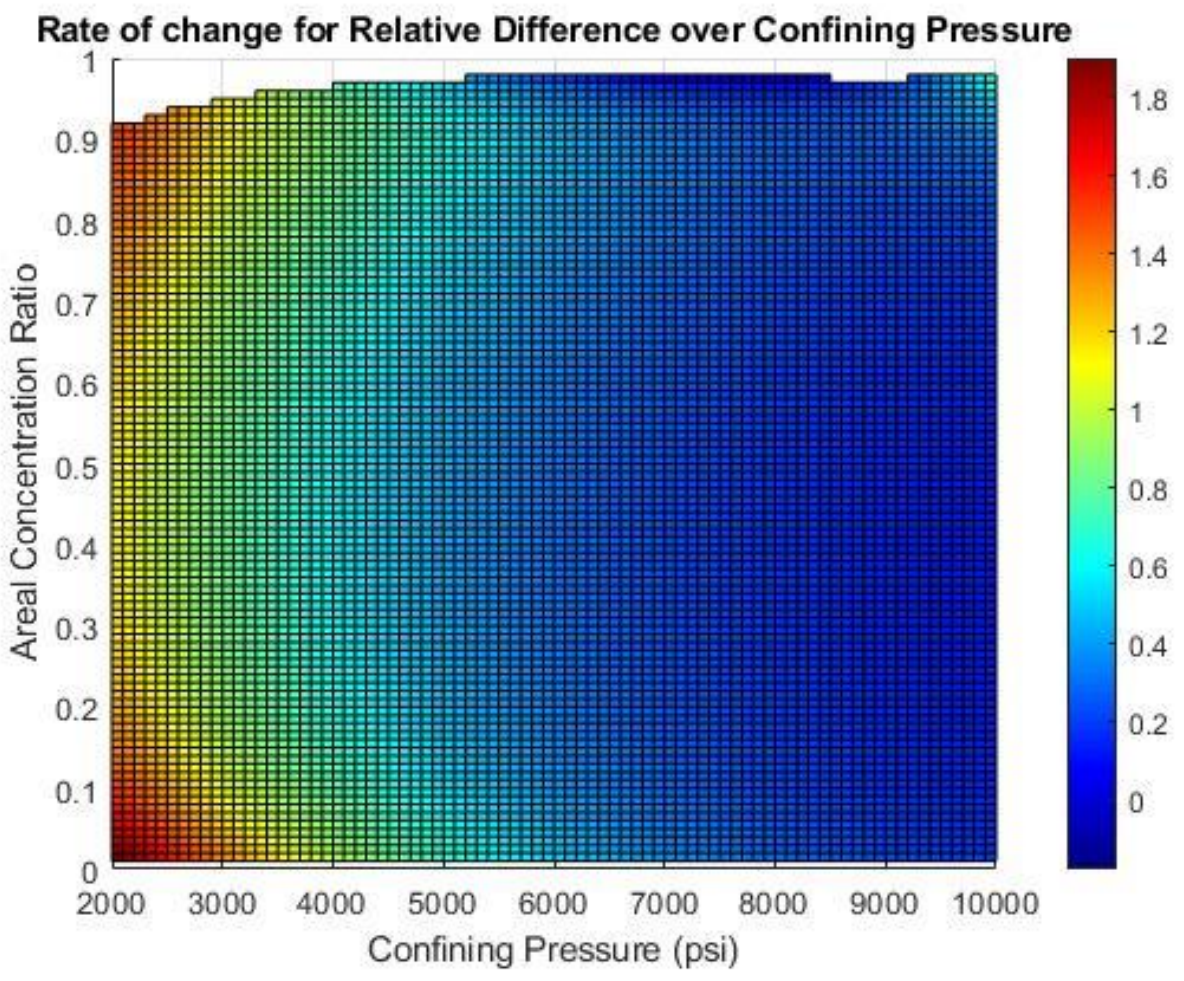

Figure 30 - Matrix of $\partial R D / \partial P_{c}$ for binary mixture $40 / 70$ sand and $20 / 40$ ceramic 


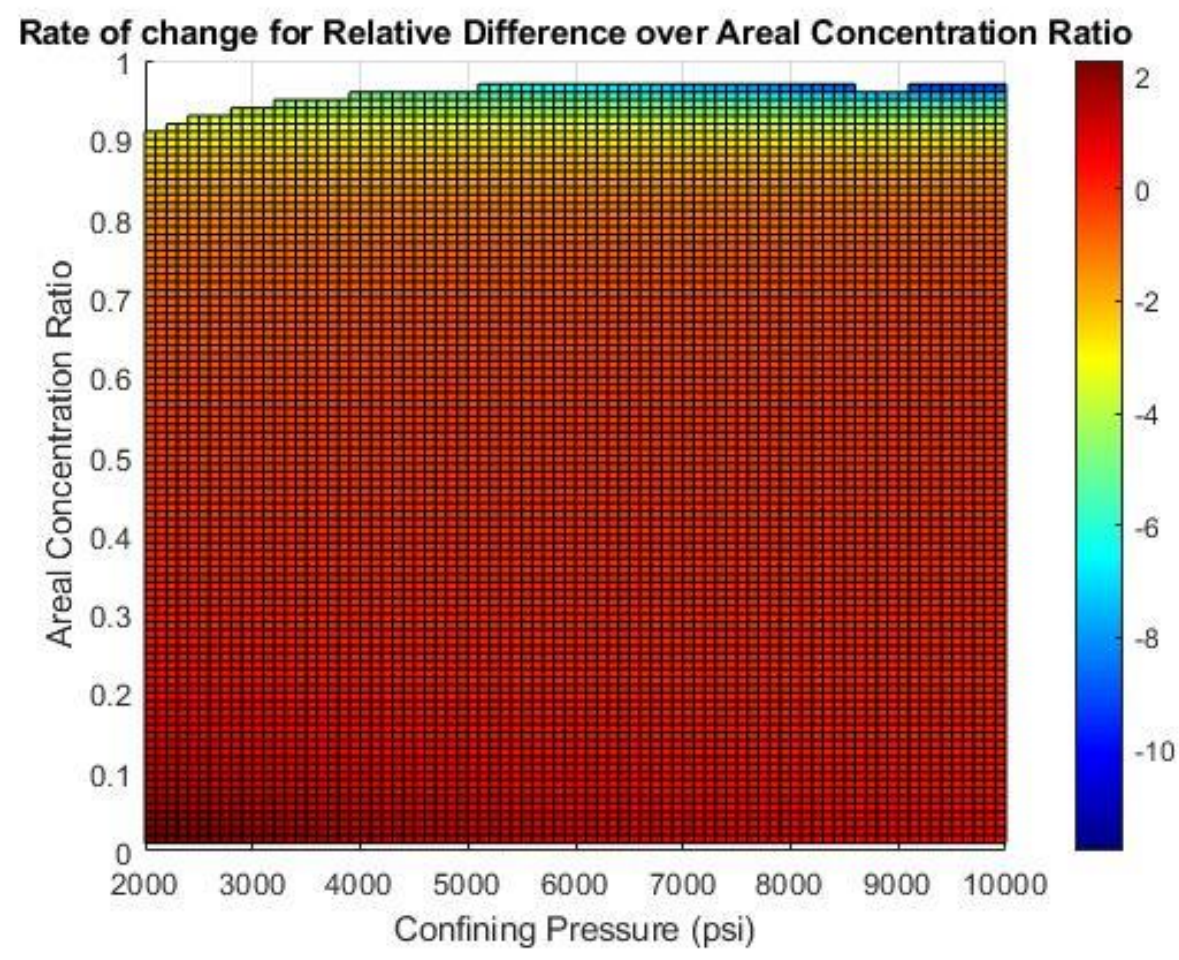

Figure 31 - Matrix of $\partial R D / \partial R$ for binary mixture $40 / 70$ sand and 20/40 ceramic

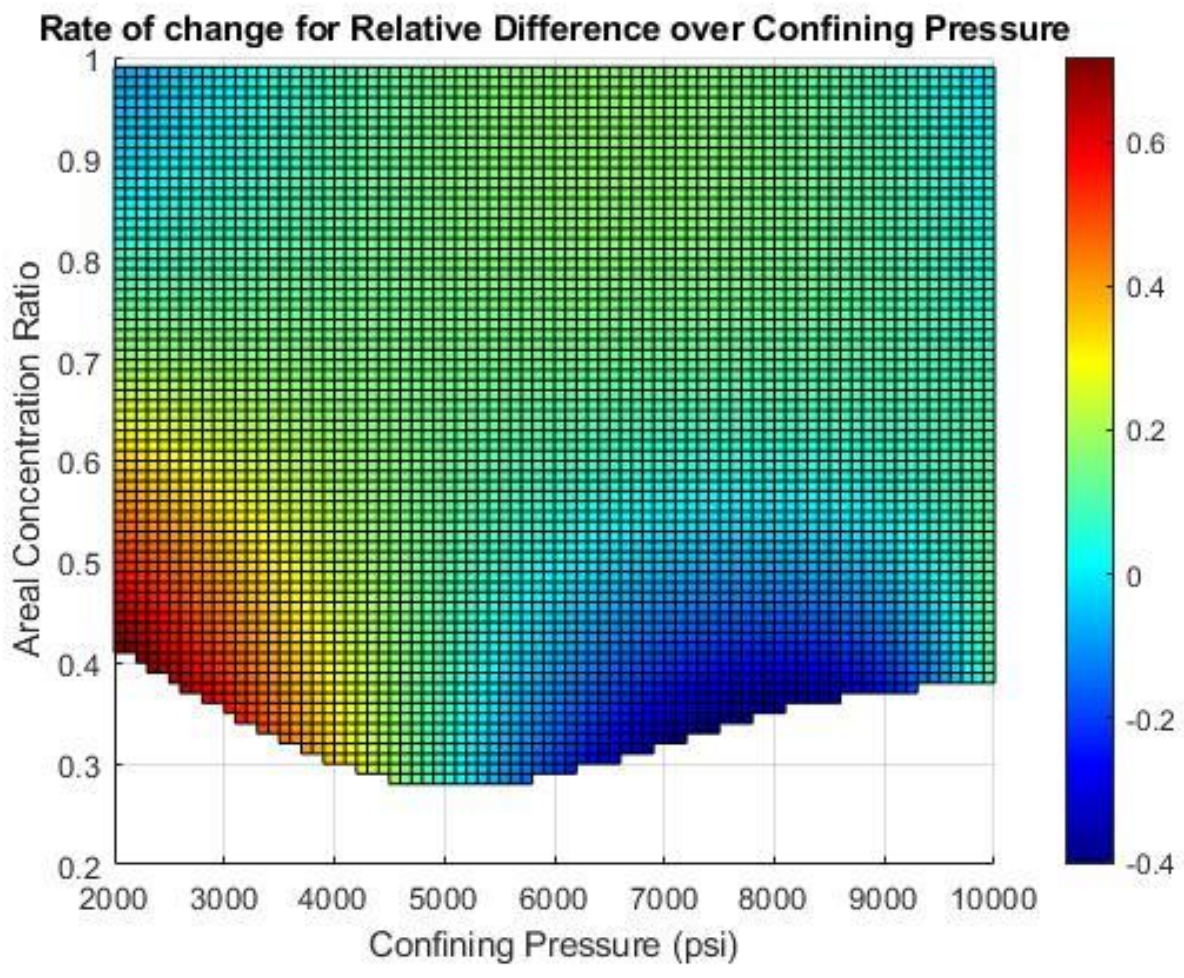

Figure 32- Matrix of $\partial R D / \partial P_{c}$ for binary mixture $40 / 70$ ceramic and $20 / 40$ sand 


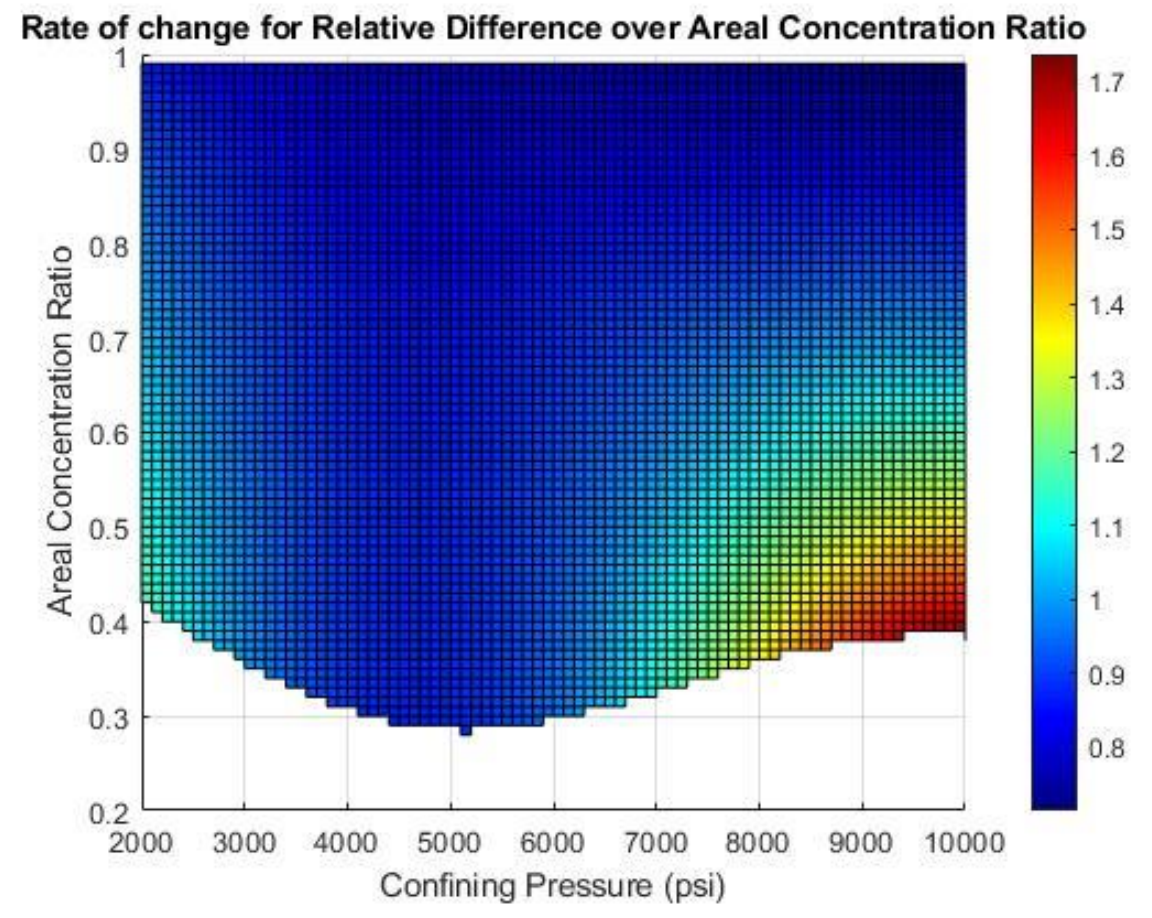

Figure 33 - Matrix of $\partial R D / \partial R$ for binary mixture $40 / 70$ ceramic and $20 / 40$ sand

For mixture 20/40 sand and 20/40 ceramic, the overestimation degree of LWAM monotnically increases when $\mathrm{R}$ increases from 0 to 1 . Figure 29 further indicates a faster rate of increase when $\mathrm{R}$ is between 0.2 and 0.5 and a slower rate of increase to a slight decrease rate when R exceeds 0.6. Lower value of confining pressure (5000 psi and below) indicates a single transition from low overestimation zone to moderate overestimation zone, and the rate of this transition is possibly high. Higher value of confining pressure (6000 and above) indicates two possible transitions from low overestimation zone to moderate overestimation zone, and eventually to high overestimation zone. However, these transitions occur at lower rate when compared to the case of transitioning in a lower value of confing pressure.

For mixture 40/70 sand and 20/40 ceramic, high overestimation zone exists for most of the $R$ and $P_{c}$ values. Rate of change in overestimation is almost nuance (i.e. around 0 ) when $R$ increases, with exception at extremely high values of $\mathrm{R}(0.9-1)$, of which condition presents a sudden 
decrease in the rate of overestimation. At lower value of confining stress (4500 psi and lower), figures 30 and 31 indicate an abrupt change from low/moderate overestimation zone to high overestimation zone when $\mathrm{R}$ enters the zone $0.2-0.6$ from the zone $0.01-0.2$ and another abrupt reverse change from hiogh overestimation zone to moderate/low overestimation zone by LWAM when $\mathrm{R}$ exits the zone 0.2-0.6. At higher value of confining stress (4500 psi and higher), high overestimation zone is dominantly present and rate of change in overestimation is nuance.

For mixture 40/70 ceramic and 20/40 sand, the low, moderate and high overestimation zones are uniformly distributed, approximately. Overestimation degree of LWAM monotnically increases when $\mathrm{R}$ increases from 0 to 1 . However, figure 33 presents that rate of overestimation is almost not considerable when $R$ increases (with exception at a portion of $R$ values below 0.65 and $P_{c}$ values above $7000 \mathrm{psi}$ ). This observation can be equally stated as almost no abrupt change between low/moderate/high estimation zones. Similarly, figure 32 presents that rate of overestimation is almost not considerable when $P_{c}$ is within the lower range or higher range.

\subsubsection{Summary}

In binary mixture 20/40 sand and 20/40 ceramic, two proppant types have similar Mesh sizes and contrast in meterial strength. Comparison matrix indicates clear dependency of Relative Difference on both confining pressure and areal concentration ratio. Relative Difference increases with faster rate when confining stress and Weight Concentration Ratio are low and increases with slowver rate when confining stress and Weight Concentration Ratio are higher.

In binary mixture 40/70 sand and 20/40 ceramic, two proppant types have contrast in Mesh sizes and material strength in conventional order (i.e. finer/weaker proppant type is injected first and coarser/stronger proppant type is injected second). Comparison matrix indicates clearer depedency of Relative Difference on confining stress than areal concentration ratio. High 
overestimation zone is dominant, and increase in confining pressure rapidly increase the Relative Difference to the high overstimation zone.

In binary mixture 40/70 ceramic and 20/40 sand, two proppant types have contrast in Mesh sizes and material strength in reverse order (i.e. finer/stronger proppant type is inejcted first and coarser/weaker proppant type is inejcted second). Comparison matrix indicates stronger dependency of Relative Difference on Weight Concentration Ratio than confining stress. All overestimation zones (low, moderate and high) are uniformaly distributed, and increase in Weight Concentration Ratio monotonically increase Relative Difference.

\subsubsection{Drawbacks of the novel semi-anbalytical model}

Albeit figures 25-27 prove a sufficient efficacy of the semi-analytical model compared to LWAM in conductivity prediction, the white color regions in figures $25-27$ infers that there are conditions (ranges of $P_{c}$ and $R$ ) in which Relative Difference falls below 0. For more details, within the area created by the $99 \times 81$ discrete values of $P_{c}$ and $R$, binary mixture $20 / 40$ sand and 20/40 ceramic returns $26.49 \%$ of Relative Difference below 0, binary mixture 20/40 ceramic and 40/70 sand returns $2.01 \%$ of Relative Difference below 0 , and binary mixture 20/40 sand and 40/70 ceramic returns $32.13 \%$ of Relative Difference below 0 . This phenomenon indicates that the novel semi-analytical model does not predict as the aimed expectation (i.e. its conductivtiy prediction should be below LWAM's prediction ) for specific ranges of $P_{c}$ and $R$, depending on the bianry mixture.

For binary mixture binary mixture 20/40 ceramic and 20/40 sand, the semi-analytical model presents moderate degree of pitfall. The sub-zero region of Relative Difference reveal the pitfall of the semi-analytical model occurs at low values of $P_{c}$ (between 2000-2500 psi, regardless of $\mathrm{R}$ values) and the low values of $\mathrm{R}$ (between $0.01-0.16$, regardless of $P_{c}$ values). For binary 
mixture 20/40 ceramic and 40/70 sand, the semi-analytical model presents lowest degree of pitfall in term of both the area and the value of Relative Difference. The sub-zero region of Relative Difference only occurs at extreme values of R (>0.9-1) and low values of $P_{c}(<4000$ psi). For binary mixture 20/40 sand and 40/70 ceramic, the semi-abnalytical model prsents highest degree of pitfall. The sub-zero region of Relative Difference only occurs at low-end values of $\mathrm{R}$ (0.01-0.3, regardless of $P_{c}$ values).

There are a number of explanations for these sub-zero regions. Interpolation for coefficients as function of Weight Concentration Ratio during composing the comparison matrices is a drawback, However, this interpolation is unavoidable because of shortage in lab data points, limited understanding of the coefficients as a dependency on areal concentraion ratio is a consequence. For example, in binary mixture 40/70 sand and 20/40 ceramic, sub-zero region has extremely high areal concentration ratio. At this condition, the binary mixture is close to pure 40/70 sand LWAM is a better estimator. Another drawback is necessity of complicated physics which may have a critical role in the sub-zero regions. For example, in binary mixtures 20/40 sand and 20/40 ceramic, crush effect of 20/40 sand can drastically reduce conductivity of the mixture. At low confining stress, 20/40 ceramic is capable of mitigating crush effect of 20/40 sand. However, as confining stress increases, this mitigation can not maintain, and the sub-zero region becomes larger. Similar explanation regarding crush effect of 20/40 sand can be state in binary 40/70 ceramic and 20/40 sand, especially when confining stress exceeds 5000 psi.

\subsection{Case study for Marcellus Shale}

\subsubsection{Reviews of confining stress data in Marcellus Shale}

Typical trait of minium horizontal stress variation inside a reservoir is a considerable factor when analyzing conductivity estimation from different models. In consequence, reviews of 
minimum horizontal stress variation in Marcellus Shale are provided in this section prior to further conductivity estimation analysis and cumulative production analysis. Raw data for minimum horizontal stress in Marcellus Shale, which is used in this section and also in the inhouse fracture propagation simulator, is modelled and detailed in Emre D. et.al (2019). This raw data provides discrete values of minimum horizontal stress coressponding to incremenatal values of depth data between $7450-7548 \mathrm{ft}(0.5 \mathrm{ft}$ increment $)$. A portion of the raw data is provided in table 6 .

Table 6 - Sample data of confining stress veresus depth, $0.5 \mathrm{ft}$ increment (Marcellus Shale)

\begin{tabular}{|c|c|}
\hline TVD (ft) & Confining stress (psi) \\
\hline 7450 & 5519.07 \\
\hline 7450.5 & 5470.42 \\
\hline 7451 & 5448.04 \\
\hline 7451.5 & 5437.37 \\
\hline 7452 & 5462.19 \\
\hline
\end{tabular}

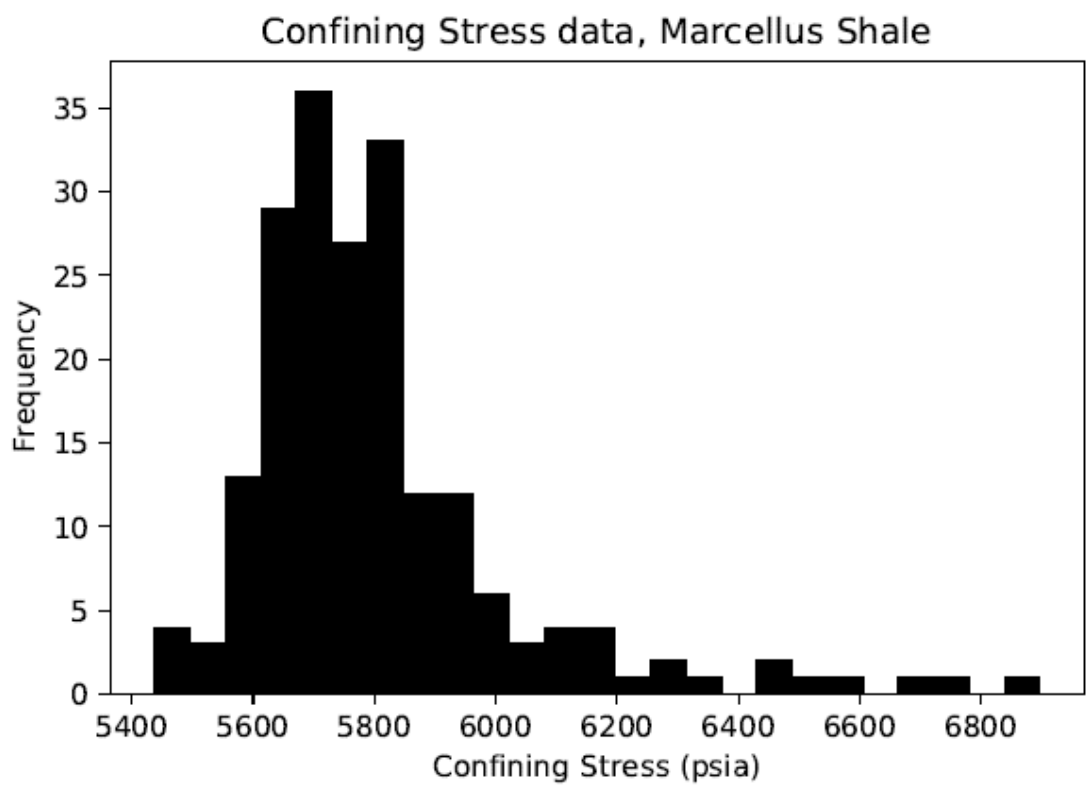

Figure 34 - Histogram of confining stress data in Marcellus Shale 
In order to interpret variation of minimum horizontal stress in the data and comply with further analysis in this section, histogram is selected to present the raw data, as in figure 34 .

Using basic statistical analysis, the data have arthimetic mean and standard deviation of 5805.52 psi and 233.75 psi, respectively. The histogram in figure 34 implies that outliers start at 6200 psi and above. Most of the data points are ranged between approximately 5400 psi and 6200 psi, which equals 2 standard deviations from the data's mean. Another analysis for the data is to interpret changes of the data points between two consecutive 0.5 - $\mathrm{ft}$ increment mesurements (figure 35). It is clear to observe a normal distribution with arthimetic mean and standard deviation of 0 and 200 psi, respectively.

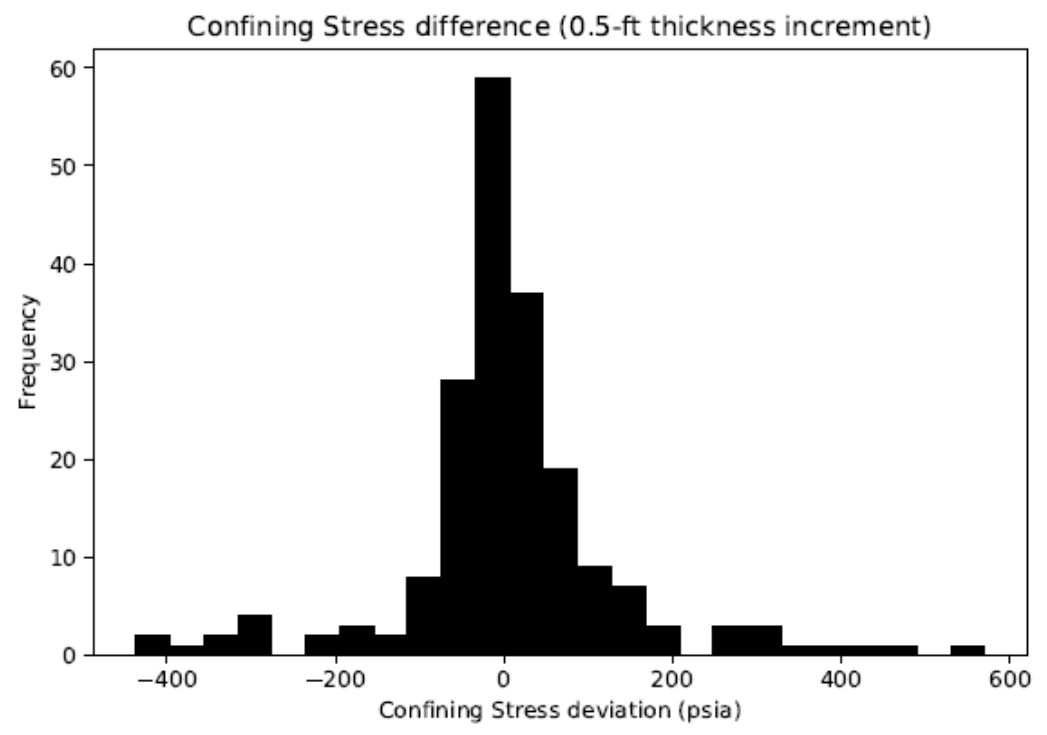

Figure 35 - Histogram of stress difference (within $0.5 \mathrm{ft}$ height), Marcellus Shale

As a result, it is stated that Marcellus Shale's confining stress is ranged between 5400-6200 psi, and difference in its values between two different depth data (within the formation's height) is at most 200 psi. The above reviews for minimum horziontal stress data in Marcellus Shale coupled with the observations in the comparison section allow predictively reasoning for the sconductivity estimation difference between LWAM and the novel model in this case study. 


\subsubsection{Post-processing for cumulative production data from $\mathrm{CMG}$}

As described in chapter 5, 10-year cumulative production data is extracted (Excel format) from CMG for both LWAM and the novel semi-analytical model. However, the simulation algorithms in CMG do not extract similar date records between the models. Consequently, linear interpolation is coded to acquire similar date records between the models. This technique's pseudo code for each conductivity model is as follows:

- The raw date recording and 10-year cumulative production from CMG for a model are denoted as Day_raw and Prod_raw

- Initiate a day range, denoted as Day, starting from 1 and ending at 3654 (10 years equaivalent) with 1-day increment. The processed 10-year cumulative production is denoted as Prod.

- For all $d$ in Day, extract d1_raw and d2_raw from Day_raw. d1_raw is the maximum value in Day_raw satisfying $d 1_{\_}$raw $\leq d$, and $d 2_{-}$raw is the minimum value in Day_raw satisfying $d 2 \_r a w \geq d$. Extract $p 1 \_r a w$ and $p 2 \_r a w$ (corespond to $d 1 \_r a w$ and $\left.d 2 \_r a w\right)$ simultanelusly with $d 1 \_r a w$ and $d 2 \_r a w$. Quantity $p$, which is in Prod and coressponds with $d$, is computed as: $p=d \cdot \frac{p 2_{\text {raw }}-p 1_{\text {raw }}}{d 2_{\text {raw }}-d 1_{\text {raw }}}+\left(p 2_{\text {raw }}-\right.$ $\left.d 2_{\text {raw }} \frac{p 2_{\text {raw }}-p 1_{\text {raw }}}{d 2_{\text {raw }}-d 1_{\text {raw }}}\right)$

Further analysis is possible after the described linear interpolation technique. Cumulative production's magnitude for both models in this case study is within $10^{8}-10^{9}$ scale. Therefore, plotting the interpolated cumulative production data to visualize the efficacy of the novel model is not practical. To mitigate issue from the scaling, difference in production data between two models is dicided as a better option to be plotted in this section. For a dry gas reservoir as Marcellus Shale, the critical period of production is typically within the first year of production, in which production 
data depends primarily on properties of fractured area. Consequently, additional analysis of difference in prodcution data between two models is concentrated on fluctation within the first year of production.

6.5.3. Binary mixture $20 / 40$ sand and $20 / 40$ ceramic

Conductivity estimation analysis

Figures 36 and 37 present the Weight Concentration Ratio distribution (along half fracture dimensions) and its histrogram, respectively.

Figures 38-42 present the following quantities (along half-fracture dimentions): Conductivtity estimation by LWAM, conductivity estimation by the novel semi-analytical model, absolute difference ( $\mathrm{mD}-\mathrm{ft})$ between the LWAM and the novel model, and relative difference $(\%)$ between LWAM and the novel model. Figure 35 presents the histogram of relative difference.

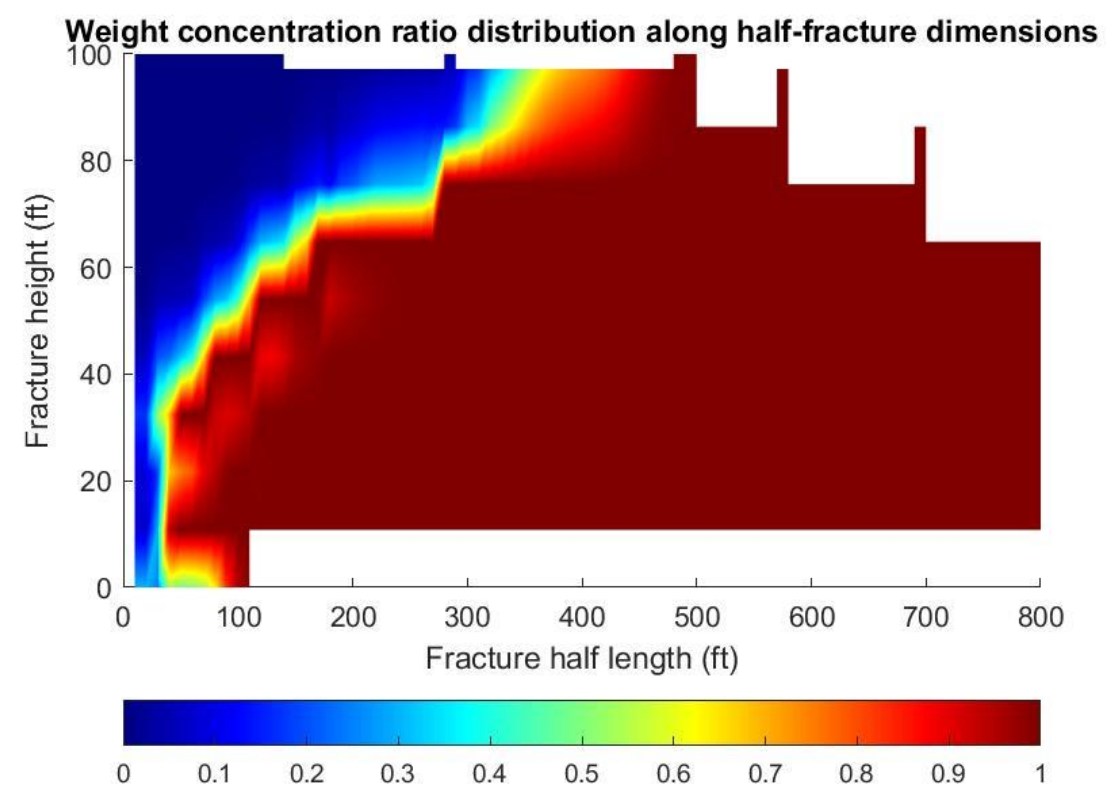

Figure 36 - Weight Concentration Ratio distribution inside half-fracture, mixture 20/40 sand and 20/40 ceramic injection 


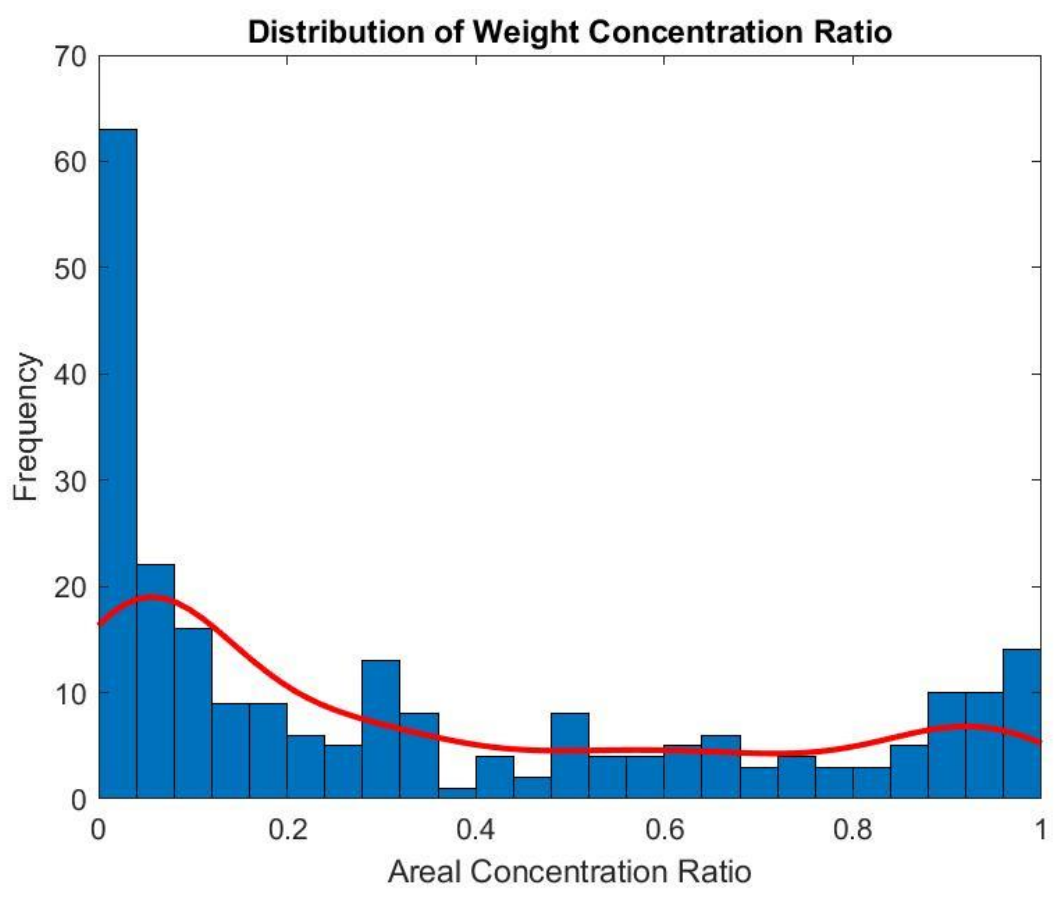

Figure 37 - Historgram of Weight Concentration Ratio distribution, mxiture 20/40 sand and 20/40 ceramic injection

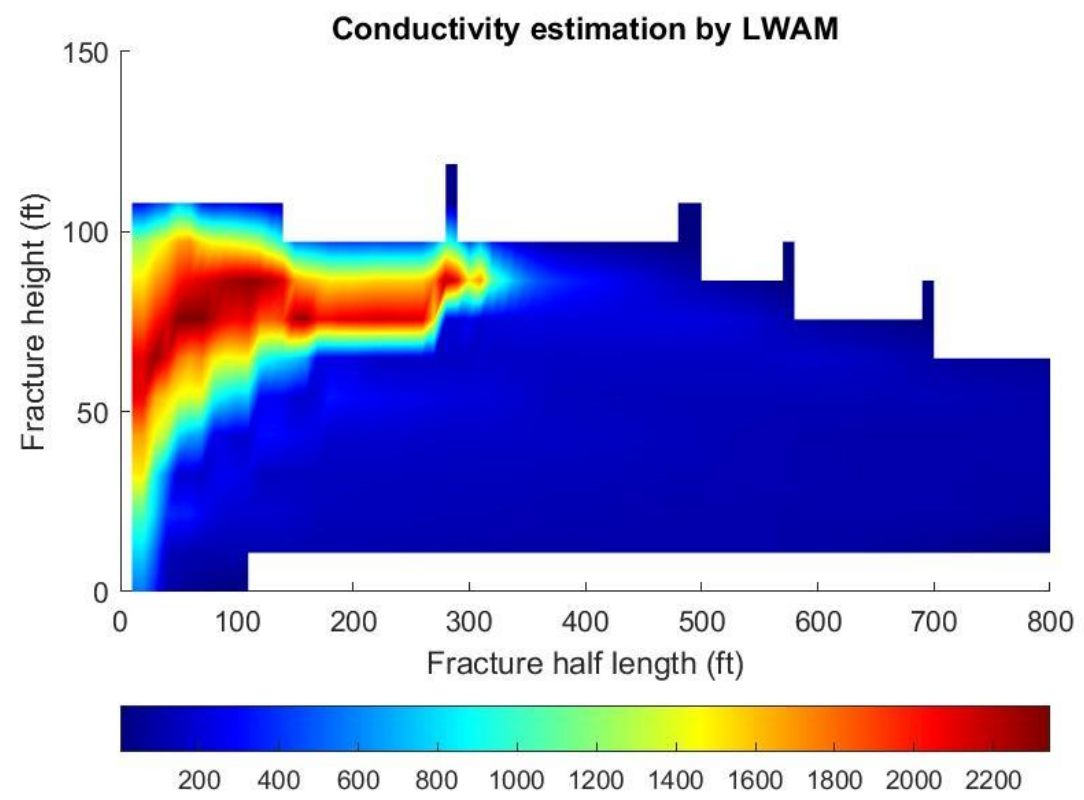

Figure 38 - Conductivity estimation inside half-fracture by LWAM, mixture 20/40 sand and 20/40 ceramic injection 


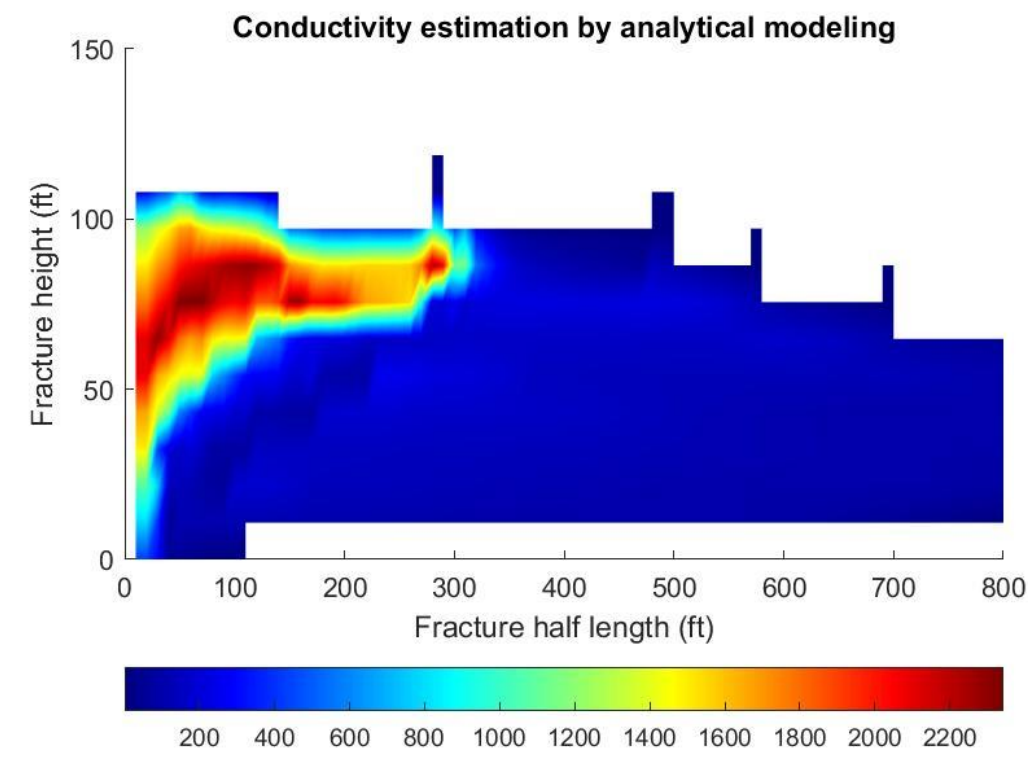

Figure 39 - Conductivity estimation inside half-fracture by novel semi-analytical model, mixture 20/40 sand and 20/40 ceramic injection

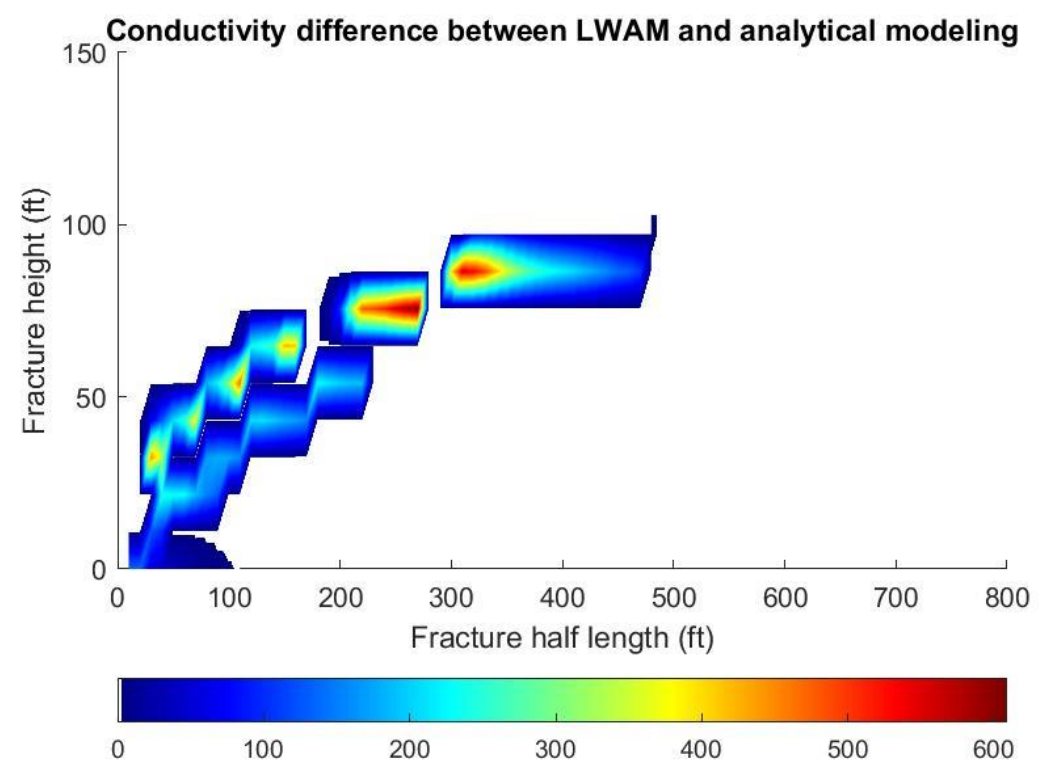

Figure 40 - Absolute difference ( $\mathrm{mD}$ - $\mathrm{ft}$ ) between LWAM and the novel semi-analytical model, mixture 20/40 sand and 20/40 ceramic injection 


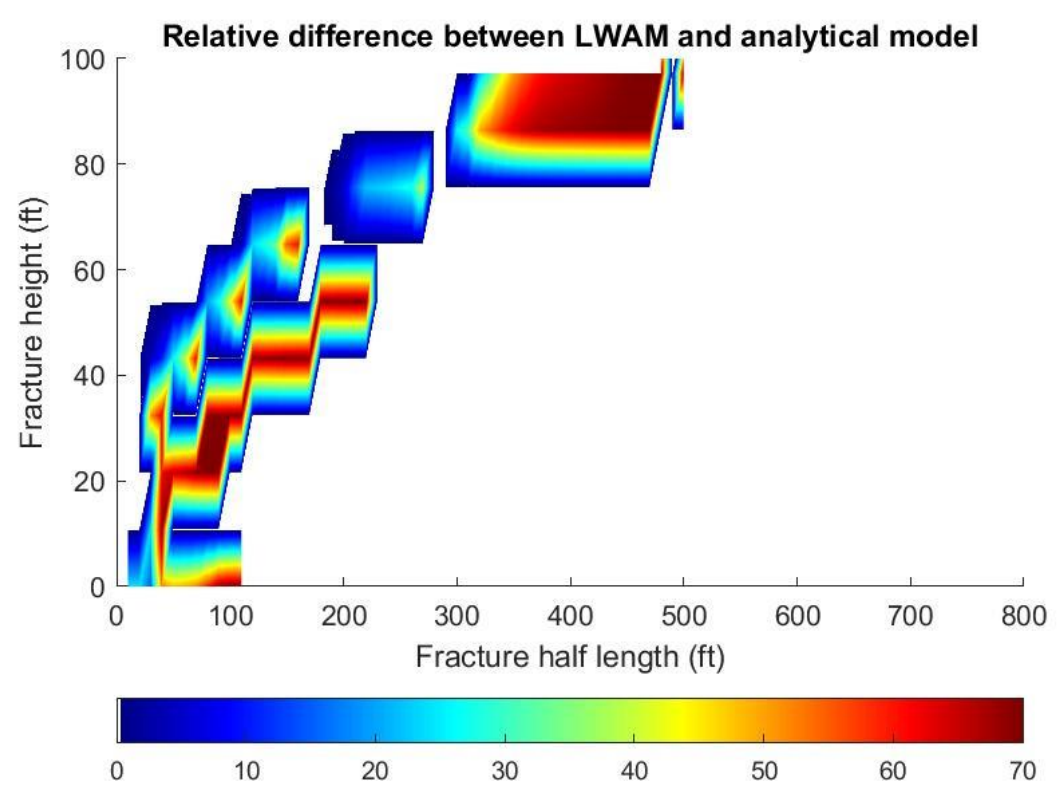

Figure 41 - Relative difference (\%) between LWAM and the novel semi-analytical model, , mixture 20/40 sand and 20/40 ceramic injection

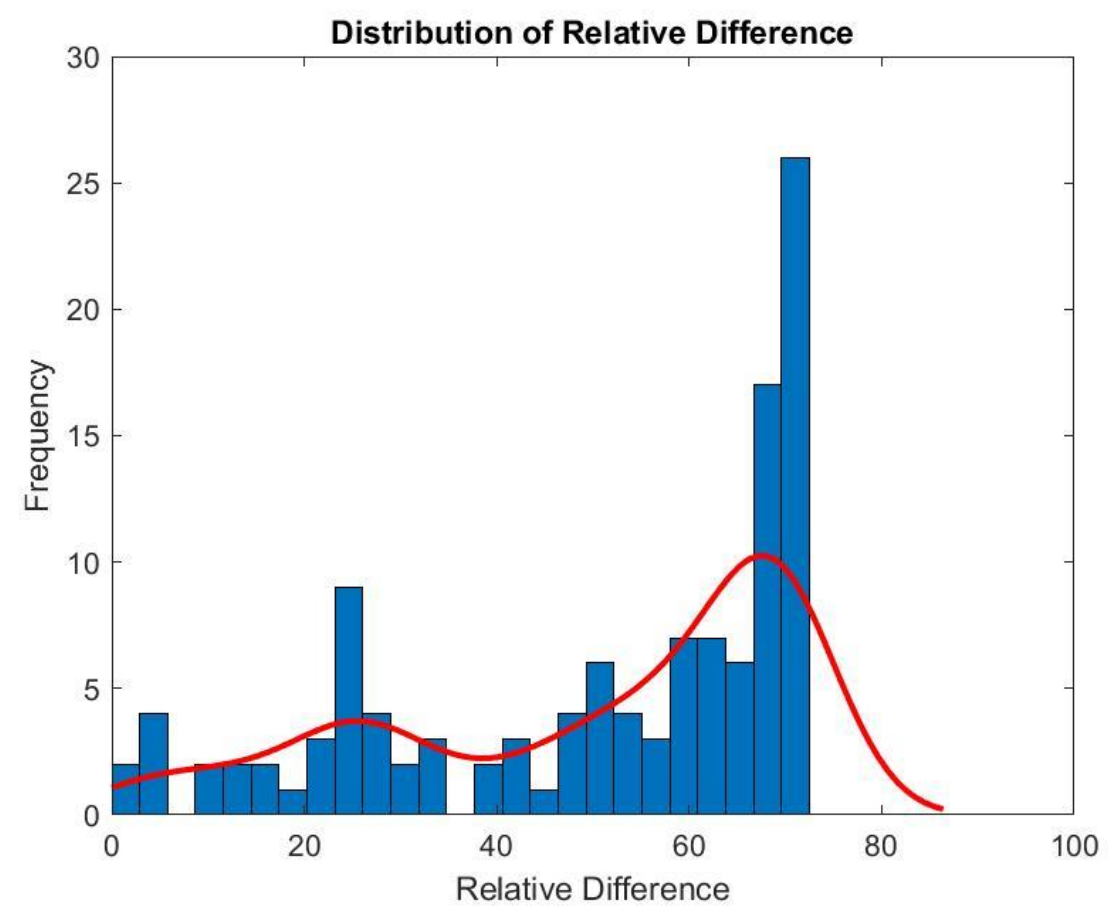

Figure 42 - Histogram of Relative difference (\%), mixture 20/40 sand and 20/40 ceramic injection 


\section{Cumulative production}

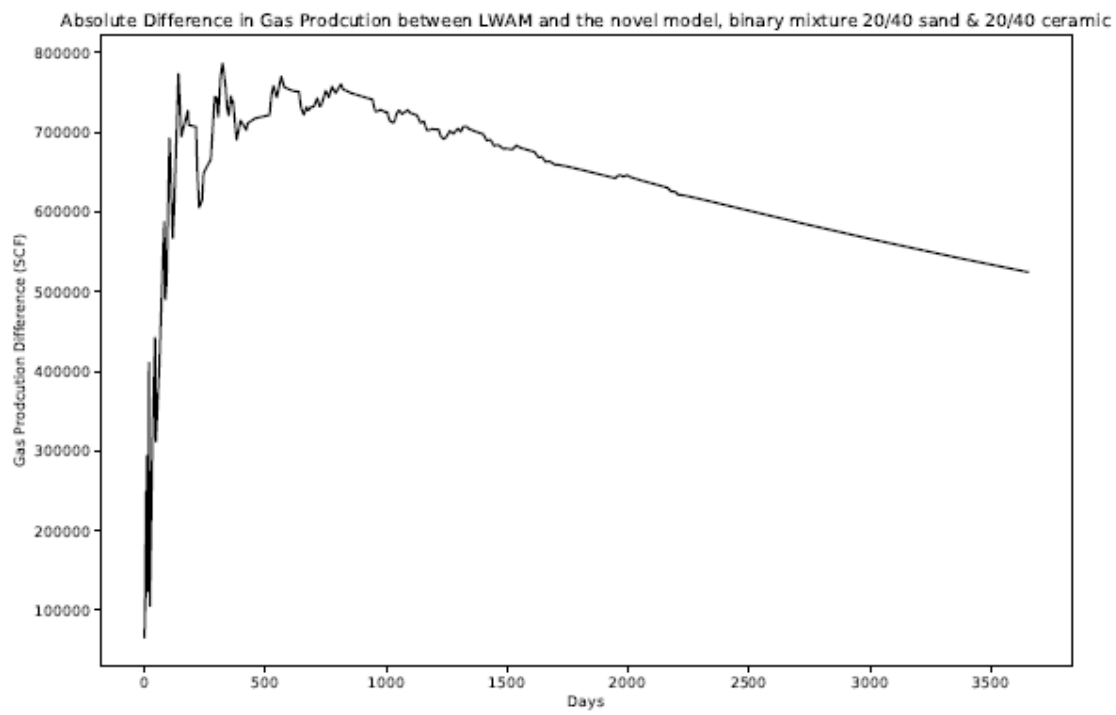

Figure 43- Absolute difference (SCF) between production data by LWAM and the novel semianalytical model, mixture 20/40 sand and 20/40 ceramic injection

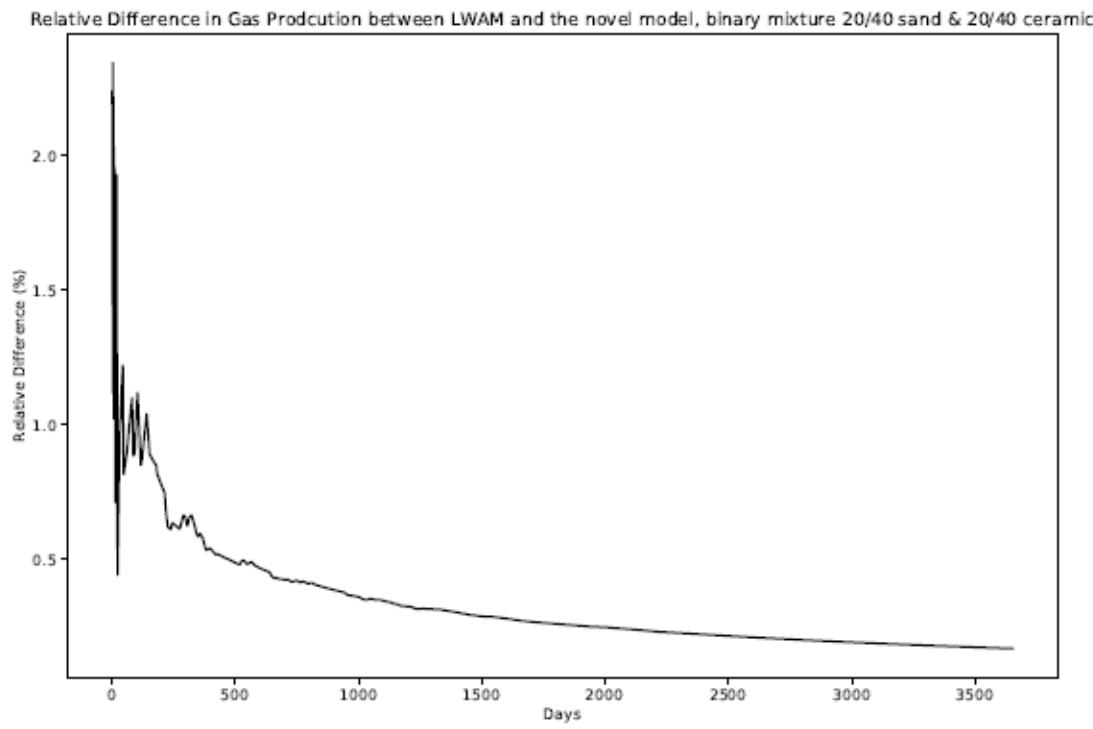

Figure 44 - Relative difference (\%) difference (SCF) between production data by LWAM and the novel semi-analytical model, mixture 20/40 sand and 20/40 ceramic injection 
Figures 43 and 44 present absolute diffrence (SCF) and relative difference (\%) in 10-year cumulative production data (interpolated data) between two models. In figures 43 and 44 , the $\mathrm{x}$ axis presents cumulative production time in days and the y axis presents absolute difference in SCF or rekative diffence in $\%$.

6.5.4. Binary mixture $40 / 70$ sand and $20 / 40$ ceramic

\section{Conductivtiy estimation analysis}

Figures 45 and 46 present the Weight Concentration Ratiodistribution (along half fracture dimensions) and its histrogram, respectively.

Figures 47-51 present the following quantities (along half-fracture dimentions): Conductivtity estimation by LWAM, conductivity estimation by the novel semi-analytical model, absolute difference between the LWAM and the novel model, and relative difference between LWAM and the novel model. Figure 42 presents the histogram of relative difference.

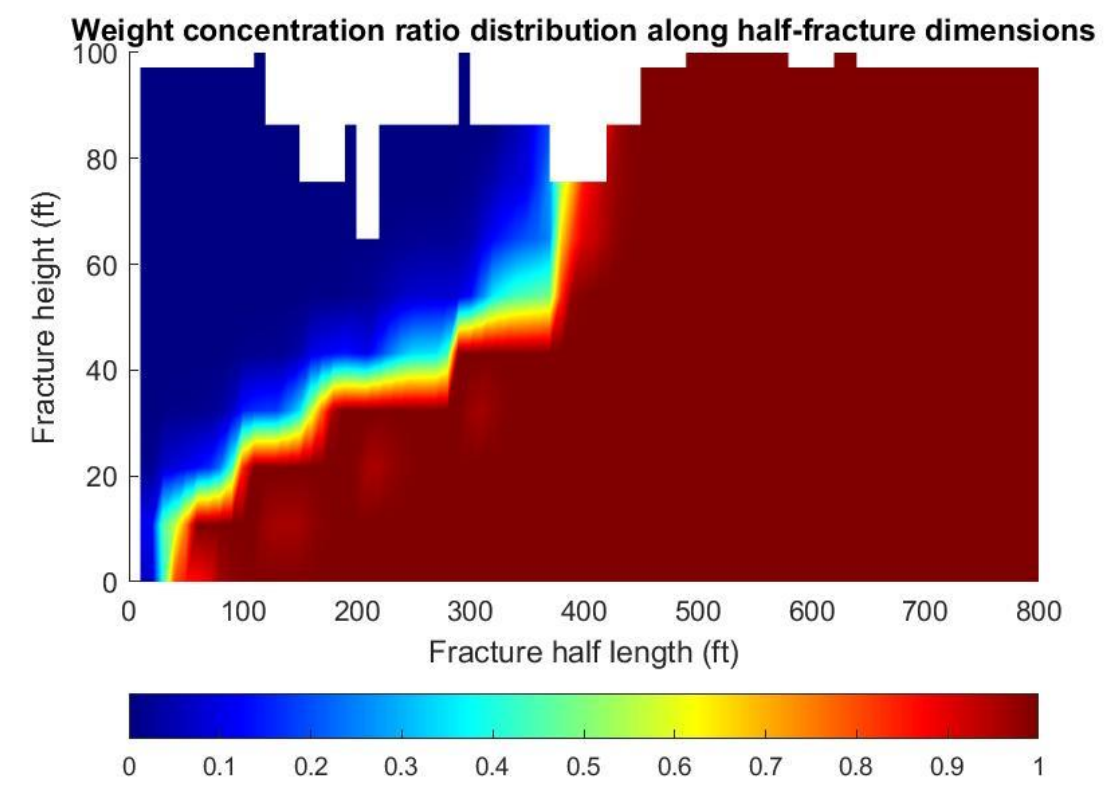

Figure 45 - Weight Concentration Ratio distribution inside half-fracture, mixture 40/70 sand and 20/40 ceramic injection 


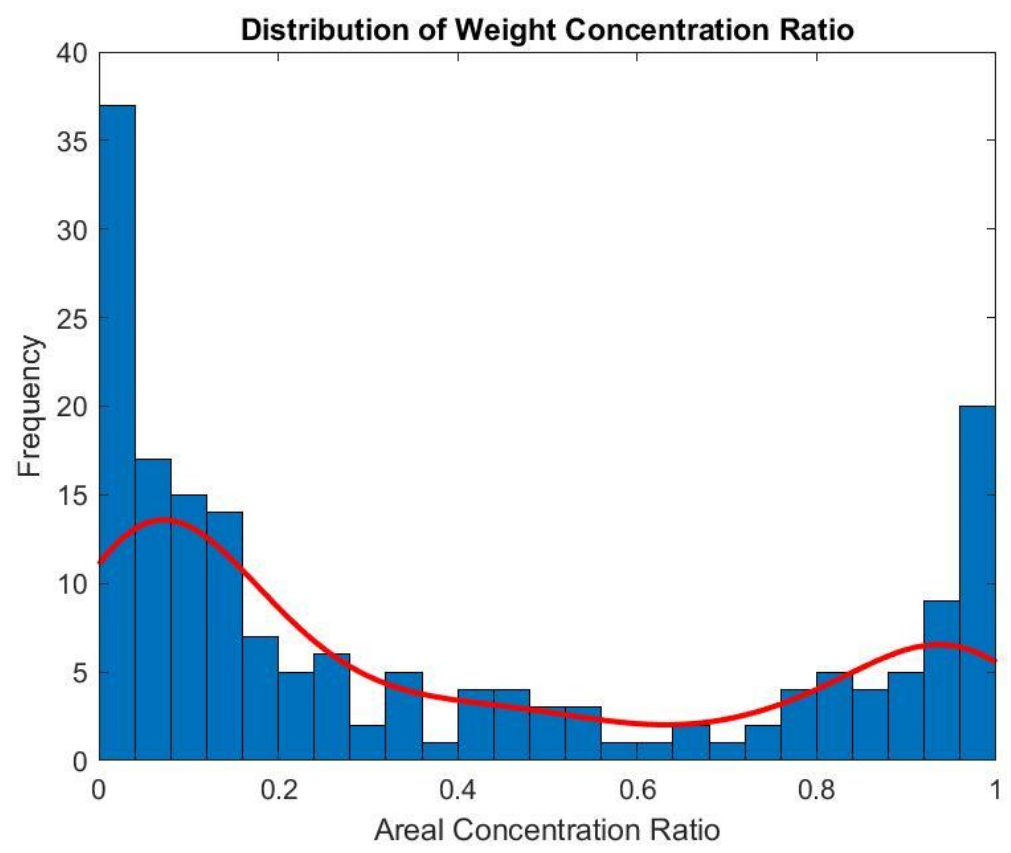

Figure 46 - Historgram of Weight Concentration Ratio distribution, mixture 40/70 sand and 20/40 ceramic injection

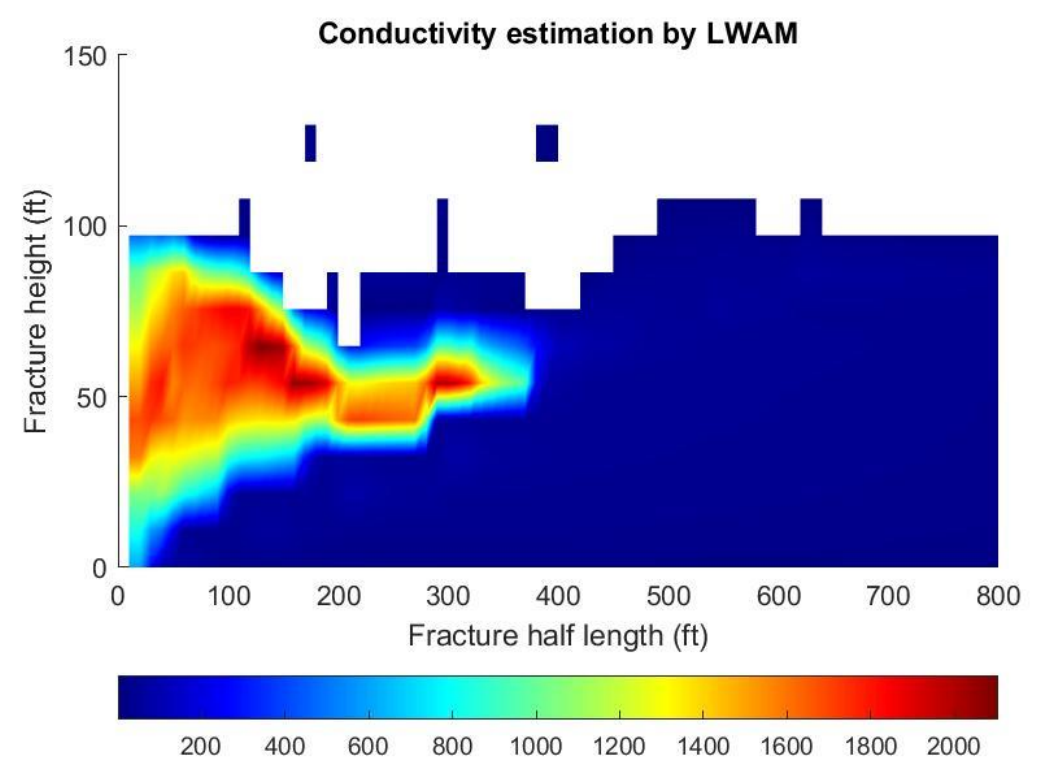

Figure 47 - Conductivity estimation inside half-fracture by LWAM, mixture 40/70 sand and 20/40 ceramic injection 


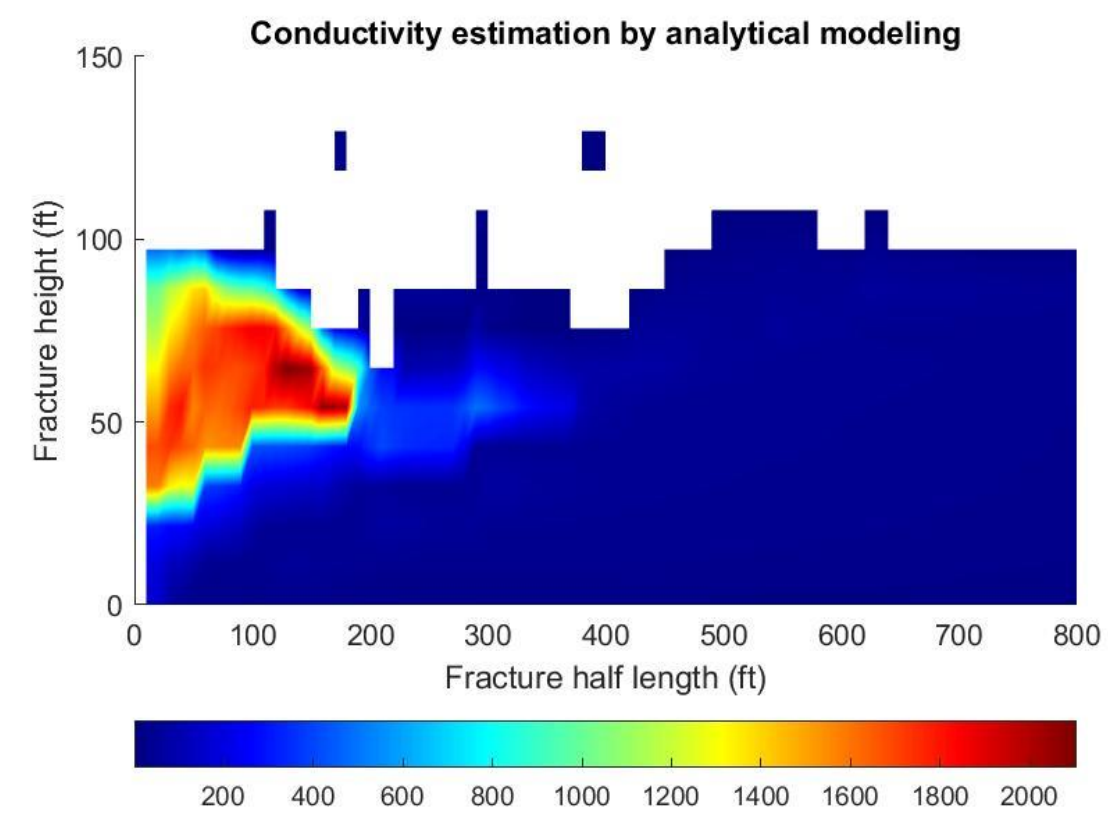

Figure 48 - Conductivity estimation inside half-fracture by novel semi-analytical model, mixture 40/70 sand and 20/40 ceramic injection

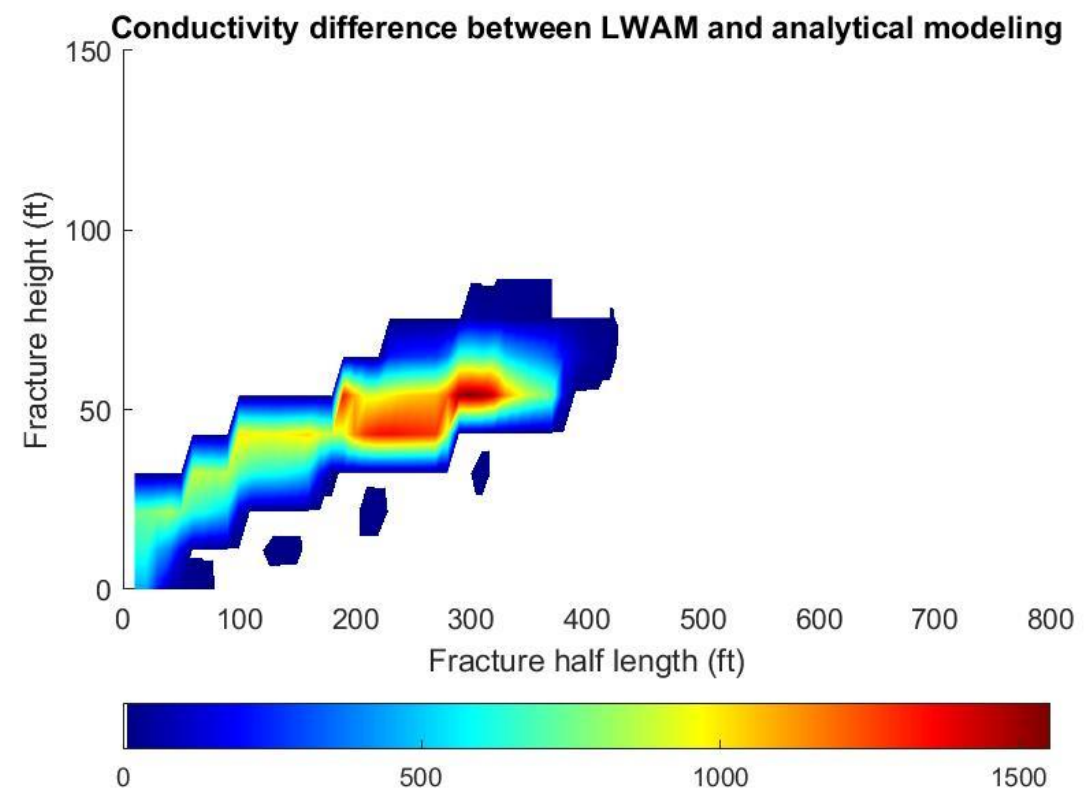

Figure 49 - Absolute difference (mD-ft) between LWAM and the novel semi-analytical model, , mixture 40/70 sand and 20/40 ceramic inejction 


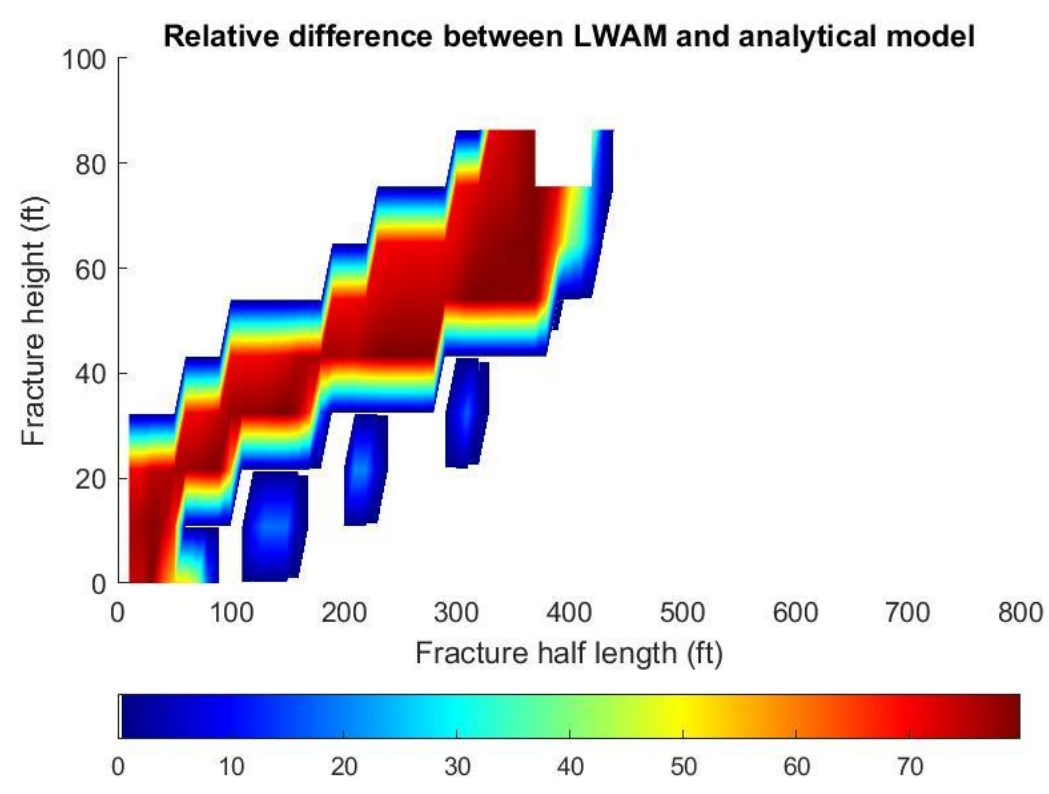

Figure 50 - Relative difference (\%) between LWAM and the novel semi-analytical model, , mixture 40/70 sand and 20/40 ceramic injection

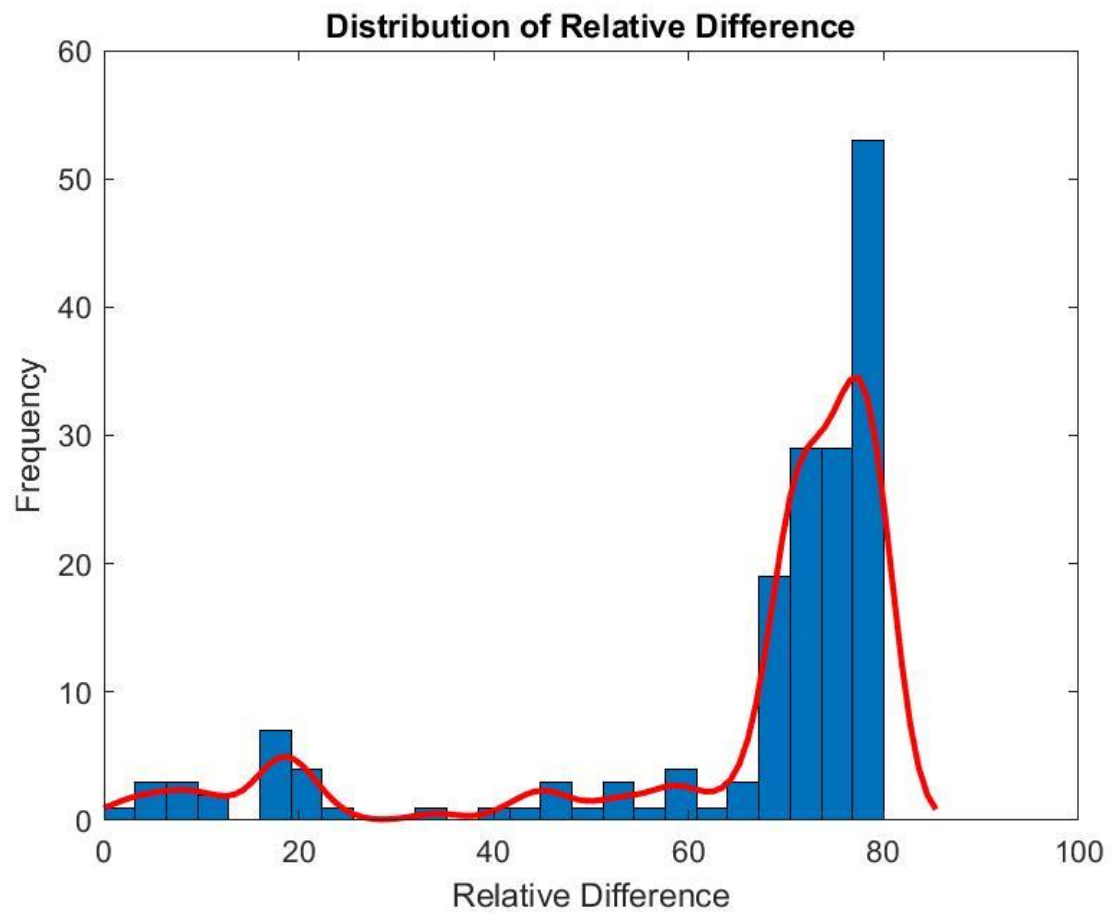

Figure 51 - Histogram of Relative difference (\%), mixture 40/70 sand and 20/40 ceramic injection 


\section{Cumulative Production}

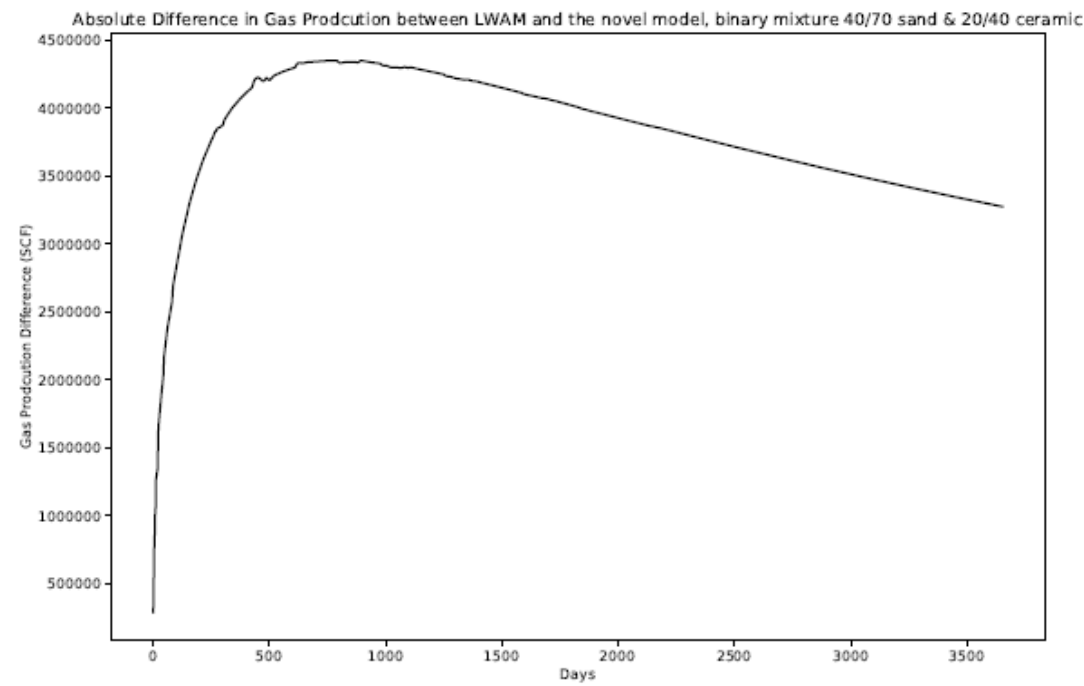

Figure 52 - Absolute difference (SCF) between production data by LWAM and the novel semianalytical model, mixture 40/70 sand and 20/40 ceramic injection

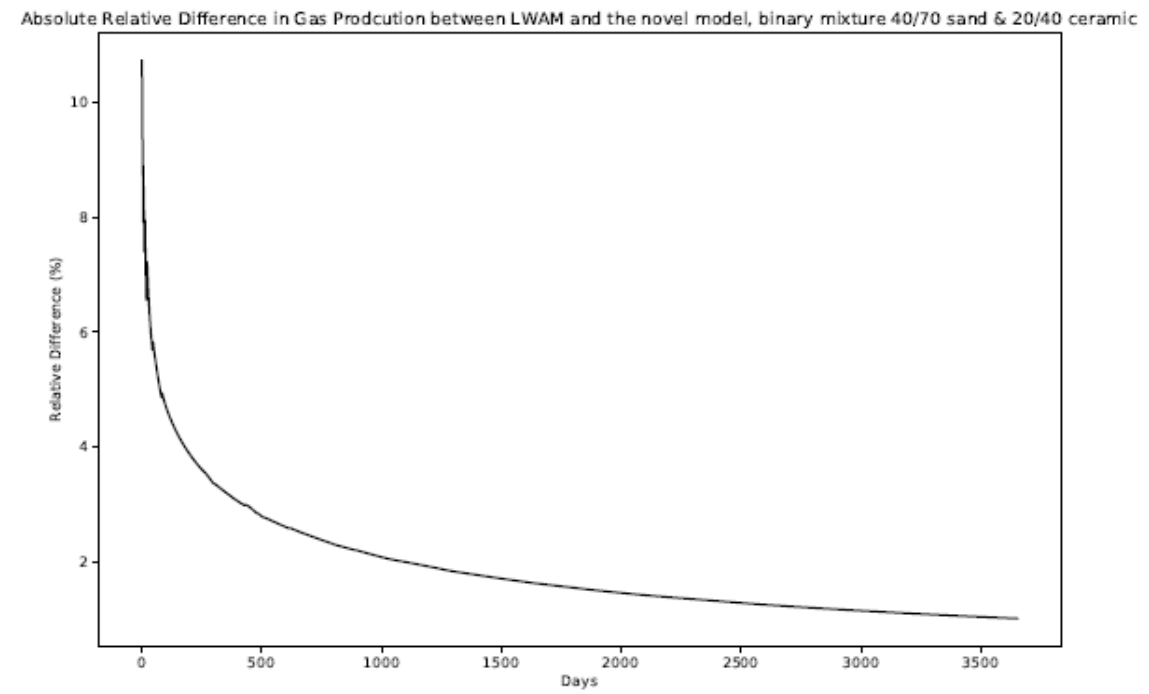

Figure 53 - Relative difference $(\%)$ between production data by LWAM and the novel semianalytical model, mixture $20 / 40$ sand and $20 / 40$ ceramic injection 
Figures 52 and 53 present absolute and relative differences in 10-year cumulative production data (interpolated data) between two models. In figures 52 and 53, the $\mathrm{x}$ axis presents cumulative production time in days and the y axis presents absolute difference in SCF or rekative diffence in $\%$.

6.5.5. Bianry mixture $40 / 70$ ceramic and $20 / 40$ sand

\section{Condutivity esimation analysis}

Figures 54 and 55 present the Weight Concentration Ratio distribution (along half fracture dimensions) and its histrogram, respectively.

Figures 56-60 present the following quantities (along half-fracture dimentions): Conductivtity estimation by LWAM, conductivity estimation by the novel semi-analytical model, absolute difference between the LWAM and the novel model, and relative difference between LWAM and the novel model. Figure 49 presents the histogram of relative difference.

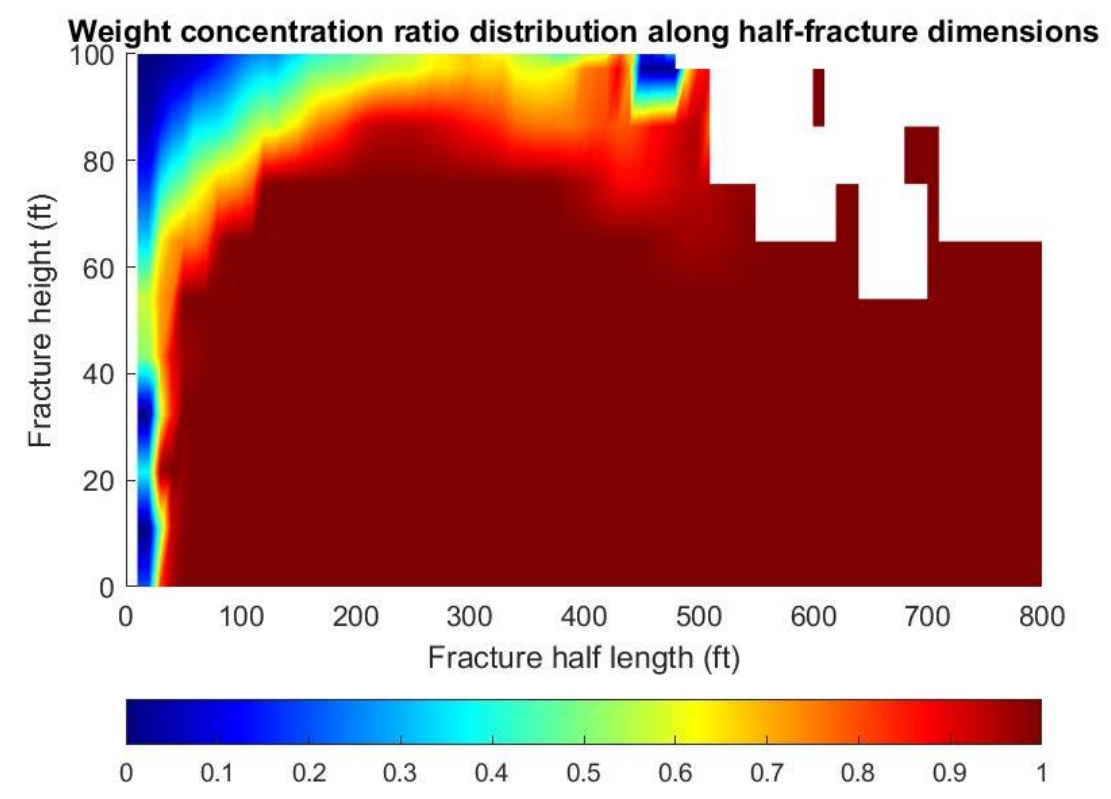

Figure 54 - Weight Concentration Ratio distribution inside half-fracture, mixture 40/70 ceramic and 20/40 sand injection 


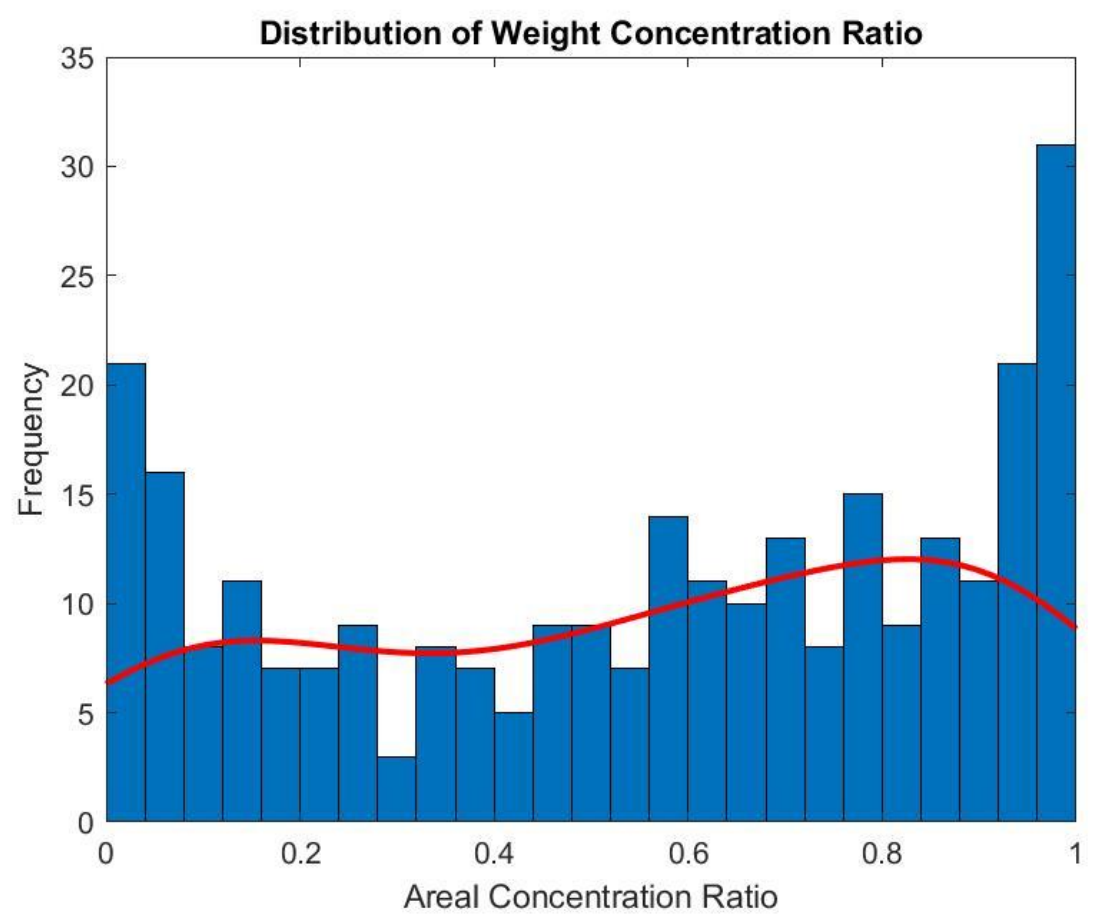

Figure 55 - Historgram of Weight Concentration Ratio distribution, mixture 40/70 ceramic and 20/40 sand injection

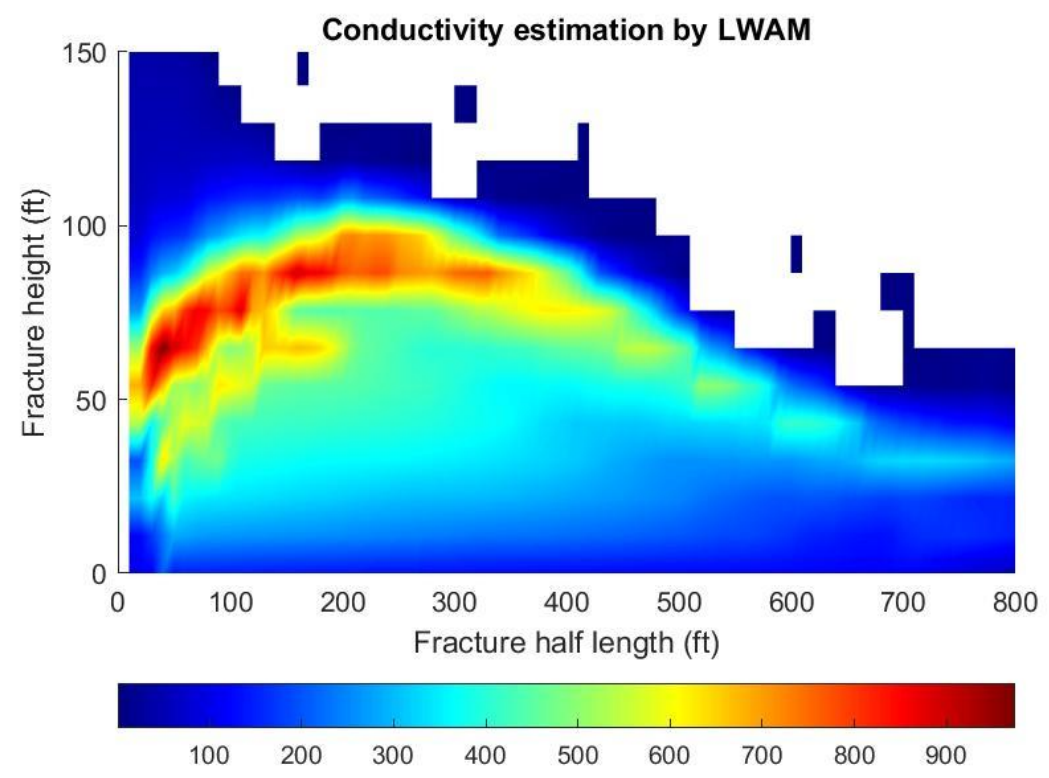

Figure 56 - Conductivity estimation inside half-fracture by LWAM, mixture 40/70 ceramic and 20/40 sand inejction 


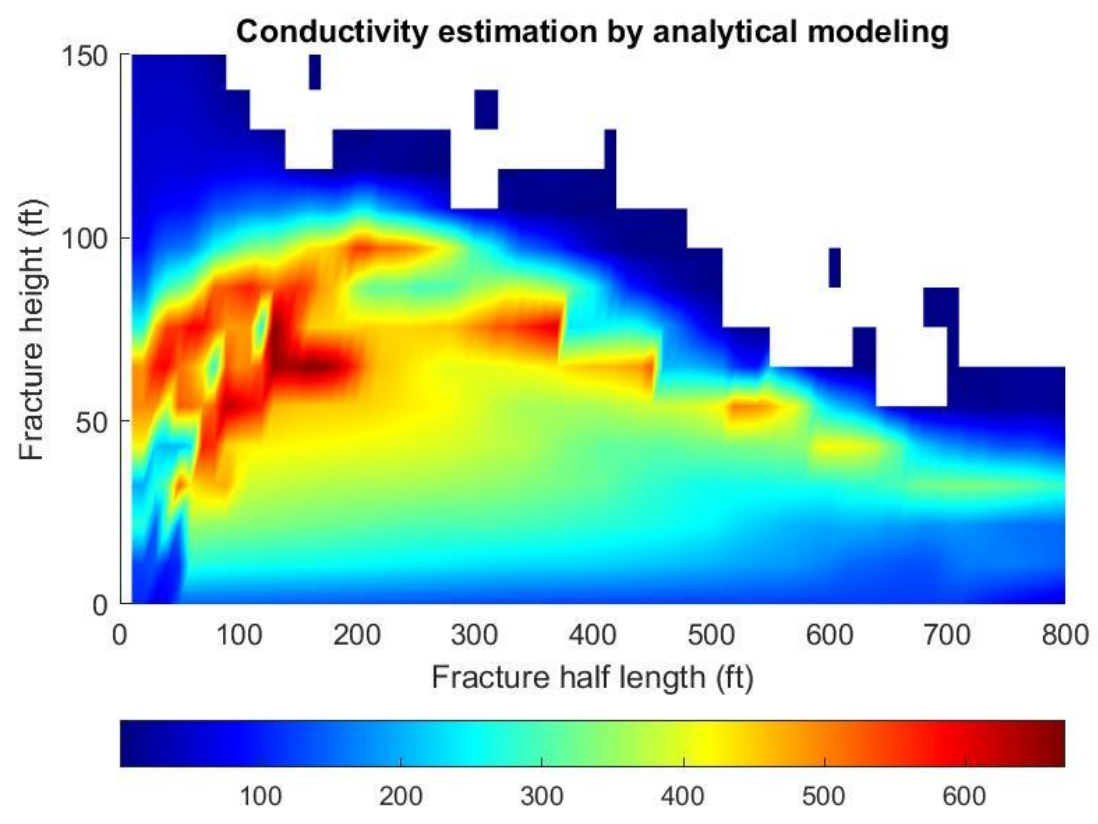

Figure 57 - Conductivity estimation inside half-fracture by LWAM, mixture 40/70 ceramic and $\underline{20 / 40 \text { sand injection }}$

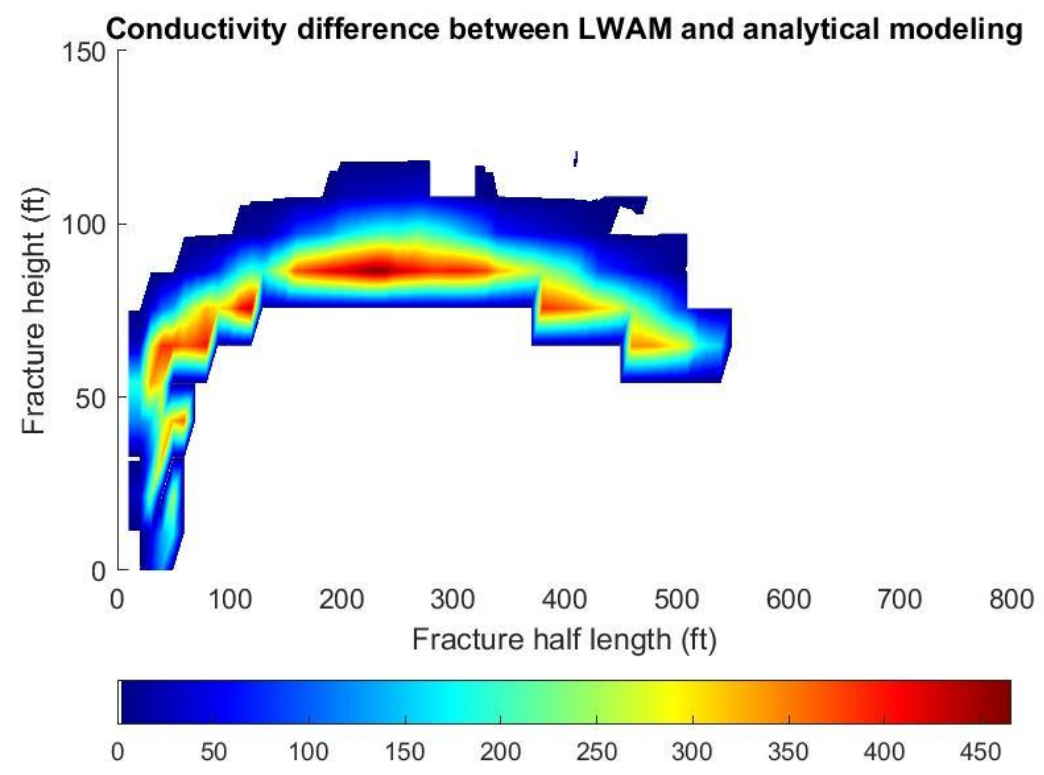

Figure 58 - Absolute difference (mD-ft) between LWAM and the novel semi-analytical model, , mixture 40/70 ceramic and 20/40 sand injection 


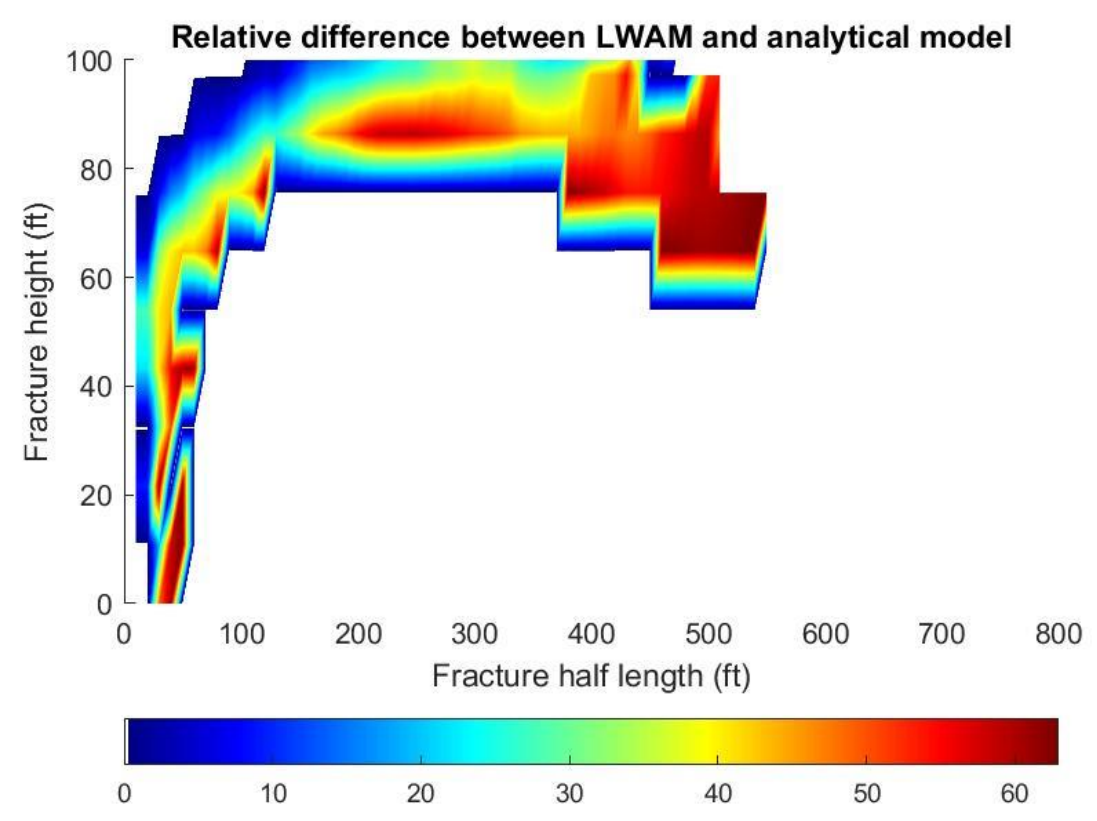

Figure 59 - Relative difference (\%) between LWAM and the novel semi-analytical model, mixture 40/70 ceramic and 20/40 sand injection

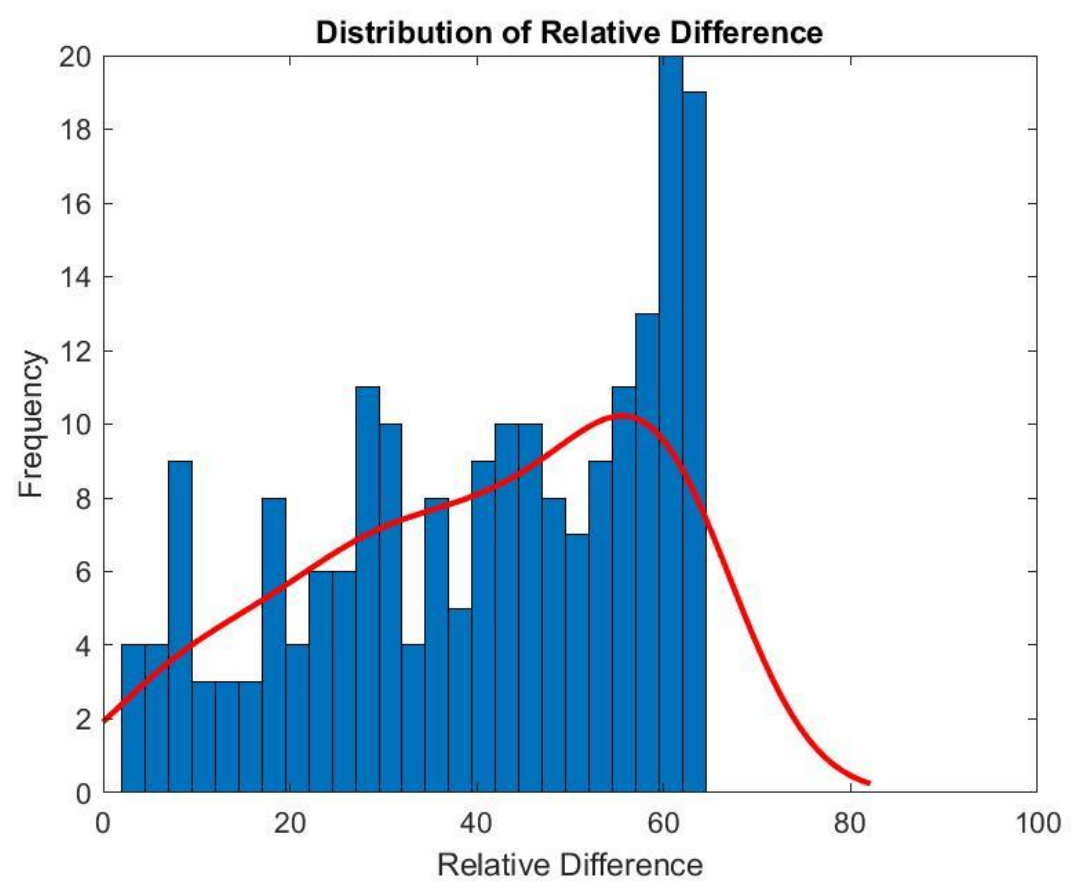

Figure 60 - Histogram of Relative difference (\%), mixture 40/70 ceramic and 20/40 sand injection 


\section{Cumulative production}

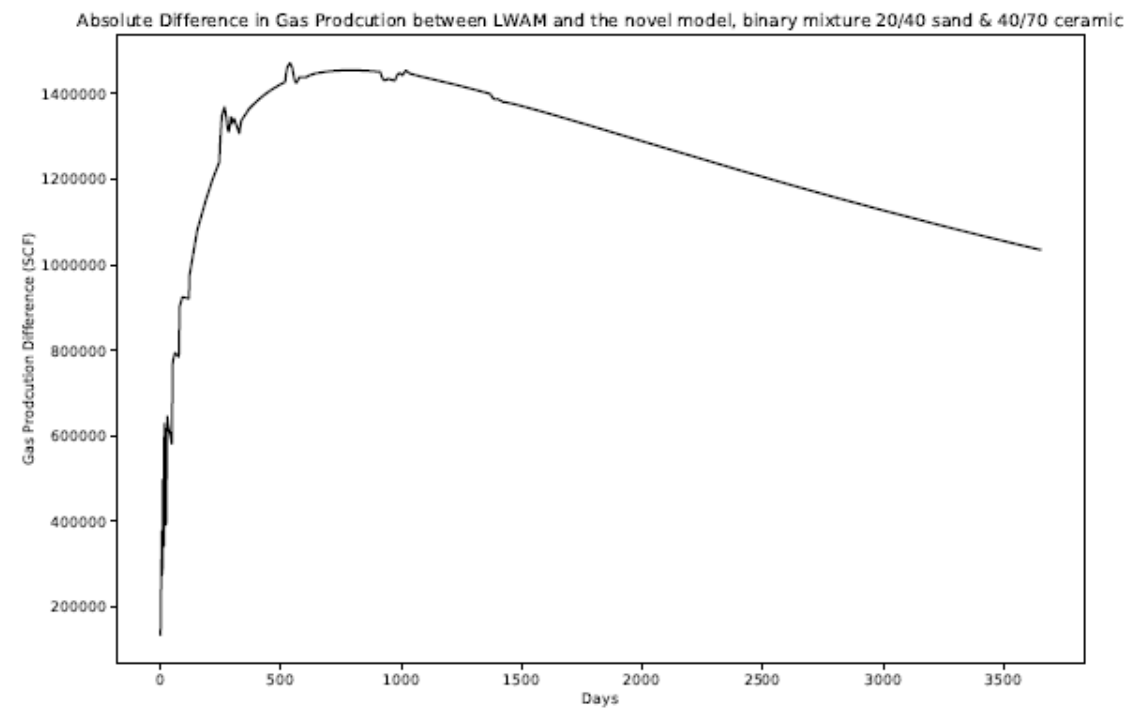

Figure 61 - Absolute difference (SCF) between production data by LWAM and the novel semianalytical model, mixture 40/70 ceramic and 20/40 sand injection

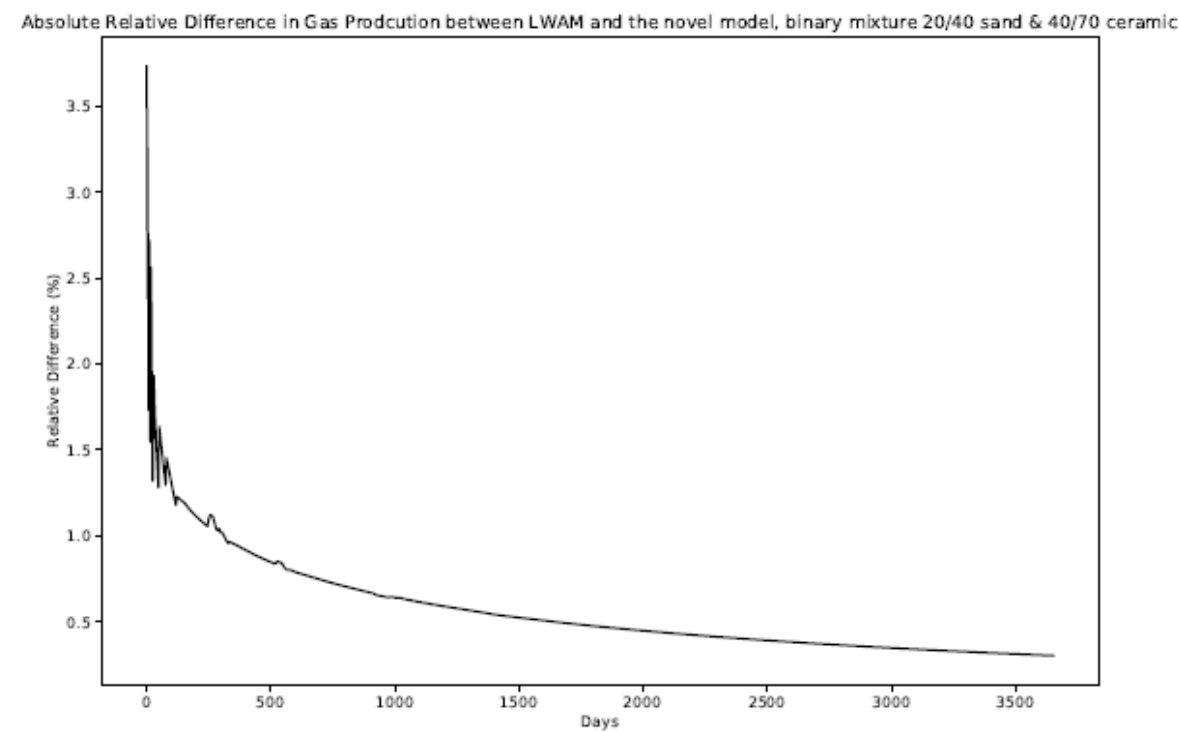

Figure 62 - Relative difference $(\%)$ between production data by LWAM and the novel semianalytical model, mixture 40/70 ceramic and 20/40 sand injection 
Figures 61 and 62 present absolute and relative differences in 10-year cumulative production data (interpolated data) between two models. In figures 61 and 62 , the $\mathrm{x}$ axis presents cumulative production time in days and the y axis presents absolute difference in SCF or rekative diffence in $\%$.

6.5.6. Predictive reasoning for conductivity estimation

Histograms and the kernel density estimation curves for all binary mixtures indicates an observation that the distribution of relative difference is dependent on the comparison matrices in section 4 when being reduced to the interested confining stress ranges (i.e. Marcellus Shale in the case study) and independent on the distribution of areal concentration ratio. In fact, the histograms and kernel density curves of Weight Concentration Ratio exhibit high degree of similarity.

For binary mixture 20/40 sand and 20/40 ceramic, figure 25 is closely concentrated on the region with reduced confining stress axis (between 5400-6200 psi). The comparison matrix presents a thin low overestimation zone (lower than 20\%), an increase in height of the moderate overestimation zone (20-60\%), and a thickest high overestimation zone (higher than 60\%). These observations indicate a kernel density estimation curve which starts at low probability at low overestimation, progressively increases in probability at moderate overestimation and highly excels when entering high overestimation. Validation is readily available in figure 42 .

For binary mixture 40/70 sand and 20/40 ceramic, figure 26 is closely concentrated on the region with reduced confining stress axis (between 5400-6200 psi). The comparison matrix presents nearly unnoticeable low overestimation zone (lower than $20 \%$ ), extremely thin moderate overestimation zone (20\%-60\%) and dominant high overestimation zone (higher than 60\%). These observations indicate a kernel density curve which starts at extremely low probability at low 
overestimation, slight increases at moderate overestimation and exhibits a drastic jump when entering high overestimation. Validation is readily available in figure 51.

For binary mixture 40/70 sand and 20/40 ceramic, figure 27 is closely concentrated on the region with reduced confining stress axis (between 5400-6200 psi). The comparison matrix presents the low (lower than 20\%) and high (higher than 50\%) overestimation zones are almost similar in size, whereas the moderate (20\%-50\%) overestimation zone is slightly larger in size. These observations indicate a kernel density curve which gradually increases as overestimation moves from low to high zones orderly and has zero significant jump when entering any overestimation zones. Validation is readily available in figure 60.

Limited to this case study for Marcellus Shale and for all studied binary mixtures, maximum difference of 200 psi in confining stress between different depths does not translate to considerable difference in separation of the overestimation zones (i.e. low, moderate and high), which maintains the predictive reasoning of the overestimation's histogram/kernel density estimation curve. However, it is obvious that applications for other formations which has different confining stress data change observations from comparison matrices, and different predictive reasoning outcomes are expected.

Conclusively, analysis of the comparison matrices and reviews of avaialble confining stress data are important in understanding the efficacy of the novel semi-analytical model in an applied case study. It is suggested that modelling for other practical binary mixtures (i.e. 100 sand and 40/70 sand) shall expand the understanding of the novel model by generating more comparison matrices.

6.5.7. Discussion for the cumulative production 
Generally, it is expected that as the novel model predicts lower permeability and conductivity compared to LWAM, its cumulative production data is also lower. The magnitude of difference in gas cumulative production between the two models is within $10^{5}-10^{6} \mathrm{SCF}$ scale, which yields a small relative difference (up to $10.73 \%$ after the first year and 3.274 MMSCF after 10 years) when compared to the magnitude of the gas cumulative production itself (within $10^{8}-10^{9}$ SCF scale). The magnitude of difference in comparison is dependent on the intrinsic property of the injected binary mixture, presumably the other simulation factors are controlled to remain (as in this case study).

Binary mixtures with contrast in Mesh sizes and densities between the two proppant types (i.e. 40/70 sand-20/40 ceramic and 40/70 ceramic-20/40 sand) exhibit a more stable behavior in cumulative production data, yield higher difference (1.035 MMSCF after 10 years) in cumulative production and consequently higher relative difference ( maximum $3.731 \%$, after the first year). Especially, the binary mixtures of which the injection order is finer and weaker proppant type, following by coarser and stronger proppant type (i.e. 40/70 sand and 20/40 ceramic) exhibit extremely stable behavior in cumulative production data, yield highest difference (3.274 MMSCF after 10 years) in cumulative production data and consequently highest relative difference (maximum $10.73 \%$ after the first year).

Binary mixtures with similarity in Mesh sizes between the two proppant types (i.e. 20/40 sand and 20/40 ceramic) exhibit a more fluctuating behavior in cumulative production data, yield lower difference ( 0.787 MMSCF after 10 years) in cumulative production and consequently lower relative difference (maximum $2.346 \%$ after the first year) compared to binary mixtures with contrast in both Mesh sizes and densities. Based on these discussions, an injection practice for a binary mixture with injection order of finer and weaker proppant type, following by coarser and 
stronger proppant type increases expectation by application of LWAM. An injection practice for a binary mixture with similarity in Mesh sizes mitigates expectation by application of LWAM.

\subsubsection{Drawbacks in the case study}

It is undeniable that modelling for the three selected binary mixtures limit further possible studies for this Marcellus Shale case. Field production data in Marcellus Shale for the studied well MIP-3H is available and its field injection mixtures are binary mixtures of sand. As reviewed in

chapter 1, the lab data for binary mixtures of sand is not selected for being modelled because of scarcity in the available data for binary mixtures of sand. As a result, prospective studies as history matching or production sensitivity are decided not feasible to be conducted, which may reduce the solidity and flexibility of the novel model. 


\section{CHAPTER 7 - CONCLUSIONS}

The novel concept of Weight Concentration Ratio defined as division of areal concentration of the $1^{\text {st }}$ injected proppant type to the total areal concentration visualizes the mixture zone inside a propped fracture. This novel concept is an integrated part in developing the novel semi-analytical model for conductivity of binary mixtures. Modelling process is conducted by separate semianalytical modelling for permeability and fracture width.

Assumption of a loaded proppant pack as a binary-sized particle assembly allows a derivation sequence for internal specific area. Previous studies of porosity and tortuosity for binary-sized particle assembly and assumptions for porous media as parallel flow tubes further allow use of Carman-Kozeny equation for modelling permeability of binary mixtures. Determination of coefficients in this permeability model is feasible by trust-region method for nonlinear least square problems with support of pre-set coefficient boundaries specific binary mixtures' permeability lab data.

Dual-layering schematic and elastic deformation allow modelling for fracture width by Hertzian contact theory. Unsatisfaction in reviews for available proppant pack width's lab data leads to its termination in use for fracture width modelling. Therfore, fracture width model is derived to be independent on coefficients. Besides Weight Concentration Ratio and confining stress, geo-mechanics involve as independent inputs in the model. These properties are known for each proppant type in a binary mixture.

The novel semi-analytical model for conductivity of binary mixtures perform validation with the conductivity lab data with an acceptable degree of accuracy for $2 / 3$ studied binary mixtures: 40/70 sand - 20/40 ceramic (7.98-9.9\%) and 40/70 ceramic - 20/40 sand (13-18.13\%). Based on validation results, trust-region method proves its effectiveness in determining the 
model's coefficients using highly qualified datasets of just two different Weight Concentration Ratios. This achievement partially allows expansion of the novel conductivity model to predict binary mixture's conductivity at arbitrary confining stress and Weight Mixing Ratio values. Undeniably, the novel conductivity model reduces efforts of conducting several API conductivities tests and misleading experimental results caused by measurement errors.

The novel conductivity model proves that LWAM overestimates conductivity of a binary mixture. Degree of overestimation is studied by relative difference between LWAM and the novel model. Comparison matrices with 2 axes of confining stress (2000-10000 psi) and Weight Concentration Ratio (0.01-0.99) are effective in examining relative difference. All comparison matrices have low $(\leq 20 \%)$, moderate $(20-60 \%)$ and high $(\geq 60 \%)$ overestimation zones.

For binary mixture 20/40 sand and 20/40 ceramic, relative difference increases monotonically in both axes to reach high overestimation zone at the $0.99-10000$ psi corner and transition rate between overestimation zones decrease moderately. For binary mixture 40/70 sand and 20/40 ceramic, relative different is dominantly in high overestimation zone which is located at $0.5-10000 \mathrm{psi}$, and transition rate between overestimation zones can be rapid. For binary mixture 40/70 ceramic and 20/40 sand, overestimation zones are uniformly distributed and transition rate between overestimation zones is low.

Case study for Marcellus Shale further quantify efficacy of the models by cumulative production data analysis (both 10-year production data and production data at the early time of production), besides conductivity estimation. Axis reduction of comparison matrices using Marcellus Shale minimum horizontal stress data allows predictive reasoning in conductivity estimation, which is correlated with histograms of relative difference. Cumulative production data analysis quantifies production over-expectation caused by application of LWAM in reservoir 
simulation. Injection practices of a binary mixture with high contrast in its proppant types' Mesh size and density significantly increase the expectation. Injection practices of a binary mixture with low contrast in its proppant types' Mesh size and density decreases the expectation. 


\section{CHAPTER 8 - RECOMMENDATION FOR FUTURE WORK}

\section{Lab data}

An expansion of the mesurements for more binary mixtures is highly supportive to continue this study. In specific, binary mixtures which are currently practiced in the field's hydraulic fracturing operations, for example 100 Mesh sand and 40/70 Mesh sand in Marcellus Shale, should need further focus.

An expansion of the mesurements for more weight mixing ratios (i.e. areal concentration ratios) is highly supportive to continue this study. Besides several efforts to understand the dependence of modelling coefficients on the weight mixing ratios, their intrinsic complexities require validation from lab mesurements to prove the accuracy of the current understanding described in this study.

A correction or modification in the mesurements for the proppant pack's width is necessary, since th current mesurement approach prevents the feasible use of the proppant pack's width lab data from reasonable modelling approach(es).

\section{The sensitivity study for mixture zone}

Scale of the sensitivity analysis can be expanded to a global sensitivity analysis. According to Morris global sensitivity design, the base case is generated as each run within analysis for one input factor. As a result, variance-based analysis for output factor(s) (i.e. mixture zone) is feasible. In addition, variance or relationships between input factors as minimum confining stress and geomechanics are known from field measurements or modelling. Contribution from these aspects can lead to better screening design and more realistic discussions for impact from the prospectively correlated input factors.

\section{Semi-analytical modeling improvement}


For the novel semi-analytical permeability model, modification from Carman-Kozeny equation does not eliminate the limitations of the this equation. Pore trajectory has been addressed under a cetain degree (related to descriptions in Dullien and F.A.L, 1992) in this thesis. However, an full analytical solution for pore trajectory is not totally feasible and out of the aims of the study. Particle size distributions another essential aspect to be more deeply concerned for better permeability modelling. One prospective approach is to derive the modified internal specific area as a function of Weight Concentration Ratio and in-lab-context particle size distribtution kernel density estimators for the two proppant types in a binary mixture. However, time contraints do not allow this direction to be modelled sucessfully.

For the novel fracture width model, the main expansions for better modelling outcomes primarily aligns to a higher degree of complexity in applying Hertzian contact theory and better relialization for the proposed dual-layering schematic. Hertzian contact theory can be applied to contact between proppant particles - rock surfaces (which are considered as elastic flat surfaces) and furthermore contact between proppant particles (which are considered as elastic spherical forms). The proppant particles - rock surfaces contact is addressed in this thesis. However, contact between proppant particles has not been addressed. Comprehensive additions in the effect of proppant layers within one proppant type (i.e. within 20/40 sand) and between two proppant proppant types (i.e. between 20/40 sand and 20/40 ceramic) both increase the complexity degree of the final fracture width model extremely. More effectively simplified form of the final fracture width model, under those additions, has not been finalized and therefore is not presented in this thesis.

Albeit dual-layering schematic intergrates the Weight Concentration Ratioconcept into the fracture width model reasonably, this arrangement is an idealization concept when compared to 
realistic distribution of particles. In reality, distribtuion of particles inside a proppant pack has a tendency to arrange randomly. This fact still allows intergration of Weight Concentration Ratioin the prospective model. However, it enforces the modelling scale to be microscopic.(i.e. between two particles), which produces extreme complexity and become out of scope for an analytical or a semi-analytical approach.

\section{Fracture/reservoir simulation}

Albeit usefulness of the in-house fracture propagation simulator in understanding of Areal Concentration Ratio, its functionality has been limited in two primary situations: pseudo-3D scaling for simulation and flexible import settings for different formations.

Additional coding efforts have been performed to visualize the Weight Concentration Ratioin pseudo-3D configuration. However, the visualization outcomes have not been satisfied for all studied binary mixtures in this thesis, which is believed to be caused by numerical errors. In addition, the import code module for fracturing parameters has been restricted to Marcellus Shale merely. Although adjustment for this module has been facilitated to import fracturing parameters from other shale formations (specifically Bakken Oil Shale), functionality after additional adjustment within the module has been improper and debugging issues have not been fixed. 


\section{REFERENCES}

1. Aditya Khanna et.al, Conductivity of narrow fractures filled with a proppant monolayer. Journal of Petroleum Science and Engineering 100: 9-13, December 2012.

2. Andrea Saltelli et.al, Sensitivity Analysis in Practice. Johns Wiley and Son Ltd, 2004.

3. Anthony C. Fischer-Cripps, Introduction to Contact Mechanics, $2^{\text {nd }}$ edition. Springer, 2007.

4. Anthony Diyokeugwu and Paul Glover, Grain-mixing modelling of the porosity and permeability of binary mixtures. SEG International Exposition and $88^{\text {th }}$ Annual Meeting, 2018.

5. Behzad Ghanbarian et.al, Tortuosity in Porous Media: A Critical Review. Soil Science of American Journal, p1462-1477, September 2013.

6. Carman, P.C, Fluid Flow Through a Granular Bed. Trans. Int. Chem. Eng. 15: 150-6

7. Courtney L. Rubin, Investigation of Gas Slippage Effect and Geo-mechanical Effect on Gas Production Prediction and Hydraulic Fracture Design - A Case Study of Marcellus Shale. West Virginia University, 2018.

8. Dean Stuart, Ning Liu and Albert Reynolds, Inverse theory for petroleum reservoir characterization and history matching, 2007.

9. Dong chen et.al, Dependence of gas shale fracture permeability on effective stress and reservoir pressure: Model match and insights. Fuel 139: 383-92, 2015.

10. Dullien and F.A.L, Porous Media Fluid Transport and Pore Structure. Academic Press, San Diego, CA, US, 1992.

11. Etherington, J.R, Mc. Donald, I.R, 2005, Is bitumen a Reserve? SPE 90242, SPE Hydrocarbon Economics and Evaluation Symposium, 2005. 
12. Emre Dundar, Aymen Alhemdi and Ming Gu, Impact of Natural Fracture-Induced Elastic Anisotropy on Completion and Fracturing Design in Different Shale Reservoirs. URTEC-2019-893-MS, Unconventional Resources Technology Conference, Denver, CO, US, July $22^{\text {nd }}-24^{\text {th }}, 2019$.

13. Eric Clinton Schultz, Conductivity of proppant mixtures. The University of Texas at Austin, 2014.

14. Gaurav, A. et.al, Improvement of Fracturing for Gas Shales. RPSEA Final Report 07122-38, August 2012.

15. Gu, H and Leung, K.H, 3D Numerical simulation of Hydraulic Fracturing Closure with Application to Mini-fracture Analysis. JPT, p:206-11, 1993.

16. H.K. Van Poolen, Theory of hydraulic Fracturing? Haliburton Oil Well cementing company, 1952.

17. Jorge Nocedeal and Stephen J. Wright, Numerical Optimization. 1999

18. Jia-Jyun dong et.al, Stress-dependent of the permeability and porosity of sandstone and shale from TCDP Hole-A. Int. Journal of Rock Mechanics and Mining Sciences, 47:1141-57, July 2010.

19. Jianchun Guo et.al, Analytical analysis of fracture conductivity for sparse distribution of proppant packs. J. Geophysics Eng. 14: 599-610, 2017.

20. Kewen Li et.al, New Mathematical Models for Calculating Proppant Embedment and Fracture Conductivity. SPE 155954, SPE Annual Technical Conference and Exhibition, San Antonio, TX, US, August 2014. 
21. King G.E. Thirsty Years of Gas Shale Fracturing: What Have We Learned? SPE 133456, SPE Annual Technical Conference and Exhibition, Florence, Italy, Sep 19-22, 2010 .

22. McDaniel Robert R. and John R, Willingham, The Effect of Various Proppants and Proppant Mixtures on Fracture Permeability. SPE 7573, Annual Fall Technical Conference and Exhibition held in Houston, Texas, US, October 1-3, 1978.

23. Michael J. Economides and Tony Martin, Modern Fracturing: Enhance Natural Gas Production. ET Publishing, 2007.

24. Ming Fan et.al, Investigation of the conductivity of a proppant mixture using an experiment/simulation-integrated approach. Journal of Natural Gas Science and Engineering, Vol 78, June 2020.

25. Ming Gu, Shale Fracturing Enhancement by Using Polymer-Free Foams and UltraLight Weight Proppants. The University of Texas at Austin, 2013.

26. M. Mota et.al, Effect of Real Particles Packing with Large Data Size Ratio on Porosity and Tortuosity of Filter Bed. University of Minho, Braga, Portugal, 2001.

27. M. Mota et.al, Binary spherical particle mixed beds: Porosity and Permeability Relationship Measurement. The journal of the Filtration Society, Vol 1: 101-06, July 2001.

28. Mohammed Mehdi Ahmadi et.al, Analytical derivation of tortuosity and permeability of mono-sized spheres: A volume average approach. Physical Review E83, 026312, February 2011.

29. M.R. Brake, An analytical elastic-perfectly plastic contact model. International Journal of Solids and Structures 49:3129-41, July 2012. 
30. Naomi A. Ogolo et.al, Effect of Grain Size on Porosity Revisited. SPE 178296-MS, Nigeria Annual International Conference and Exhibition, Lagos, Nigeria, August 4-6, 2015.

31. Nelio Henderson et.al, A three-parameter Kozeny-Carman generalized equation for fractal porous media. Chemical Engineering Science 65: 4432-42, April 2010.

32. Nordgren, R.P, Propagation of a Vertical Hydraulic Fracture. SPE Journal, 253:306-14, 1972.

33. Olena Babak and Jonah Resnick, On the Use of Particle-Size-Distribution Data for Permeability Prediction. SPE Reservoir Evaluation and Engineering, February 2016.

34. Optimization toolbox documentation, MATLAB® (version 2019b), 2019.

35. Panda, Manmath N. and Larry W. Lake, Estimation of Single-Phase Permeability from Parameters of Particle Size Distribution. AAPG Bulletin, Vol. 78, No. 7, pp. 1028-1039.

36. Perkins, T.K and Kern, L.R, Widths of Hydraulic Fractures. Journal of Petroleum Technology, 13:937-49, 1961

37. Ricardo Dias et.al, Tortuosity variation in a low density binary particulate bed. Separation Purification Technology, 51: 180-84, 2006.

38. Valentin L. Popov, Contact Mechanics and Friction. Springer, 2010.

39. W.J. Stronge, Impact Mechanics. Cambridge University Press, 2000.

40. Yuanping Gao et.al, New Mathematical Models for Calculating the Proppant Embedment and Conductivity. SPE 155954, International Petroleum Technology Conference, San Antonio, TX, US. October 8-10, 2012.

41. Zoback, Mark D., Reservoir Geomechanics. Cambridge University Press, New York, 2010. 


\section{APPENDIX}

\section{FRACPRO® database}

The FRACPRO® database used in this thesis is selected for all available 20/40 sand, 20/40 ceramic, 40/70 sand and 40/70 ceramic from the public FRACPRO ${ }^{\circledR}$ database (located in FRACPRO® commercial software). Selection is based on similarity in measurement conditions compared to Eric's experiment conditions (for example: $2 \mathrm{lb} / \mathrm{ft}^{2}$ proppant concentration, applied stress range, temperature, tested fluid)

1. FRACPRO® database for $20 / 40$ sand (table 7 )

\begin{tabular}{|c|c|c|c|c|c|c|}
\hline \multicolumn{7}{|c|}{ Arizona } \\
\hline $\begin{array}{l}\text { Effective stress } \\
\text { ( psi) }\end{array}$ & $\begin{array}{l}\text { Permeability } \\
\text { (D) }\end{array}$ & $\begin{array}{l}\text { Perm at } \\
\text { Reservoir } \\
\text { Temp } \\
\text { (D) }\end{array}$ & $\begin{array}{l}\text { Average } \\
\text { Width } \\
\text { (in) }\end{array}$ & $\begin{array}{c}\text { Average } \\
\text { Width after } \\
\text { Embedment } \\
\text { (in) }\end{array}$ & $\begin{array}{l}\text { Conductivity } \\
\text { after } \\
\text { Embedment } \\
(\mathrm{mD} \cdot \mathrm{ft})\end{array}$ & $\begin{array}{l}\text { Beta Factor } \\
\left(\mathrm{atm} \cdot \mathrm{s}^{2} / \mathrm{g}\right)\end{array}$ \\
\hline 0 & 315 & 315 & 0.2406 & 0.23 & $5,956.30$ & 0.000155 \\
\hline 2,000 & 274.3 & 274.3 & 0.235 & 0.22 & $5,058.70$ & 0.00018 \\
\hline 4,000 & 153.956 & 150.021 & 0.2294 & 0.22 & $2,696.70$ & 0.000338 \\
\hline 6,000 & 79.595 & 68.615 & 0.2238 & 0.2101 & $1,201.40$ & 0.000694 \\
\hline 8,000 & 33.997 & 26.147 & 0.2182 & 0.2045 & 445.6 & 0.001755 \\
\hline 10,000 & 9.4 & 8.145 & 0.2126 & 0.1989 & 135 & 0.007123 \\
\hline 12,000 & 2.599 & 2.482 & 0.207 & 0.1933 & 40 & 0.028915 \\
\hline 14,000 & 0.719 & 0.687 & 0.2014 & 0.1877 & 10.7 & 0.117305 \\
\hline 16,000 & 0.199 & 0.19 & 0.1958 & 0.1821 & 2.9 & 0.475658 \\
\hline 18,000 & 0.055 & 0.053 & 0.1902 & 0.1765 & 0.8 & 1.931716 \\
\hline 20,000 & 0.015 & 0.014 & 0.1846 & 0.1709 & 0.2 & 7.959611 \\
\hline \multicolumn{7}{|c|}{ Jordan } \\
\hline $\begin{array}{l}\text { Effective stress } \\
\text { ( psi) }\end{array}$ & $\begin{array}{l}\text { Permeability } \\
\text { (D) }\end{array}$ & $\begin{array}{l}\text { Perm at } \\
\text { Reservoir } \\
\text { Temp } \\
\text { (D) }\end{array}$ & $\begin{array}{l}\text { Average } \\
\text { Width } \\
\text { (in) }\end{array}$ & $\begin{array}{c}\text { Average } \\
\text { Width after } \\
\text { Embedment } \\
\text { (in) }\end{array}$ & $\begin{array}{l}\text { Conductivity } \\
\text { after } \\
\text { Embedment } \\
(\mathrm{mD} \cdot \mathrm{ft})\end{array}$ & $\begin{array}{l}\text { Beta Factor } \\
\left(\mathrm{atm} \cdot \mathrm{s}^{2} / \mathrm{g}\right)\end{array}$ \\
\hline 0 & 273.212 & 273.212 & 0.2297 & 0.2185 & $4,974.00$ & 0.000152 \\
\hline 2,000 & 244.538 & 244.538 & 0.2266 & 0.2154 & $4,389.80$ & 0.000172 \\
\hline 4,000 & 174.534 & 170.073 & 0.2236 & 0.2124 & $3,009.80$ & 0.000251 \\
\hline 6,000 & 89.229 & 76.92 & 0.2205 & 0.2093 & $1,341.70$ & 0.000532 \\
\hline 8,000 & 36.049 & 27.726 & 0.2175 & 0.2063 & 476.5 & 0.001463 \\
\hline 10,000 & 14.564 & 12.62 & 0.2144 & 0.2032 & 213.7 & 0.004024 \\
\hline 12,000 & 5.884 & 5.62 & 0.2114 & 0.2001 & 93.7 & 0.011072 \\
\hline
\end{tabular}




\begin{tabular}{|c|c|c|c|c|c|c|}
\hline 14,000 & 2.377 & 2.271 & 0.2083 & 0.1971 & 37.3 & 0.030464 \\
\hline 16,000 & 0.96 & 0.917 & 0.2053 & 0.194 & 14.8 & 0.083816 \\
\hline 18,000 & 0.388 & 0.371 & 0.2022 & 0.191 & 5.9 & 0.230604 \\
\hline 20,000 & 0.157 & 0.15 & 0.1991 & 0.1879 & 2.3 & 0.634468 \\
\hline \multicolumn{7}{|c|}{ Ottawa } \\
\hline $\begin{array}{l}\text { Effective stress } \\
\qquad(\mathrm{psi})\end{array}$ & $\begin{array}{l}\text { Permeability } \\
\text { (D) }\end{array}$ & $\begin{array}{l}\text { Perm at } \\
\text { Reservoir } \\
\text { Temp } \\
\text { (D) }\end{array}$ & $\begin{array}{l}\text { Average } \\
\text { Width } \\
\text { (in) }\end{array}$ & $\begin{array}{c}\text { Average } \\
\text { Width after } \\
\text { Embedment } \\
\text { (in) }\end{array}$ & $\begin{array}{l}\text { Conductivity } \\
\text { after } \\
\text { Embedment } \\
(\mathrm{mD} \cdot \mathrm{ft})\end{array}$ & $\begin{array}{l}\text { Beta Factor } \\
\left(\mathrm{atm} \cdot \mathrm{s}^{2} / \mathrm{g}\right)\end{array}$ \\
\hline 0 & 273.212 & 273.212 & 0.2297 & 0.2185 & $4,974.00$ & 0.000152 \\
\hline 2,000 & 244.538 & 244.538 & 0.2266 & 0.2154 & $4,389.80$ & 0.000172 \\
\hline 4,000 & 174.534 & 170.073 & 0.2236 & 0.2124 & $3,009.80$ & 0.000251 \\
\hline 6,000 & 89.229 & 76.92 & 0.2205 & 0.2093 & $1,341.70$ & 0.000532 \\
\hline 8,000 & 36.049 & 27.726 & 0.2175 & 0.2063 & 476.5 & 0.001463 \\
\hline 10,000 & 14.564 & 12.62 & 0.2144 & 0.2032 & 213.7 & 0.004024 \\
\hline 12,000 & 5.884 & 5.62 & 0.2114 & 0.2001 & 93.7 & 0.011072 \\
\hline 14,000 & 2.377 & 2.271 & 0.2083 & 0.1971 & 37.3 & 0.030464 \\
\hline 16,000 & 0.96 & 0.917 & 0.2053 & 0.194 & 14.8 & 0.083816 \\
\hline 18,000 & 0.388 & 0.371 & 0.2022 & 0.191 & 5.9 & 0.230604 \\
\hline 20,000 & 0.157 & 0.15 & 0.1991 & 0.1879 & 2.3 & 0.634468 \\
\hline \multicolumn{7}{|c|}{ Boss } \\
\hline $\begin{array}{l}\text { Effective stress } \\
\qquad(\text { psi) }\end{array}$ & $\begin{array}{l}\text { Permeability } \\
\text { (D) }\end{array}$ & $\begin{array}{l}\text { Perm at } \\
\text { Reservoir } \\
\text { Temp } \\
\text { (D) }\end{array}$ & $\begin{array}{l}\text { Average } \\
\text { Width } \\
\text { (in) }\end{array}$ & $\begin{array}{c}\text { Average } \\
\text { Width after } \\
\text { Embedment } \\
\text { (in) }\end{array}$ & $\begin{array}{l}\text { Conductivity } \\
\text { after } \\
\text { Embedment } \\
(\mathrm{mD} \cdot \mathrm{ft})\end{array}$ & $\begin{array}{l}\text { Beta Factor } \\
\left(\mathrm{atm} \cdot \mathrm{s}^{2} / \mathrm{g}\right)\end{array}$ \\
\hline 0 & 244.586 & 244.586 & 0.2314 & 0.2201 & $4,487.10$ & 0.000171 \\
\hline 2,000 & 209.18 & 209.18 & 0.2275 & 0.2162 & $3,768.50$ & 0.000202 \\
\hline 4,000 & 123.5 & 120.343 & 0.2236 & 0.2122 & $2,128.30$ & 0.000359 \\
\hline 6,000 & 56.975 & 49.115 & 0.2195 & 0.2083 & 852.4 & 0.000834 \\
\hline 8,000 & 26.65 & 20.497 & 0.2156 & 0.2043 & 349 & 0.001907 \\
\hline 10,000 & 12.466 & 10.801 & 0.2116 & 0.2003 & 180.3 & 0.004363 \\
\hline 12,000 & 5.831 & 5.569 & 0.2076 & 0.1964 & 91.1 & 0.00998 \\
\hline 14,000 & 2.727 & 2.605 & 0.2037 & 0.1924 & 41.8 & 0.022829 \\
\hline 16,000 & 1.276 & 1.218 & 0.1997 & 0.1885 & 19.1 & 0.052221 \\
\hline 18,000 & 0.597 & 0.57 & 0.1958 & 0.1845 & 8.8 & 0.119456 \\
\hline 20,000 & 0.279 & 0.267 & 0.1918 & 0.1805 & 4 & 0.273254 \\
\hline \multicolumn{7}{|c|}{ Brady } \\
\hline $\begin{array}{l}\text { Effective stress } \\
\text { ( psi) }\end{array}$ & $\begin{array}{l}\text { Permeability } \\
\text { (D) }\end{array}$ & $\begin{array}{l}\text { Perm at } \\
\text { Reservoir } \\
\text { Temp } \\
\text { (D) }\end{array}$ & $\begin{array}{l}\text { Average } \\
\text { Width } \\
\text { (in) }\end{array}$ & $\begin{array}{c}\text { Average } \\
\text { Width after } \\
\text { Embedment } \\
\text { (in) }\end{array}$ & $\begin{array}{l}\text { Conductivity } \\
\text { after } \\
\text { Embedment } \\
(\mathrm{mD} \cdot \mathrm{ft})\end{array}$ & $\begin{array}{l}\text { Beta Factor } \\
\left(\mathrm{atm} \cdot \mathrm{s}^{2} / \mathrm{g}\right)\end{array}$ \\
\hline 0 & 311.366 & 311.366 & 0.2304 & 0.2177 & $5,649.30$ & 0.000139 \\
\hline
\end{tabular}




\begin{tabular}{|c|c|c|c|c|c|c|}
\hline 2,000 & 255.787 & 255.787 & 0.227 & 0.2144 & $4,569.10$ & 0.000172 \\
\hline 4,000 & 141.3 & 137.688 & 0.2236 & 0.211 & $2,420.80$ & 0.000326 \\
\hline 6,000 & 61.687 & 53.177 & 0.2203 & 0.2076 & 920 & 0.000795 \\
\hline 8,000 & 31.1 & 23.919 & 0.2169 & 0.2043 & 407.1 & 0.001662 \\
\hline 10,000 & 16.13 & 13.977 & 0.2135 & 0.2009 & 234 & 0.003372 \\
\hline 12,000 & 8.366 & 7.991 & 0.2102 & 0.1975 & 131.5 & 0.006838 \\
\hline 14,000 & 4.339 & 4.144 & 0.2068 & 0.1941 & 67 & 0.013869 \\
\hline 16,000 & 2.25 & 2.149 & 0.2034 & 0.1908 & 34.2 & 0.028128 \\
\hline 18,000 & 1.167 & 1.115 & 0.2001 & 0.1874 & 17.4 & 0.057048 \\
\hline 20,000 & 0.605 & 0.578 & 0.1967 & 0.184 & 8.9 & 0.115701 \\
\hline \multicolumn{7}{|c|}{ Poland } \\
\hline $\begin{array}{l}\text { Effective stress } \\
\text { ( psi) }\end{array}$ & $\begin{array}{l}\text { Permeability } \\
\text { (D) }\end{array}$ & $\begin{array}{l}\text { Perm at } \\
\text { Reservoir } \\
\text { Temp } \\
\text { (D) }\end{array}$ & $\begin{array}{l}\text { Average } \\
\text { Width } \\
\text { (in) }\end{array}$ & $\begin{array}{c}\text { Average } \\
\text { Width after } \\
\text { Embedment } \\
\text { (in) }\end{array}$ & $\begin{array}{l}\text { Conductivity } \\
\text { after } \\
\text { Embedment } \\
(\mathrm{mD} \cdot \mathrm{ft})\end{array}$ & $\begin{array}{l}\text { Beta Factor } \\
\left(\mathrm{atm} \cdot \mathrm{s}^{2} / \mathrm{g}\right)\end{array}$ \\
\hline 0 & 326.382 & 326.382 & 0.2348 & 0.2234 & $6,076.60$ & 0.000128 \\
\hline 2,000 & 253.86 & 253.86 & 0.2315 & 0.2201 & $4,656.60$ & 0.000167 \\
\hline 4,000 & 127.62 & 124.358 & 0.2282 & 0.2168 & $2,246.90$ & 0.000348 \\
\hline 6,000 & 48.63 & 41.921 & 0.2249 & 0.2135 & 745.9 & 0.000968 \\
\hline 8,000 & 22.92 & 17.628 & 0.2216 & 0.2102 & 308.8 & 0.002152 \\
\hline 10,000 & 10.803 & 9.36 & 0.2183 & 0.2069 & 161.4 & 0.004784 \\
\hline 12,000 & 5.091 & 4.863 & 0.215 & 0.2036 & 82.5 & 0.010636 \\
\hline 14,000 & 2.4 & 2.292 & 0.2117 & 0.2003 & 38.3 & 0.023642 \\
\hline 16,000 & 1.131 & 1.08 & 0.2084 & 0.197 & 17.7 & 0.052556 \\
\hline 18,000 & 0.533 & 0.509 & 0.2051 & 0.1937 & 8.2 & 0.116828 \\
\hline 20,000 & 0.251 & 0.24 & 0.2018 & 0.1904 & 3.8 & 0.259703 \\
\hline \multicolumn{7}{|c|}{ Accupak } \\
\hline $\begin{array}{l}\text { Effective stress } \\
\text { ( psi) }\end{array}$ & $\begin{array}{l}\text { Permeability } \\
\text { (D) }\end{array}$ & $\begin{array}{l}\text { Perm at } \\
\text { Reservoir } \\
\text { Temp } \\
\text { (D) }\end{array}$ & $\begin{array}{l}\text { Average } \\
\text { Width } \\
\text { (in) }\end{array}$ & $\begin{array}{c}\text { Average } \\
\text { Width after } \\
\text { Embedment } \\
\text { (in) }\end{array}$ & $\begin{array}{l}\text { Conductivity } \\
\text { after } \\
\text { Embedment } \\
(\mathrm{mD} \cdot \mathrm{ft})\end{array}$ & $\begin{array}{l}\text { Beta Factor } \\
\left(\mathrm{atm} \cdot \mathrm{s}^{2} / \mathrm{g}\right)\end{array}$ \\
\hline 0 & 402.545 & 402.545 & 0.2311 & 0.2184 & $7,327.80$ & 0.000113 \\
\hline 2,000 & 368.61 & 368.61 & 0.228 & 0.2154 & $6,615.10$ & 0.000125 \\
\hline 4,000 & 257.667 & 251.081 & 0.225 & 0.2123 & $4,441.30$ & 0.000186 \\
\hline 6,000 & 129.437 & 111.581 & 0.2219 & 0.2092 & $1,945.00$ & 0.000401 \\
\hline 8,000 & 57.122 & 43.933 & 0.2188 & 0.2061 & 754.5 & 0.000997 \\
\hline 10,000 & 25.209 & 21.843 & 0.2157 & 0.203 & 369.5 & 0.00248 \\
\hline 12,000 & 11.125 & 10.626 & 0.2126 & 0.1999 & 177 & 0.006164 \\
\hline 14,000 & 4.91 & 4.689 & 0.2095 & 0.1968 & 76.9 & 0.015324 \\
\hline 16,000 & 2.167 & 2.069 & 0.2064 & 0.1937 & 33.4 & 0.038096 \\
\hline 18,000 & 0.956 & 0.913 & 0.2033 & 0.1906 & 14.5 & 0.094707 \\
\hline 20,000 & 0.422 & 0.403 & 0.2002 & 0.1875 & 6.3 & 0.235445 \\
\hline
\end{tabular}


2. FRACPRO ${ }^{\circ}$ database for $20 / 40$ ceramic (table 8 )

\begin{tabular}{|c|c|c|c|c|c|c|}
\hline \multicolumn{7}{|c|}{ Carbolite } \\
\hline $\begin{array}{l}\text { Effective stress } \\
\quad(\mathrm{psi})\end{array}$ & $\begin{array}{l}\text { Permeability } \\
\text { (D) }\end{array}$ & $\begin{array}{l}\text { Perm at Reservoir } \\
\text { Temp } \\
\text { (D) }\end{array}$ & $\begin{array}{l}\text { Average } \\
\text { Width } \\
\text { (in) }\end{array}$ & $\begin{array}{l}\text { Average Width } \\
\text { after } \\
\text { Embedment } \\
\text { (in) }\end{array}$ & $\begin{array}{c}\text { Conductivity after } \\
\text { Embedment } \\
(\mathrm{mD} \cdot \mathrm{ft})\end{array}$ & $\begin{array}{l}\text { Beta Factor } \\
\left(\mathrm{atm} \cdot \mathrm{s}^{2} / \mathrm{g}\right)\end{array}$ \\
\hline 0 & 540 & 540 & 0.2339 & 0.22 & $9,871.20$ & 0.000095 \\
\hline 2,000 & 507.6 & 507.6 & 0.2338 & 0.22 & $9,275.80$ & 0.000102 \\
\hline 4,000 & 406.761 & 406.761 & 0.2337 & 0.22 & $7,430.60$ & 0.00013 \\
\hline 6,000 & 332.621 & 332.621 & 0.2336 & 0.2191 & $6,074.20$ & 0.000163 \\
\hline 8,000 & 196.022 & 196.022 & 0.2336 & 0.2191 & $3,578.50$ & 0.000291 \\
\hline 10,000 & 112.061 & 112.061 & 0.2335 & 0.219 & $2,045.00$ & 0.00054 \\
\hline 12,000 & 77.546 & 77.546 & 0.2334 & 0.2189 & $1,414.70$ & 0.00081 \\
\hline 14,000 & 53.662 & 53.662 & 0.2333 & 0.2188 & 978.6 & 0.001215 \\
\hline 16,000 & 37.134 & 37.134 & 0.2333 & 0.2188 & 677 & 0.001824 \\
\hline 18,000 & 25.697 & 25.697 & 0.2332 & 0.2187 & 468.3 & 0.002738 \\
\hline 20,000 & 17.782 & 17.782 & 0.2331 & 0.2186 & 324 & 0.004109 \\
\hline \multicolumn{7}{|c|}{ Carboprop } \\
\hline $\begin{array}{l}\text { Effective stress } \\
\quad(\mathrm{psi})\end{array}$ & $\begin{array}{l}\text { Permeability } \\
\text { (D) }\end{array}$ & $\begin{array}{l}\text { Perm at Reservoir } \\
\text { Temp } \\
\text { (D) }\end{array}$ & $\begin{array}{l}\text { Average } \\
\text { Width } \\
\text { (in) }\end{array}$ & $\begin{array}{l}\text { Average Width } \\
\text { after } \\
\text { Embedment } \\
\text { (in) }\end{array}$ & $\begin{array}{l}\text { Conductivity after } \\
\text { Embedment } \\
(\mathrm{mD} \cdot \mathrm{ft})\end{array}$ & $\begin{array}{l}\text { Beta Factor } \\
\left(\mathrm{atm} \cdot \mathrm{s}^{2} / \mathrm{g}\right)\end{array}$ \\
\hline 0 & 443.563 & 443.563 & 0.1976 & 0.1841 & $6,803.80$ & 0.000104 \\
\hline 2,000 & 416.49 & 416.49 & 0.1966 & 0.183 & $6,351.50$ & 0.000112 \\
\hline 4,000 & 359.25 & 359.25 & 0.1955 & 0.1819 & $5,446.70$ & 0.00013 \\
\hline 6,000 & 305.789 & 305.789 & 0.1944 & 0.1809 & $4,609.00$ & 0.000154 \\
\hline 8,000 & 238.78 & 238.78 & 0.1934 & 0.1798 & $3,577.80$ & 0.0002 \\
\hline 10,000 & 173.29 & 173.29 & 0.1923 & 0.1787 & $2,581.10$ & 0.000281 \\
\hline 12,000 & 127.572 & 127.572 & 0.1912 & 0.1777 & $1,888.80$ & 0.000388 \\
\hline 14,000 & 106.23 & 106.23 & 0.1902 & 0.1766 & $1,563.40$ & 0.00047 \\
\hline 16,000 & 88.458 & 88.458 & 0.1891 & 0.1755 & $1,294.00$ & 0.00057 \\
\hline 18,000 & 73.66 & 73.66 & 0.188 & 0.1745 & $1,071.00$ & 0.000692 \\
\hline 20,000 & 61.337 & 61.337 & 0.187 & 0.1734 & 886.4 & 0.000839 \\
\hline \multicolumn{7}{|c|}{ Econoprop } \\
\hline $\begin{array}{l}\text { Effective stress } \\
\quad \text { ( psi) }\end{array}$ & $\begin{array}{l}\text { Permeability } \\
\text { (D) }\end{array}$ & $\begin{array}{l}\text { Perm at Reservoir } \\
\text { Temp } \\
\text { (D) }\end{array}$ & $\begin{array}{l}\text { Average } \\
\text { Width } \\
\text { (in) }\end{array}$ & $\begin{array}{l}\text { Average Width } \\
\text { after } \\
\text { Embedment } \\
\text { (in) }\end{array}$ & $\begin{array}{l}\text { Conductivity after } \\
\text { Embedment } \\
(\mathrm{mD} \cdot \mathrm{ft})\end{array}$ & $\begin{array}{c}\text { Beta Factor } \\
\left(\mathrm{atm} \cdot \mathrm{s}^{2} / \mathrm{g}\right)\end{array}$ \\
\hline 0 & 441.273 & 441.273 & 0.2382 & 0.2252 & $8,281.60$ & 0.000104 \\
\hline 2,000 & 396.297 & 396.297 & 0.2359 & 0.2229 & $7,360.60$ & 0.000118 \\
\hline 4,000 & 302.391 & 302.391 & 0.2336 & 0.2206 & $5,557.80$ & 0.000158 \\
\hline 6,000 & 200.974 & 200.974 & 0.2312 & 0.2182 & $3,654.80$ & 0.000245 \\
\hline 8,000 & 120.974 & 120.974 & 0.2289 & 0.2159 & $2,176.50$ & 0.000422 \\
\hline
\end{tabular}




\begin{tabular}{|c|c|c|c|c|c|c|}
\hline 10,000 & 69 & 69 & 0.2266 & 0.2136 & $1,228.00$ & 0.000771 \\
\hline 12,000 & 39.25 & 39.25 & 0.2242 & 0.2112 & 690.9 & 0.001412 \\
\hline 14,000 & 22.327 & 22.327 & 0.2219 & 0.2089 & 388.7 & 0.002588 \\
\hline 16,000 & 12.7 & 12.7 & 0.2196 & 0.2066 & 218.6 & 0.004744 \\
\hline 18,000 & 7.225 & 7.225 & 0.2173 & 0.2043 & 123 & 0.008693 \\
\hline 20,000 & 4.11 & 4.11 & 0.2149 & 0.2019 & 69.2 & 0.015932 \\
\hline \multicolumn{7}{|c|}{ Naplite } \\
\hline $\begin{array}{l}\text { Effective stress } \\
\text { ( psi) }\end{array}$ & $\begin{array}{l}\text { Permeability } \\
\text { (D) }\end{array}$ & $\begin{array}{l}\text { Perm at Reservoir } \\
\text { Temp } \\
\text { (D) }\end{array}$ & $\begin{array}{l}\text { Average } \\
\text { Width } \\
\text { (in) }\end{array}$ & $\begin{array}{l}\text { Average Width } \\
\text { after } \\
\text { Embedment } \\
\text { (in) }\end{array}$ & $\begin{array}{l}\text { Conductivity after } \\
\text { Embedment } \\
(\mathrm{mD} \cdot \mathrm{ft})\end{array}$ & $\begin{array}{l}\text { Beta Factor } \\
\left(\mathrm{atm} \cdot \mathrm{s}^{2} / \mathrm{g}\right)\end{array}$ \\
\hline 0 & 540 & 540 & 0.2405 & 0.2262 & $10,181.00$ & 0.000094 \\
\hline 2,000 & 510.222 & 510.222 & 0.2388 & 0.2245 & $9,546.20$ & 0.0001 \\
\hline 4,000 & 410.376 & 410.376 & 0.2371 & 0.2228 & $7,619.00$ & 0.000127 \\
\hline 6,000 & 299.008 & 299.008 & 0.2354 & 0.2211 & $5,508.40$ & 0.00018 \\
\hline 8,000 & 183.897 & 183.897 & 0.2336 & 0.2193 & $3,361.30$ & 0.000307 \\
\hline 10,000 & 100.05 & 100.05 & 0.2319 & 0.2176 & $1,814.40$ & 0.000601 \\
\hline 12,000 & 76.5 & 76.5 & 0.2302 & 0.2159 & $1,376.30$ & 0.000809 \\
\hline 14,000 & 58.493 & 58.493 & 0.2285 & 0.2142 & $1,043.90$ & 0.001087 \\
\hline 16,000 & 44.725 & 44.725 & 0.2267 & 0.2124 & 791.8 & 0.001461 \\
\hline 18,000 & 34.198 & 34.198 & 0.225 & 0.2107 & 600.5 & 0.001964 \\
\hline 20,000 & 26.148 & 26.148 & 0.2233 & 0.209 & 455.4 & 0.00264 \\
\hline \multicolumn{7}{|c|}{ Sinter Ball Bauxite } \\
\hline $\begin{array}{l}\text { Effective stress } \\
\text { ( psi) }\end{array}$ & $\begin{array}{l}\text { Permeability } \\
\text { (D) }\end{array}$ & $\begin{array}{l}\text { Perm at Reservoir } \\
\text { Temp } \\
\text { (D) }\end{array}$ & $\begin{array}{l}\text { Average } \\
\text { Width } \\
\text { (in) }\end{array}$ & $\begin{array}{l}\text { Average Width } \\
\text { after } \\
\text { Embedment } \\
\text { (in) }\end{array}$ & $\begin{array}{l}\text { Conductivity after } \\
\text { Embedment } \\
(\mathrm{mD} \cdot \mathrm{ft})\end{array}$ & $\begin{array}{l}\text { Beta Factor } \\
\left(\mathrm{atm} \cdot \mathrm{s}^{2} / \mathrm{g}\right)\end{array}$ \\
\hline 0 & 511.855 & 511.855 & 0.1856 & 0.1723 & $7,349.20$ & 0.000094 \\
\hline 2,000 & 491.655 & 491.655 & 0.1847 & 0.1714 & $7,022.00$ & 0.000098 \\
\hline 4,000 & 403.975 & 403.975 & 0.1838 & 0.1705 & $5,739.10$ & 0.000119 \\
\hline 6,000 & 344.477 & 344.477 & 0.1829 & 0.1696 & $4,867.80$ & 0.000141 \\
\hline 8,000 & 291.475 & 291.475 & 0.182 & 0.1687 & $4,096.70$ & 0.000167 \\
\hline 10,000 & 226.275 & 226.275 & 0.1811 & 0.1678 & $3,163.20$ & 0.000217 \\
\hline 12,000 & 162.795 & 162.795 & 0.1802 & 0.1668 & $2,263.50$ & 0.000304 \\
\hline 14,000 & 135.7 & 135.7 & 0.1793 & 0.1659 & $1,876.50$ & 0.000367 \\
\hline 16,000 & 113.115 & 113.115 & 0.1784 & 0.165 & $1,555.60$ & 0.000443 \\
\hline 18,000 & 94.288 & 94.288 & 0.1775 & 0.1641 & $1,289.50$ & 0.000534 \\
\hline 20,000 & 78.595 & 78.595 & 0.1766 & 0.1632 & $1,069.00$ & 0.000644 \\
\hline \multicolumn{7}{|c|}{ CarboHSP } \\
\hline $\begin{array}{l}\text { Effective stress } \\
\text { ( psi) }\end{array}$ & $\begin{array}{l}\text { Permeability } \\
\text { (D) }\end{array}$ & $\begin{array}{l}\text { Perm at Reservoir } \\
\text { Temp } \\
\text { (D) }\end{array}$ & $\begin{array}{l}\text { Average } \\
\text { Width } \\
\text { (in) }\end{array}$ & $\begin{array}{l}\text { Average Width } \\
\text { after } \\
\text { Embedment } \\
\text { (in) }\end{array}$ & $\begin{array}{l}\text { Conductivity after } \\
\text { Embedment } \\
(\mathrm{mD} \cdot \mathrm{ft})\end{array}$ & $\begin{array}{l}\text { Beta Factor } \\
\left(\mathrm{atm} \cdot \mathrm{s}^{2} / \mathrm{g}\right)\end{array}$ \\
\hline
\end{tabular}




\begin{tabular}{|c|c|c|c|c|c|c|}
\hline 0 & 542.261 & 542.261 & 0.1892 & 0.175 & $7,908.40$ & 0.000094 \\
\hline 2,000 & 502.604 & 502.604 & 0.1867 & 0.1725 & $7,225.60$ & 0.000101 \\
\hline 4,000 & 436.547 & 436.547 & 0.1842 & 0.17 & $6,185.10$ & 0.000117 \\
\hline 6,000 & 359.627 & 359.627 & 0.1817 & 0.1675 & $5,020.50$ & 0.000143 \\
\hline 8,000 & 272.174 & 272.174 & 0.1792 & 0.165 & $3,743.10$ & 0.00019 \\
\hline 10,000 & 201.534 & 201.534 & 0.1767 & 0.1625 & $2,729.70$ & 0.000259 \\
\hline 12,000 & 157.279 & 157.279 & 0.1742 & 0.16 & $2,097.60$ & 0.000334 \\
\hline 14,000 & 158.323 & 158.323 & 0.1718 & 0.1575 & $2,078.60$ & 0.000331 \\
\hline 16,000 & 159.374 & 159.374 & 0.1693 & 0.155 & $2,059.20$ & 0.000329 \\
\hline 18,000 & 160.432 & 160.432 & 0.1668 & 0.1526 & $2,039.60$ & 0.000327 \\
\hline 20,000 & 161.497 & 161.497 & 0.1643 & 0.1501 & $2,019.50$ & 0.000325 \\
\hline
\end{tabular}

3. FRACPRO® database for $40 / 70$ sand (table 9)

\begin{tabular}{|c|c|c|c|c|c|c|}
\hline \multicolumn{7}{|c|}{ Arizona } \\
\hline $\begin{array}{l}\text { Effective stress } \\
\text { ( psi) }\end{array}$ & $\begin{array}{l}\text { Permeability } \\
\text { (D) }\end{array}$ & $\begin{array}{l}\text { Perm at } \\
\text { Reservoir Temp } \\
\text { (D) }\end{array}$ & $\begin{array}{l}\text { Average } \\
\text { Width } \\
\text { (in) }\end{array}$ & $\begin{array}{l}\text { Average Width } \\
\text { after } \\
\text { Embedment } \\
\text { (in) }\end{array}$ & $\begin{array}{l}\text { Conductivity after } \\
\text { Embedment } \\
(\mathrm{mD} \cdot \mathrm{ft})\end{array}$ & $\begin{array}{c}\text { Beta Factor } \\
\left(\mathrm{atm} \cdot \mathrm{s}^{2} / \mathrm{g}\right)\end{array}$ \\
\hline 0 & 62.715 & 62.715 & 0.2366 & 0.23 & $1,209.20$ & 0.000575 \\
\hline 2,000 & 53.495 & 53.495 & 0.2313 & 0.23 & $1,007.80$ & 0.000685 \\
\hline 4,000 & 43.165 & 42.062 & 0.2261 & 0.22 & 773.90 & 0.000867 \\
\hline 6,000 & 32.328 & 27.868 & 0.2208 & 0.2155 & 500.50 & 0.001191 \\
\hline 8,000 & 18.773 & 14.438 & 0.2155 & 0.2102 & 252.9 & 0.002166 \\
\hline 10,000 & 10.15 & 8.795 & 0.2102 & 0.2049 & 150.2 & 0.004259 \\
\hline 12,000 & 5.488 & 5.242 & 0.2049 & 0.1996 & 87.2 & 0.008375 \\
\hline 14,000 & 2.967 & 2.834 & 0.1996 & 0.1944 & 45.9 & 0.016472 \\
\hline 16,000 & 1.604 & 1.532 & 0.1943 & 0.1891 & 24.1 & 0.032397 \\
\hline 18,000 & 0.867 & 0.828 & 0.189 & 0.1838 & 12.7 & 0.06373 \\
\hline 20,000 & 0.469 & 0.448 & 0.1837 & 0.1785 & 6.7 & 0.125259 \\
\hline \multicolumn{7}{|c|}{ Jordan } \\
\hline $\begin{array}{l}\text { Effective stress } \\
\text { ( psi) }\end{array}$ & $\begin{array}{l}\text { Permeability } \\
\text { (D) }\end{array}$ & $\begin{array}{l}\text { Perm at Resvr } \\
\text { Temp } \\
\text { (D) }\end{array}$ & $\begin{array}{l}\text { Avg } \\
\text { Width } \\
\text { (in) }\end{array}$ & $\begin{array}{l}\text { Avg Width after } \\
\text { Embedment } \\
\text { (in) }\end{array}$ & $\begin{array}{l}\text { Conductivity after } \\
\text { Embedment } \\
(\mathrm{mD} \cdot \mathrm{ft})\end{array}$ & $\begin{array}{l}\text { Beta Factor } \\
\left(\mathrm{atm} \cdot \mathrm{s}^{2} / \mathrm{g}\right)\end{array}$ \\
\hline 0 & 92.182 & 92.182 & 0.2318 & 0.2265 & $1,740.20$ & 0.000345 \\
\hline 2,000 & 71.502 & 71.502 & 0.2289 & 0.2237 & $1,332.60$ & 0.000459 \\
\hline 4,000 & 60.731 & 59.179 & 0.2261 & 0.2208 & $1,088.80$ & 0.000552 \\
\hline 6,000 & 45.884 & 39.554 & 0.2232 & 0.2179 & 718.20 & 0.000758 \\
\hline 8,000 & 27.348 & 21.033 & 0.2203 & 0.215 & 376.9 & 0.001359 \\
\hline 10,000 & 16.131 & 13.977 & 0.2174 & 0.2121 & 247.1 & 0.002466 \\
\hline 12,000 & 10.66 & 10.182 & 0.2145 & 0.2093 & 177.5 & 0.003936 \\
\hline 14,000 & 7.073 & 6.756 & 0.2116 & 0.2064 & 116.2 & 0.006254 \\
\hline 16,000 & 4.711 & 4.5 & 0.2088 & 0.2035 & 76.3 & 0.009893 \\
\hline
\end{tabular}




\begin{tabular}{|c|c|c|c|c|c|c|}
\hline 18,000 & 3.15 & 3.009 & 0.2059 & 0.2006 & 50.3 & 0.015581 \\
\hline 20,000 & 2.114 & 2.02 & 0.203 & 0.1977 & 33.3 & 0.024438 \\
\hline \multicolumn{7}{|c|}{ Ottawa } \\
\hline $\begin{array}{l}\text { Effective stress } \\
\qquad(\mathrm{psi})\end{array}$ & $\begin{array}{l}\text { Permeability } \\
\text { (D) }\end{array}$ & $\begin{array}{l}\text { Perm at } \\
\text { Reservoir Temp } \\
\text { (D) }\end{array}$ & $\begin{array}{l}\text { Average } \\
\text { Width } \\
\text { (in) }\end{array}$ & $\begin{array}{l}\text { Average Width } \\
\text { after } \\
\text { Embedment } \\
\text { (in) }\end{array}$ & $\begin{array}{l}\text { Conductivity after } \\
\text { Embedment } \\
(\mathrm{mD} \cdot \mathrm{ft})\end{array}$ & $\begin{array}{l}\text { Beta Factor } \\
\left(\mathrm{atm} \cdot \mathrm{s}^{2} / \mathrm{g}\right)\end{array}$ \\
\hline 0 & 65 & 65 & 0.24 & 0.2344 & $1,269.60$ & 0.000768 \\
\hline 2,000 & 54 & 54 & 0.24 & 0.2344 & $1,054.70$ & 0.000962 \\
\hline 4,000 & 38 & 37.029 & 0.24 & 0.2344 & 723.20 & 0.001478 \\
\hline 6,000 & 23 & 19.827 & 0.24 & 0.2344 & 387.30 & 0.002726 \\
\hline 8,000 & 12 & 9.229 & 0.24 & 0.2344 & 180.3 & 0.00603 \\
\hline 10,000 & 6.261 & 5.425 & 0.24 & 0.2344 & 106 & 0.013336 \\
\hline 12,000 & 3.267 & 3.12 & 0.24 & 0.2344 & 60.9 & 0.029493 \\
\hline 14,000 & 1.704 & 1.628 & 0.24 & 0.2344 & 31.8 & 0.065227 \\
\hline 16,000 & 0.889 & 0.849 & 0.24 & 0.2344 & 16.6 & 0.144257 \\
\hline 18,000 & 0.464 & 0.443 & 0.24 & 0.2344 & 8.7 & 0.319039 \\
\hline 20,000 & 0.242 & 0.231 & 0.24 & 0.2344 & 4.5 & 0.705586 \\
\hline \multicolumn{7}{|c|}{ Badger } \\
\hline $\begin{array}{l}\text { Effective stress } \\
\text { ( psi) }\end{array}$ & $\begin{array}{l}\text { Permeability } \\
\text { (D) }\end{array}$ & $\begin{array}{l}\text { Perm at } \\
\text { Reservoir Temp } \\
\text { (D) }\end{array}$ & $\begin{array}{l}\text { Average } \\
\text { Width } \\
\text { (in) }\end{array}$ & $\begin{array}{l}\text { Average Width } \\
\text { after } \\
\text { Embedment } \\
\text { (in) }\end{array}$ & $\begin{array}{l}\text { Conductivity after } \\
\text { Embedment } \\
(\mathrm{mD} \cdot \mathrm{ft})\end{array}$ & $\begin{array}{l}\text { Beta Factor } \\
\left(\mathrm{atm} \cdot \mathrm{s}^{2} / \mathrm{g}\right)\end{array}$ \\
\hline 0 & 62.715 & 62.715 & 0.2274 & 0.2221 & $1,161.00$ & 0.00056 \\
\hline 2,000 & 53.495 & 53.495 & 0.225 & 0.2197 & 979.60 & 0.00067 \\
\hline 4,000 & 43.165 & 42.062 & 0.2226 & 0.2173 & 761.80 & 0.000854 \\
\hline 6,000 & 32.328 & 27.868 & 0.2202 & 0.2149 & 499.1 & 0.001183 \\
\hline 8,000 & 18.773 & 14.438 & 0.2178 & 0.2125 & 255.7 & 0.002187 \\
\hline 10,000 & 10.15 & 8.795 & 0.2154 & 0.2101 & 154 & 0.00438 \\
\hline 12,000 & 5.488 & 5.242 & 0.213 & 0.2077 & 90.7 & 0.008775 \\
\hline 14,000 & 2.967 & 2.834 & 0.2106 & 0.2053 & 48.5 & 0.017578 \\
\hline 16,000 & 1.604 & 1.532 & 0.2082 & 0.2029 & 25.9 & 0.035213 \\
\hline 18,000 & 0.867 & 0.828 & 0.2058 & 0.2005 & 13.8 & 0.070541 \\
\hline 20,000 & 0.469 & 0.448 & 0.2033 & 0.1981 & 7.4 & 0.141311 \\
\hline \multicolumn{7}{|c|}{ Brady } \\
\hline $\begin{array}{l}\text { Effective stress } \\
\text { ( psi) }\end{array}$ & $\begin{array}{l}\text { Permeability } \\
\text { (D) }\end{array}$ & $\begin{array}{l}\text { Perm at } \\
\text { Reservoir Temp } \\
\text { (D) }\end{array}$ & $\begin{array}{l}\text { Average } \\
\text { Width } \\
\text { (in) }\end{array}$ & $\begin{array}{l}\text { Average Width } \\
\text { after } \\
\text { Embedment } \\
\text { (in) }\end{array}$ & $\begin{array}{l}\text { Conductivity after } \\
\text { Embedment } \\
(\mathrm{mD} \cdot \mathrm{ft})\end{array}$ & $\begin{array}{l}\text { Beta Factor } \\
\left(\mathrm{atm} \cdot \mathrm{s}^{2} / \mathrm{g}\right)\end{array}$ \\
\hline 0 & 83.632 & 83.632 & 0.2297 & 0.2245 & $1,564.50$ & 0.000363 \\
\hline 2,000 & 71.51 & 71.51 & 0.2266 & 0.2213 & $1,318.90$ & 0.000432 \\
\hline 4,000 & 50.745 & 49.448 & 0.2234 & 0.2182 & 899.00 & 0.000631 \\
\hline
\end{tabular}




\begin{tabular}{|c|c|c|c|c|c|c|}
\hline 6,000 & 26.042 & 22.45 & 0.2203 & 0.215 & 402.3 & 0.001319 \\
\hline 8,000 & 13.575 & 10.441 & 0.2171 & 0.2119 & 184.3 & 0.002709 \\
\hline 10,000 & 9.018 & 7.814 & 0.214 & 0.2087 & 135.9 & 0.004257 \\
\hline 12,000 & 5.991 & 5.722 & 0.2108 & 0.2056 & 98 & 0.00669 \\
\hline 14,000 & 3.98 & 3.802 & 0.2077 & 0.2024 & 64.1 & 0.010513 \\
\hline 16,000 & 2.644 & 2.526 & 0.2045 & 0.1993 & 41.9 & 0.016521 \\
\hline 18,000 & 1.757 & 1.678 & 0.2014 & 0.1961 & 27.4 & 0.025962 \\
\hline 20,000 & 1.167 & 1.115 & 0.1982 & 0.193 & 17.9 & 0.040797 \\
\hline \multicolumn{7}{|c|}{ Carbo-northern } \\
\hline $\begin{array}{l}\text { Effective stress } \\
\text { ( psi) }\end{array}$ & $\begin{array}{l}\text { Permeability } \\
\text { (D) }\end{array}$ & $\begin{array}{l}\text { Perm at } \\
\text { Reservoir Temp } \\
\text { (D) }\end{array}$ & $\begin{array}{l}\text { Average } \\
\text { Width } \\
\text { (in) }\end{array}$ & $\begin{array}{l}\text { Average Width } \\
\text { after } \\
\text { Embedment } \\
\text { (in) }\end{array}$ & $\begin{array}{l}\text { Conductivity after } \\
\text { Embedment } \\
(\mathrm{mD} \cdot \mathrm{ft})\end{array}$ & $\begin{array}{l}\text { Beta Factor } \\
\left(\mathrm{atm} \cdot \mathrm{s}^{2} / \mathrm{g}\right)\end{array}$ \\
\hline 0 & 102.43 & 102.43 & 0.2158 & 0.2093 & $1,786.70$ & 0.000306 \\
\hline 2,000 & 56 & 56 & 0.2108 & 0.2043 & 953.50 & 0.000605 \\
\hline 4,000 & 47 & 45.799 & 0.2058 & 0.1993 & 760.70 & 0.000738 \\
\hline 6,000 & 33 & 28.448 & 0.2008 & 0.1943 & 460.7 & 0.001099 \\
\hline 8,000 & 19 & 14.613 & 0.1958 & 0.1893 & 230.5 & 0.00205 \\
\hline 10,000 & 10 & 8.665 & 0.1908 & 0.1843 & 133.1 & 0.00423 \\
\hline 12,000 & 7.527 & 7.189 & 0.1858 & 0.1793 & 107.4 & 0.00583 \\
\hline 14,000 & 4.871 & 4.653 & 0.1808 & 0.1743 & 67.6 & 0.009527 \\
\hline 16,000 & 3.152 & 3.011 & 0.1758 & 0.1693 & 42.5 & 0.01557 \\
\hline 18,000 & 2.04 & 1.949 & 0.1708 & 0.1643 & 26.7 & 0.025444 \\
\hline 20,000 & 1.32 & 1.261 & 0.1658 & 0.1593 & 16.7 & 0.041579 \\
\hline \multicolumn{7}{|c|}{ Frac Sand } \\
\hline $\begin{array}{l}\text { Effective stress } \\
\quad(\mathrm{psi})\end{array}$ & $\begin{array}{l}\text { Permeability } \\
\text { (D) }\end{array}$ & $\begin{array}{l}\text { Perm at } \\
\text { Reservoir Temp } \\
\text { (D) }\end{array}$ & $\begin{array}{l}\text { Average } \\
\text { Width } \\
\text { (in) }\end{array}$ & $\begin{array}{l}\text { Average Width } \\
\text { after } \\
\text { Embedment } \\
\text { (in) }\end{array}$ & $\begin{array}{l}\text { Conductivity after } \\
\text { Embedment } \\
(\mathrm{mD} \cdot \mathrm{ft})\end{array}$ & $\begin{array}{c}\text { Beta Factor } \\
\left(\mathrm{atm} \cdot \mathrm{s}^{2} / \mathrm{g}\right)\end{array}$ \\
\hline 0 & 216.504 & 216.504 & 0.2274 & 0.2221 & $4,007.80$ & 0.000138 \\
\hline 2,000 & 50 & 50 & 0.225 & 0.2197 & 915.60 & 0.000723 \\
\hline 4,000 & 41 & 39.952 & 0.2226 & 0.2173 & 723.60 & 0.000905 \\
\hline 6,000 & 20 & 17.241 & 0.2202 & 0.2149 & 308.80 & 0.002036 \\
\hline 8,000 & 8 & 6.153 & 0.2178 & 0.2125 & 109 & 0.005732 \\
\hline 10,000 & 1 & 0.867 & 0.2154 & 0.2101 & 15.2 & 0.060064 \\
\hline 12,000 & 0.743 & 0.71 & 0.213 & 0.2077 & 12.3 & 0.08404 \\
\hline 14,000 & 0.288 & 0.276 & 0.2106 & 0.2053 & 4.7 & 0.244665 \\
\hline 16,000 & 0.112 & 0.107 & 0.2082 & 0.2029 & 1.8 & 0.712291 \\
\hline 18,000 & 0.044 & 0.042 & 0.2058 & 0.2005 & 0.7 & 2.073684 \\
\hline 20,000 & 0.017 & 0.016 & 0.2033 & 0.1981 & 0.3 & 6.037087 \\
\hline
\end{tabular}

4. FRACPRO $®$ database for $40 / 70$ ceramic (table 10 ) 


\begin{tabular}{|c|c|c|c|c|c|c|}
\hline \multicolumn{7}{|c|}{ Interprop } \\
\hline $\begin{array}{l}\text { Effective stress } \\
\text { ( psi) }\end{array}$ & $\begin{array}{l}\text { Permeability } \\
\text { (D) }\end{array}$ & $\begin{array}{l}\text { Perm at } \\
\text { Reservoir } \\
\text { Temp } \\
\text { (D) }\end{array}$ & $\begin{array}{l}\text { Average } \\
\text { Width } \\
\text { (in) }\end{array}$ & $\begin{array}{l}\text { Average Width } \\
\text { after } \\
\text { Embedment } \\
\text { (in) }\end{array}$ & $\begin{array}{l}\text { Conductivity after } \\
\text { Embedment } \\
(\mathrm{mD} \cdot \mathrm{ft})\end{array}$ & $\begin{array}{l}\text { Beta Factor } \\
\left(\mathrm{atm} \cdot \mathrm{s}^{2} / \mathrm{g}\right)\end{array}$ \\
\hline 0 & 308.016 & 308.016 & 0.2109 & 0.20 & $5,259.90$ & 0.00006 \\
\hline 2,000 & 292.212 & 292.212 & 0.2079 & 0.20 & $4,917.30$ & 0.000064 \\
\hline 4,000 & 248.716 & 248.716 & 0.2049 & 0.20 & $4,123.40$ & 0.000075 \\
\hline 6,000 & 187.932 & 187.932 & 0.2019 & 0.196 & $3,068.90$ & 0.000101 \\
\hline 8,000 & 139.941 & 139.941 & 0.199 & 0.193 & $2,250.40$ & 0.000137 \\
\hline 10,000 & 89.288 & 89.288 & 0.196 & 0.19 & $1,413.60$ & 0.000218 \\
\hline 12,000 & 69.345 & 69.345 & 0.193 & 0.187 & $1,080.60$ & 0.000283 \\
\hline 14,000 & 43.68 & 43.68 & 0.19 & 0.184 & 669.8 & 0.000456 \\
\hline 16,000 & 27.564 & 27.564 & 0.187 & 0.181 & 415.8 & 0.000735 \\
\hline 18,000 & 17.426 & 17.426 & 0.184 & 0.178 & 258.5 & 0.001182 \\
\hline 20,000 & 11.036 & 11.036 & 0.181 & 0.1751 & 161 & 0.001898 \\
\hline \multicolumn{7}{|c|}{ Interprop } \\
\hline $\begin{array}{l}\text { Effective stress } \\
\text { ( psi) }\end{array}$ & $\begin{array}{l}\text { Permeability } \\
\text { (D) }\end{array}$ & $\begin{array}{l}\text { Perm at } \\
\text { Reservoir } \\
\text { Temp } \\
\text { (D) }\end{array}$ & $\begin{array}{l}\text { Average } \\
\text { Width } \\
\text { (in) }\end{array}$ & $\begin{array}{l}\text { Average Width } \\
\text { after } \\
\text { Embedment } \\
\text { (in) }\end{array}$ & $\begin{array}{l}\text { Conductivity after } \\
\text { Embedment } \\
(\mathrm{mD} \cdot \mathrm{ft})\end{array}$ & $\begin{array}{l}\text { Beta Factor } \\
\left(\mathrm{atm} \cdot \mathrm{s}^{2} / \mathrm{g}\right)\end{array}$ \\
\hline 0 & 141 & 141 & 0.2 & 0.1939 & $2,278.00$ & 0.001441 \\
\hline 2,000 & 141 & 141 & 0.2 & 0.1939 & $2,278.00$ & 0.001441 \\
\hline 4,000 & 114 & 114 & 0.2 & 0.1939 & $1,841.80$ & 0.001879 \\
\hline 6,000 & 97 & 97 & 0.2 & 0.1939 & $1,567.10$ & 0.002299 \\
\hline 8,000 & 85 & 85 & 0.2 & 0.1939 & $1,373.20$ & 0.002712 \\
\hline 10,000 & 75 & 75 & 0.2 & 0.1939 & $1,211.70$ & 0.003172 \\
\hline 12,000 & 55 & 55 & 0.2 & 0.1939 & 888.60 & 0.004674 \\
\hline 14,000 & 40.333 & 40.333 & 0.2 & 0.1939 & 651.60 & 0.006887 \\
\hline 16,000 & 29.578 & 29.578 & 0.2 & 0.1939 & 477.90 & 0.010148 \\
\hline 18,000 & 21.69 & 21.69 & 0.2 & 0.1939 & 350.40 & 0.014954 \\
\hline 20,000 & 15.906 & 15.906 & 0.2 & 0.1939 & 257 & 0.022036 \\
\hline \multicolumn{7}{|c|}{ Carbolite } \\
\hline $\begin{array}{l}\text { Effective stress } \\
\text { ( psi) }\end{array}$ & $\begin{array}{l}\text { Permeability } \\
\text { (D) }\end{array}$ & $\begin{array}{l}\text { Perm at } \\
\text { Reservoir } \\
\text { Temp } \\
\text { (D) }\end{array}$ & $\begin{array}{l}\text { Average } \\
\text { Width } \\
\text { (in) }\end{array}$ & $\begin{array}{l}\text { Average Width } \\
\text { after } \\
\text { Embedment } \\
\text { (in) }\end{array}$ & $\begin{array}{l}\text { Conductivity after } \\
\text { Embedment } \\
(\mathrm{mD} \cdot \mathrm{ft})\end{array}$ & $\begin{array}{l}\text { Beta Factor } \\
\left(\mathrm{atm} \cdot \mathrm{s}^{2} / \mathrm{g}\right)\end{array}$ \\
\hline 0 & 203.111 & 203.111 & 0.1964 & 0.1898 & $3,212.80$ & 0.00026 \\
\hline 2,000 & 135 & 135 & 0.1924 & 0.1858 & $2,090.40$ & 0.000389 \\
\hline 4,000 & 100 & 100 & 0.1884 & 0.1818 & $1,515.10$ & 0.000524 \\
\hline 6,000 & 80 & 80 & 0.1844 & 0.1778 & $1,185.40$ & 0.000653 \\
\hline 8,000 & 60 & 60 & 0.1804 & 0.1738 & 869.10 & 0.000868 \\
\hline 10,000 & 35 & 35 & 0.1764 & 0.1698 & 495.30 & 0.00148 \\
\hline
\end{tabular}




\begin{tabular}{|c|c|c|c|c|c|c|}
\hline 12,000 & 25 & 25 & 0.1724 & 0.1658 & 345.4 & 0.002065 \\
\hline 14,000 & 18.91 & 18.91 & 0.1684 & 0.1618 & 255 & 0.002723 \\
\hline 16,000 & 13.47 & 13.47 & 0.1644 & 0.1578 & 177.1 & 0.00381 \\
\hline 18,000 & 9.599 & 9.599 & 0.1604 & 0.1538 & 123 & 0.005328 \\
\hline 20,000 & 6.838 & 6.838 & 0.1564 & 0.1498 & 85.4 & 0.007454 \\
\hline \multicolumn{7}{|c|}{ Carboprop } \\
\hline $\begin{array}{l}\text { Effective stress } \\
\qquad(\mathrm{psi})\end{array}$ & $\begin{array}{l}\text { Permeability } \\
\text { (D) }\end{array}$ & $\begin{array}{l}\text { Perm at } \\
\text { Reservoir } \\
\text { Temp } \\
\text { (D) }\end{array}$ & $\begin{array}{l}\text { Average } \\
\text { Width } \\
\text { (in) }\end{array}$ & $\begin{array}{l}\text { Average Width } \\
\text { after } \\
\text { Embedment } \\
\text { (in) }\end{array}$ & $\begin{array}{l}\text { Conductivity after } \\
\text { Embedment } \\
(\mathrm{mD} \cdot \mathrm{ft})\end{array}$ & $\begin{array}{l}\text { Beta Factor } \\
\left(\mathrm{atm} \cdot \mathrm{s}^{2} / \mathrm{g}\right)\end{array}$ \\
\hline 0 & 178.322 & 178.322 & 0.2061 & 0.2001 & $2,974.10$ & 0.000258 \\
\hline 2,000 & 140 & 140 & 0.2037 & 0.1977 & $2,306.80$ & 0.000349 \\
\hline 4,000 & 110 & 110 & 0.2013 & 0.1953 & $1,790.40$ & 0.000471 \\
\hline 6,000 & 80 & 80 & 0.1989 & 0.1929 & $1,286.00$ & 0.000702 \\
\hline 8,000 & 65 & 65 & 0.1965 & 0.1905 & $1,031.80$ & 0.000911 \\
\hline 10,000 & 50 & 50 & 0.1941 & 0.1881 & 783.70 & 0.001265 \\
\hline 12,000 & 40 & 40 & 0.1917 & 0.1857 & 618.90 & 0.001672 \\
\hline 14,000 & 30.454 & 30.454 & 0.1892 & 0.1833 & 465.10 & 0.002352 \\
\hline 16,000 & 23.659 & 23.659 & 0.1868 & 0.1809 & 356.6 & 0.003225 \\
\hline 18,000 & 18.38 & 18.38 & 0.1844 & 0.1784 & 273.3 & 0.004423 \\
\hline 20,000 & 14.279 & 14.279 & 0.182 & 0.176 & 209.5 & 0.006067 \\
\hline
\end{tabular}

\section{Coefficient extraction in fracture width model}

Effective stress and average width after embedment are selected from tables 6-9. Since embedment is modelled in this thesis, average width after embedment is selected in replacement of average width data in the tables. An initial scatter plot between $3^{\text {rd }}$ square root of effective stress and average width after embedment indicates linear relationship, which is descried in notations as:

$$
w_{f}=I-S^{3} \sqrt{P_{c}}
$$

Where I and S are intercept and slope for a linear equation. In addition, fracture width model for a single proppant type is derived in chapter 4 , equation (4.27) as:

$$
w_{f}=w_{f 0}-\frac{4 w_{f 0}}{(\pi \sqrt[3]{9}) \times \sqrt[3]{E_{p}\left(1-v_{p}^{2}\right)^{2}}} \sqrt[3]{P_{c}}
$$


As a result, I and $\mathrm{S}$ are equivalent as follows:

$$
I=w_{f 0}, S=\frac{4 w_{f 0}}{(\pi \sqrt[3]{9}) \times \sqrt[3]{E_{p}\left(1-v_{p}^{2}\right)^{2}}}
$$

Eventually, initial fracture width and geo-mechanics term, two coefficients required to be extracted, are computed as follows:

$$
w_{f 0}=I, \sqrt[3]{E_{p}\left(1-v_{p}^{2}\right)^{2}}=\frac{4 I}{S \pi \sqrt[3]{9}}
$$

For a single proppant type (i.e. 20/40 sand, 20/40 ceramic, 40/70 sand, 40/70 ceramic), there are 5-7 different data tables. Therefore, each single proppant type has 5-7 pairs of coefficients. Within each single proppant type, observations for the samples do not raise any drastic differences between the samples, and average values of all available samples are computed as representative coefficients.

\section{Sensitivity study}

Table 11 provides initial numerical results (mixture zone area percentage) of all sensitivity incremental points for 8 studied parameters (exception of injection time parameters):

Table 11 - Initial numerical results of all sensitivity incremental points for 8 studied parameters (exception of injection time parameters)

\begin{tabular}{|c|c|c|c|c|c|c|c|c|}
\hline Increments & Diameter 1 & Diameter 2 & Density 1 & Density 2 & $\begin{array}{c}\text { Injection } \\
\text { rate }\end{array}$ & $\begin{array}{c}\text { Confining } \\
\text { Stress }\end{array}$ & $\begin{array}{c}\text { Poisson } \\
\text { Ratio }\end{array}$ & $\begin{array}{c}\text { Young } \\
\text { Modulus }\end{array}$ \\
\hline$-25 \%$ & 51.8293 & 60.0671 & 51.1765 & 58.6667 & 61.0442 & 48.494 & 55.2901 & 56.9395 \\
\hline$-20 \%$ & 52.6316 & 60.2694 & 51.3514 & 59.1973 & 58.2707 & 48.494 & 56.2712 & 55.74913 \\
\hline$-15 \%$ & 53.4591 & 59.0604 & 52.4691 & 58.194 & 58.6716 & 51.7134 & 56.2712 & 54.57627 \\
\hline$-10 \%$ & 53.481 & 58.0537 & 53.125 & 56.8562 & 56.0284 & 54.1935 & 56.4189 & 55.40541 \\
\hline$-5 \%$ & 54.2484 & 57.4324 & 54.3408 & 56.7568 & 57.4394 & 54.0453 & 55.4455 & 56.27119 \\
\hline BASE CASE & 55.8528 & 55.8528 & 55.8528 & 55.8528 & 55.8528 & 55.8528 & 55.8528 & 55.8528 \\
\hline $5 \%$ & 56.2712 & 54.9669 & 55.7432 & 55.8528 & 55.5556 & 57.1429 & 54.9342 & 56.81063 \\
\hline
\end{tabular}




\begin{tabular}{|l|c|c|c|c|c|c|c|c|}
\hline $10 \%$ & 54.485 & 53.9735 & 56.8027 & 54.9153 & 53.6278 & 57.2881 & 55.0489 & 55.62701 \\
\hline $15 \%$ & 55 & 53.3557 & 58.1882 & 53.6913 & 53.5168 & 58.9474 & 56.6225 & 56.02606 \\
\hline $20 \%$ & 57.0934 & 52.5253 & 58.7814 & 53.4884 & 53.7538 & 58.1315 & 56.9536 & 56.02606 \\
\hline $25 \%$ & 58.7189 & 52.0134 & 59.707 & 53.0201 & 53.5294 & 60.1449 & 56.9079 & 55.30547 \\
\hline
\end{tabular}

Mixture zone area percentage for the base case is 55.8528 in table 10. Table 11 provides

relative deviations (i.e. percentage) from the base case value of all sensitivity incremental points

for 8 studied parameters (exception of injection time parameters):

Table 12 - Relative deviations from the base case value of all sensitivity incremental points for 8 studied parameters (exception of injection time parameters)

\begin{tabular}{|c|c|c|c|c|c|c|c|c|}
\hline Increments & Diameter 1 & Diameter 2 & Density 1 & Density 2 & $\begin{array}{c}\text { Injection } \\
\text { rate }\end{array}$ & $\begin{array}{c}\text { Confining } \\
\text { Stress }\end{array}$ & $\begin{array}{c}\text { Poisson } \\
\text { Ratio }\end{array}$ & $\begin{array}{c}\text { Young } \\
\text { Modulus }\end{array}$ \\
\hline$-25 \%$ & -7.2038 & 7.5454 & -8.3725 & 5.0381 & 9.2948 & -13.1753 & -1.0075 & 1.9457 \\
\hline$-20 \%$ & -5.7673 & 7.9076 & -8.0594 & 5.9881 & 4.3291 & -13.1753 & 0.7491 & -0.1856 \\
\hline$-15 \%$ & -4.2857 & 5.7430 & -6.0582 & 4.1917 & 5.0468 & -7.4113 & 0.7491 & -2.2855 \\
\hline$-10 \%$ & -4.2465 & 3.9405 & -4.8839 & 1.7965 & 0.3144 & -2.9708 & 1.0136 & -0.8010 \\
\hline$-5 \%$ & -2.8726 & 2.8281 & -2.7071 & 1.6185 & 2.8407 & -3.2362 & -0.7292 & 0.7491 \\
\hline BASE CASE & 0 & 0 & 0 & 0 & 0 & 0 & 0 & 0 \\
\hline $5 \%$ & 0.7491 & -1.5861 & -0.1962 & 0.0000 & -0.5321 & 2.3098 & -1.6447 & 1.7149 \\
\hline $10 \%$ & -2.4489 & -3.3647 & 1.7007 & -1.6785 & -3.9837 & 2.5698 & -1.4393 & -0.4043 \\
\hline $15 \%$ & -1.5269 & -4.4709 & 4.1813 & -3.8700 & -4.1824 & 5.5406 & 1.3781 & 0.3102 \\
\hline $20 \%$ & 2.2212 & -5.9576 & 5.2434 & -4.2333 & -3.7581 & 4.0798 & 1.9709 & 0.3102 \\
\hline $25 \%$ & 5.1315 & -6.8741 & 6.9006 & -5.0717 & -4.1599 & 7.6847 & 1.8891 & -0.9800 \\
\hline
\end{tabular}

Table 13 provides initial numerical results and relative deviations (i.e. percentage) from

the base case of all sensitivity incremental points for 2 studied injection time parameters:

Table 13 - initial numerical results and relative deviations from the base case of all sensitivity incremental points for 2 studied injection time parameters

\begin{tabular}{|c|c|c|c|c|}
\hline & \multicolumn{2}{|c|}{ Former proppant type's time injection } & \multicolumn{2}{c|}{ Latter proppant type's time injection } \\
\hline Increments & $\%$ Mixture zone & \% Deviation & \% Mixture zone & $\%$ Deviation \\
\hline$-25 \%$ & 52.9801 & -2.8727 & 55.4455 & -0.4073 \\
\hline$-20 \%$ & 53.1353 & -2.7175 & 56.0403 & 0.1875 \\
\hline$-15 \%$ & 53.4426 & -2.4102 & 55.7756 & -0.0772 \\
\hline
\end{tabular}




\begin{tabular}{|c|c|c|c|c|}
\hline$-10 \%$ & 53.5948 & -2.258 & 55.6667 & -0.1861 \\
\hline$-5 \%$ & 55.2288 & -0.624 & 54.8173 & -1.0355 \\
\hline $0 \%$ & 55.8528 & 0 & 55.8528 & 0 \\
\hline $5 \%$ & 55.082 & -0.7708 & 56.3758 & 0.523 \\
\hline $10 \%$ & 55.814 & -0.0388 & 56.9024 & 1.0496 \\
\hline $15 \%$ & 56.8106 & 0.9578 & 57.1906 & 1.3378 \\
\hline $20 \%$ & 58.6667 & 2.8139 & 57.2391 & 1.3863 \\
\hline $25 \%$ & 56.2914 & 0.4386 & 57.2391 & 1.3863 \\
\hline
\end{tabular}

Table 14 summarizes absolute values of lowest and highest deviations from the base case value for all 10 studied parameters:

Table 14 - absolute values of lowest and highest deviations from the base case value for all 10 studied parameters

\begin{tabular}{|c|c|c|c|}
\hline Studied Parameters & Lowest & Highest & Total of absolute values \\
\hline Injection time (latter) & -1.0355 & 1.3863 & 2.4218 \\
\hline Poisson Ratio & -1.01356 & 1.970895 & 2.984452 \\
\hline Young Modulus & -2.28552 & 1.714921 & 4.000444 \\
\hline Injection Time (former) & -2.8727 & 2.8139 & 5.6866 \\
\hline Proppant Density 2 & -5.98806 & 5.071724 & 11.05979 \\
\hline Proppant Diameter 1 & -7.20376 & 5.131524 & 12.33528 \\
\hline Injection Rate & -9.29479 & 4.182422 & 13.47721 \\
\hline Proppant Diameter 2 & -7.90757 & 6.874141 & 14.78171 \\
\hline Proppant Density 1 & -8.37254 & 6.900639 & 15.27318 \\
\hline Confining Pressure & -13.1753 & 7.684664 & 20.86001 \\
\hline
\end{tabular}

\section{Efficacy of trust-region method}

Figures 63 to 68 present efficacy of the trust-region method (the method's fundamental is described chapter 2) applied for coefficient extraction from the novel permeability model in this thesis (chapter 4). In figures 62-68, the black hollow dots are values of the objective function (equations (4.43) and (4.44) in chapter 4). The lines are figurative outcomes from trust-region algorithm through implication of MATLAB® R2019b Optimization Toolbox. 


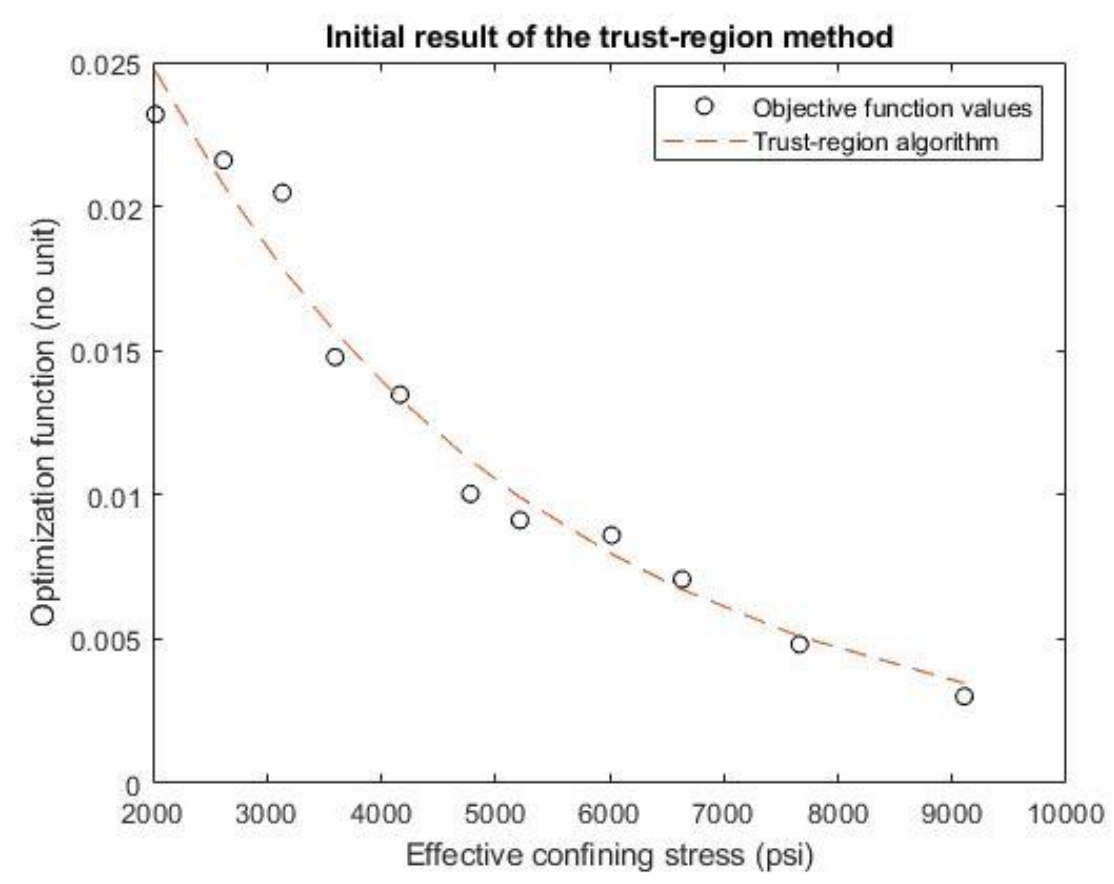

Figure 63 - Initial result of trust-region method, mixture 20/40 sand and 20/40 ceramic $(50 \% / 50 \%)$

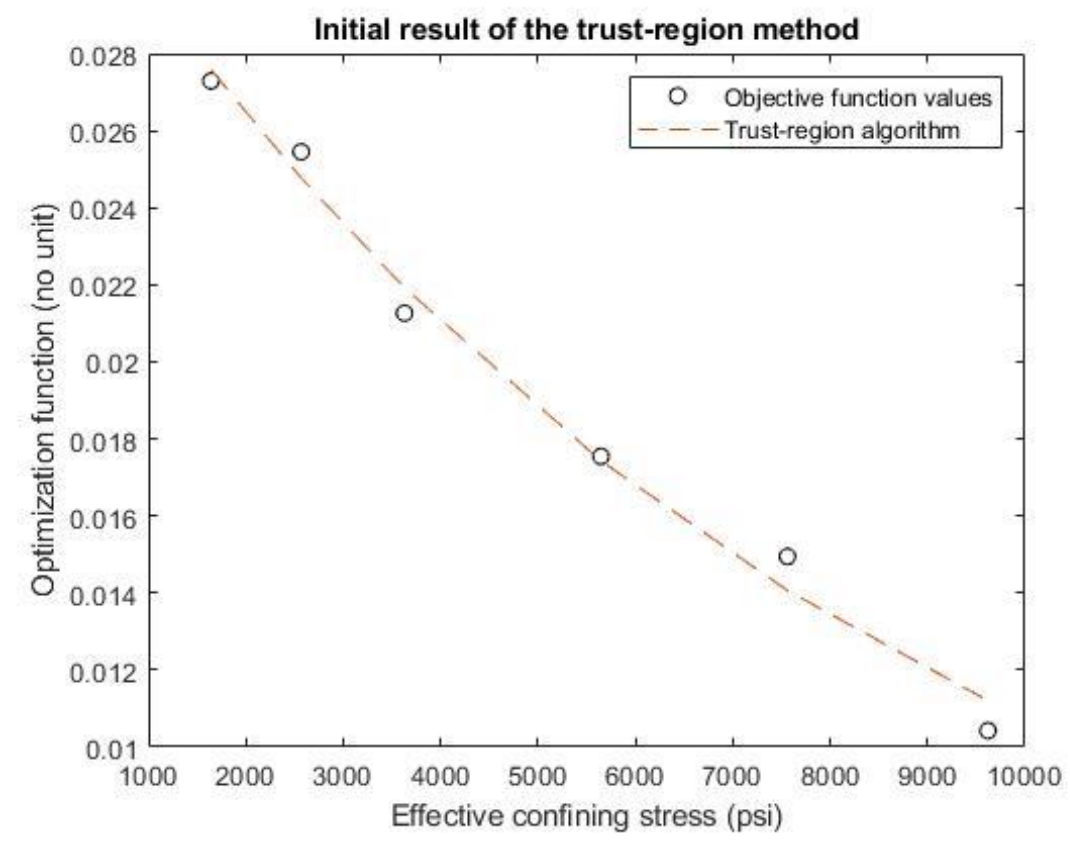

Figure 64- Initial result of trust-region method, mixture 20/40 sand and 20/40 ceramic $(25 \% / 75 \%)$ 


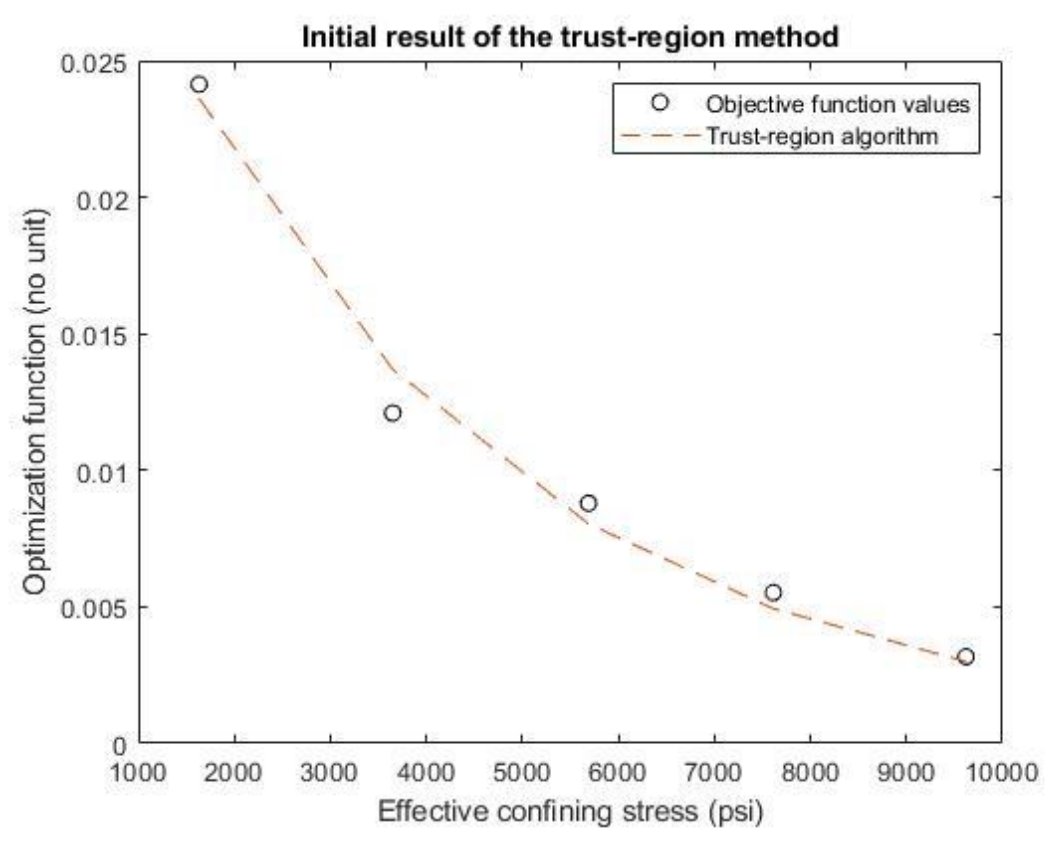

Figure 65 - Initial result of trust-region method, mixture 40/70 sand and 20/40 ceramic $\underline{(50 \% / 50 \%)}$

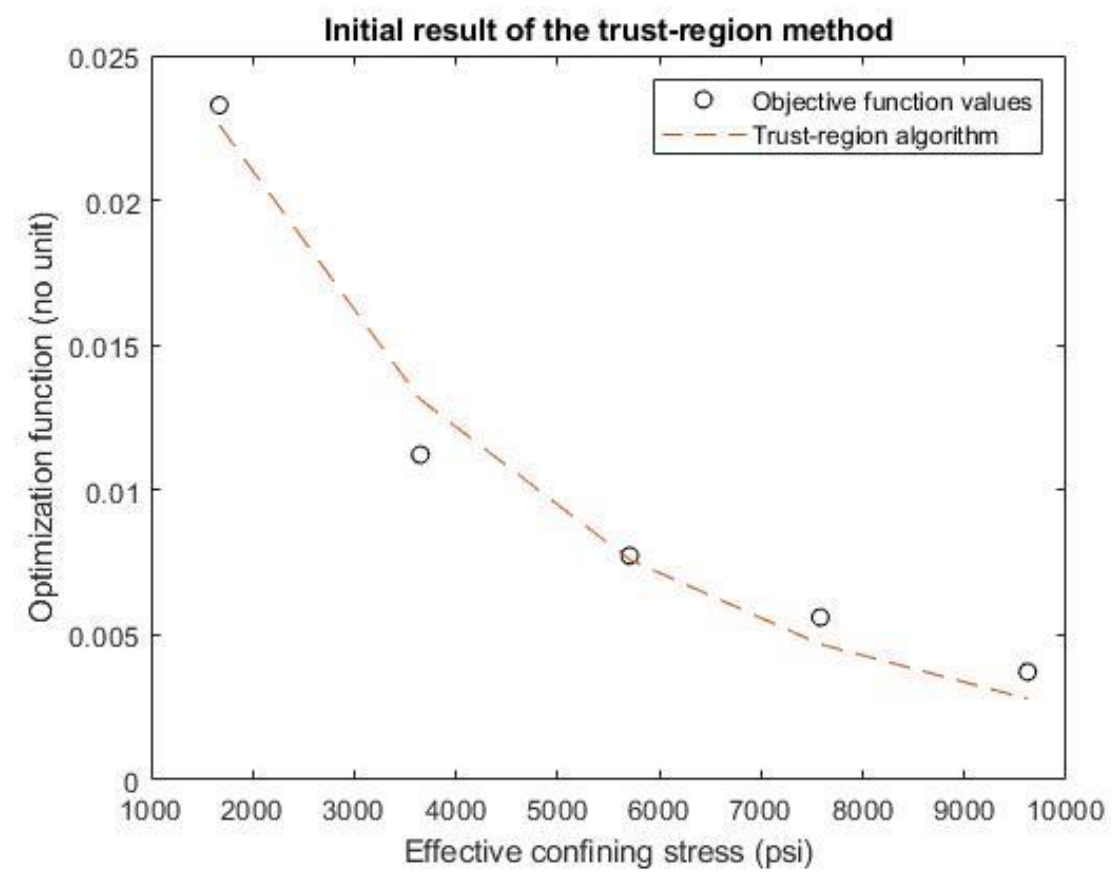

Figure 66 - Initial result of trust-region method, mixture 40/70 sand and 20/40 ceramic $\underline{(25 \% / 75 \%)}$ 


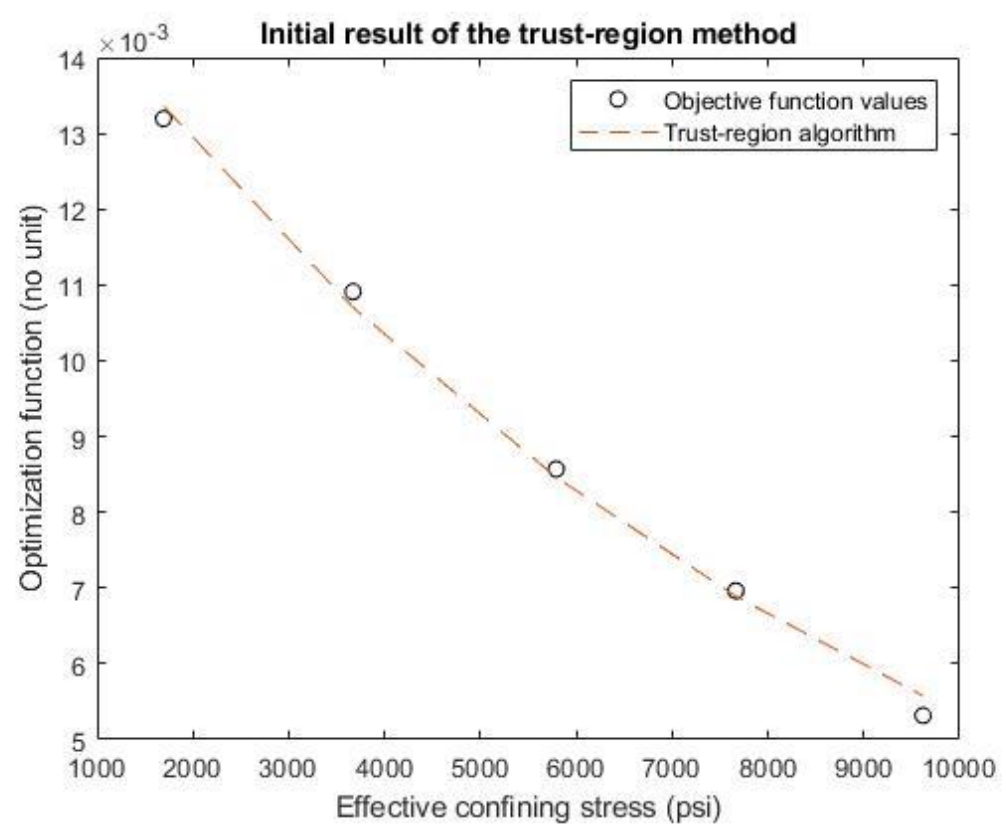

Figure 67 - Initial result of trust-region method, mixture 20/40 sand and 40/70 ceramic (50\%/50\%)

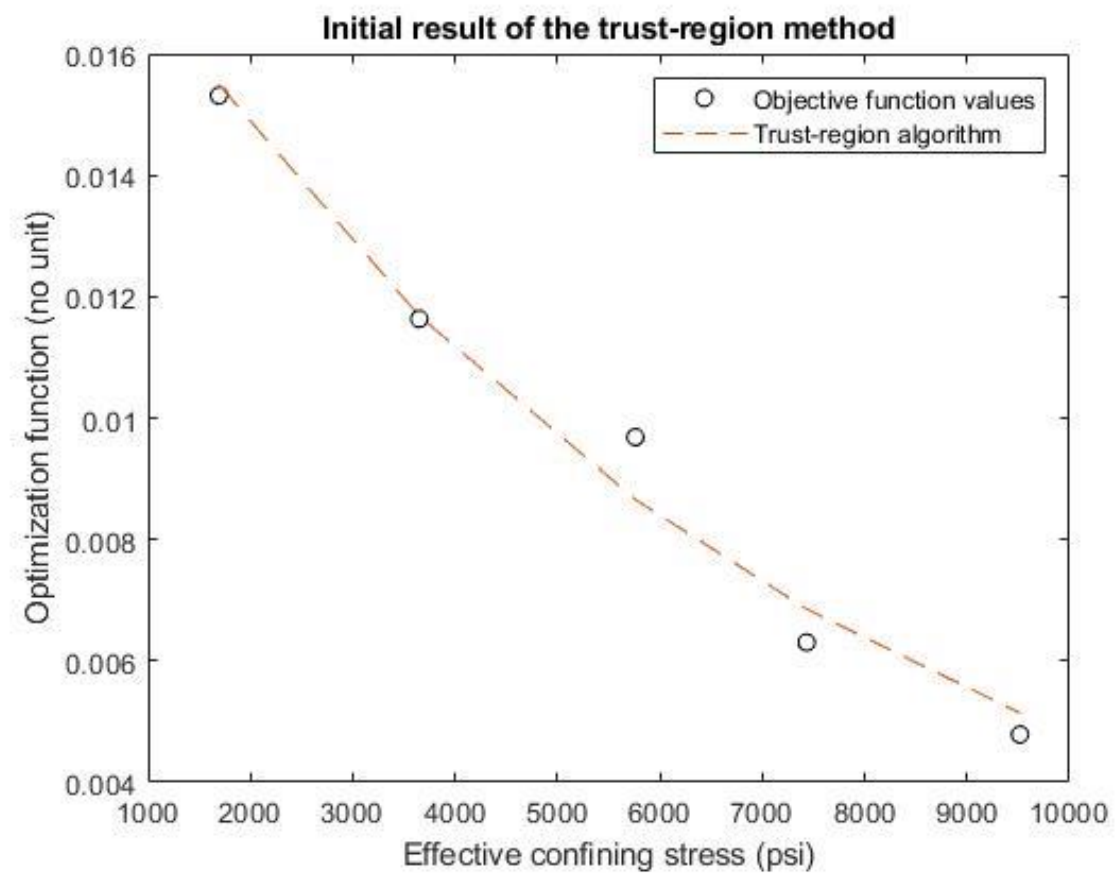

Figure 68 - Initial result of trust-region method, mixture 20/40 sand and 40/70 ceramic (50\%/50\%) 